U.S. Department of the Interior

U.S. Geological Survey

In Cooperation with the

New Hampshire Department of Environmental Services

\title{
Testing and Application of Diffusion Samplers to Identify Temporal Trends in Volatile-Organic Compounds
}

By Philip T. Harte, Michael J. Brayton, Wayne Ives, Sharon Perkins, Carroll Brown Jr., and Richard E. Willey

U.S. Geological Survey Open-File Report 00-196

Pembroke, New Hampshire

2000 


\title{
U.S. DEPARTMENT OF THE INTERIOR BRUCE BABBITT, Secretary
}

\author{
U.S. GEOLOGICAL SURVEY \\ Charles G. Groat, Director
}

The use of firm, trade, and brand names in this report is for identification purposes only and does not constitute endorsement by the U.S. Geological Survey.

For additional information write to:

District Chief

U.S. Geological Survey

New Hampshire/Vermont District

361 Commerce Way

Pembroke, NH 03275-3718

or through our website at

http://nh.water.usgs.gov
Copies of this report can be purchased from:

U.S. Geological Survey

Information Services

Box 25286

Federal Center

Denver, CO 80225 


\section{CONTENTS}

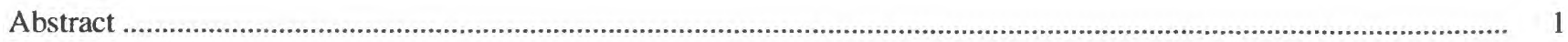

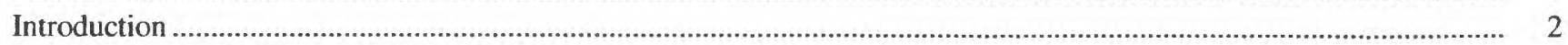

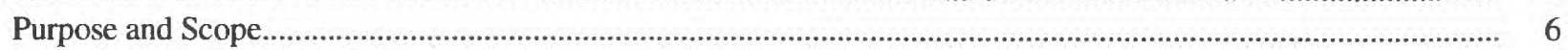

Description of Study Area ...................................................................................................................

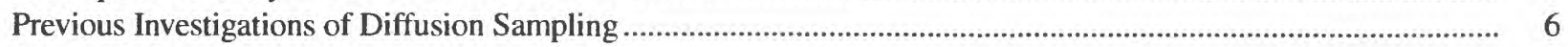

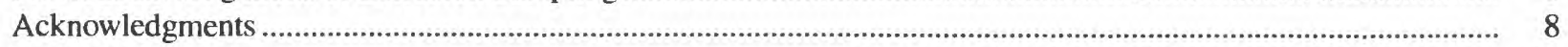

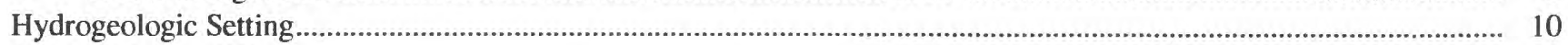

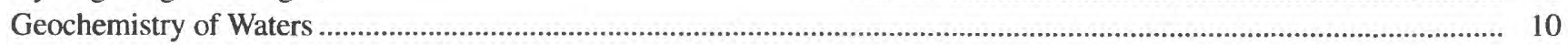

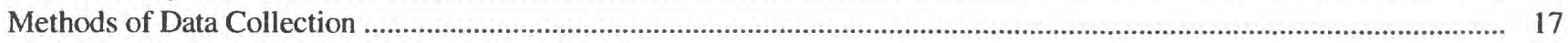

Description of Chemical-Monitoring Program .............................................................................................. 17

Sampling Methods and Techniques............................................................................................................... 19

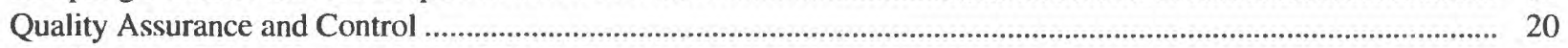

Conceptualization of Contributing Area of Water Samples ................................................................................... 21

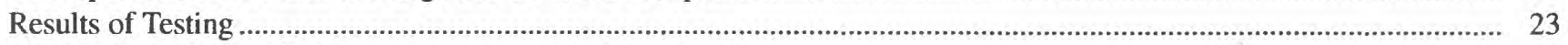

Comparison of Diffusion Samplers with Other Samplers .............................................................................. 23

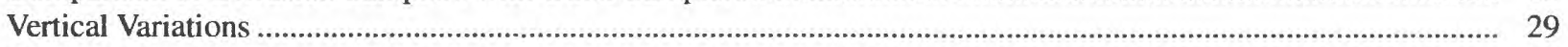

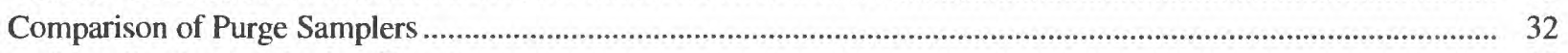

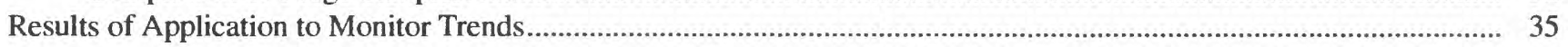

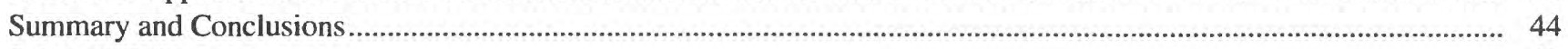

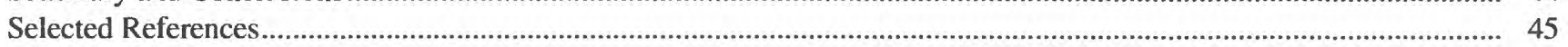

Appendices 1-6:

1. Procedures for Preparation, Installation, and Collection of Diffusion Bag Samples in Wells ................................ 47

2. Explanation of Abbreviations ...................................................................................................................... 49

2a. Sampling Information and Field Parameters, May 1997 to September 1999, Milford, New Hampshire.......... 51

2b. Detected Ions and Compounds, May 1997 to September 1999 .................................................................... 63

2c. Major Detected Volatile-organic Compounds (VOC's), May 1997 to September 1999 .................................... 75

3. Comparison of Concentrations of Volatile-organic Compounds Tetrachloroethylene (PCE),

Trichloroethylene (TCE), and cis-1,2-dichloroethene (cis-1,2DCE) from Diffusion and Peristaltic-pump

Samples at Coincident Sampled Depth Intervals.

4. Comparison of Concentrations of Volatile-organic Compounds Tetrachloroethylene (PCE),

Trichloroethylene (TCE), and cis-1,2-dichloroethene (cis-1,2DCE) from Diffusion and Bladder-pump

Samples at Coincident Sampled Depth Intervals.

5. Relative Percent Difference (RPD) for Individual Well Comparison of Peristaltic Samples and Diffusion Samples.

6. Absolute Relative Percent Difference (ARPD) Information for Positive Detections in Duplicate Sample

Comparison.

\section{FIGURES}

1-3. Maps showing:

1. Location of the Milford-Souhegan Glacial-Drift aquifer (MSGD), Milford, New Hampshire

2. Extent of contaminant plume of total volatile organics (A) and ground-water head contour map

(B) in the MSGD aquifer

3. Remedial system, contaminant plume in source area, and monitoring wells at source area of the

Savage Superfund Well Site.

4. Photograph of diffusion sampler (A) and well identifier (B) used to label wells..

5-8. Graphs showing lithologic and borehole logs for wells in the source area along a:

5. North to south transect, including wells B95-15, B95-13, and B95-12. 
6. West to east transect, including wells B95-15, PW-12R, and PW-13D ................................................. 12

7. West to east transect, including wells PW-2R, B95-13, and PW-14D ..................................................... 13

8. West to east transect, including wells B95-8, B95-12, and MW-16C ...................................................... 14

9. Maps showing water-table surface for pre-remedial construction (May 1997) (A) and post-remedial construction (November 1998) (B)

10. Diagrams showing angular direction of maximum ground-water gradient from true north $(\mathrm{A})$ and gradient

(B) computed from three-point planar solution from wells B95-12, B95-15, and B95-13 .................................. 16

11. Conceptual diagram showing horizontal contributing areas to a well for various purge rates ................................. 22

12-14. Graphs showing:

12. Ground-water levels (A) and concentration of tetrachloroethylene (PCE) in samples collected by various methods (B) for well B95-13.

13. Ground-water levels (A) and concentration of tetrachloroethylene (PCE) in samples collected by various methods (B) for well B95-15

14. Linear regression of concentrations from peristaltic and diffusion samples for tetrachloroethylene (PCE) (A), trichloroethylene (TCE) (B), and cis-1,2-dichloroethane (cis-1,2DCE) (C)

15. Scatter plot showing comparison between deployment time of diffusion sampler and difference of measured concentrations of tetrachloroethylene (PCE) from diffusion and peristaltic-pump samples (A) and comparison of percent difference (B)

16-23. Graphs showing:

16. Concentrations of tetrachloroethylene (PCE) from tests comparing peristaltic and bladder pumps, for PCE and volume purged (A), and PCE and purge rate (B), April 14, 1999.

17-21. Concentrations of volatile organic compounds (VOC's) (tetrachloroethylene (PCE), trichloroethylene (TCE), and cis-1,2-dichloroethane (cis-DCE), and total VOC's (total VOC) from diffusion samplers for wells:

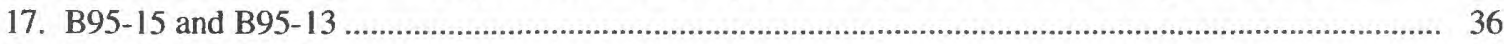

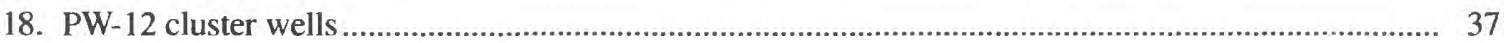

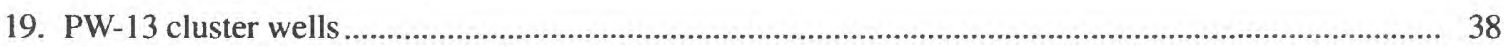

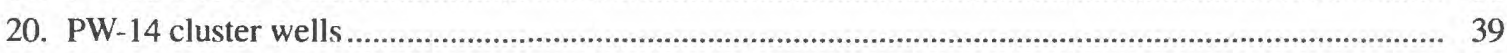

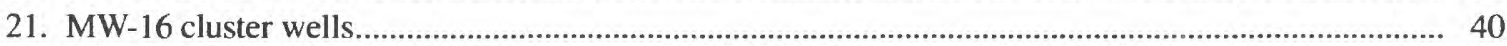

22. Concentrations of methane $\left(\mathrm{CH}_{4}\right)$ and the ratio of cis-1,2-dichloroethane (cis-1,2DCE) to tetrachloroethylene (PCE) for wells B95-13 (A) and B95-15 (B).

23. Future time trends in concentrations of volatile organic compounds (VOC's) as a ratio of initial concentrations of tetrachloroethylene (PCE) (A) and total VOC's (B)

\section{TABLES}

1. Well screen data and geology for selected wells in the study area..

2. Median concentrations of key geochemical parameters in uncontaminated and contaminated with volatile organic (compounds) water samples from the study area

3. Instruments used, instrumentation method code, and method detection limits, for analyses of water samples ..... 18

4. Volatile-organic compounds analyzed and detected in water samples collected by peristaltic pump and diffusion samplers from wells in Milford, New Hampshire, from May 1998 to July 1999.

5. Volatile-organic compounds analyzed and detected in water samples collected by bladder pump and diffusion samplers from wells in Milford, New Hampshire, from May 1998 to April 1999

6. Statistical summary of concentrations of volatile-organic compounds from peristaltic and diffusion samples ..... 30

7. Summary of absolute relative percent differences (ARPD) between laboratory duplicate samples and relative percent difference (RPD) between peristaltic samples and diffusion samples.

8. Variations in concentrations of PCE, TCE, and cis-1,2-DCE from vertical strings of diffusion samplers, in July and October 1999 .

9. Water-quality results from test comparing peristaltic and bladder pumps at well B95-13 (well number 408), April 14, 1999

10. Summary statistics comparing concentrations of tetrachloroethylene (PCE) and trichloroethylene (TCE) grouped by pump type from samples collected at well B95-13 (well number 408), April 14, 1999. 


\begin{tabular}{|c|c|c|}
\hline Multiply & By & To obtain \\
\hline \multicolumn{3}{|c|}{ Length } \\
\hline inch (in.) & 25.4 & millimeter \\
\hline foot $(f t)$ & 0.3048 & meter \\
\hline mile (mi) & 1.609 & kilometer \\
\hline \multicolumn{3}{|c|}{ Area } \\
\hline square mile $\left(\mathrm{mi}^{2}\right)$ & 2.590 & square kilometer \\
\hline \multicolumn{3}{|c|}{ Volume } \\
\hline cubic foot $\left(\mathrm{ft}^{3}\right)$ & 0.02832 & cubic meter \\
\hline gallon (gal) & 3.785 & liter \\
\hline \multicolumn{3}{|c|}{ Flow } \\
\hline cubic feet per second $\left(\mathrm{ft}^{3} / \mathrm{s}\right)$ & 0.02832 & cubic meter per second \\
\hline gallon per minute (gal $/ \mathrm{min}$ ) & 0.06308 & liter per second \\
\hline million gallons per day (Mgal/d) & 0.04381 & cubic meter per second \\
\hline million gallons per day (Mgal/d) & 1.547 & cubic feet per second (cfs) \\
\hline \multicolumn{3}{|c|}{ Hydraulic Conductivity } \\
\hline foot per day $(\mathrm{ft} / \mathrm{d})$ & 0.3048 & meter per day \\
\hline \multicolumn{3}{|c|}{$\begin{array}{l}\text { Temperature in degrees Fahrenheit }\left({ }^{\circ} \mathrm{F}\right) \text { can be converted to degrees Celsius }\left({ }^{\circ} \mathrm{C}\right) \text { as follows } \\
\qquad{ }^{\circ} \mathrm{C}=5 / 9\left({ }^{\circ} \mathrm{F}-32\right) .\end{array}$} \\
\hline
\end{tabular}

Vertical Datum: In this report "sea level" refers to the National Geodetic Vertical Datum of 1929 (NGVD of 1929) - a geodetic datum derived from a general adjustment of the first-order level nets of both the United States and Canada, formerly called Sea Level Datum of 1929. 


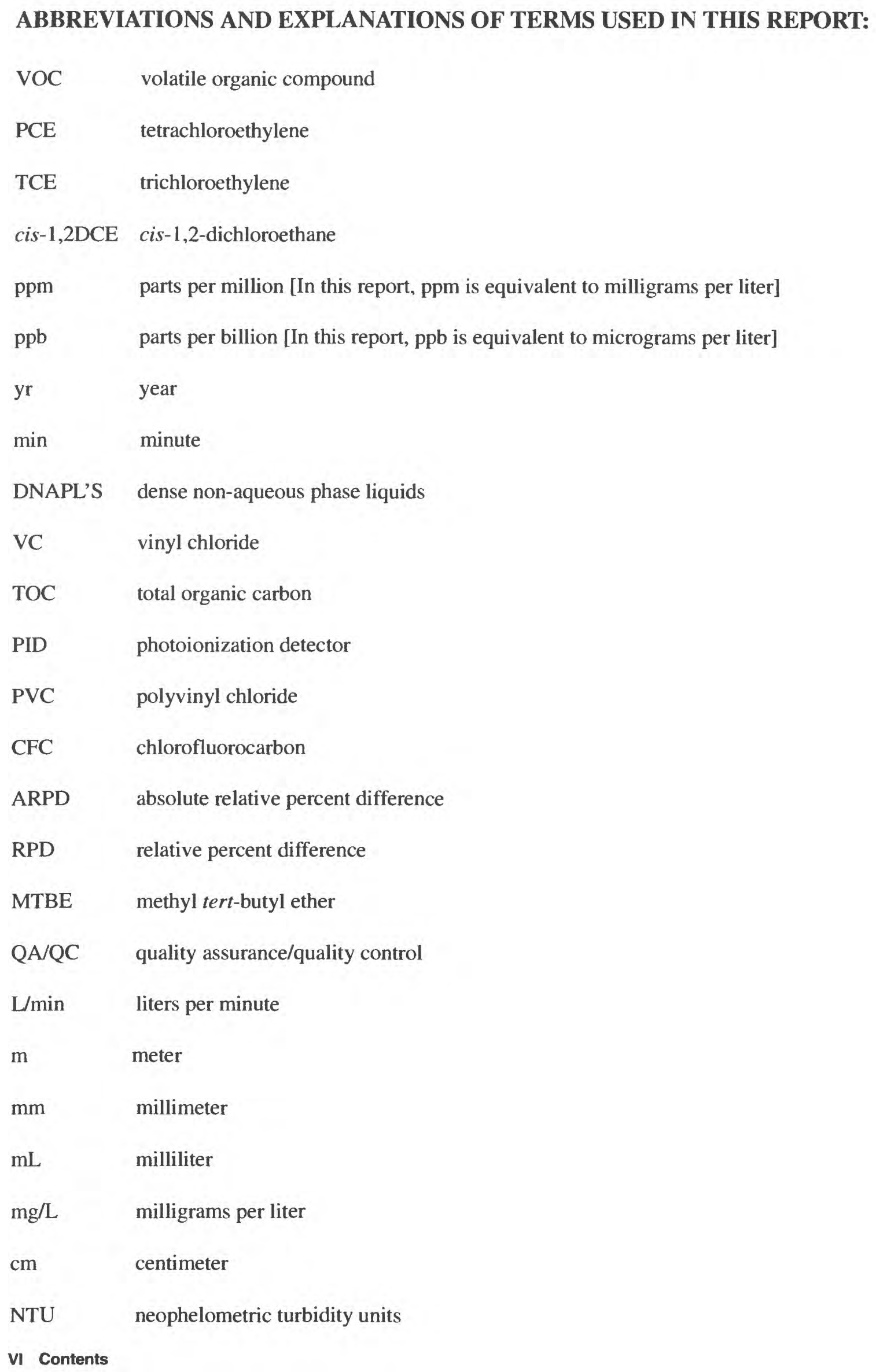




\section{Well identification}

$\begin{array}{ll}\text { obswell } & \text { observation well } \\ \text { airwell } & \text { soil vapor extraction well } \\ \text { sparwell } & \text { soil sparge well } \\ \text { injwell } & \text { recharge well } \\ \text { extrawell } & \text { extraction well }\end{array}$

The following abbreviations are used in well names:

\section{$\underline{\text { Suffix }}$}

$\mathrm{S}$ or A shallow cluster well

$\mathrm{M}$ or B medium cluster well

D or C deep cluster well

$\mathrm{R} \quad$ bedrock well

\section{$\underline{\text { Prefix }}$}

SVE soil vapor extraction well

SP soil sparge well

IW interior wall extraction well

EW exterior wall extraction well

PW or B or MI or MW observation wells

RW recharge wells

P piezometer

\section{Lithology abbreviations}

f fine

m medium

c coarse

Wx weathered 


\title{
Testing and Application of Diffusion Samplers to Identify Temporal Trends in Volatile-Organic Compounds
}

\author{
By Philip T. Harte, Michael J. Brayton, Wayne Ives ${ }^{1}$, Sharon Perkins ${ }^{1}$, Carroll Brown Jr. ${ }^{1}$, and \\ Richard E. Willey²
}

\section{Abstract}

Methods for ground-water sampling have evolved over time. This evolution has been driven by changing theories on how to obtain representative aquifer water samples. Passive sampling is a fairly recent method that relies on the natural flushing capacity of a well to obtain representative samples. The use of diffusion samplers is one method of passive sampling and works well under certain conditions.

As part of a 2-year study to determine the temporal variability and trends in concentrations of volatile organic compounds (VOC's) in a large plume $\left(0.5 \mathrm{mi}^{2}\right.$ area) of contaminated ground water in a glacial-drift aquifer, results of VOC analyses of samples collected with diffusion bag samplers were compared with those of samples collected with other types of samplers. The area of study is the primary source area of the large VOC plume and is located adjacent to a a river that losses flow and recharges the aquifer. The concentrations of VOC's, primarily tetrachloroethylene (PCE), trichloroethylene (TCE), and cis-1,2-dichloroethene (cis-1,2DCE), in samples collected with diffusion samplers show a strong positive linear correlation (root-mean square error of 0.94 and above) with concentrations from purged samples following low-flow sampling procedures. A total of 20 coupled diffusion and peristaltic-pump samples were collected from 7 wells completed in high-permeability glacial-drift. The mean concentration of PCE in the diffusion samples was 1,152 parts per billion (ppb) and the mean from the peristalticpump samples was $1,119 \mathrm{ppb}$. The standard deviations also were similar. The mean concentrations of TCE were slightly higher in diffusion samples $(89.2 \mathrm{ppb})$ than peristaltic-pump samples $(75.4 \mathrm{ppb})$. The mean concentration of $c i s-1,2 \mathrm{DCE}$ in diffusion samples $(95.0 \mathrm{ppb})$ was virtually identical to the mean in peristaltic-pump samples.

Although VOC concentrations changed dramatically at several wells over the sampled period, trends in VOC's detected using diffusion samplers corresponded with trends in VOC's from other lowflow sampling methods. For example, at two wells where coupled diffusion and peristaltic-pump samples were collected, VOC concentrations varied by a half order of magnitude over a two-month period. Although the diffusion sampler was installed and left in the well for the entire period, VOC concentrations in the diffusion sampler at the time of retrieval generally matched those in the instantaneous samples collected with the peristaltic pump on the same day, suggesting relatively rapid equilibration of the diffusion sampler to VOC concentrations in the well.

The use of diffusion samplers allowed for the understanding of contaminant transport conditions at the study site because it allowed for an increase in the frequency of sampling without an associated increase in labor cost. For example, spatially variable declines in PCE concentrations were identified over the two-year study that are related to spatial variations in sediment lithology and the location of the plume within the ground-water flow system. Wells screened in coarse-grained gravel layers and located

\footnotetext{
${ }^{1}$ New Hampshire Department of Environmental Services.

${ }^{2}$ U.S. Environmental Protection Agency.
} 
along the northern part of the plume, close to the river boundary, showed the largest decline in concentrations of PCE. At several wells, concentrations of TCE and cis-1,2DCE increased, suggesting that small scale biodegradation is occurring. Temporary increases in concentrations of the primary VOC's followed several large recharge events, suggesting that VOC's are being desorbed from the aquifer matrix.

\section{INTRODUCTION}

The Savage Well Superfund Site, named after the former Savage municipal water-supply well for the Town of Milford, is underlain by a large $\left(0.5 \mathrm{mi}^{2}\right)$ plume of volatile organic compounds (VOC's) (figs. 1 and 2$)$. The area is underlain by a highly transmissive sand and gravel aquifer. A discontinued tool manufacturing facility, has been identified as the primary source of volatile organic compounds (mostly tetrachloroethylene (PCE)) that led to contamination of the Savage well. The State of New Hampshire Department of Environmental Services (NHDES) and the U.S. Environmental Protection Agency (USEPA) have constructed a remedial system for the primary source area (fig. 3). The remedial system includes a barrier wall, which encapsulates the highest concentrations of dissolved PCE and most likely some dense non-aqueous phase liquids (DNAPL's), and various injection and extraction wells (vapor and water) to capture and treat the dissolved contaminant plume. The barrier wall was constructed from July to November 1998. Remedial operations of wells were tested between December 1998 to March 1999 but full operation started in May 1999.

The U.S. Geological Survey (USGS), in cooperation with NHDES, has established a detailed monitoring system for the source area that includes (1) continuous observations of ground-water levels and physical water properties, (2) manual measurements of ground-water levels to complement the continuous network, and (3) a geochemical and water-quality sampling program. Furthermore, a solute-transport model of the glacial-drift aquifer has been constructed and used to simulate the remedial system.

The main purpose of the geochemical and water-quality sampling program is to document the rate of cleanup of the VOC plume. The sampling program began in May 1997, using low-flow sampling procedures (described in a later section of the report). To facilitate the sampling program, passive diffusion sampling began in 1998 to provide high frequency sample collection to coincide with the beginnings of remedial operations. Passive diffusion sampling, using the method delineated in U.S. Patent No. 5,804,743, is an easy and inexpensive approach to sampling.

Passive diffusion sampling offers time-saving advantages over purged sampling following low-flow procedures. During this study, diffusion sampling was done in 1/5th the time of low-flow sampling; therefore, in an equivalent amount of time, five times as many samples were collected with diffusion samplers than with lowflow procedures. Previously, the frequency of VOC data collection in ground water was usually low because of the labor-intensive nature of sampling. Thus, standard guidelines for the collection of ground-water quality samples suggest a quarterly per annum time basis (Wiedemeier and others, 1998, p. 52) partly because of the infeasibility of increased sampling. A quarterly or longer sampling frequency, however, may be insufficient to characterize time trends. For example, seasonal variability of ground-water flow has been demonstrated by the primary author as a mechanism in increasing the transverse dispersion of contaminants in the aquifer and will complicate analysis of long-term trends. Furthermore, anthropogenic factors in the study area, such as construction and operation of the remedial system, also cause short- and long-term changes in VOC concentrations. The use of diffusion samplers allows for more frequent measurements thereby facilitating the identification of shortand long-term trends. 


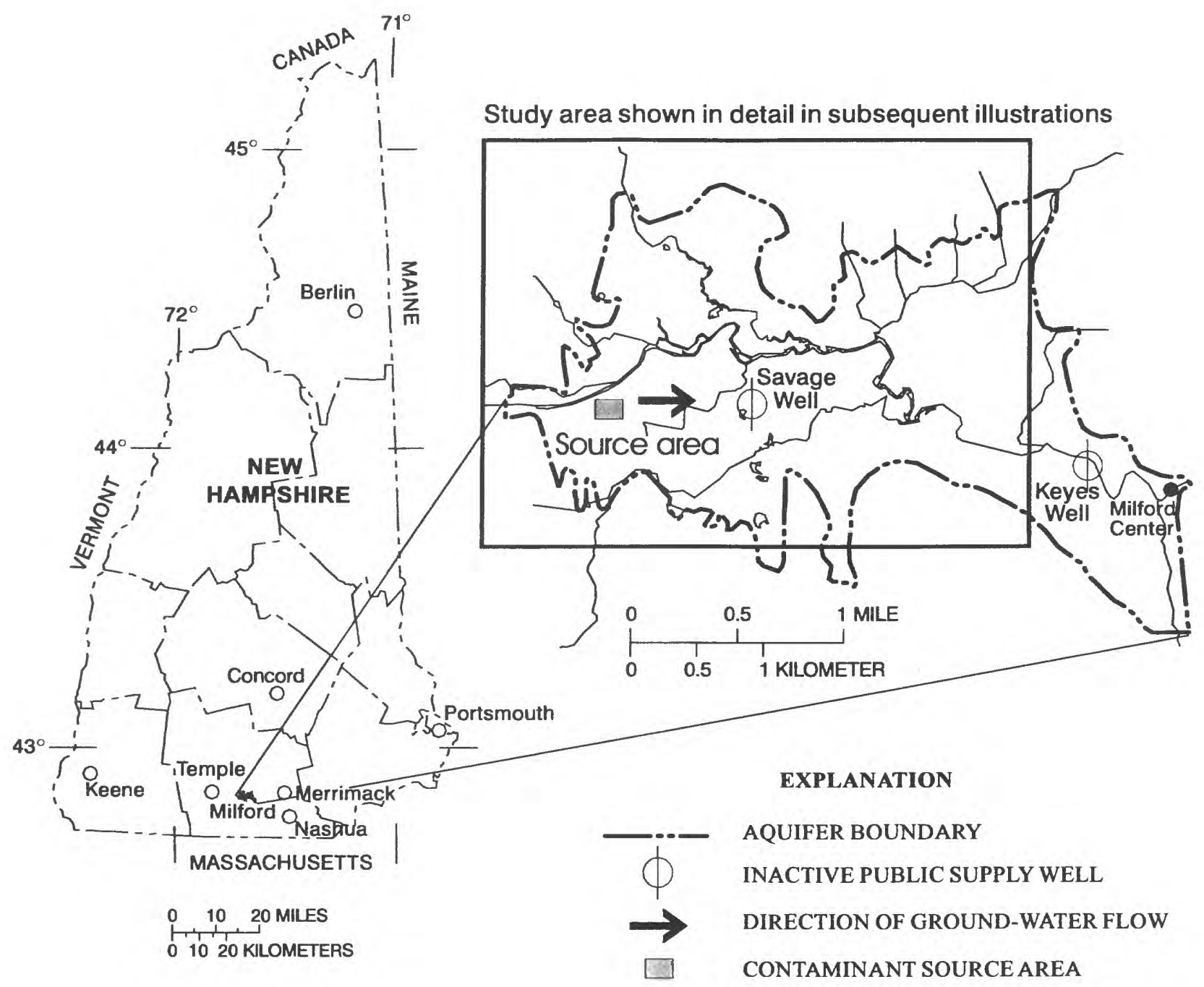

Figure 1. Location of the Milford-Sounegan Glacial-Drift aquifer, Milford, New Hampshire. 
(A)

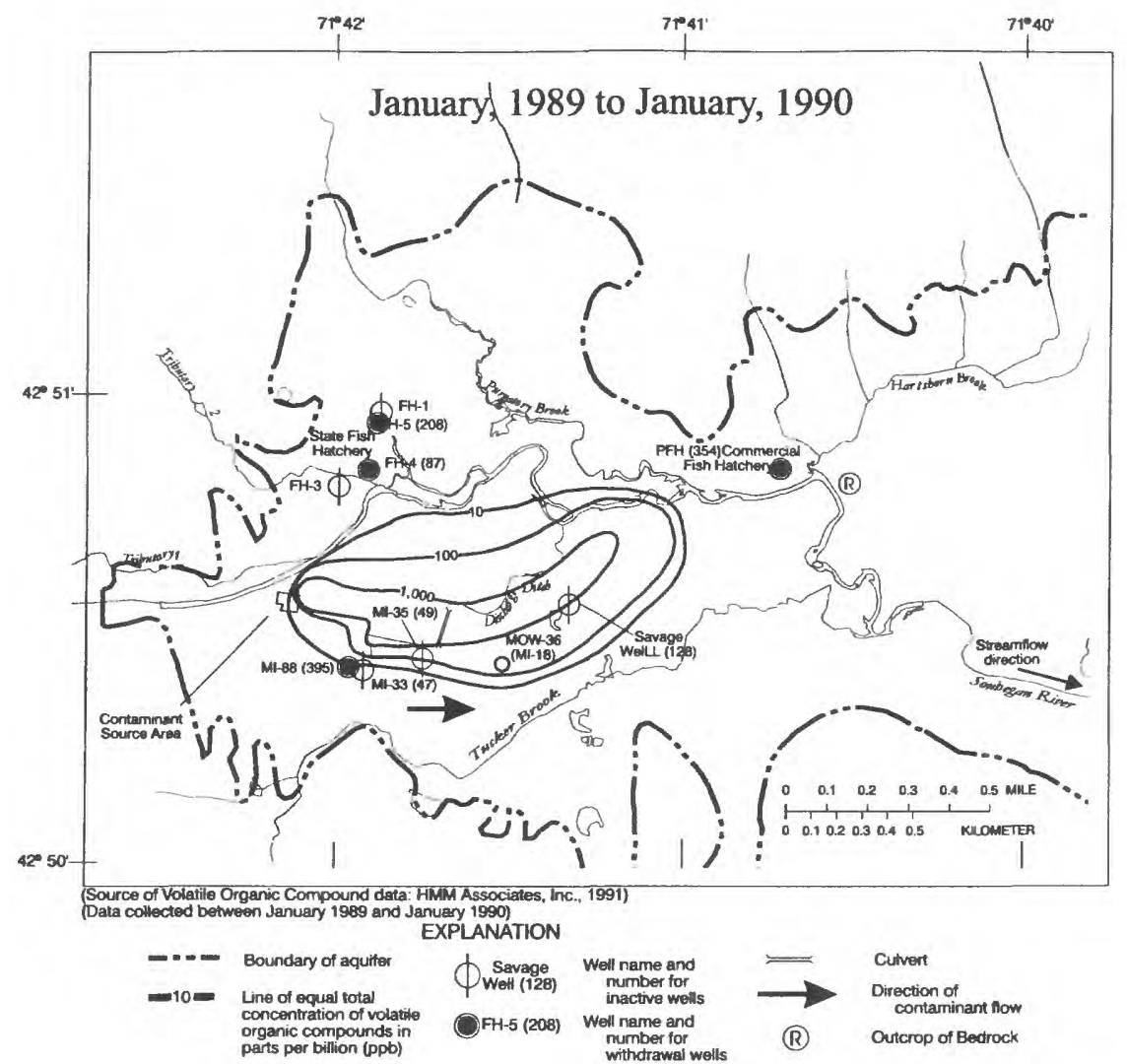

(B)

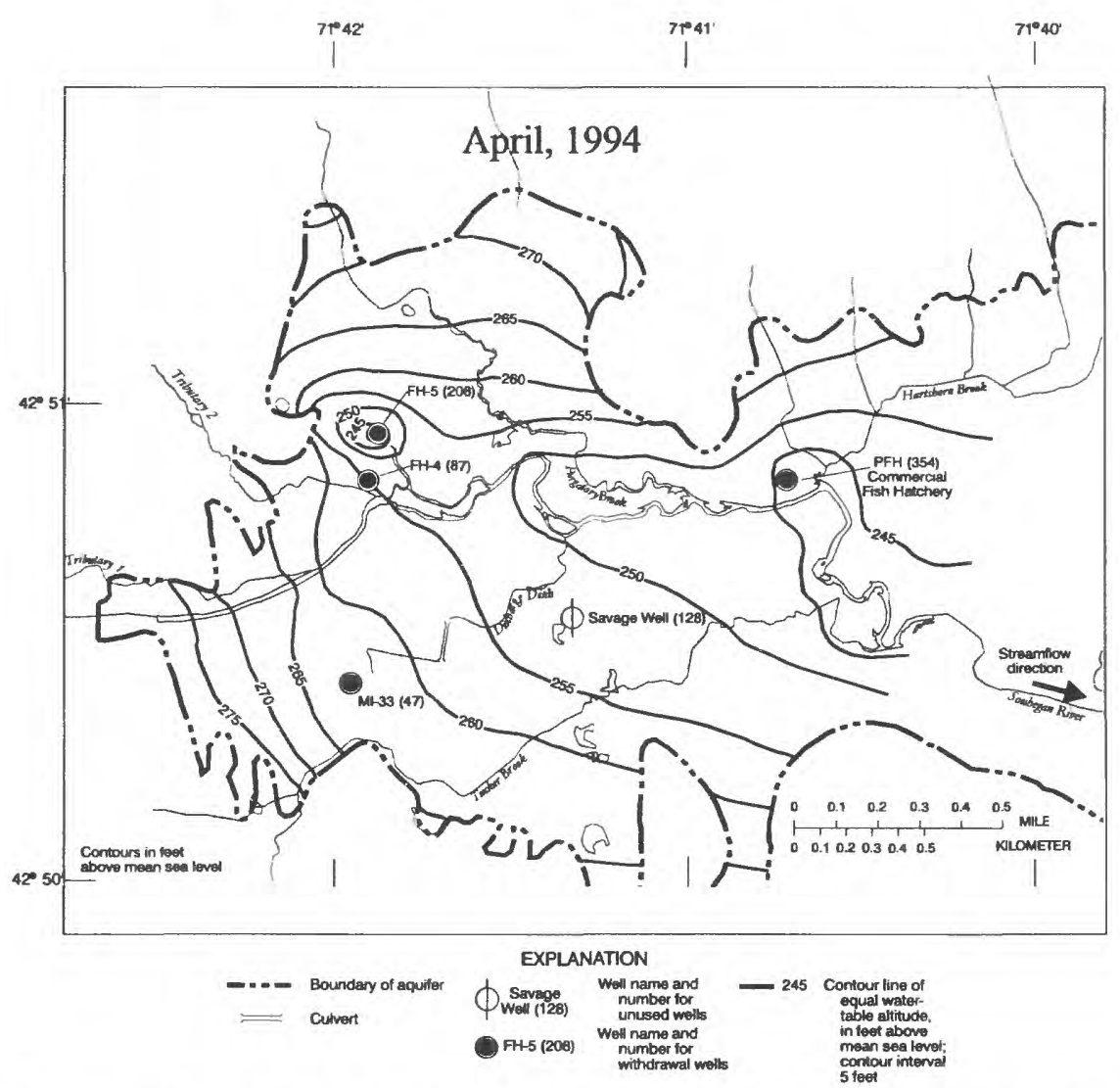

Figure 2. Extent of contaminant plume of total volatile organic compounds (A) and ground-water head contour map (B) in the Milford-Souhegan Glacial-Drift aquifer, Milford, New Hampshire. 


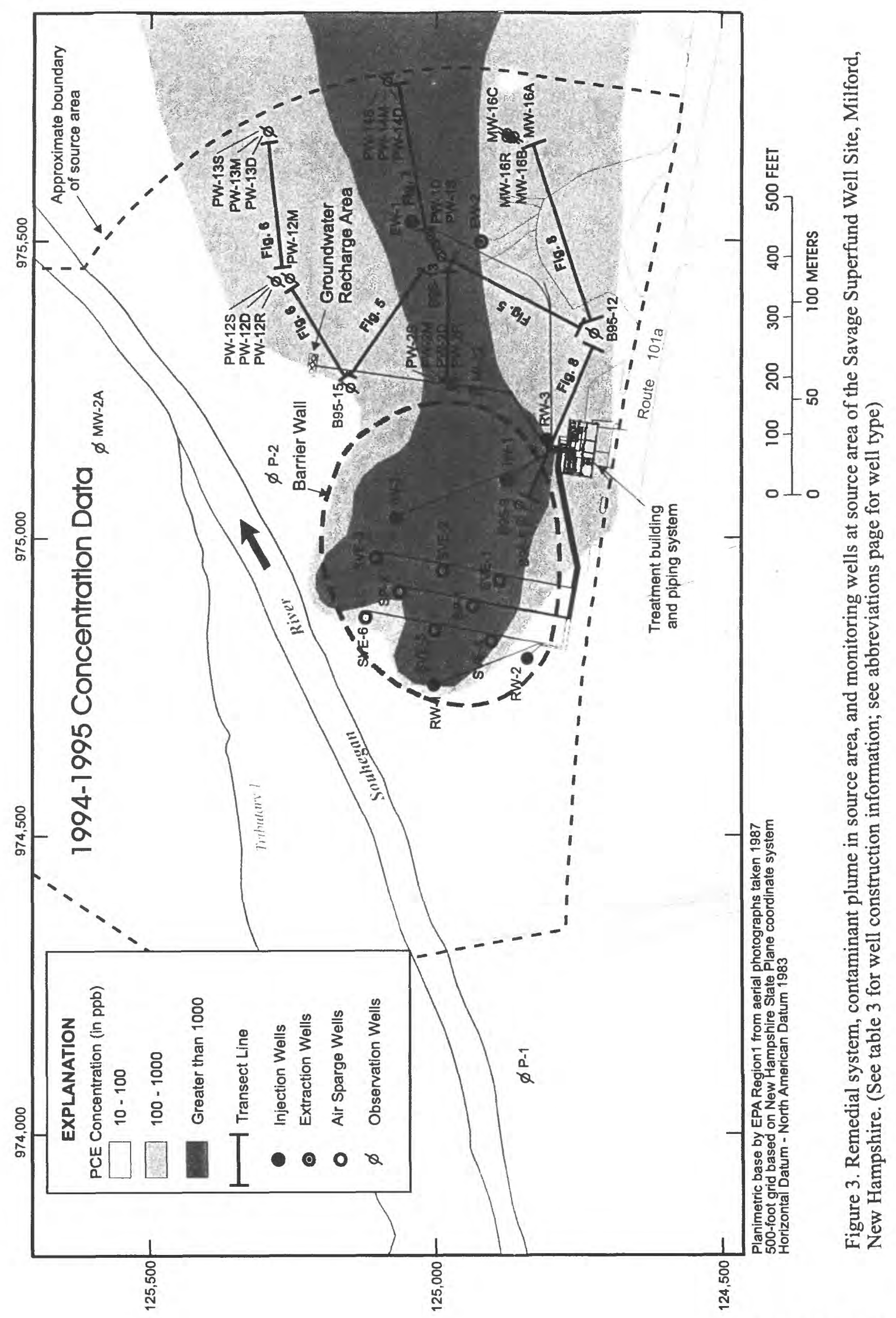

INTRODUCTION 5 


\section{Purpose and Scope}

This report summarizes the results of a 2-year data collection effort (1997-99) to understand the temporal variability of VOC's in ground water at an area previously identified as the primary source of a large VOC plume. The report describes general geologic and geochemical characteristics of the source area, compares VOC concentrations in samples obtained by diffusion samplers and by other sampling methods, and presents an analysis of time trends of VOC concentrations.

Comparisons of results of VOC concentration in samples from passive samplers and collected by purged methods are presented for seven wells completed in unconsolidated, glacial drift. At two of the seven wells, testing of diffusion sampling included comparisons with more than one purged water-sampling device on more than one occasion. All purged water samples were collected following USEPA low-flow sampling procedures.

Time trends in concentrations of VOC's from diffusion samplers are presented for 16 wells (14 glacial-drift wells and two bedrock wells). Seven of the sixteen wells had diffusion-sampling results tested by comparing with purged water-sampling results as previously mentioned. At one other well, a bedrock well, diffusion-sampling results from a vertical string of samplers were compared to one purged sample.

The primary VOC's detected in the study area include tetrachloroethylene (PCE), trichloroethylene (TCE), and cis-1,2-dichloroethene (cis-1,2DCE). Other VOC's were detected but at levels insufficient for comparison.

\section{Description of Study Area}

The study area coincides with the area identified as the primary source area of VOC's to the Savage Well Superfund Site in Milford, New Hampshire (figs. 2 and 3). It is located in the western part of the Savage Well Superfund Site. The source area was the site of a now discontinued tool company where solvents were discharged into the subsurface for many years until the early 1980's. Although discharges have ceased, the underlying contaminant-soaked sediments and immiscible solvents continued to contaminate ground water flowing easterly underneath the site until a barrier wall was constructed. This large plume continues to threaten existing groundwater usage at State and commercial fish hatcheries (fig. 2) and restricts the full beneficial use of this resource.

The barrier wall is constructed of low permeability materials and encapsulates the highest concentrations of contaminants. The barrier wall encircles $0.008 \mathrm{mi}^{2}$ area. The wall fully penetrates the unconsolidated glacial drift (both stratified drift and glacial till) and sits atop the bedrock. Various injection and extraction wells (fig. 3 and table 1) were constructed to insure hydraulic isolation and reduce contaminant mass inside the barrier wall and to capture and treat the contaminants outside the barrier wall. PCE is the primary contaminant and it's maximum concentrations range from 100,000 parts per billion (ppb) inside the wall to $10,000 \mathrm{ppb}$ outside the wall. Secondary VOC contaminants (TCE and $c$ is-1,2DCE) concentrations are typically 1-2 orders of magnitude less than those of PCE.

The study area is underlain by up to $100 \mathrm{ft}$ of sands and gravels, and a discontinuous till overlying a biotite granite and gneiss bedrock. Ground-water flow is to the east at velocities of up to several feet per day in the unconsolidated sediments. A partially penetrating river, called the Souhegan River, bounds the northwestern part of the source area. Here the river losses flow and recharges the aquifer on average of about $4 \mathrm{ft}^{3} / \mathrm{s}$.

\section{Previous Investigations of Diffusion Sampling}

Methods for ground-water sampling continue to evolve over time. This evolution is driven by advances in understanding of ground-water flow and chemical transport in the aquifer and wells, improvements in equipment, and efforts to reduce sampling costs. Water-quality data collection practices at Superfund sites offer an example of the evolution in ground-water sampling. Retrieval of ground-water samples have utilized decreasingly smaller volumes and lower rates of pumpage since the advent of contaminant sampling. In the early to mid 1980's, samples (for analysis) were commonly collected only after the purging of large volumes of water at high pumping 
Table 1. Well screen data and geology for selected wells in the study area

IAll data in feet: altitude in feet above mean sea level, NGVD29; Aquifer code: S\&G = sand and gravel, $\mathrm{f}-\mathrm{c}=$ fine to coarse, G\&S = gravel and sand, rk=bedrock, --, no data available; site type names explained in abbreviation section of report; all wells shown in figure 3 except PW-3, PW-4, PW-6, PW-8, and PW-10 cluster wells]

\begin{tabular}{|c|c|c|c|c|c|c|c|c|c|}
\hline Well No. & Well name & Easting & Northing & Site type & $\begin{array}{l}\text { Altitude of } \\
\text { land surface }\end{array}$ & $\begin{array}{l}\text { Top of opening } \\
\text { below land } \\
\text { surface }\end{array}$ & $\begin{array}{l}\text { Bottom of } \\
\text { opening } \\
\text { below land } \\
\text { surface }\end{array}$ & $\begin{array}{l}\text { Depth to bed- } \\
\text { rock below } \\
\text { land surface }\end{array}$ & $\begin{array}{l}\text { Screen } \\
\text { material }\end{array}$ \\
\hline 46 & MI-32 & 975247.2 & 124933.7 & obswell & 270.2 & 30.0 & 75.0 & 95 & $\mathrm{~S} \& \mathrm{G}$ \\
\hline 233 & $M W-16 A$ & 975671.2 & 124863.1 & obswell & 267.5 & 16.9 & 26.9 & -- & S\&G \\
\hline 310 & $\mathrm{MW}-2 \mathrm{~A}$ & 975148.9 & 125591.3 & obswell & 266.6 & 29.0 & 39.0 & -- & $S \& G$ \\
\hline 321 & MW-16B & 975671.0 & 124868.6 & obswell & 267.6 & 39.6 & 49.6 & - & Sand, f-c \\
\hline 335 & P-1 & 974088.3 & 124847.5 & obswell & 276.6 & 13.9 & 14.9 & - & S\&G \\
\hline 336 & P-2 & 975100.9 & 125281.9 & obswell & 268.6 & 17.0 & 18.0 & -- & S\&G \\
\hline 344 & $M W-16 C$ & 975678.1 & 124877.1 & obswell & 267.4 & 73.2 & 83.2 & 87.5 & S\&G \\
\hline 345 & MW-16R & 975670.8 & 124875.2 & obswell & 266.5 & 88.0 & 138.0 & 87.5 & rock \\
\hline 404 & B95-09 & 975039.81 & 124825.60 & obswell & 270.31 & 10.0 & 20.0 & - & $\mathrm{S} \& \mathrm{G}$ \\
\hline 407 & B95-12 & 975343.81 & 124724.70 & obswell & 269.45 & 55.0 & 60.0 & 76 & G\&S \\
\hline 408 & B95-13 & 975490.62 & 125002.0 & obswell & 267.01 & 60.0 & 65.0 & 90.5 & S\&G \\
\hline 409 & B95-15 & 975254.0 & 125149.40 & obswell & 269.61 & 85.0 & 95.0 & 96.5 & G\&S \\
\hline 531 & PW-1D & 975507.1 & 125010.99 & obswell & 266.88 & 84.48 & 94.48 & 94 & Till/rk \\
\hline 535 & PW-2R & 975254.74 & 124973.56 & obswell & 268.92 & 113.9 & 133.93 & 102 & rock \\
\hline 536 & PW-3S & 975059.0 & 125239.0 & obswell & 269.83 & 19.76 & 29.76 & -- & S\&G \\
\hline 537 & PW-3D & 975059.1 & 125239.1 & obswell & 269.84 & 84.85 & 94.85 & 94.5 & $\mathrm{~S} \& \mathrm{G}$ \\
\hline 538 & PW-4M & 974970.0 & 124767.0 & obswell & 271.81 & 31.87 & 41.87 & -- & S\&G \\
\hline 539 & PW-4D & 974970.1 & 124767.0 & obswell & 272.01 & 62.0 & 72.0 & 70 & S\&G/rk \\
\hline 543 & PW-6S & 975016.0 & 124942.0 & obswell & 276.65 & 23.63 & 33.63 & - & S\&G \\
\hline 544 & PW-6M & 975016.1 & 124942.1 & obswell & 276.37 & 40.39 & 50.39 & -- & S\&G \\
\hline 545 & PW-6D & 975016.2 & 124942.2 & obswell & 276.98 & 87.6 & 97.6 & 94 & S\&G/rk \\
\hline 546 & PW-6R & 975016.3 & 124942.3 & obswell & 276.32 & 101.04 & 111.04 & 95 & rock \\
\hline 549 & PW-8M & 974856.2 & 125140.4 & obswell & 273.34 & 31.37 & 41.37 & -- & S\&G \\
\hline 551 & PW-10M & 975152.0 & 125127.0 & obswell & 273.98 & 50.15 & 60.15 & - & S\&G \\
\hline 552 & PW-10D & 975152.1 & 125127.1 & obswell & 273.80 & 94.71 & 104.71 & -- & S\&G \\
\hline 555 & PW-12S & 975432.0 & 125281.0 & obswell & 265.73 & 18.1 & 28.1 & -- & S\&G \\
\hline 556 & PW-12M & 975437.17 & 125255.65 & obswell & 265.81 & 57.8 & 68.0 & -- & S\&G \\
\hline 557 & PW-12D & 975432.20 & 125281.20 & obswell & 265.69 & 87.0 & 97.0 & -- & Sand \\
\hline 558 & PW-12R & 975432.30 & 125281.30 & obswell & 265.66 & 113.9 & 134.0 & 100 & rock \\
\hline 559 & PW-13S & 975682.00 & 125294.00 & obswell & 267.68 & 20.3 & 30.3 & -- & S\&G \\
\hline 560 & PW-13M & 975682.10 & 125294.10 & obswell & 267.86 & 59.8 & 70.0 & -- & $\mathrm{S} \& \mathrm{G}$ \\
\hline 561 & PW-13D & 975682.20 & 125294.20 & obswell & 267.55 & 94.3 & 104.35 & 103 & Gravel/rk \\
\hline 562 & PW-14S & 975765.00 & 125085.00 & obswell & 266.76 & 20.03 & 30.03 & -- & $\mathrm{S} \& \mathrm{G}$ \\
\hline 563 & PW-14M & 975765.10 & 125085.10 & obswell & 266.76 & 60.0 & 70.0 & - & Sand,c-f \\
\hline 564 & PW-14D & 975765.20 & 125085.20 & obswell & 266.77 & 102.71 & 112.71 & 111.5 & Sand,c-f/rk \\
\hline 565 & EW-1 & 975535.23 & 125046.05 & extrawell & 266.88 & 63.55 & 93.55 & -- & S\&G \\
\hline 566 & EW-2 & 975492.89 & 124936.25 & extrawell & 267.05 & 51.22 & 81.22 & 81.5 & S\&G \\
\hline 567 & IW-1 & 975105.37 & 124871.14 & extrawell & 272.4 & 78.32 & 108.32 & 108.3 & Sand \\
\hline 568 & IW-2 & 975037.83 & 125068.37 & extrawell & 277.03 & 78.32 & 108.32 & -- & S\&G \\
\hline 569 & RW-1 & 974751.80 & 125000.52 & injwell & 273.67 & 31.65 & 41.65 & -- & Gravel \\
\hline 570 & RW-2 & 974799.44 & 124838.74 & injwell & 273.38 & 22.04 & 32.04 & -- & S\&G \\
\hline 571 & RW-3 & 975168.45 & 124805.82 & injwell & 269.96 & 18.450 & 28.450 & -- & Gravel \\
\hline 572 & SP-1 & 974885.08 & 124935.83 & Sparwell & 274.45 & 60.66 & 65.66 & 66.8 & Sand \\
\hline 573 & SP-2 & 974910.85 & 125063.90 & Sparwell & 275.34 & 59.71 & 64.71 & -- & Sand \\
\hline 574 & SVE-1 & 974927.14 & 124888.11 & airwell & 274.99 & 8.37 & 23.36 & -- & -- \\
\hline 575 & SVE-2 & 974946.49 & I24988.03 & airwell & 276.25 & 9.41 & 24.41 & - & -- \\
\hline 576 & SVE-3 & 974966.91 & 125106.60 & airwell & 273.38 & 12.34 & 27.34 & - & -- \\
\hline 577 & SVE-4 & 974828.74 & 124901.85 & airwell & 274.02 & 12.66 & 27.66 & - & -- \\
\hline 578 & SVE-5 & 974846.81 & 125001.08 & airwell & 274.76 & 7.870 & 23.87 & -- & -- \\
\hline 579 & SVE-6 & 974870.28 & 125128.88 & airwell & 273.7 & 12.39 & 27.39 & -- & -- \\
\hline
\end{tabular}


rates. Typically, a minimum of three casing volumes of water were extracted from the well prior to sampling as an attempt to obtain representative water samples. High turbidity in the water samples, a common effect of large volume pumping, was reduced by filtering. Continuing research in contaminant transport found that high rates and volumes of pumping resulted in a number of undesirable effects - such as problems in disposing of contaminated water, and mobilization of particulates surrounding the well as witnessed by high turbidity. The presence of large particulates in sampled water could elevate concentrations of contaminants even if filtration is used and potentially overexaggerate the magnitude of contaminant transport because these particles are mobilized only locally around a pumped well.

With the advent of low-flow and low-volume sampling methods (Pohlmann and others, 1994; McFarlane, 1996), less turbulent approaches have been developed that seek to minimize the entrainment of large locally mobile particulates suspended in the water sample. An extension of this low-flow, less turbulent trend is the passive (no purge) sampling approach and specifically, diffusion sampling (Vroblesky and Hyde, 1997). Diffusion sampling and(or) samplers, as the name implies, work on the principle of diffusion: the movement of chemical compounds as a consequence of concentration gradients. Water-diffusion samplers consist of deionized, contaminant-free water enclosed in polyethylene bags (fig. 4), which are suspended in wells in a mesh sleeve or section of slotted pvc pipe. Contaminants in the well water such as chlorinated VOC's and aromatic VOC's are able to diffuse through the polyethylene bag into the previously contaminant-free water until the concentrations in the bag water and well water equilibrate.

Two types of passive-diffusion samplers have been used in previous studies - a water-vapor sampler and a water-water sampler (like that used for this study). The water-vapor sampler consists of a $40 \mathrm{~mL}$ glass vial enclosed in a water-free sealable polyethylene bag. Concentrations of VOC's in the vapor phase can range from 0.27 to 27.3 times higher than in the water phase (Mullaney and others, 1999). Therefore, it is difficult to infer a correlation between concentrations in water-vapor samplers and water-water samplers. For this reason, watervapor diffusion method should not be used to infer ground-water concentrations.

Water-vapor samplers were used by Vroblesky and Robertson (1996) to collect time-series VOC data and to monitor changes in VOC concentrations of ground water discharging to surface-water bodies. Previous studies using water-water samplers include work at several Air Force Bases [Hanscom Air Force Base in Massachusetts (Forest Lyford, U.S. Geological Survey, oral commun., 1999); and McClellan Air Force Base in California (Parsons Engineering Science, Inc., 1999)]. In both those studies, VOC concentrations from diffusion samplers compared favorably to VOC concentrations from purged water samples collected in accordance with low-flow procedures (also used in this study). Vroblesky and Hyde (1997) found that the concentrations of VOC's (primarily PCE, TCE, cis-1,2DCE, trans-1,2-dichloroethene (trans-1,2DCE), 151-DCA, and vinyl chloride (VC)) in water-diffusion samples retrieved at five wells during one-round of sampling were within 10 percent of concentrations in samples retrieved by submersible and bladder pumps and bailers.

Diffusion sampling may not be an effective sampling method for all VOC's. VOC's with low vapor pressures and(or) extremely high solubilities may not reach equilibrium between the water column and the contents of the sampler within a reasonable time frame (Paul Hare, General Electric Company, written commun., 1999). For example, acetone was observed not to reach equilibrium after 10 days, while most of the chlorinated solvents quickly reached equilibrium within several days.

\section{Acknowledgments}

This study, which is part of a larger remedial effort of the Savage Well Superfund Site, is a collaborative effort between Federal, State, and local governments, and private companies and individuals. The authors wish to express thanks to Richard Goehlert, remedial project manager of the Savage Well Superfund Site of the U.S. Environmental Protection Agency, Region 1; Thomas Andrews of the New Hampshire Department of Environmental Services; and Joseph Newton of Camp, Dresser, and McKee, Inc., for their cooperation and support. Methane data were analyzed by Cindy Mosedale and Dean Moosavai of the University of New Hampshire. Total organic carbon data were analyzed by Dr. William McDowell also of the University of New Hampshire. The 
(A)

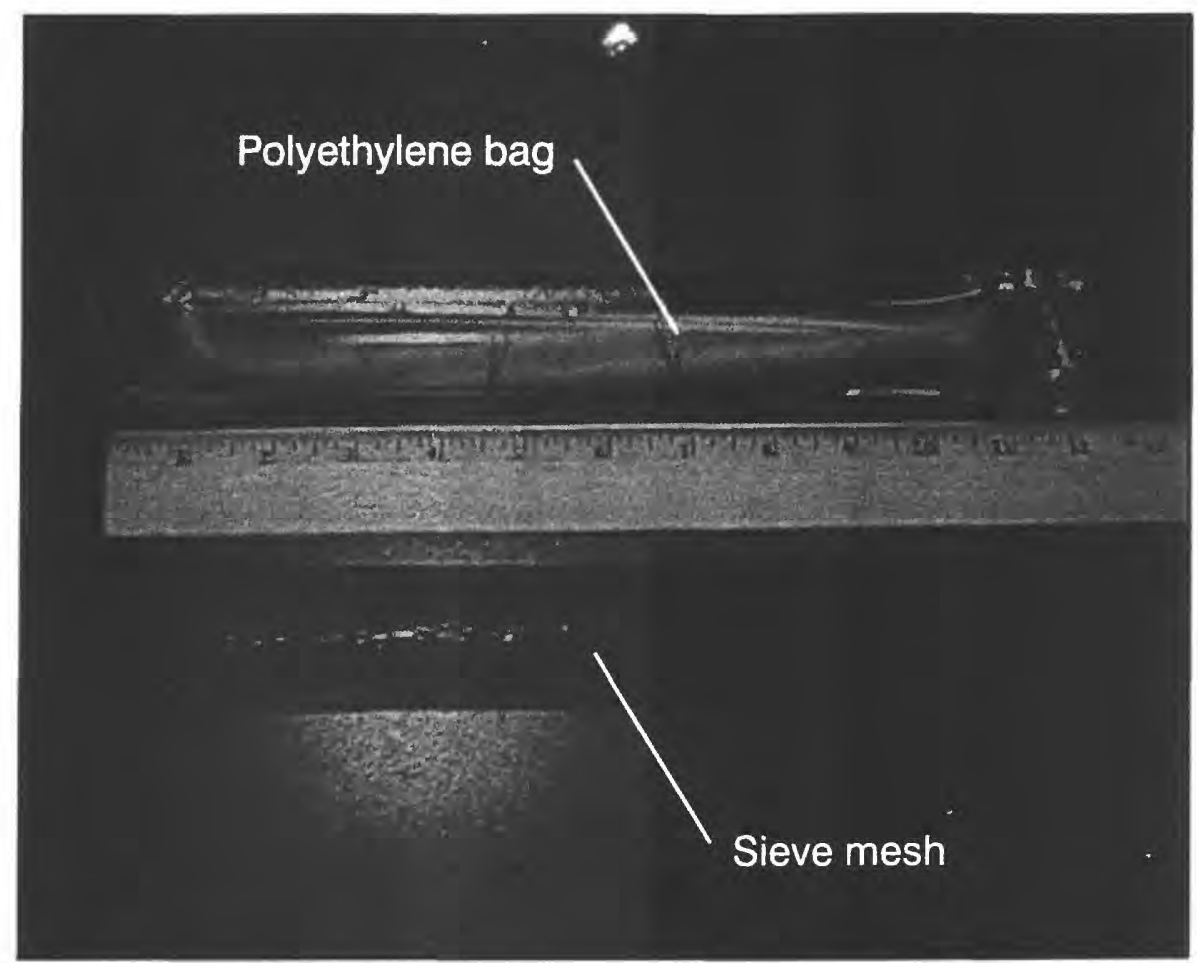

(B)

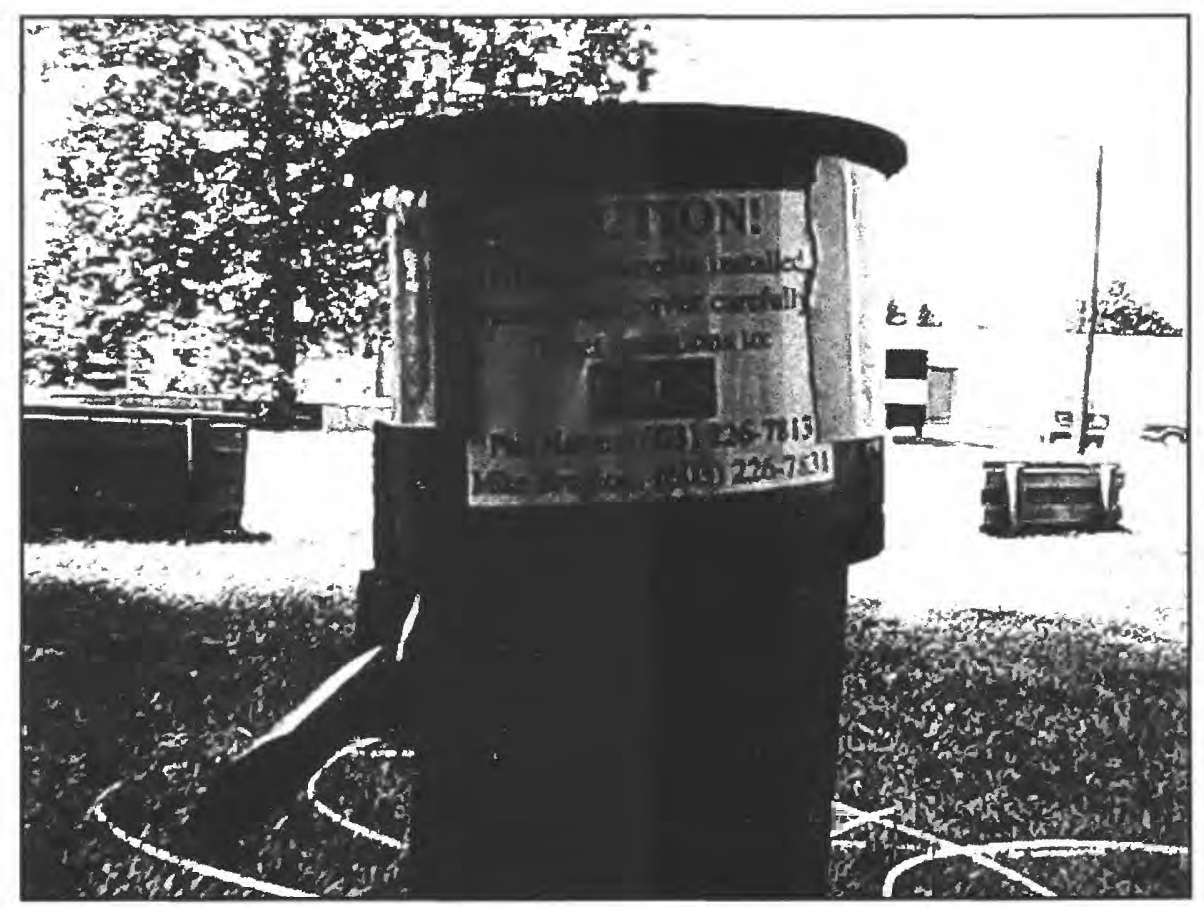

Figure 4. Diffusion sampler (A) and well identifier (B) used to label wells. 
majority of the VOC analyses and geochemical analyses were done by the New Hampshire Department of Environmental Services Laboratory. Scott Clifford of the U.S. Environmental Protection Agency, Region 1, also performed additional VOC analyses with the U.S. Environmental Protection Agency, Region 1 Mobile Laboratory.

\section{HYDROGEOLOGIC SETTING}

The unconsolidated sediments beneath the study site consist of up to 100-ft thick deposits of predominantly sand and gravel. Borehole geophysical logs (natural gamma and electromagnetic conductivity) and lithologic logs from wells along a north to south transect of the site (fig. 5) and west to east transect (figs. 6-8) show the sand and gravel sequences are interspersed with discontinuous finer grained sands at depths of $40 \mathrm{ft}$ and $70 \mathrm{ft}$. Coarsegrained deposits (cobbles and gravels) occur at the uppermost layer near the water table (at a depth of 6-14 ft), at around $60 \mathrm{ft}$, and at the base of the unconsolidated sediments at $90 \mathrm{ft}$. Till, which discontinuously mantles the bedrock, is thickest to the west (not shown on figures) and thins to the east.

The stratigraphy appears to suggest a sequence of multiple glacial advances. The deep, coarse-grained deposits at 85-90 ft below land surface (figs. 5-8) suggest that subglacial meltwater may have contributed to deep erosion into the bedrock from the glacier. The remaining deposits suggest meltwater deposition in the form of deltas, outwash, and lastly a glacial outburst deposit as witnessed by the coarse cobble zone near the uppermost sequence.

Ground water flows easterly through the study area and receives recharge from the Souhegan River, which loses an average of approximately $4 \mathrm{ft}^{3} / \mathrm{s}$ to the aquifer. Water-table maps from pre- and post-wall construction indicate that construction of the low-permeability barrier wall has not impeded recharge from the Souhegan River (fig. 9). The direction and magnitude of maximum ground-water gradients computed from a three-point planar solution (Johnston and Harte, 1998) for the downgradient side of the site shows that completion of the barrier wall in November 1998, coupled with operation of extraction wells (EW1 and EW2, fig. 3) since mid-May 1999, have moderated variations in direction of gradients (fig. 10a) and increased the maximum gradients (fig. 10b).

\section{GEOCHEMISTRY OF WATERS}

The geochemistry of ground water is an important factor in assessing the potential for biodegradation of chlorinated aliphatic compounds like PCE and will therefore affect analysis of time trends. Processes such as reductive dechlorination occur when electron donors are available and competing electron acceptors are eliminated (Wiedemeier and others, 1998). The principal electron donor in the absence of anthropogenic sources is organic carbon in the aquifer. Electron acceptors include oxygen, nitrate, iron, and sulfate.

The sampled waters at the site are characterized by low total organic carbon (TOC) (less than $2 \mathrm{mg} / \mathrm{L}$ ). A listing of median concentrations of key geochemical parameters, grouped by uncontaminated and contaminated wells and by depth of well (shallow, medium, and deep) is given in table 2. TOC ranges from 0.83 to $1.67 \mathrm{mg} / \mathrm{L}$. Dissolved oxygen decreases with depth and is lower in contaminated wells than in uncontaminated wells. Whereas oxygen levels appear to be reduced in the contaminated parts of the aquifer, other electron acceptors show no appreciable difference between uncontaminated and contaminated wells. Chloride concentrations are affected at the site by road-salting along the southern part of the plume, which skews comparisons between background and contaminated areas. In general, the geochemical data suggest that ground waters underneath the site are not conducive to widespread biological degradation of PCE at rapid rates (such as with degradation half lives of 1 year or less) over a large part of the source area. 

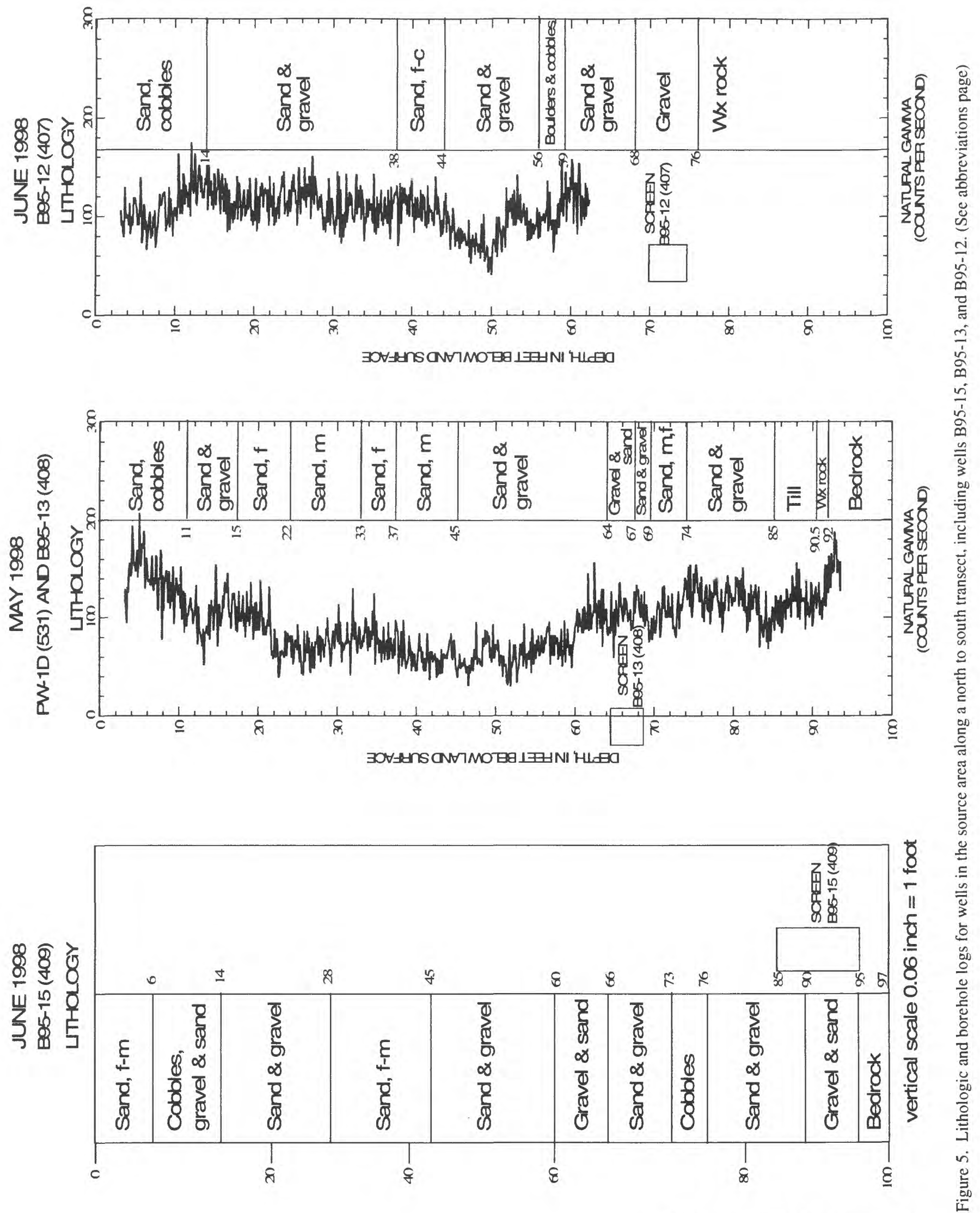

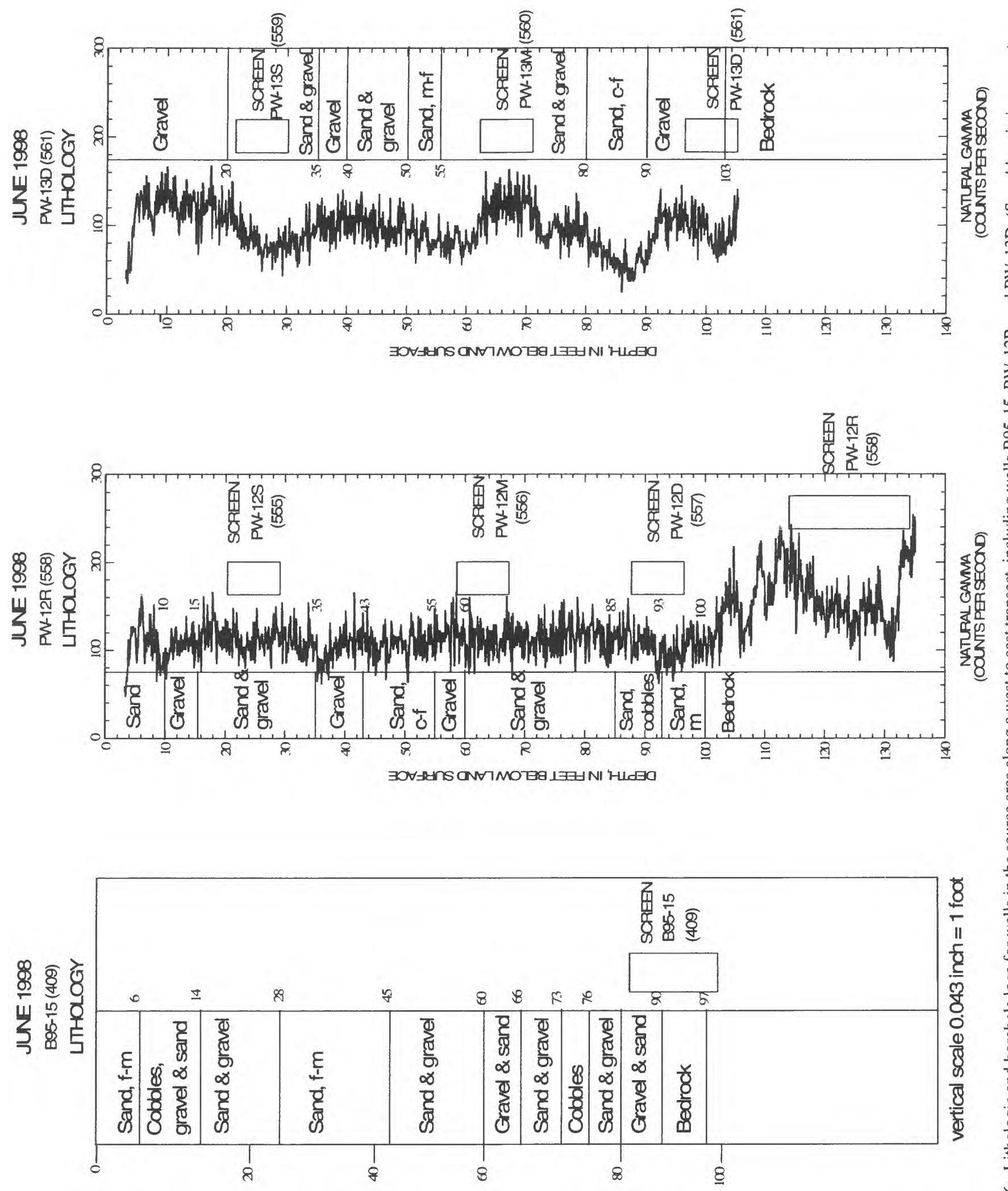

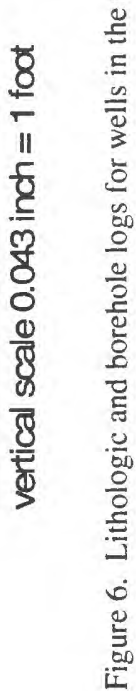



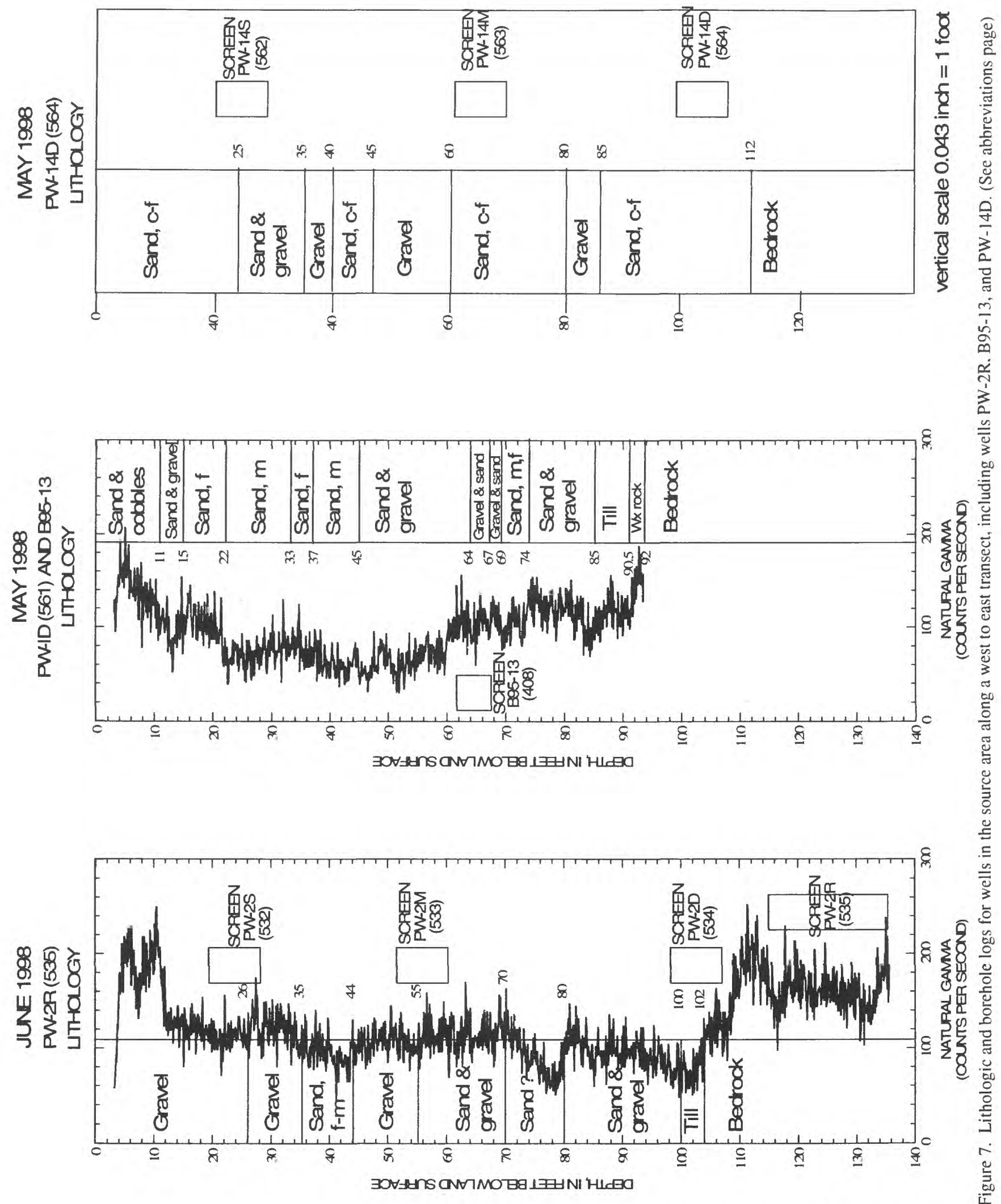

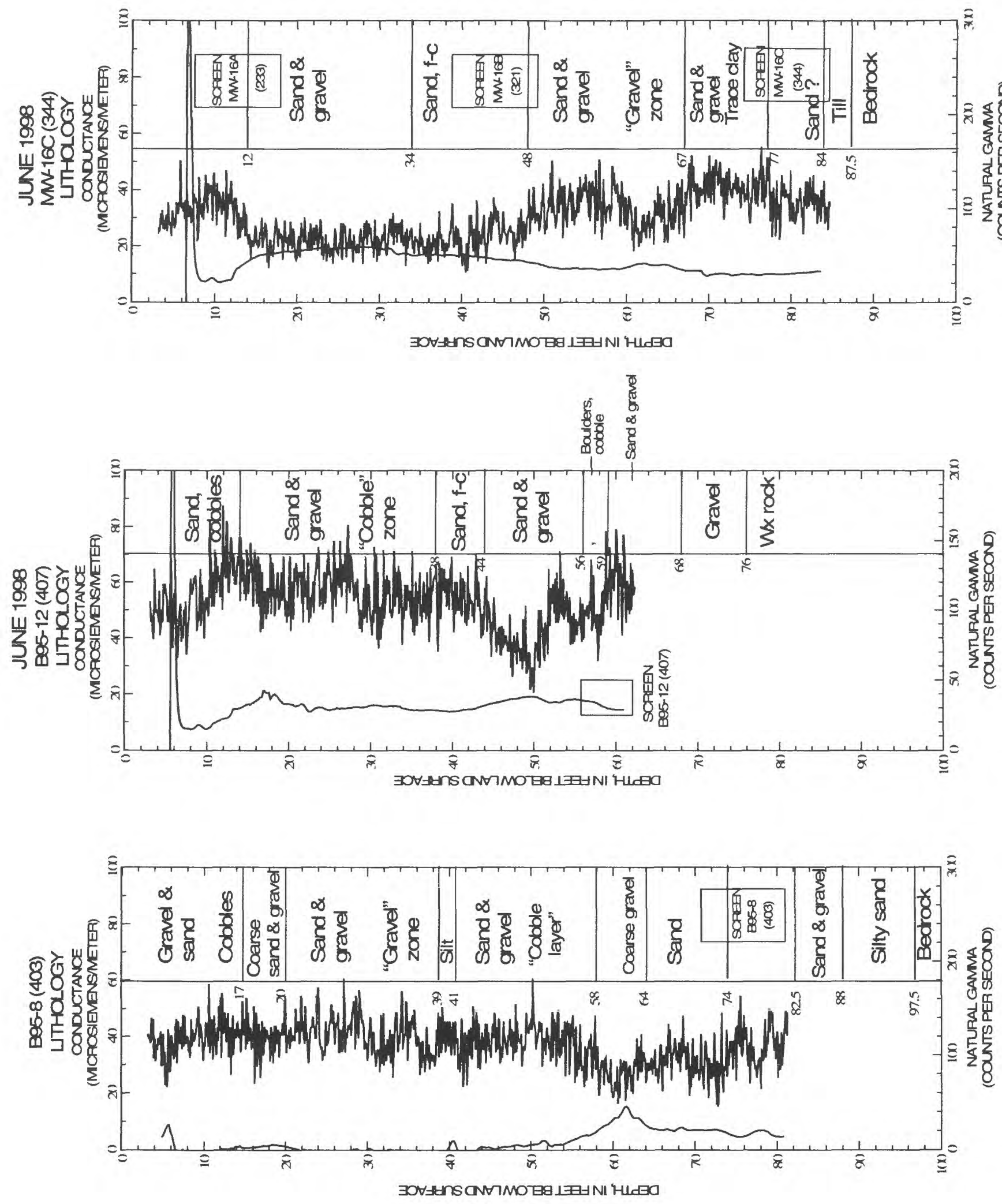
(A)

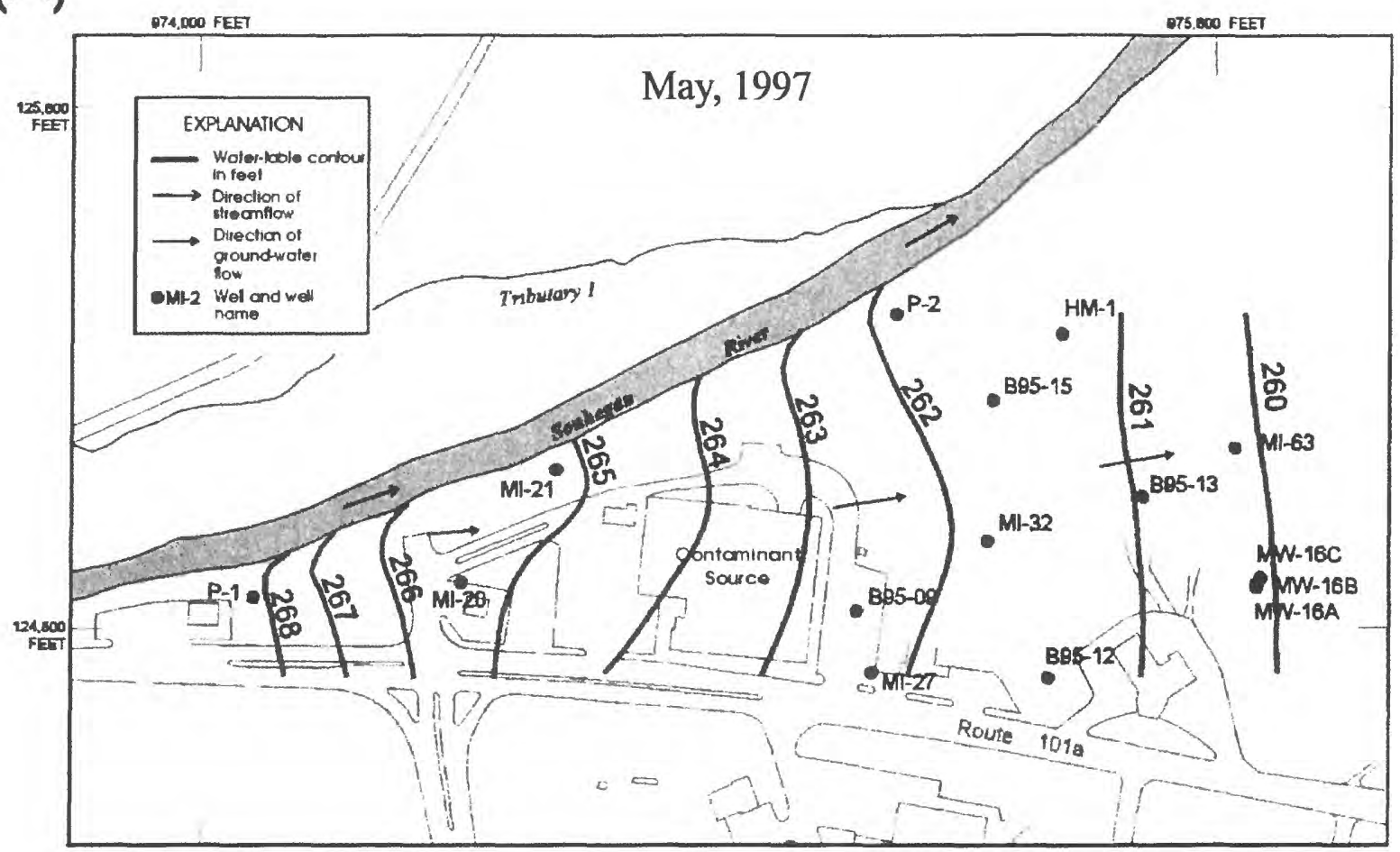

(B)

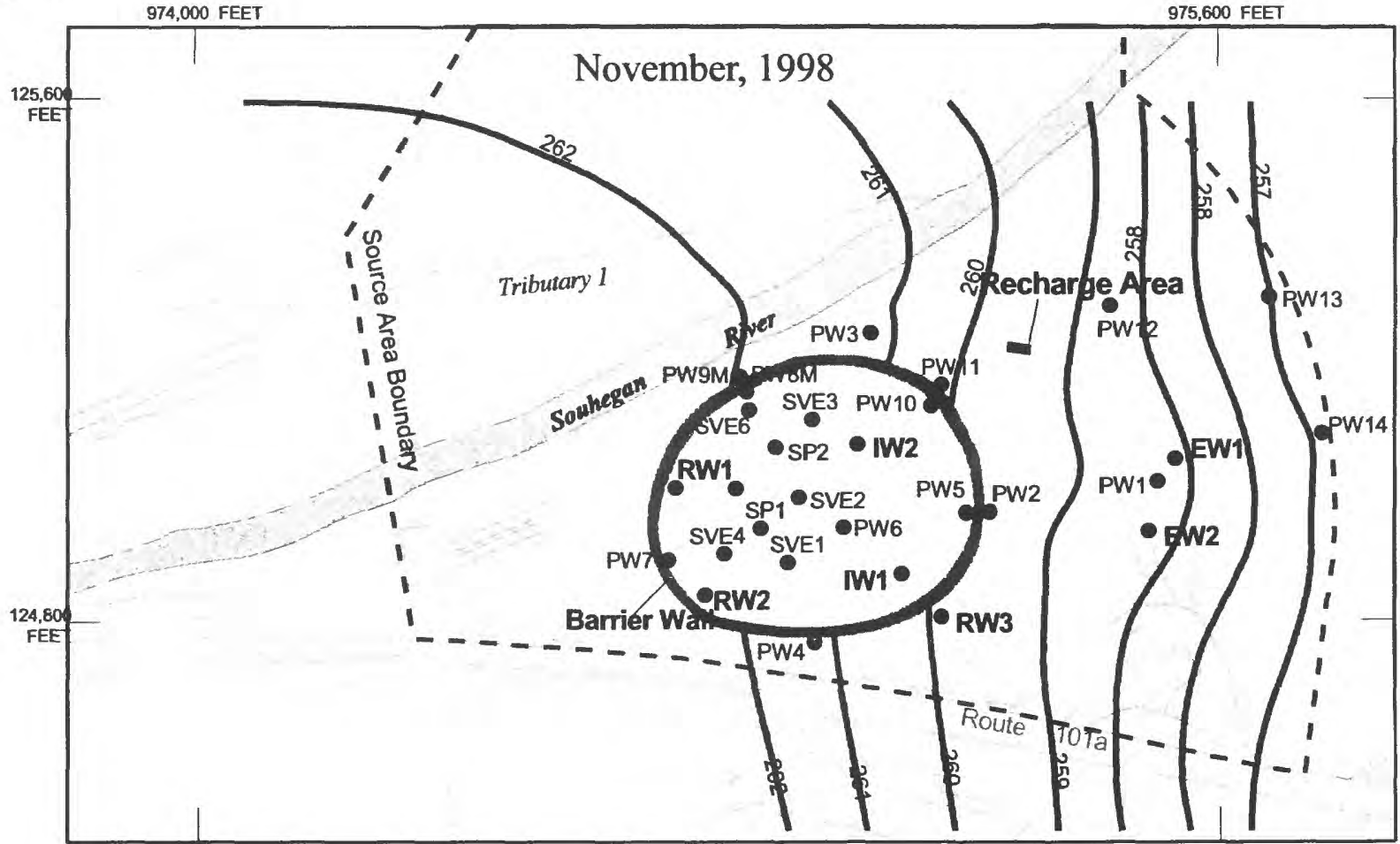

Plonimetic base by EPA Region 1 from ceria photgraphs taken 1987 Remedial construction data from Camp, Dresser, and Mckee inc., 1999

Figure 9. Water-table surface for pre-remedial construction (May 1997) (A) and post-remedial construction (November 1998) (B). 


\section{Angular Direction of maximum gradient, from true north}

(A)

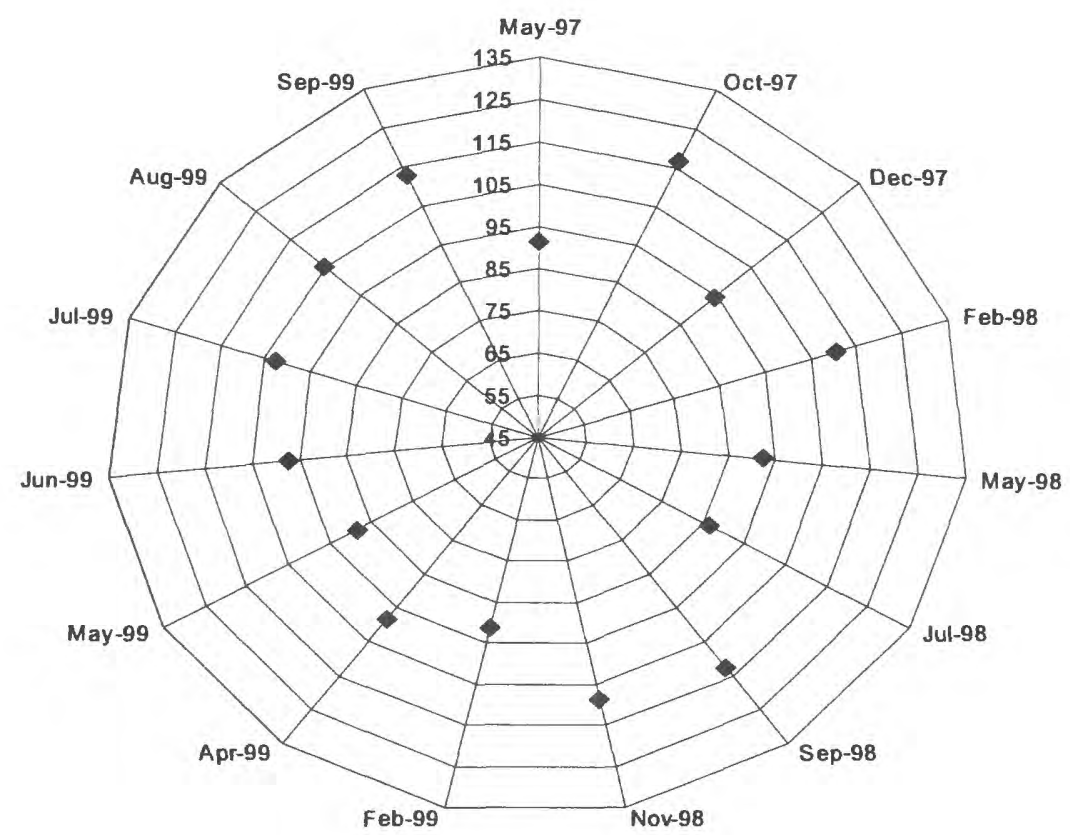

Maximum gradient, ft/ft

(B)

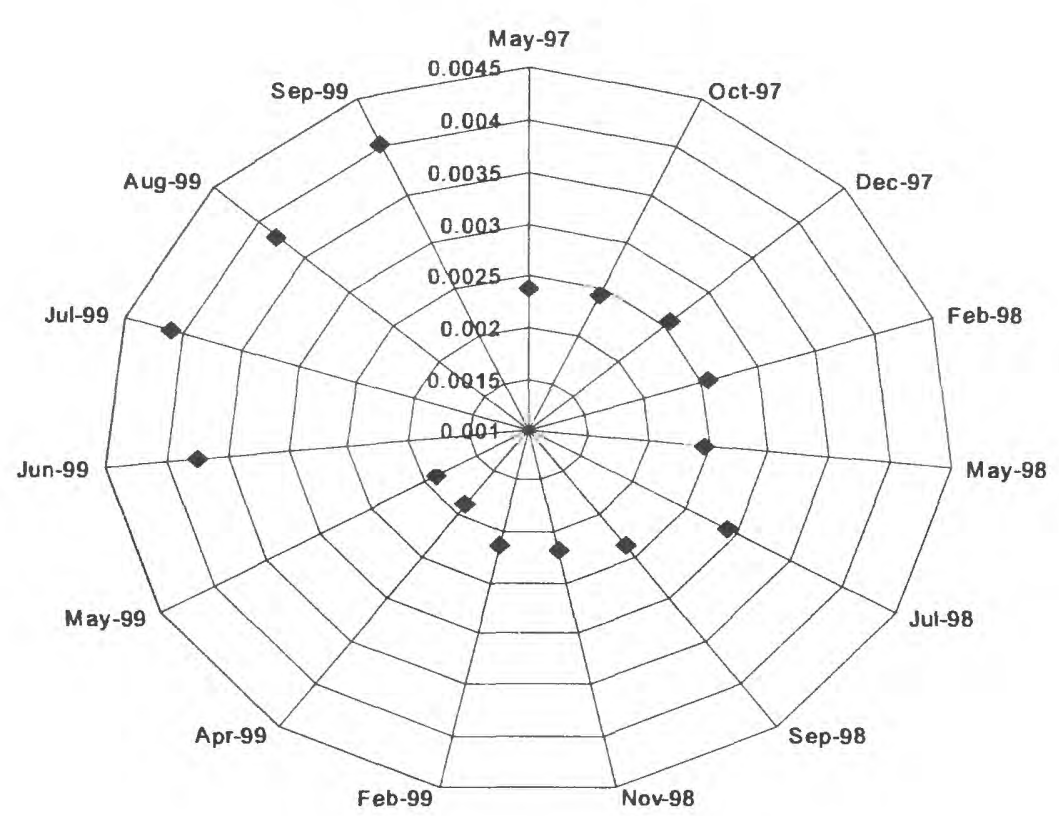

Figure 10. Angular direction of maximum ground-water gradient from true north (A) and gradient (B) computed from three-point planar solution from wells B95-12, B95-15, and B9513.(Well locations shown in figure 3) 
Table 2. Median concentrations of key geochemical parameters in uncontaminated and contaminated with volatile organic (compounds) water samples from the study area

[Deep wells greater than 80 feet; Medium wells from 40-80 feet; Shallow wells are from 0-40 feet below land surface; mg/L means milligram per liter; ppm means part per million; < means less than; data from May 1997 to April 1999]

\begin{tabular}{|c|c|c|c|c|c|c|}
\hline & \multicolumn{2}{|c|}{ Deep wells } & \multicolumn{2}{|c|}{ Medium wells } & \multicolumn{2}{|c|}{ Shallow wells } \\
\hline & $\begin{array}{l}\text { Uncontami- } \\
\text { nated }\end{array}$ & Contaminated & $\begin{array}{l}\text { Uncontami- } \\
\text { nated }\end{array}$ & Contaminated & $\begin{array}{l}\text { Uncontami- } \\
\text { nated }\end{array}$ & Contaminated \\
\hline Number of samples & 5 & 10 & 17 & 12 & 15 & 4 \\
\hline $\mathrm{pH}$ & 6.3 & 7.11 & 5.83 & 5.86 & 5.9 & 5.8 \\
\hline Eh & 214 & 0 & 279 & 292 & 194 & 230 \\
\hline Dissolved oxygen (mg/L) & 0.4 & 0.55 & 3 & 0.7 & 2 & 0.8 \\
\hline Carbon dioxide (mg/L) & 15 & 18.8 & 20.5 & 25 & 23.5 & 30 \\
\hline Water temperature (degrees celsius) & 11.5 & 13.6 & 12.1 & 11.1 & 11 & 11.4 \\
\hline Ferrous iron (mg/L) & 0 & 0 & 0 & 0 & 0 & 0 \\
\hline Methane (ppm) & 3.5 & 3.0 & 1.79 & 3.15 & 1.91 & 6.1 \\
\hline Total organic carbon (mg/L) & 0.83 & 0.94 & 1.13 & 0.86 & 1.67 & 0.9 \\
\hline Alkalinity $\left(\mathrm{mg} / \mathrm{L}\right.$ as $\left.\mathrm{CaCO}_{3}\right)$ & 17.5 & 58.4 & 9.2 & 14.8 & 13.5 & 15 \\
\hline Nitrate $(\mathrm{mg} / \mathrm{L})$ & $<0.05$ & 0.32 & 0.34 & 0.55 & 0.12 & 1.03 \\
\hline Nitrate+nitrite $(\mathrm{mg} / \mathrm{L})$ & $<0.05$ & 0.72 & 1.3 & 0.55 & 0.27 & 1.79 \\
\hline Sulfate $(\mathrm{mg} / \mathrm{L})$ & 9 & 12 & 13 & 10 & 11 & 24.5 \\
\hline Chloride (mg/L) & 9 & 29 & 13 & 21 & 20.5 & 22.5 \\
\hline
\end{tabular}

\section{METHODS OF DATA COLLECTION}

Well data are referenced by local name as assigned by driller or principal investigative party. Well data are also referenced in several locations by a project number to allow for cross-referencing in this report, as well as with previous reports of the area. For example, well B95-15 is the principal local name and well number 409 is the number assigned by the project. Only the principal local name will be used in the report after the first cross reference.

\section{Description of Chemical-Monitoring Program}

From May 1997 to April 1999, water samples were collected bimonthly at a minimum of 2 wells (B95-15 (well number 409) and B95-13 (well number 408) and a maximum of 6 wells (B95-15, B95-13, B95-12 (well number 407), PW-13M (well number 560), PW-14M (well number 563)(fig. 3)). Samples were collected by multiple methods including diffusion samplers and low-flow purged samplers: peristaltic, bladder, and Voss pumps. Additional wells were sampled using low-flow sampling techniques on several occasions including May 1997, June 1997, December 1997, May 1998, July 1998, September 1998, November and December 1998, and April 1999. From May 1999 to September 1999 samples were collected with diffusion samplers.

A list of constituents analyzed, methods of analysis, and detection limits is provided in table 3. Measured constituents are subdivided by field and laboratory methods. Samples for analysis of volatile organic compounds were collected in $40 \mathrm{~mL}$ septum vials and analyzed within 2 weeks of sample collection by USEPA method 8260B (U.S. Environmental Protection Agency, 1996a). Samples were analyzed by State of New Hampshire Department of Environmental Services Laboratory. During a detailed sampling test in April 1999, a USEPA, Region 1 mobile laboratory was used to analyze samples. Aqueous samples were analyzed using USEPA Region's 1 standard operating procedures for head-space screening for VOC's with a Shimadzu Gas Chromotogram 14A equipped with a $30 \mathrm{~m}, 0.53 \mathrm{~mm}$ DBPS- 624 column and a photoionization detector (PID). Concentrations were calculated using the external standard technique (Clifford, Scott, U.S. Environmental Protection Agency, written commun., 1999). 
Table 3. Instruments used, instrumentation method code, and method detection limits, for analyses of water samples

[A complete listing of constituent names are provided in appendix 2; $\mathrm{cm}$ mean centimeter; $\mathrm{mg} / \mathrm{L}$ means milligrams per liter; ppm means part per million; NTU means neophelometric turbidity units; EPA means Environmental Protection Agency]

\begin{tabular}{|c|c|c|c|}
\hline $\begin{array}{l}\text { Location of } \\
\text { analysis }\end{array}$ & Constituent & Instrument or method code & $\begin{array}{l}\text { Method detection limit } \\
\text { or range }\end{array}$ \\
\hline \multirow[t]{9}{*}{ Field } & Temp & YSI Model 54A Oxygen Meter & 1.0 degrees Celsius \\
\hline & SC & Hach Model 44600 Conductivity/TDS Meter & $0.1 \mathrm{micro}-\mathrm{seimens} / \mathrm{cm}$ \\
\hline & $\mathrm{pH}$ & Orion 915600 combination $\mathrm{pH}$ probe & $0.02 \mathrm{pH}$ units \\
\hline & DO & YSI Model 54A Oxygen Meter & $0.1 \mathrm{mg} / \mathrm{L}$ \\
\hline & DO & Chemetrics kit 7501,7512 & $0-1 \mathrm{ppm}, 1-10 \mathrm{ppm}$ \\
\hline & $\mathrm{CO}_{2}$ & Chemetrics kit K1910 & $10-100 \mathrm{ppm}$ \\
\hline & $\mathrm{Fe}^{2+}$ & Hach kit \#26672 & $0.0-10.0 \mathrm{mg} / \mathrm{L}$ \\
\hline & Turbidity & Hach $2100 \mathrm{P}$ turbidimeter & $0.01-1000 \mathrm{NTU}$ \\
\hline & Eh & Orion $9678 \mathrm{BN}$ ion selective probe & millivolts \\
\hline \multirow[t]{20}{*}{ Laboratory } & $\mathrm{NH}^{4+}$ & EPA 350.1 & $0.25 \mathrm{mg} / \mathrm{L}$ \\
\hline & $S_{2}$ & EPA 376.2 & $0.1 \mathrm{mg} / \mathrm{L}$ \\
\hline & $\mathrm{Cl}-$ & EPA 325.2 & $2 \mathrm{mg} / \mathrm{L}$ \\
\hline & $\mathrm{SO}_{4}{ }^{2-}$ & EPA 300.0 & $1 \mathrm{mg} / \mathrm{L}$ \\
\hline & $\mathrm{NO}_{2}-$ and $\mathrm{NO}_{3}-$ & EPA 353.2 & $0.05 \mathrm{mg} / \mathrm{L}$ \\
\hline & $\mathrm{NO}_{3-}$ & EPA 353.2 & $0.05 \mathrm{mg} / \mathrm{L}$ \\
\hline & $\mathrm{NO}_{3-}$ & Chemetrics R6923 after $12 / 98$ & $0-70 \mathrm{mg} / \mathrm{L}$ \\
\hline & $\mathrm{NO}_{2-}^{-}$ & EPA 353.2 & $0.05 \mathrm{mg} / \mathrm{L}$ \\
\hline & $\mathrm{PO}_{4}{ }^{3-}$ & EPA 365.3 & $0.001 \mathrm{mg} / \mathrm{L}$ \\
\hline & $\mathrm{CA}^{2+}$ & EPA 200.7 & $1 \mathrm{mg} / \mathrm{L}$ \\
\hline & Fe total & EPA 200.7 & $0.05 \mathrm{mg} / \mathrm{L}$ \\
\hline & $\mathrm{Mg}^{2+}$ & EPA 200.7 & $0.1 \mathrm{mg} / \mathrm{L}$ \\
\hline & $\mathrm{Mn}^{2+}$ & EPA 200.7 & $0.01 \mathrm{mg} / \mathrm{L}$ \\
\hline & $\mathrm{K}+$ & EPA 200.7 & $0.4 \mathrm{mg} / \mathrm{L}$ \\
\hline & $\mathrm{Na}+$ & EPA 200.7 & $1 \mathrm{mg} / \mathrm{L}$ \\
\hline & $\mathrm{CH}_{4}$ & Methods described by McAuliffe (1971) and Crill and others, (1988) & $0.01 \mathrm{mg} / \mathrm{L}$ \\
\hline & TOC & EPA 415.1 & $2 \mathrm{mg} / \mathrm{L}$ \\
\hline & Br- & Orion $9635 \mathrm{BN}$ ion selective probe & $0.001 \mathrm{mg} / \mathrm{L}$ \\
\hline & $\mathrm{CaCO}_{3}$ & Titration to 4.5 endpoint using Hach digital titrator & $0.1 \mathrm{mg} / \mathrm{L}$ \\
\hline & Volatile organic compounds & EPA Schedule 8260 & 0.002 to $0.250 \mathrm{mg} / \mathrm{L}$ \\
\hline
\end{tabular}




\section{Sampling Methods and Techniques}

Ground-water samples for VOC analysis were collected by four different sampling techniques: diffusion sampler, peristaltic pump, Voss sampler, and bladder pump. Purged samples using pumps were collected on the same day immediately after diffusion samplers were retrieved. Samples were collected in order of increasing cumulative volume purged in the following sequence: diffusion, Voss, peristaltic, and bladder. For the peristaltic and bladder pumps, samples were collected according to USEPA, Region 1, Standard Operating Procedures (SOP) for low-flow purging and sampling (U.S. Environmental Protection Agency, 1996b).

Diffusion-bag samples were placed at the midpoint of a well screen from a typical period of 2 weeks to 2 months. Diffusion-bags samples were created from a sealed polyethylene bag filled with VOC-free-deionized water. After retrieval of the bags from the well, a small hole is cut in the bag and contents are poured into a 40-mL septum vial. Bags were enclosed in either a mesh screen or a short section of polyvinyl-chloride (PVC) screen and suspended in the well with teflon coated wire and a stainless steel weight. The steps involved in the preparation, installation, and retrieval of diffusion samplers are described in appendix 1 .

A Voss sample was collected once at one well. A Voss sampler is a modified bailer approach to sampling. An inflatable bladder above the bailer separates the water in the well casing from the water in the well screen. A pump inside the bailer extracts water from the volume below the bladder and discharges water above the bladder. Bladder integrity can be monitored by the rise in water levels in the sealed water column above the bladder. After extracting a minimum of one volume of water from the sample interval, the pump is shut off and the bailer removed to the surface where water samples are drawn from the bailer. For the well sampled, the top of the Voss sampler was lowered to $1.0 \mathrm{ft}$ above the top of the well screen. At this depth, the sampler intake is at the midpoint of the well screen and the bladder is at $0.8 \mathrm{ft}$ above the top of the screen. Purging lasted for 7 minutes at a rate of $0.71 \mathrm{~L} / \mathrm{min}$ or 1.4 volumes of water from the sample interval. Because no water discharges to the surface, no field parameters were monitored during purging. The Voss sampler was then withdrawn to land surface and the contents of the sampler were then poured into a $40-\mathrm{mL}$ septum vial.

Peristaltic-pump samples were collected by inserting a dedicated polyethylene tube for each well at the midpoint of the well screen, attaching the tube to the pump, and purging water following low-flow sampling techniques. Field parameters monitored during purging include water level, pumping rate, specific conductance, $\mathrm{pH}$, Eh, dissolved oxygen, water temperature, and turbidity. Specific conductance, $\mathrm{pH}$, Eh, dissolved oxygen, and water temperature were monitored in a flow-through chamber. In addition, for about 20 percent of the samples, downhole dissolved oxygen and water-temperature probes were placed directly below the purge intake for comparison with readings made at land surface with the flow-through chamber (appendix 2a). Purge rates from the peristaltic pump ranged from $0.1 \mathrm{~L} / \mathrm{min}$ to $0.5 \mathrm{~L} / \mathrm{min}$. Samples for VOC analysis were collected in $40-\mathrm{mL}$ septum vials after field parameters stabilized. Criteria for parameter stabilization followed USEPA (1996), Region 1 Standard Operating Procedures.

Bladder-pump samples were collected on five dates by placing a bladder pump at the midpoint of the well screen and withdrawing water through 1/4-in. copper tubes. Copper tubes were used because of their ability to prevent degassing of chemicals, particularly chlorofluorocarbons (CFC's), which were collected during this study (but not included in this report). The bladder pump and lines were not dedicated to specific wells but were cleaned before use at each well according to standard operating practices, which included using nutrient-free detergent, methanol, and deionized washes. Water was purged following low-flow sampling procedures. Purge rates from bladder pumps ranged from 0.5 to $1.0 \mathrm{~L} / \mathrm{min}$. Samples were collected in $40-\mathrm{mL}$ septum vials after field-parameter stabilization. 


\section{Quality Assurance and Control}

Ground-water samples were collected in cooperation with NHDES. Selected constituents were analyzed at the NHDES laboratory and at the USGS office in Pembroke, N.H. Field-parameter data were collected by NHDES and USGS field personnel. Specific analytical methods used for particular constituents are listed in table 3.

On all VOC sampling dates, a trip blank accompanied the sampling party to and from the collection site. Samples were delivered to the NHDES laboratory and transferred with a chain of custody form after visual inspection by receiving laboratory personnel. Project method protocols included the use of method (equipment) blanks, trip blanks, field duplicates, and split samples. Equipment blanks were collected for diffusion samplers by methods described in appendix 1.

Equipment blanks were contaminated on four out of ten sample dates. This contamination could have occurred during blank sample preparation and transport or during handling at the analyzing laboratory. Three of the four equipment-blank samples showed detectable levels of acetone on September 30, 1998, February 8, 1999 , and April 15, 1999, but no detection of primary constituents (PCE, TCE, and cis-1,2DCE). Acetone was not detected in ground-water samples for those dates. PCE was detected in one of the four equipment blanks on February 19,1998 , but the concentration $(3.5 \mathrm{ppb})$ was only marginally greater than the detection limit ( $2 \mathrm{ppb})$ and was insignificant in relation to the PCE concentrations of ground-water samples (ranging from 830 to $4,100 \mathrm{ppb})$. No VOC's were detected in the trip blanks.

Differences between duplicates and split samples were evaluated by use of the Absolute Relative Percent Difference (ARPD) formula:

$$
A R P D=\frac{\left|x_{1}-x_{2}\right|}{\frac{x_{1}+x_{2}}{2}} \times 100,
$$

where

$x_{1}$ is original sample, and

$x_{2}$ is replicate sample.

Differences between samples collected by different methods (for example, low-flow and diffusion) were evaluated by use of the Relative Percent Difference (RPD) formula:

$$
R P D=\frac{x_{1}-x_{2}}{\frac{x_{1}+x_{2}}{2}} \times 100,
$$

Duplicate VOC field samples were analyzed by NHDES Laboratory following USEPA schedule $8260 \mathrm{~B}$. Laboratory standard-operating procedure included the use of the following steps: initial instrument calibration, check sample, laboratory blanks, matrix spikes, matrix duplicates, and laboratory fortified blanks (which include five of the primary expected VOC constituents). Approximately 3.5 percent of 350 total VOC samples were analyzed as field duplicates. The mean ARPD of duplicates with positive detections was 4.5 percent for PCE, 4.8 percent for TCE, and 4.1 percent for $c$ is-1,2DCE. Standard deviations of ARPD between duplicates were less than 5 percent. The maximum ARPD of a duplicate was 10.9 percent and occurred for PCE and cis-1,2DCE (appendix 6).

Detailed testing of the effect of volume, flow rate, and pump type on PCE and TCE concentrations was done at well B95-13 on April 14, 1999. Two pump types were used, bladder and peristaltic, in a sequentially higher purge rate and volumetric order of sampling. The USEPA mobile laboratory was used to analyze results. A split sample was analyzed by the NHDES laboratory. The split sample was collected using a peristaltic pump and yielded an 18.5 percent ARPD in PCE concentration and a 9.5 percent ARPD in TCE concentration. Three sets of duplicate samples were analyzed by the USEPA mobile lab for samples collected using a peristaltic ( 2 sets) and a bladder pump ( 1 set). In addition, a laboratory duplicate was done on a peristaltic sample. The laboratory sample 
yielded a PCE ARPD of 6.8 percent and a TCE ARPD of 13 ? percent. The remaining duplicates all had lower ARPD than the laboratory duplicate. The peristaltic duplicates had ARPD of 4.5 to 8.7 percent for PCE. The bladder duplicate had a ARPD of 1 percent for PCE and a ARPD of 1.7 for TCE.

A split sample was shared with members of the USGS New England Coastal Basins National Water Quality Assessment Program (NAWQA). Samples were sent for analyses to the USGS National Water-Quality Laboratory and NHDES laboratory and analyzed for major ions, metals, and VOC's (data are on file at the Pembroke, N.H. office). The USGS national laboratory analyzes approximately 15 more VOC constituents than the NHDES laboratory. Constituent concentrations of less than 15 percent ARPD resulted except for magnesium, which varied by more than 50 percent. The only positive detection for VOC's occurred for methyl tert-butyl ether (MTBE), which had a ARPD of 13 percent.

Field-parameter data collected by the USGS followed water-quality sampling methods and criteria in the USGS National Field Manual for the Collection of Water-Quality Data (U.S. Geological Survey, 1998). Field techniques of USGS personnel trained to make water-quality measurements are verified annually by participation in the National Field Quality Assurance Program, which sends unknown samples to participants to test parameters such as $\mathrm{pH}$, alkalinity, and specific conductance. Field probes and instruments are calibrated using known standards. Laboratory analysis conducted by USGS include testing for bromide, alkalinity, and nitrate. Bromide testing was conducted on approximately 160 samples from October 1997 to September 1999, using an ionspecific probe. Ten percent of these samples were duplicate samples with matching concentrations of less than 15 percent ARPD. Alkalinity titrations were performed on 196 samples from May 1997 to September 1999 , following USGS national water-quality procedures (U.S. Geological Survey, 1998). Five percent of these samples were duplicate samples with matching concentrations of less than 5 percent ARPD. Nitrate testing using colorometric kits in the laboratory was performed from November 1998 to September 1999 on 90 samples. Nine percent of these samples were duplicate samples with generally less than 25 percent ARPD.

Additional field parameters tested for quality assurance and control included carbon dioxide, ferrous iron, and dissolved oxygen. Field-testing equipment are listed in table 3. Approximately five to ten percent of measurements were duplicates with generally less than 20 percent ARPD for carbon dioxide and ferrous iron and less than 5 percent ARPD for dissolved oxygen.

\section{CONCEPTUALIZATION OF CONTRIBUTING AREA OF WATER SAMPLES}

Understanding the differences in the volume of aquifer contributing to a specific water sample may help explain variations in water-sample concentrations. Both passive (diffusion sampling) and low-flow sampling methods collect water from a relatively small volume of the aquifer around the well opening. Diffusion samplers collect water from the smallest volume around the well, whereas, low-flow sampling potentially collects water from a slightly larger area, probably less than $10 \mathrm{ft}$ from the well.

In diffusion sampling there is no drawdown and the sample represents an equilibrium condition between water in the diffusion sampler and ground water flowing through the well under natural flow conditions. Therefore, the natural flushing rate of the well is an important mechanism in collecting representative diffusion samples. The natural flushing rate can be relatively large and approach rates of several liters per minute in properly constructed wells tapping high-permeability aquifers.

In low-flow sampling, drawdown can range from negligible amounts (less than $0.01 \mathrm{ft}$ ) to large amounts (more than $10 \mathrm{ft}$ ). For the case of negligible drawdowns, the horizontal area contributing water is primarily upgradient from the well. For large drawdowns, the horizontal contributing area also will encompass areas downgradient of the well if drawdowns reach an equilibrium. Prior to equilibrium, sampled waters include borehole water as well as aquifer water. The effect of drawdown on the size and configuration of the horizontal contributing area is shown in figure $\mathbf{1 1}$ for a simplified case as semi-elliptical areas around the well.

The vertical contributing area also will affect the horizontal contributing area. Purged low-flow samples may interrogate relatively short radial distances over the full screen length or large lateral distances for a fraction of the screen length. 


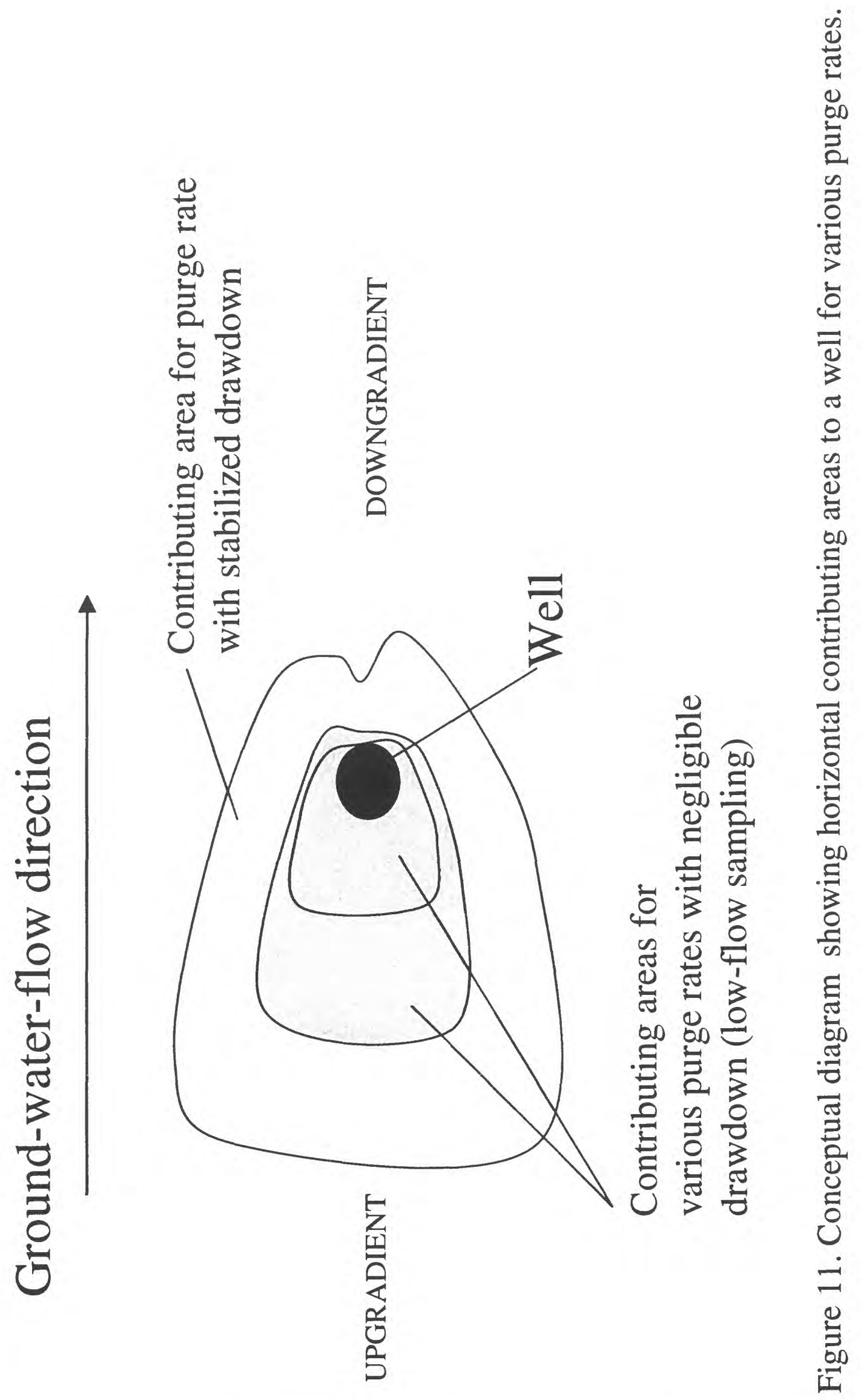




\section{RESULTS OF TESTING}

Testing of diffusion samplers involved comparing results of VOC analyses of samples collected from diffusion samplers with those collected by purge methods. Similarity of results with standard low-flow methods suggest that diffusion samplers are suitable for use in sampling ground water for VOC's. Differences in results, however, particularly in cases in which diffusion samples have VOC concentrations greater than those collected by another method may also suggest an acceptable test given the potential difference in contributing areas associated with the two methods. For example, water samples from purged methods may originate from a longer vertical length of the well opening than waters from diffusion samples. Therefore, because of vertical heterogeneity of contaminant concentrations in the aquifer, variations in contributing areas of waters will affect sample concentrations producing dissimilar results between diffusion and purged methods. The fact that the results are different does not necessarily constitute that diffusion sampling is necessarily inferior to purge sampling.

\section{Comparison of Diffusion Samplers with Other Samplers}

The list of VOC's analyzed (USEPA schedule 8260B) and comparison of detections between peristaltic and diffusion, and bladder and diffusion samples are given in tables 4 and 5. For the bladder and diffusion comparison, which consist of only three samples, there is exact agreement of VOC's detected. For the peristaltic and diffusion comparison, which consists of twenty samples, three compounds other than the primary VOC's (PCE, TCE, and cis-1,2DCE) were detected and include 1,1,1-trichloroethane and carbon disulfide, which were detected in the peristaltic samples but not in the diffusion samples, and methylene chloride, which was detected in the diffusion sample but not in the peristaltic sample. All VOC's detected by only one of the two methods have relatively high vapor pressures (more than $100 \mathrm{~mm}$ of mercury at 25 degrees Celsius). Therefore, differences in diffusion rates may not be the primary mechanism in causing positive detections in only one of the methods. The primary mechanism is more likely analytical precision, because the detected concentrations were all just slightly greater than the detection level (table 4).

PCE concentration results from the two primary wells in which multiple sample methods were utilized and waters withdrawn for comparison (wells B95-13 and B95-15) are shown in figures 12 and 13. Diffusion samplers provided results comparable to samples obtained with a peristaltic pump (see well B95-15 and B95-13 results in appendix 3). VOC concentrations in samples obtained using bladder pumps were higher than concentrations in samples from the diffusion bags and peristaltic pumps (see well B95-13 results in appendix 4).

The repeated similarity between VOC concentrations in purged peristaltic samples and concentrations in diffusion samples indicates that diffusion samples provide results effectively contemporaneous to the time of retrieval. For example, diffusion samplers were installed at the end of the previous sampling round (anywhere from 2 weeks to 2 months) yet the concentrations of contaminants in the diffusion sampler reflect the concentration of the water passing through the well at the time of retrieval because VOC concentrations compare to VOC concentrations in the purged samples collected within hours of diffusion bag retrieval. This point is illustrated by the November 1998 sample at well B95-15 (fig. 13). Water collected from the diffusion sampler (which had been installed in September when PCE concentrations were 2,000 ppb) in November yielded a concentration of $500 \mathrm{ppb}$ of PCE, a concentration comparable to the $375 \mathrm{ppb}$ of PCE detected in the peristaltic sample also in November.

Concentrations of VOC's in 20 samples collected by diffusion samples in 7 glacial-drift wells ${ }^{1}$ correlate well with concentrations from low-flow peristaltic samples from the same wells (fig. 14). The linear regressions produce root-mean squares of 0.966 for PCE, 0.942 for TCE, and 0.979 for cis-1,2DCE. The PCE and cis1,2DCE regression lines are virtually identical to the 1:1 line. The TCE regression line shows that TCE concentrations for the diffusion samples are greater than concentrations for the peristaltic samples.

\footnotetext{
${ }^{1}$ Results from bedrock wells were not corroborated against purged samples due to limitations on the scope of the project.
} 
Table 4. Volatile-organic compounds analyzed and detected in water samples collected by peristaltic pump and diffusion samplers from wells in Milford, New Hampshire, from May 1998 to July 1999

[Detected compounds are in boldface type; ppb means parts per billion; RDL means reporting detection limit]

\begin{tabular}{|c|c|c|c|c|c|}
\hline \multirow{2}{*}{ Compound name } & \multicolumn{2}{|c|}{$\begin{array}{l}\text { Fraction of detects to } \\
\text { total number of samples }\end{array}$} & \multirow{2}{*}{ Compound name } & \multicolumn{2}{|c|}{$\begin{array}{l}\text { Fraction of detects to } \\
\text { total number of samples }\end{array}$} \\
\hline & Peristaltic & Diffusion & & Peristaltic & Diffusion \\
\hline 1,1,2,2-Tetrachloroethane & $0 / 20$ & $0 / 20$ & tert-Butylbenzene & $0 / 20$ & $0 / 20$ \\
\hline 1,1,1,2-Tetrachloroethane & $0 / 20$ & $0 / 20$ & Carbon tetrachloride & $0 / 20$ & $0 / 20$ \\
\hline${ }^{1} 1,1,1$-Trichloroethane & $1 / 20$ & $0 / 20$ & ${ }^{2}$ Carbon disulfide & $1 / 20$ & $0 / 20$ \\
\hline 1,1-Dichloroethylene & $0 / 20$ & $0 / 20$ & $o$-Chlorotoluene & $0 / 20$ & $0 / 20$ \\
\hline 1,1-Dichloroethane & $0 / 20$ & $0 / 20$ & p-Chlorotoluene & $0 / 20$ & $0 / 20$ \\
\hline 1,1,2-Trichloroethane & $0 / 20$ & $0 / 20$ & Chloroethane & $0 / 20$ & $0 / 20$ \\
\hline 1,1-Dichloropropene & $0 / 20$ & $0 / 20$ & Chloromethane & $0 / 20$ & $0 / 20$ \\
\hline 1,2,4-Trimethylbenzene & $0 / 20$ & $0 / 20$ & Chloroform & $0 / 20$ & $0 / 20$ \\
\hline 1,3,5-Trimethylbenzene & $0 / 20$ & $0 / 20$ & Chlorobenzene & $0 / 20$ & $0 / 20$ \\
\hline 1,2-Dibromo-3-chlororpropane & $0 / 20$ & $0 / 20$ & Dibromomethane & $0 / 20$ & $0 / 20$ \\
\hline trans-1,2-Dichloroethene & $0 / 20$ & $0 / 20$ & Dibromochloromethane & $0 / 20$ & $0 / 20$ \\
\hline trans-1,3-Dichloropropene & $0 / 20$ & $0 / 20$ & Dichlorobromomethane & $0 / 20$ & $0 / 20$ \\
\hline 1,2,3-Tricholoropropane & $0 / 20$ & $0 / 20$ & Dichlorodifluoromethane & $0 / 20$ & $0 / 20$ \\
\hline 1,3-Dichloropropane & $0 / 20$ & $0 / 20$ & Diethyl ether & $0 / 20$ & $0 / 20$ \\
\hline 1,2-Dichloroethane & $0 / 20$ & $0 / 20$ & Ethylene dibromide & $0 / 20$ & $0 / 20$ \\
\hline 1,2-Dichloropropane & $0 / 20$ & $0 / 20$ & Ethylbenzene & $0 / 20$ & $0 / 20$ \\
\hline 1,2-Dichlorobenzene & $0 / 20$ & $0 / 20$ & Hexachlorobutadiene & $0 / 20$ & $0 / 20$ \\
\hline 1,2,3-Trichlorobenzene & $0 / 20$ & $0 / 20$ & Isopropylbenzene & $0 / 20$ & $0 / 20$ \\
\hline 1,2,4-Trichlorobenzene & $0 / 20$ & $0 / 20$ & Methyl-tert-butyl ether (MTBE) & $0 / 20$ & $0 / 20$ \\
\hline 2,2-Dichloropropane & $0 / 20$ & $0 / 20$ & ${ }^{3}$ Methylene chloride & $0 / 20$ & $1 / 20$ \\
\hline cis-1,2-Dichloroethene (cis-1,2DCE) & $20 / 20$ & $20 / 20$ & Naphthalene & $0 / 20$ & $0 / 20$ \\
\hline 2-Butanone (MEK) & $0 / 20$ & $0 / 20$ & Para-isopropyltoluene & $0 / 20$ & $0 / 20$ \\
\hline 2-Hexanone & $0 / 20$ & $0 / 20$ & n-Propylbenzene & $0 / 20$ & $0 / 20$ \\
\hline 4-Methyl-2-Pentanone (MIBK) & $0 / 20$ & $0 / 20$ & Styrene & $0 / 20$ & $0 / 20$ \\
\hline Acetone & $0 / 20$ & $0 / 20$ & Tetrachloroethylene (PCE) & $20 / 20$ & $20 / 20$ \\
\hline Bromobenzene & $0 / 20$ & $0 / 20$ & Tetrahydrofuran (THF) & $0 / 20$ & $0 / 20$ \\
\hline Benzene & $0 / 20$ & $0 / 20$ & Trichlorofluoromethane & $0 / 20$ & $0 / 20$ \\
\hline Bromochloromethane & $0 / 20$ & $0 / 20$ & Trichloroethylene (TCE) & $20 / 20$ & $19 / 20$ \\
\hline Bromoform & $0 / 20$ & $0 / 20$ & Toluene & $0 / 20$ & $0 / 20$ \\
\hline Bromomethane & $0 / 20$ & $0 / 20$ & Vinyl chloride & $0 / 20$ & $0 / 20$ \\
\hline$n$-Butylbenzene & $0 / 20$ & $0 / 20$ & Xylenes (total) & $0 / 20$ & $0 / 20$ \\
\hline sec-Butylbenzene & $0 / 20$ & $0 / 20$ & & & \\
\hline
\end{tabular}

\footnotetext{
${ }^{1}$ Detected value $12 \mathrm{ppb}$ (RDL $10 \mathrm{ppb}$ ).

${ }^{2}$ Detected value $2.7 \mathrm{ppb}$ (RDL $2.0 \mathrm{ppb}$ ).

${ }^{3}$ Detected value $21 \mathrm{ppb}$ (RDL $20 \mathrm{ppb}$ ).
} 
Table 5. Volatile-organic compounds analyzed and detected in wc. 3r samples collected by bladder pump and diffusion samplers from wells in Milford, New Hampshire, from May 1998 to April 1999

[Detected compounds are in boldface type]

\begin{tabular}{|c|c|c|c|c|c|}
\hline \multirow{2}{*}{ Compound name } & \multicolumn{2}{|c|}{$\begin{array}{l}\text { Fraction of detects to } \\
\text { total number of samples }\end{array}$} & \multirow{2}{*}{ Compound name } & \multicolumn{2}{|c|}{$\begin{array}{l}\text { Fraction of detects to } \\
\text { total number of samples }\end{array}$} \\
\hline & Bladder & Diffusion & & Bladder & Diffusion \\
\hline 1,1,2,2-Tetrachloroethane & $0 / 3$ & $0 / 3$ & Carbon tetrachloride & $0 / 3$ & $0 / 3$ \\
\hline 1,1,1,2-Tetrachloroethane & $0 / 3$ & $0 / 3$ & Carbon disulfide & $0 / 3$ & $0 / 3$ \\
\hline 1,1,1-Trichloroethane & $0 / 3$ & $0 / 3$ & o-Chlorotoluene & $0 / 3$ & $0 / 3$ \\
\hline 1,1-Dichloroethylene & $0 / 3$ & $0 / 3$ & p-Chlorotoluene & $0 / 3$ & $0 / 3$ \\
\hline 1,1-Dichloroethane & $0 / 3$ & $0 / 3$ & Chloroethane & $0 / 3$ & $0 / 3$ \\
\hline 1,1,2-Trichloroethane & $0 / 3$ & $0 / 3$ & Chloromethane & $0 / 3$ & $0 / 3$ \\
\hline 1,1-Dichloropropene & $0 / 3$ & $0 / 3$ & Chloroform & $0 / 3$ & $0 / 3$ \\
\hline 1,2,4-Trimethylbenzene & $0 / 3$ & $0 / 3$ & Chlorobenzene & $0 / 3$ & $0 / 3$ \\
\hline 1,3,3-Trimethylbenzene & $0 / 3$ & $0 / 3$ & Dibromomethane & $0 / 3$ & $0 / 3$ \\
\hline 1,2-Dibromo-3-chlororpropane & $0 / 3$ & $0 / 3$ & Dibromochloromethane & $0 / 3$ & $0 / 3$ \\
\hline trans-1,2-Dichloroethene & $0 / 3$ & $0 / 3$ & Dichlorobromomethane & $0 / 3$ & $0 / 3$ \\
\hline trans-1,3-Dichloropropene & $0 / 3$ & $0 / 3$ & Dichlorodifluoromethane & $0 / 3$ & $0 / 3$ \\
\hline 1,2,3-Tricholoropropane & $0 / 3$ & $0 / 3$ & Diethyl ether & $0 / 3$ & $0 / 3$ \\
\hline 1,3-Dichloropropane & $0 / 3$ & $0 / 3$ & Ethylene dibromide & $0 / 3$ & $0 / 3$ \\
\hline 1,2-Dichloroethane & $0 / 3$ & $0 / 3$ & Ethylbenzene & $0 / 3$ & $0 / 3$ \\
\hline 1,2-Dichloropropane & $0 / 3$ & $0 / 3$ & Hexachlorobutadiene & $0 / 3$ & $0 / 3$ \\
\hline 1,2-Dichlorobenzene & $0 / 3$ & $0 / 3$ & Isopropylbenzene & $0 / 3$ & $0 / 3$ \\
\hline 1,2,3-Trichlorobenzene & $0 / 3$ & $0 / 3$ & Methyl-tert-butyl ether (MTBE) & $0 / 3$ & $0 / 3$ \\
\hline 1,2,4-Trichlorobenzene & $0 / 3$ & $0 / 3$ & Methylene chloride & $0 / 3$ & $0 / 3$ \\
\hline 2,2-Dichloropropane & $0 / 3$ & $0 / 3$ & Naphthalene & $0 / 3$ & $0 / 3$ \\
\hline cis-1,2-Dichloroethene (cis-1,2DCE) & $3 / 3$ & $3 / 3$ & Para-isopropyltoluene & $0 / 3$ & $0 / 3$ \\
\hline 2-Butanone (MEK) & $0 / 3$ & $0 / 3$ & $n$-Propylbenzene & $0 / 3$ & $0 / 3$ \\
\hline 2-Hexanone & $0 / 3$ & $0 / 3$ & Styrene & $0 / 3$ & $0 / 3$ \\
\hline 4-Methyl-2-Pentanone (MIBK) & $0 / 3$ & $0 / 3$ & Tetrachloroethylene (PCE) & $3 / 3$ & $3 / 3$ \\
\hline Bromobenzene & $0 / 3$ & $0 / 3$ & Tetrahydrofuran (THF) & $0 / 3$ & $0 / 3$ \\
\hline Benzene & $0 / 3$ & $0 / 3$ & Trichlorofluoromethane & $0 / 3$ & $0 / 3$ \\
\hline Bromochloromethane & $0 / 3$ & $0 / 3$ & Trichloroethylene (TCE) & $3 / 3$ & $3 / 3$ \\
\hline Bromoform & $0 / 3$ & $0 / 3$ & Toluene & $0 / 3$ & $0 / 3$ \\
\hline Bromomethane & $0 / 3$ & $0 / 3$ & Vinyl chloride & $0 / 3$ & $0 / 3$ \\
\hline$n$-Butylbenzene & $0 / 3$ & $0 / 3$ & Xylenes (total) & $0 / 3$ & $0 / 3$ \\
\hline sec-Butylbenzene & $0 / 3$ & $0 / 3$ & & & \\
\hline tert-Butylbenzene & $0 / 3$ & $0 / 3$ & & & \\
\hline
\end{tabular}


(A)

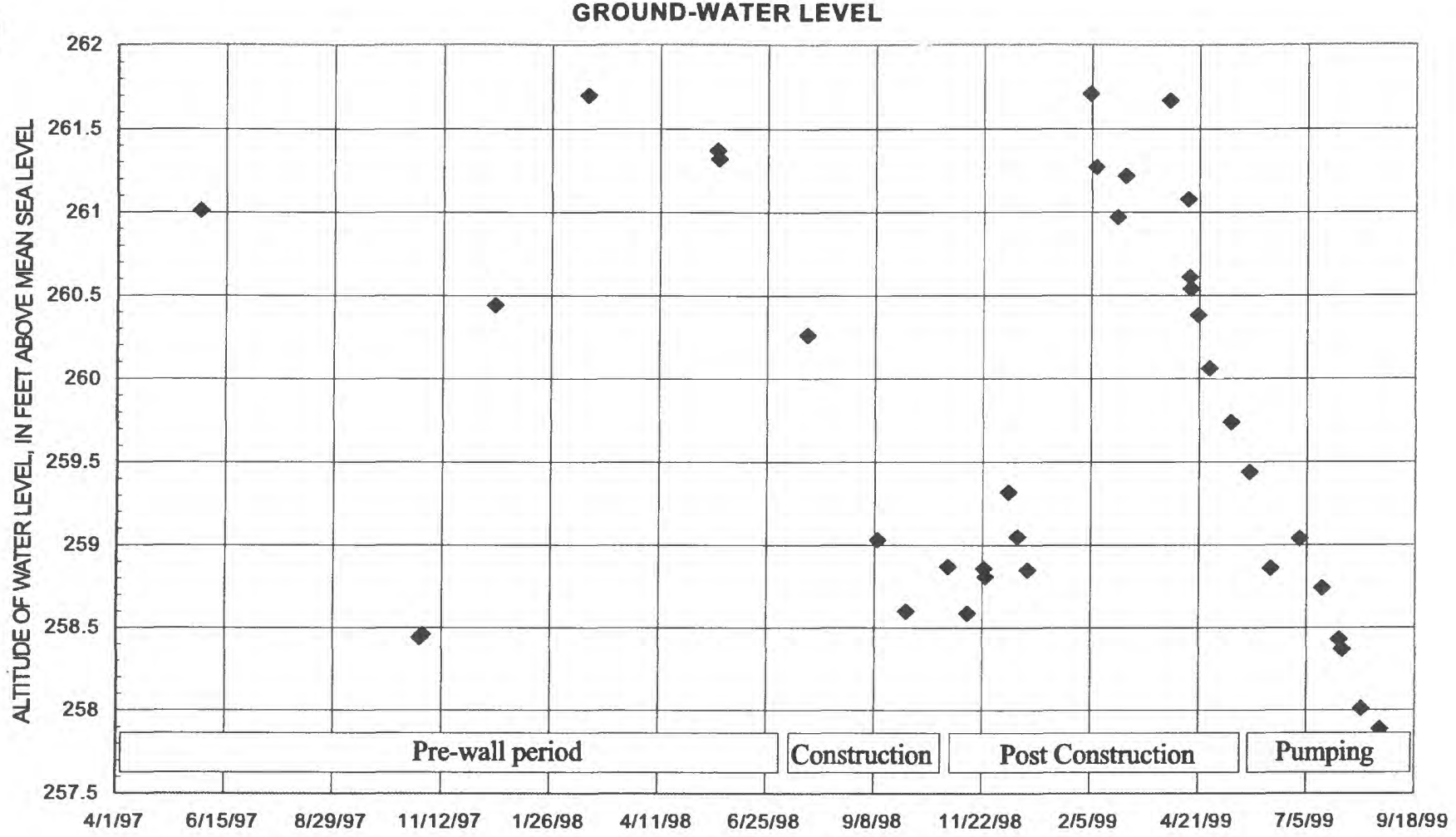

(B)

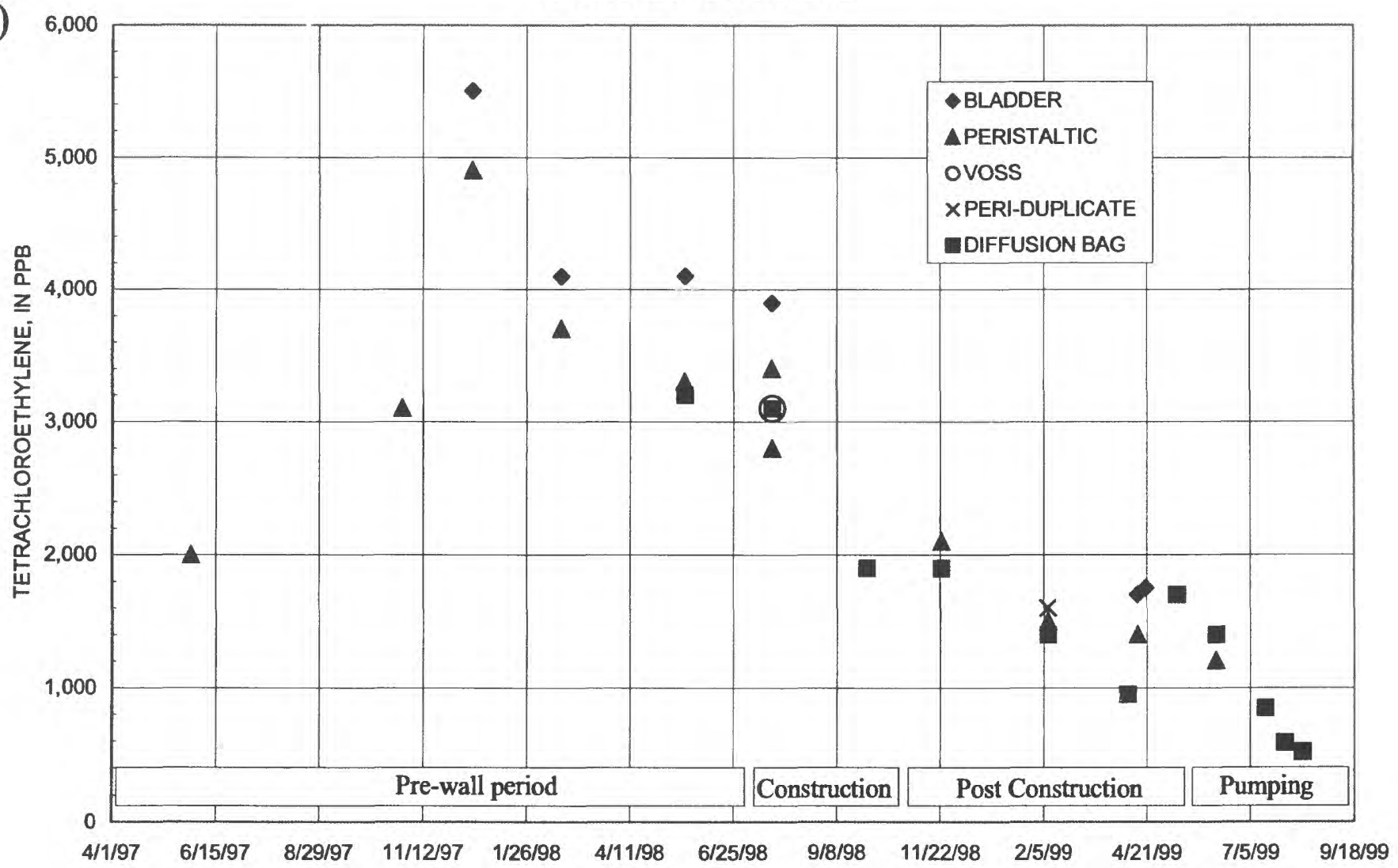

Figure 12. Ground-water levels (A) and concentration of tetrachloroethylene (PCE) in samples collected by various methods (B) for well B95-13. 
(A)

GROUND-WATER LEVEL

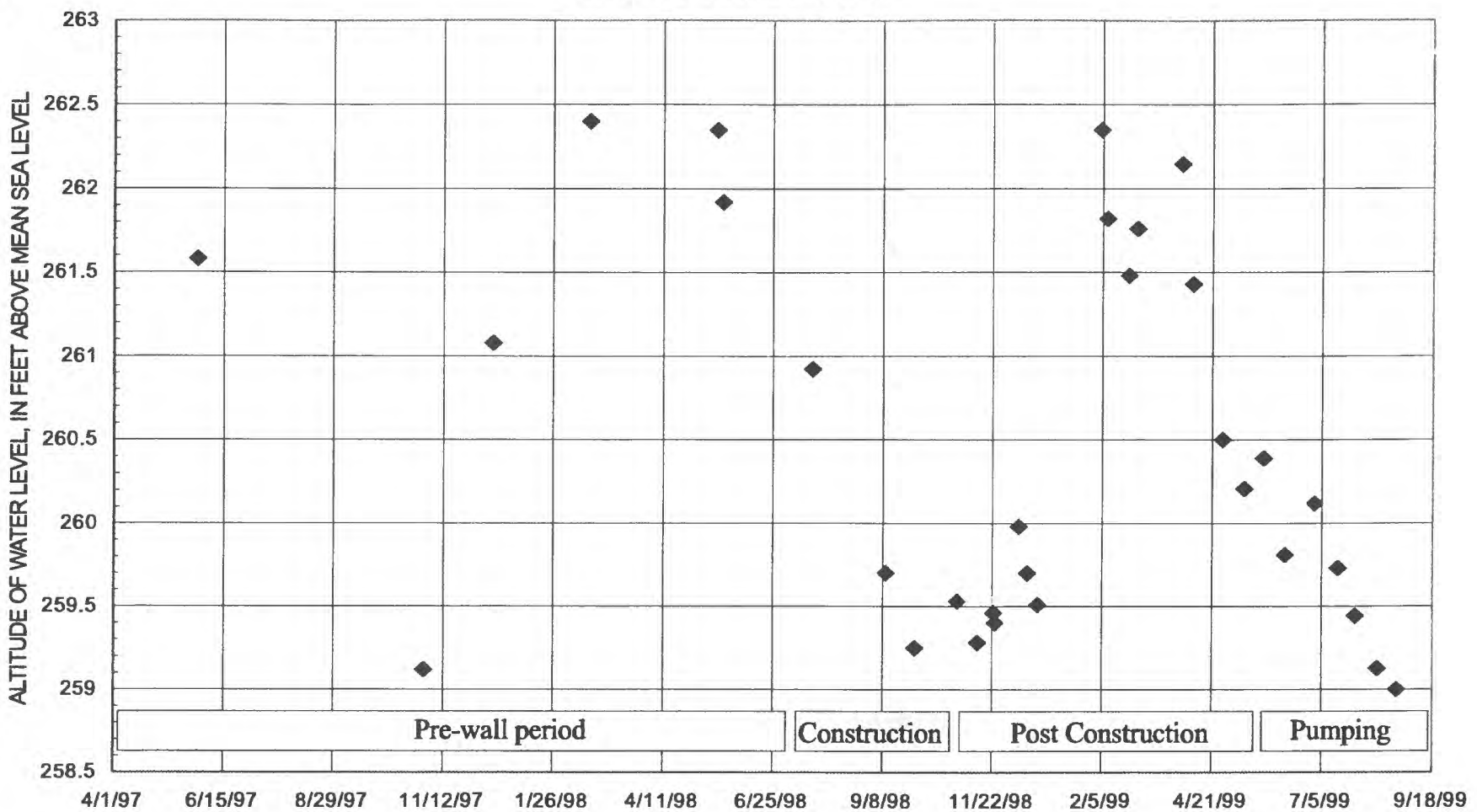

(B)

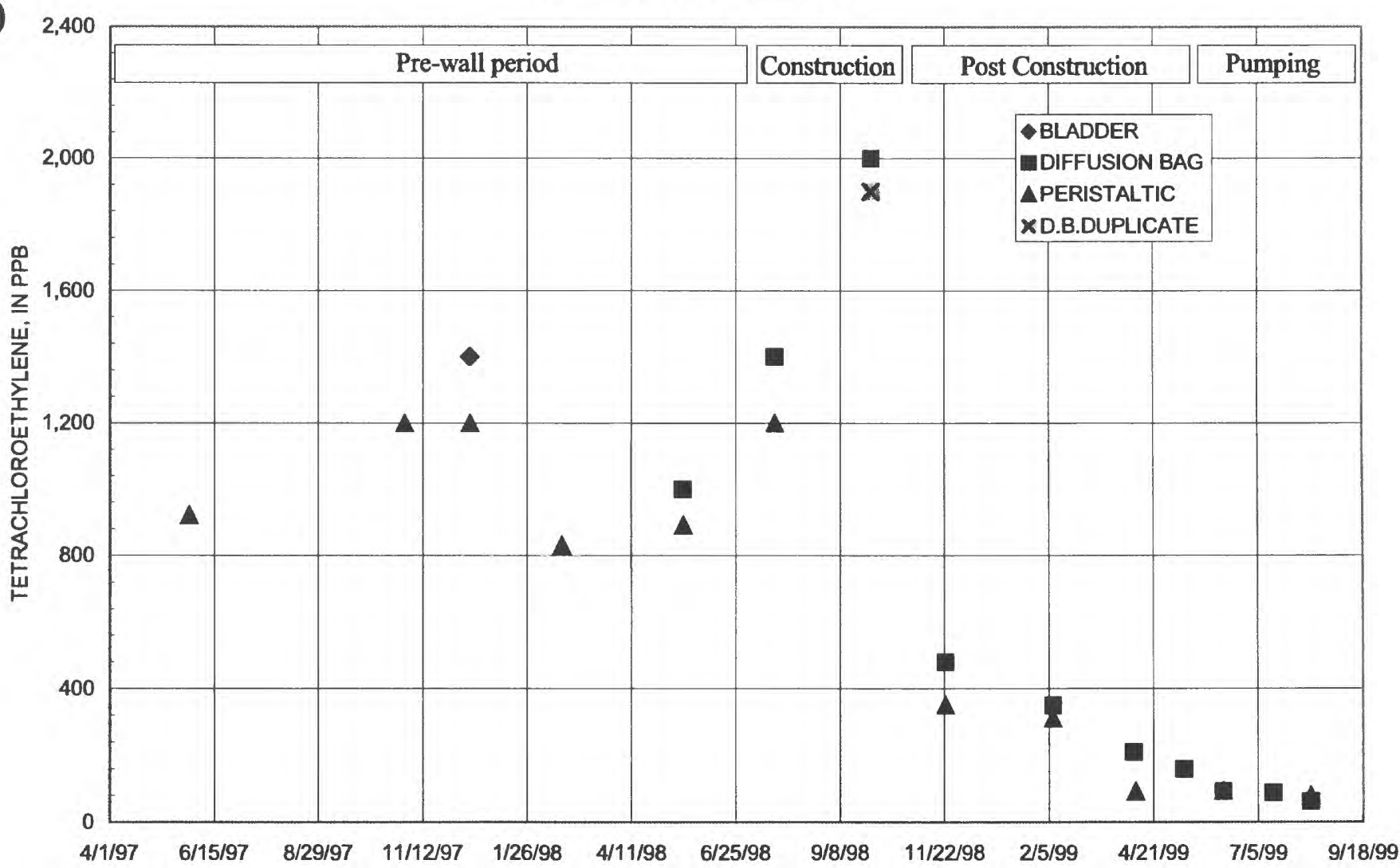

Figure 13. Ground-water levels (A) and concentration of tetrachloroethylene (PCE) in samples collected by various methods (B) for well B95-15. 
(A)

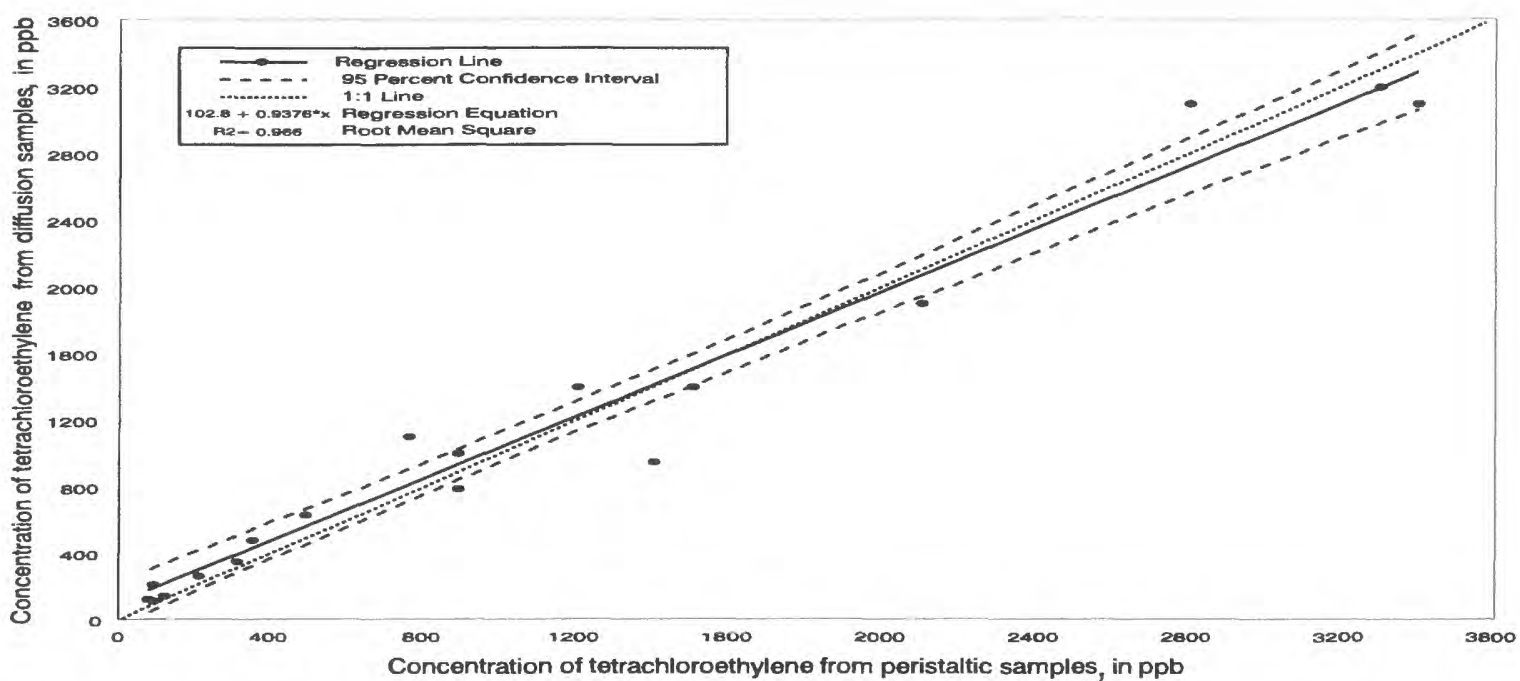

(B)

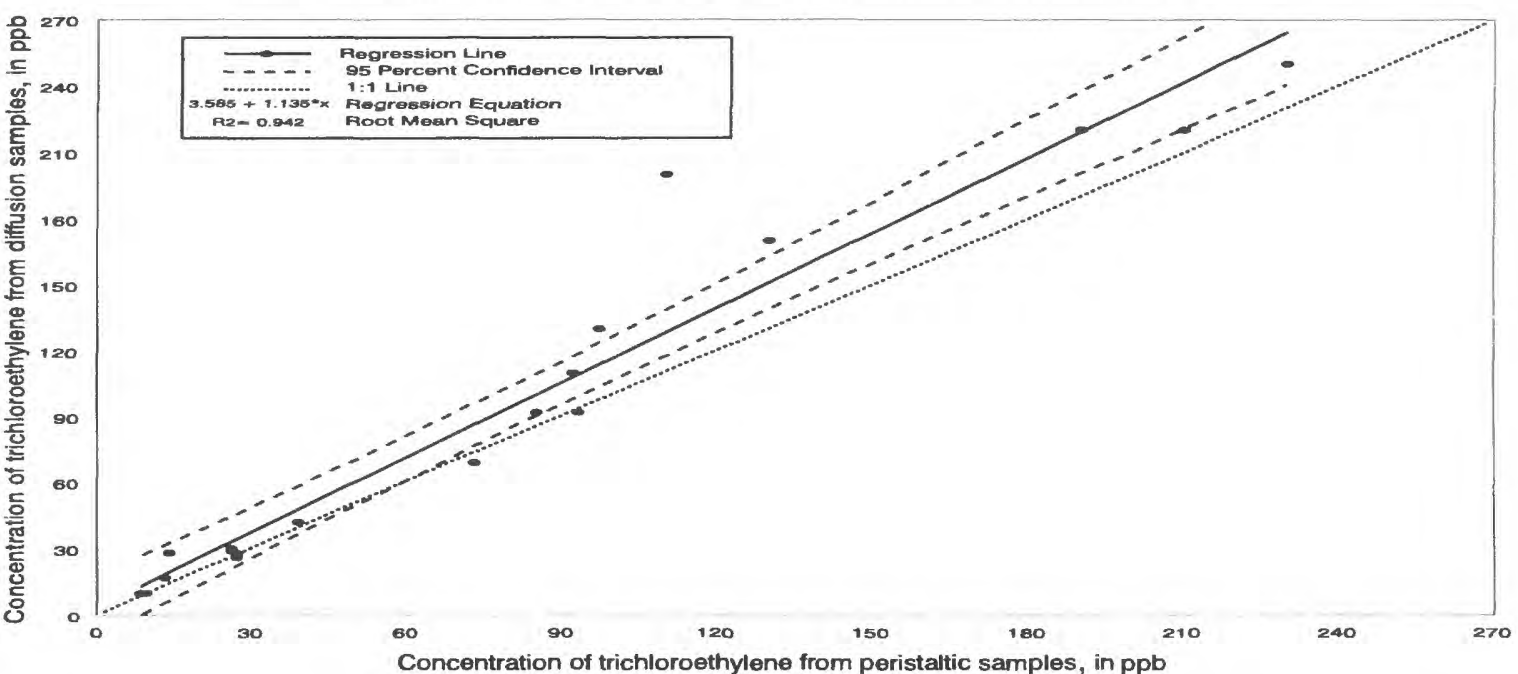

(C)

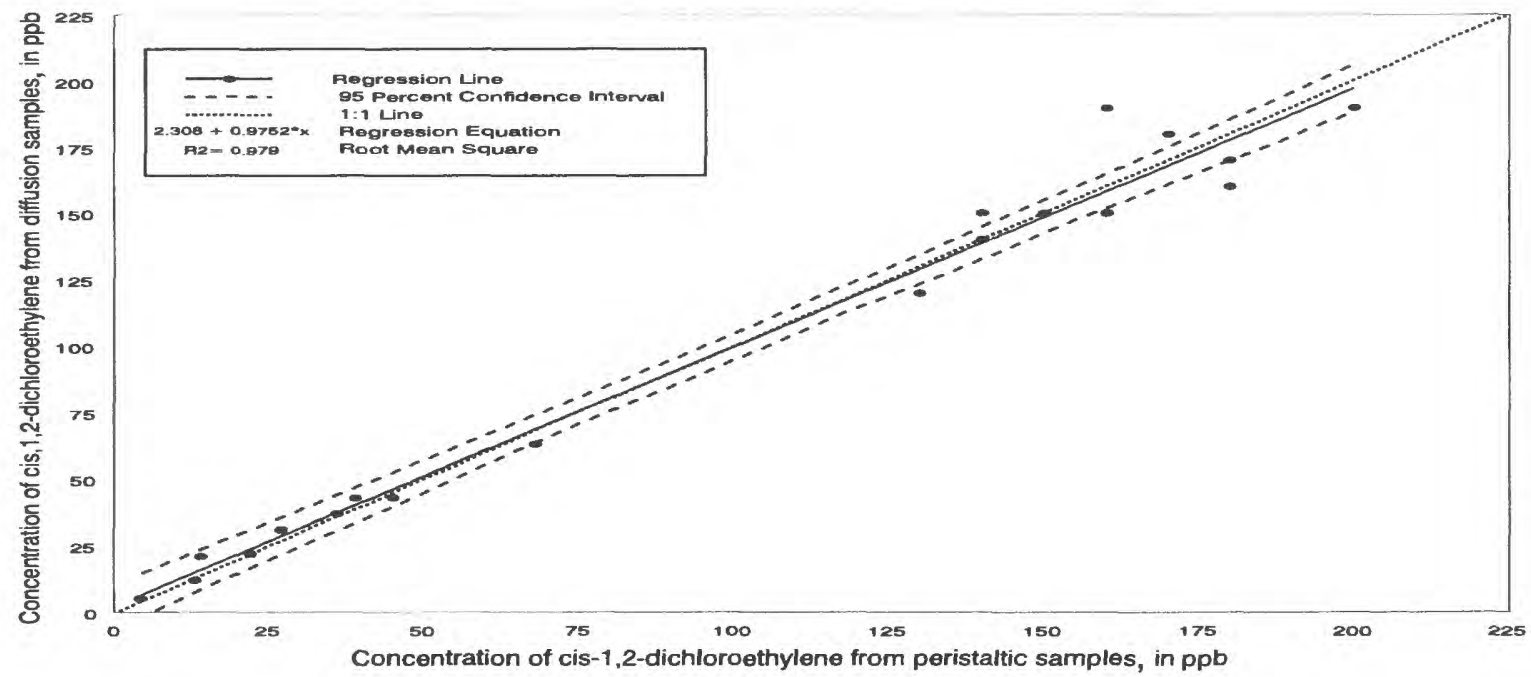

Figure 14. Linear regression of concentrations from peristaltic and diffusion samples for tetrachloroethylene (PCE) (A), trichloroethylene (TCE) (B), and cis-1,2-dischloroethane (cis-1,2DCE) (C). 
The mean PCE concentration for diffusion samples is $1152 \mathrm{ppb}$ and the mean from the peristaltic samples is 1,119.1 ppb (table 6). The standard deviations also are similar. A two-tailed students t-test of equal variance between the two data sets indicates a 96-percent probability that the means are from the same population. Comparison of results for other VOC's also shows excellent agreement. The mean TCE concentration for diffusion samples is slightly higher than the mean concentration for peristaltic samples, whereas, the means for cis-1,2DCE are identical for both methods.

Relative Percent Differences (RPD) of VOC concentrations between peristaltic and diffusion samples indicate that diffusion samples provide "on average" higher concentrations than peristaltic samples (table 7). Compared to duplicate results that show much smaller differences (except for cis-1,2DCE), diffusion sample results are larger than differences associated with analytical inaccuracies.

The effects of deployment time on VOC concentration from diffusion samplers were evaluated by plotting the measured concentration differences between the diffusion samples and peristaltic samples against deployment time of diffusion samplers. A plot of linear scatter (fig. 15a) of the data shows a wide spread of data relative to the $y$-axis and thus a poor linear correlation $\left(R^{2}\right.$ of 0.157$)$. The percent difference in differential concentrations also were plotted (fig. 15b) and also shows a wide scatter of data. In figure $15 \mathrm{~b}$ a natural $\log (\mathrm{Ln})$ regression was fitted to the data but a poor fit $\left(\mathrm{R}^{2}\right.$ of 0.15$)$ resulted as well. In both graphs, the effect of deployment time is not observable and the wide scatter of data points suggest differences are caused by factors other than the time required for equilibration, such as differences in contributing areas of sampled water.

The evidence discussed in this section indicates that whereas diffusion samples provide VOC concentrations that are slightly higher than concentrations from peristaltic samples, the differences are not statistically different at a 96 percent probability. The mean concentration of VOC's, the RPD's, and graphical illustrations all show a tendency for slightly higher concentrations from diffusion samples than peristaltic pump samples.

\section{Vertical Variations}

Vertical variations in concentrations of VOC's were detected in strings of diffusion samplers installed in two wells (B95-13 and MW-16 (well number 345) table 8) in July 1999. The first string of samplers consisted of three bags with a 2-ft spacing and installed in a 5-ft long, 2-in.-diameter screen (well B95-13) in sand and gravel. The uppermost diffusion sampler was placed $1 / 2 \mathrm{ft}$ below the top of screen and the lowermost sampler was $1 / 2 \mathrm{ft}$ above the bottom of screen. Concentrations of PCE were one-third lower in the sample from the uppermost sampler, set near the top of the screen, than concentrations from the middle and lowermost samplers. The uppermost sampler is adjacent to a slightly finer grained sand layer, whereas the middle and lowermost samplers are adjacent to a coarser grained layer of sands and gravels. The variation in concentrations of TCE and cis-1,2DCE was much smaller than the variation in concentrations of PCE.

The second string of samplers consisted of four bags with a 6-ft spacing installed in a 38-ft long, 6-indiameter open borehole in bedrock well MW-16R (well number 345). Two of the four samplers were placed side by side at the midpoint between upper and lower samplers to test the effects of different enclosures (mesh sleeve versus a pvc-slotted pipe) on water flow and diffusion to the diffusion bag. PCE concentrations differ vertically and also between enclosure types. TCE concentrations show little difference vertically or between types of enclosures. Cis-1,2DCE concentrations increase with depth and show little differences between enclosure types.

The string of samplers test was repeated in bedrock well MW-16R in October 1999 because of the differences in PCE concentrations between enclosures in July. The results of the October test show a much smaller difference in PCE concentrations between the enclosures, with a nine percent APRD as opposed to a 48 percent APRD for the July test. Furthermore, larger vertical variations were encountered for PCE in October 1999 than in July. In addition, vertical variations in concentrations were measured for TCE and cis-1,2DCE in October, unlike July concentrations that indicated negligible differences. 
Table 6. Statistical summary of concentrations of volatile-organic compounds from peristaltic and diffusion samples [ppb means part per billion]

\begin{tabular}{|c|c|c|c|c|c|c|}
\hline & \multicolumn{2}{|c|}{$\begin{array}{l}\text { Tetrachloroethylene } \\
\text { (PCE) }\end{array}$} & \multicolumn{2}{|c|}{$\begin{array}{l}\text { Trichloroethylene } \\
\text { (TCE) }\end{array}$} & \multicolumn{2}{|c|}{$\begin{array}{l}\text { cis-1,2-dichloroethene } \\
\text { (cis-1,2DCE) }\end{array}$} \\
\hline & Peristaltic & Diffusion & Peristaltic & Diffusion & Peristaltic & Diffusion \\
\hline Number of samples & 20 & 20 & 20 & 20 & 20 & 20 \\
\hline Mean, in ppb & $1,119.1$ & $1,152$. & 75.4 & 89.2 & 95.0 & 95.0 \\
\hline Median, in ppb & 890 & 975 & 56 & 55.5 & 99 & 91.5 \\
\hline Standard deviation of sample, in ppb & $1,048.4$ & $1,000.3$ & 69.7 & 81.5 & 70.5 & 69.5 \\
\hline Maximum, in ppb & 3,400 . & 3,200 . & 230 & 250 & 200 & 190. \\
\hline Minimum, in ppb & 78 & 110 & 8.4 & 10 & 4.2 & 5.2 \\
\hline
\end{tabular}

Table 7. Summary of absolute relative percent differences (ARPD) between laboratory duplicate samples and relative percent difference (RPD) between peristaltic samples and diffusion samples

[PCE, Tetrachloroethylene; TCE. Trichloroethylene; cis-1,2DCE, cis-1,2-dichloroethylene; negative values indicate that sample concentrations from diffusion sampler were greater than those from the perstaltic pump; \% means percent: see appendix 5 for individual calculation of RPD; see appendix 6 for individual calculation of ARPD; only duplicate results from NHDES laboratory which include all three primary constiuents (PCE, TCE, and cis-1,2DCE) are considered for ARPD calculations]

\begin{tabular}{lcccccc}
\hline & $\begin{array}{c}\text { Duplicate } \\
\text { samples }\end{array}$ & $\begin{array}{c}\text { Method } \\
\text { samples }\end{array}$ & $\begin{array}{c}\text { Duplicate } \\
\text { samples }\end{array}$ & $\begin{array}{c}\text { Method } \\
\text { samples }\end{array}$ & $\begin{array}{c}\text { Duplicate } \\
\text { samples }\end{array}$ & $\begin{array}{c}\text { Method } \\
\text { samples }\end{array}$ \\
\cline { 2 - 7 } & $\begin{array}{c}\text { ARPD } \\
\text { PCE }\end{array}$ & $\begin{array}{c}\text { RPD } \\
\text { PCE }\end{array}$ & $\begin{array}{c}\text { ARPD } \\
\text { TCE }\end{array}$ & $\begin{array}{c}\text { RPD } \\
\text { TCE }\end{array}$ & $\begin{array}{c}\text { ARPD } \\
\text { cis-1,2DCE }\end{array}$ & $\begin{array}{c}\text { RPD } \\
\text { cis-1,2DCE }\end{array}$ \\
\hline Mean & $4.50 \%$ & $-13.42 \%$ & $4.81 \%$ & $-16.30 \%$ & $4.10 \%$ & $-3.00 \%$ \\
Median & $4.32 \%$ & $-15.38 \%$ & $4.20 \%$ & $-12.60 \%$ & $4.30 \%$ & $0.00 \%$ \\
Standard deviation & $4.04 \%$ & $24.40 \%$ & $4.18 \%$ & $18.49 \%$ & $1.74 \%$ & $12.53 \%$ \\
Number of samples & 10 & 20 & 6 & 20 & 5 & 20 \\
Maximum & $10.91 \%$ & $38.30 \%$ & $10.91 \%$ & $5.63 \%$ & $5.41 \%$ & $11.76 \%$ \\
Minimum & $0.00 \%$ & $-79.07 \%$ & $0.00 \%$ & $-66.67 \%$ & $1.16 \%$ & $-40.00 \%$ \\
\hline
\end{tabular}

Table 8. Variations in concentrations of PCE, TCE, and cis-1,2DCE in vertical strings of diffusion samplers, in July and October 1999

[Residence times for July sample was 14 days; residence times for October sample was 49 days; tetrachloroethylene (PCE), trichloroethylene (TCE); cis-1.2dichloroethane (cis-1,2DCE); ppb means parts per billion; mesh means polyethylene mesh holder; - means no data; pvc means poly vinyl chloride holder]

\begin{tabular}{|c|c|c|c|c|c|c|c|c|c|}
\hline \multirow[b]{2}{*}{$\begin{array}{l}\text { Well name and } \\
\text { number } \\
\text { (fig. 3) }\end{array}$} & \multirow{2}{*}{$\begin{array}{c}\text { Open } \\
\text { interval, } \\
\text { in feet } \\
\text { below } \\
\text { land } \\
\text { surface }\end{array}$} & \multirow{2}{*}{$\begin{array}{l}\text { Location of } \\
\text { midpoint of } \\
\text { sampler, in } \\
\text { feet below } \\
\text { land surface }\end{array}$} & \multirow[b]{2}{*}{$\begin{array}{l}\text { Type of } \\
\text { sample } \\
\text { enclosure }\end{array}$} & \multicolumn{3}{|c|}{ July 1999} & \multicolumn{3}{|c|}{ October 1999} \\
\hline & & & & $\begin{array}{l}\text { PCE, } \\
\text { in } \mathrm{ppb}\end{array}$ & $\begin{array}{l}\text { TCE, } \\
\text { in ppb }\end{array}$ & $\begin{array}{l}\text { cis-1,2 } \\
\text { DCE, } \\
\text { in ppb }\end{array}$ & $\begin{array}{l}\text { PCE, } \\
\text { in ppb }\end{array}$ & $\begin{array}{l}\text { TCE, } \\
\text { in } \mathrm{ppb}\end{array}$ & $\begin{array}{l}\text { cis-1,2 } \\
\text { DCE, } \\
\text { in ppb }\end{array}$ \\
\hline \multirow{3}{*}{$\begin{array}{l}\text { B95-13 } \\
\text { (well number 408) }\end{array}$} & \multirow[t]{3}{*}{$60-65$} & 60.5 & mesh & 290 & 40 & 100 & -- & -- & - \\
\hline & & 62.5 & mesh & 590 & 40 & 100 & -- & -- & - \\
\hline & & 64.5 & mesh & 590 & 40 & 110 & -- & -- & -- \\
\hline \multirow{4}{*}{$\begin{array}{l}\text { MW-16R } \\
\quad \text { (well number } 345 \text { ) }\end{array}$} & \multirow{4}{*}{$100-138$} & 108.5 & pve & 78 & 25 & 32 & 270 & 37 & 43 \\
\hline & & 114.5 & pvc & 180 & 32 & 35 & 340 & 83 & 110 \\
\hline & & 114.5 & mesh & 110 & 29 & 38 & 310 & 66 & 98 \\
\hline & & 120.5 & pvc & 110 & 49 & 110 & 630 & 98 & 190 \\
\hline
\end{tabular}


(A)

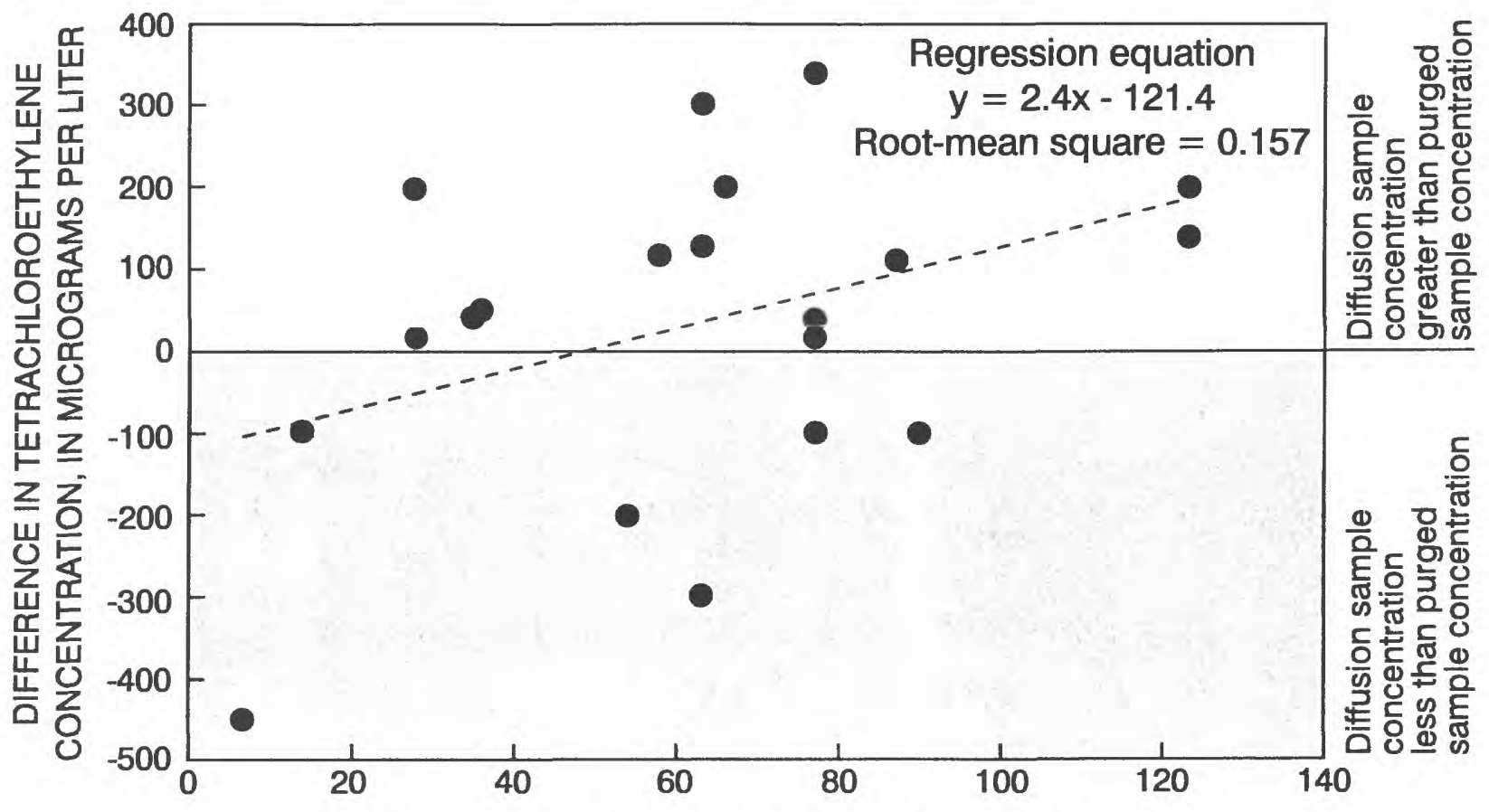

DEPLOYMENT TIME OF DIFFUSION SAMPLER, IN DAYS

(B)

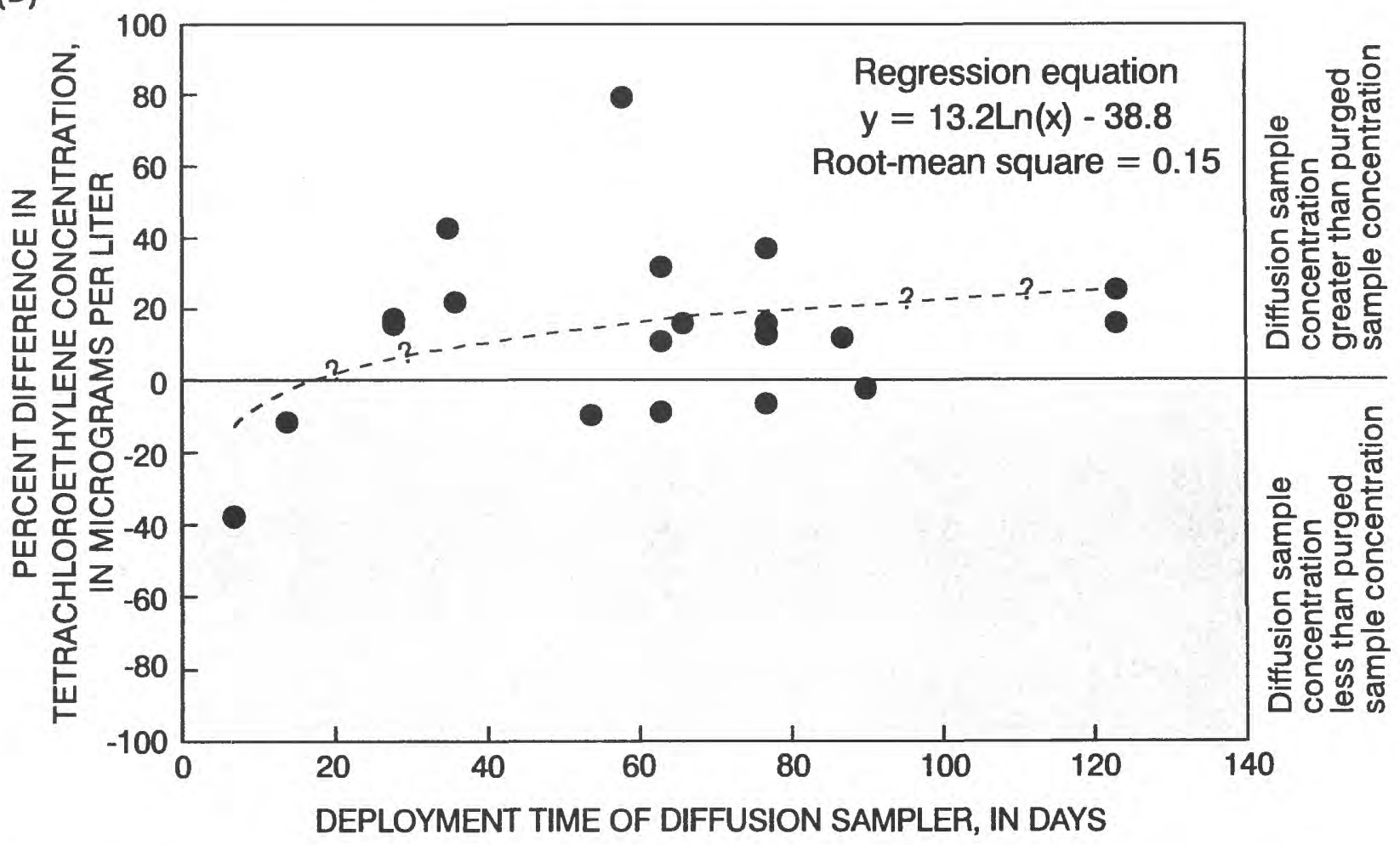

Figure 15. Comparison between deployment time of diffusion sampler and difference of measured concentrations of tetrachloroethylene (PCE) from diffusion and peristaltic-pump samples (A) and comparison of percent difference $(B)$. 


\section{Comparison of Purge Samplers}

Because most of the diffusion-sample results were compared to results from samples collected with a peristaltic pump, an additional test was performed at well B95-13 to evaluate differences in PCE and TCE concentrations between samples retrieved by bladder and peristaltic pumps. The test was designed not only to evaluate differences in concentration of samples retrieved by these pumps, but also to investigate differences in concentrations with changes in purge rates and volume. Nine samples were collected at ascending and then descending purge rates (table 9 ). Samples are labeled in table 9 (column 1) by pump type, purge rate, and whether the samples were collected during a forward sequence (ascending rate of purge) or reverse sequence (descending rate of purge). For example, samples p. $25 \mathrm{f}$ and p. $48 \mathrm{f}$ denote samples collected with the peristaltic pump, during an ascending purge rate, 0.25 and $0.48 \mathrm{~L} / \mathrm{min}$, respectively. Under all cases, drawdowns were negligible during the test.

A sequential plot (fig. 16a) of PCE concentrations shows an increase in concentration during the ascending rate of purging and a small decline during the descending rate of purging, which indicates that purge rates affect PCE concentrations more than the cumulative volume purged. A plot of purge rate in relation to concentration shows a moderate trend toward higher concentrations with higher purge rates (fig. 16b). The type of pump also appears to effect the PCE concentration. Three of the four bladder samples had higher PCE concentrations than the five peristaltic samples (table 9).

Sample statistics indicate that PCE concentrations of bladder-pump samples are generally greater than concentrations from peristaltic-pump samples but not statistically different at the 95 percent confidence level (table 10). The computed ${ }^{2} \mathrm{p}$-values from the students two tailed t-test are greater than the confidence level of 0.05 indicate that the bladder results are statistically similar to the peristaltic results. The difference in mean concentrations between bladder and peristaltic results is larger, although not statistically different, when all samples are analyzed then when only samples of similar purge rates are compared. The p-value from the student's two-tailed t-test for all samples is much smaller $(0.06)$ than the p-value for samples with similar purge rates $(0.34)$. This large difference suggests that purge rates affect PCE concentrations more than pump type. The mean TCE concentrations also are generally greater for bladder-pump samples than peristaltic-pump samples (table 10) but at the levels detected, differences are within the margin of analytical precision.

The effect of purge rate on PCE concentrations is a consequence of the physical and chemical heterogeneity of the plume. Imbrigiotta and others (1988) reported similar results and hypothesized that sampled observation wells, which showed increases in contaminants for high purge rates, were screened in low concentration zones adjacent to high concentration zones. Therefore, during high purge rates, water was pulled from the high to low concentration zones.

General chemical parameters of waters withdrawn by different types of pumps suggest that higher concentrations of PCE in bladder-pump samples than peristaltic-pump samples are neither the result of increased turbidity in the bladder samples, nor conversely, decreased concentrations of dissolved gases like oxygen or carbon dioxide, but probably the result of ${ }^{3}$ degassing of samples collected with the peristaltic pump. Turbidity concentrations from peristaltic samples were similar to bladder samples (except for sample b.1). Dissolved oxygen and carbon dioxide concentrations were also similar between peristaltic and bladder samples regardless of purge rate. Values of $\mathrm{pH}$, however, were higher for peristaltic samples, and indicate some degassing occurred with the peristaltic pump. This may also explain the slightly lower VOC concentration in the peristaltic sample compared to the bladder sample.

The results of the detailed test comparing sampling with bladder and peristaltic pumps show that PCE and TCE concentrations from samples collected with both pumps are similar for the range in concentrations tested. The RPD of the mean concentration of PCE between bladder and peristaltic samples for similar purge rates

\footnotetext{
${ }^{2}$ The p-value is also called the attained significance level (Helsel and Hirsch, 1992).

${ }^{3}$ Degassing of constituents occurs when water samples are subjected to negative pressures, which can occur with use of peristaltic pumps.
} 


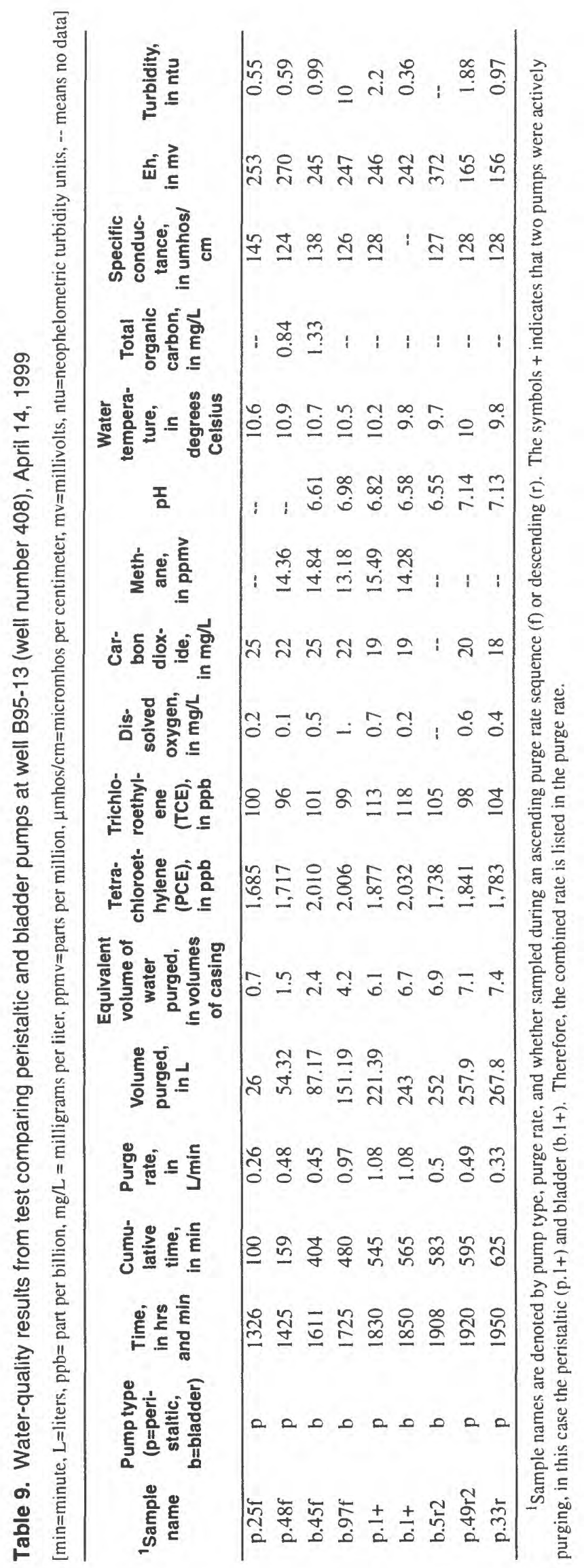




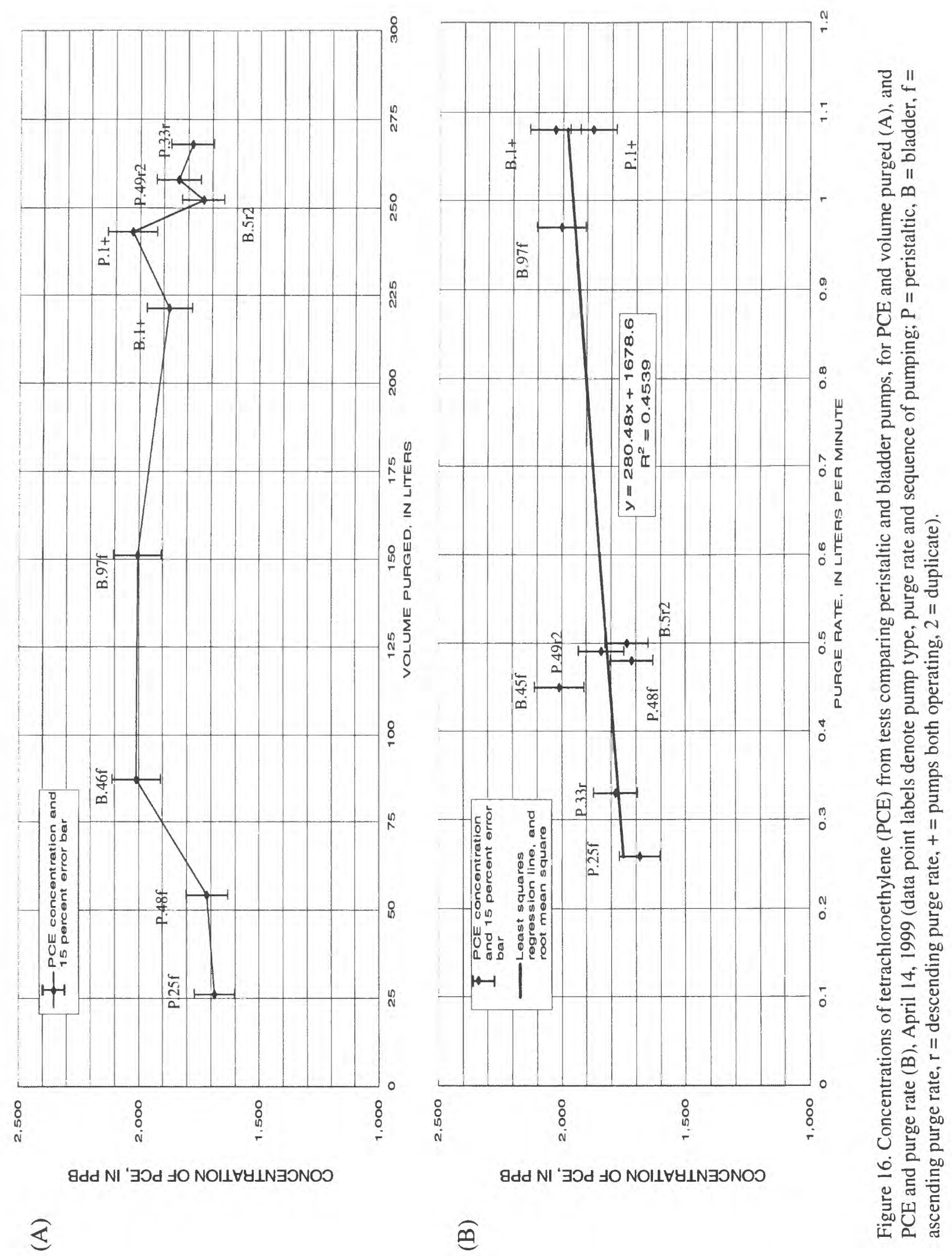


Table 10. Summary statistics comparing concentrations of tetrachloroethylene (PCE) and trichloroethylene (TCE) grouped by pump type from samples collected at well B95-13 (well number 408), April 14, 1999

[L/min means liter per minute; ppb means part per billion; \% means percent; -- means no data]

\begin{tabular}{|c|c|c|c|c|}
\hline & \multicolumn{2}{|c|}{ All samples } & \multicolumn{2}{|c|}{$\begin{array}{c}\text { Comparable purge rates } \\
\text { (excluding b.97, p.25f, and p.33r samples; table 9) }\end{array}$} \\
\hline & $\begin{array}{l}\text { Bladder } \\
\text { pump }\end{array}$ & $\begin{array}{l}\text { Peristaltic } \\
\text { pump }\end{array}$ & $\begin{array}{l}\text { Bladder } \\
\text { pump }\end{array}$ & $\begin{array}{c}\text { Peristaltic } \\
\text { pump }\end{array}$ \\
\hline Number of samples & 4 & 5 & 3 & 3 \\
\hline Mean purge rate, in $\mathrm{L} / \mathrm{min}$ & 0.75 & 0.53 & 0.68 & 0.68 \\
\hline Mean concentration of $\mathrm{PCE}$, in ppb & 1,947 . & $1,781$. & 1,927 . & 1,812 . \\
\hline Standard deviation of sample & 139.5 & 80.8 & 163.8 & 83.9 \\
\hline $95 \%$ confidence interval & $2,065-1,829$ & $1,844-1,718$ & $2,078-1,776$ & $1,890-1,734$ \\
\hline $\mathrm{p}$-value from students t-test (two-tailed) & 0.06 & -- & 0.34 & -- \\
\hline Mean TCE, in ppb & 105.8 & 102.2 & 108. & 102.8 \\
\hline Standard deviation of sample & 7.4 & 6.0 & 7.3 & 6.6 \\
\hline
\end{tabular}

(bladder samples, $1,927 \mathrm{ppb}$, and peristaltic, $1,812 \mathrm{ppb}$, table 10) is 6.2 percent. This RPD is one-half the RPD of the mean concentration of PCE between peristaltic and diffusion samples (-13.42 percent, table 7). Therefore, because the difference in concentrations of PCE between bladder and peristaltic samples is less than that of peristaltic and diffusion samples, peristaltic samples are considered to be adequate for validation of diffusion sampler results at tested wells.

\section{RESULTS OF APPLICATION TO MONITOR TRENDS}

The preceding sections document the evidence supporting the suitability of diffusion samplers in collecting high-frequency time-series data on VOC's if a minimum deployment time of 1 week or more is used. The following section discusses results of this high-frequency sampling, which occurred from November 1998 to October 1999.

Fifteen wells were chosen to collect detailed time-series data of post-wall construction conditions. All of the fifteen wells are located outside of the barrier wall (fig. 3). Trends were analyzed for the concentration of individual primary detected VOC's (PCE, TCE, and cis-1,2DCE), the ratios between the concentration of these compounds, and the total VOC's, which were determined by summing the concentration of the three detected VOC's (PCE, TCE, and cis-1,2DCE). As in the testing phase, VOC's other than the primary compounds were largely undetected.

PCE was the primary VOC detected prior to construction of the barrier wall. Concentrations of PCE show declines of at least a half order of magnitude at 8 of the 15 wells sampled (figs. 17-21) since the start of barrier wall construction in July 1998 (the barrier wall was constructed from July to November 1998, and remedial operations of wells were tested between December 1998 to March 1999, but full operation started in May 1999). These wells include PW-12M, PW-12D, PW-12R, MW-16R, B95-15, B95-13, PW-13M, and PW-13D. Wells with the largest declines in PCE (PW-12M, B95-15, and PW-13D) are screened in coarse-grained gravel layers and are along the northern flank of the plume where ground-water flow is rapid from recharge of the river. Several wells where small declines in PCE have occurred are screened in slightly finer grained layers of sand, including wells PW-14M and PW-14D, and MW-16B and MW-16C. These wells are in the central to southern flank of the plume. At well B95-13, located adjacent to remedial extraction wells EW-1 and EW-2 (fig. 3), PCE declines appear to increase after remedial wells were placed into full operation in mid-May 1999.

Several short-term changes in PCE also are evident in addition to the gross overall declines measured over the time of study. Transient declines and rises in concentration, including a sharp decline and rise in PCE at well PW-12S were detected in June and July of 1999 (fig. 18). This well is near a recharge gallery (fig. 3) where 
(A)

B95-13

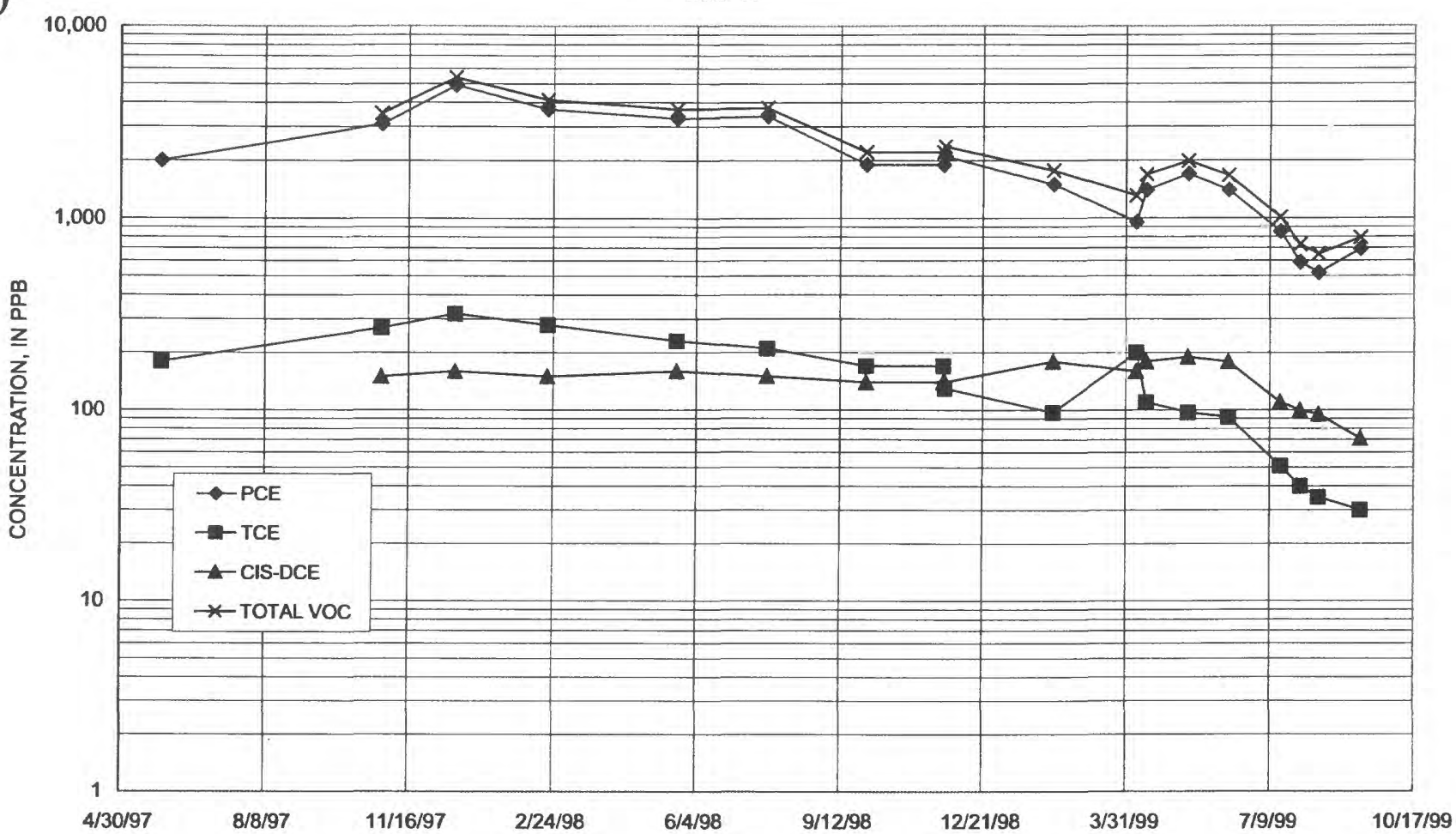

(B)

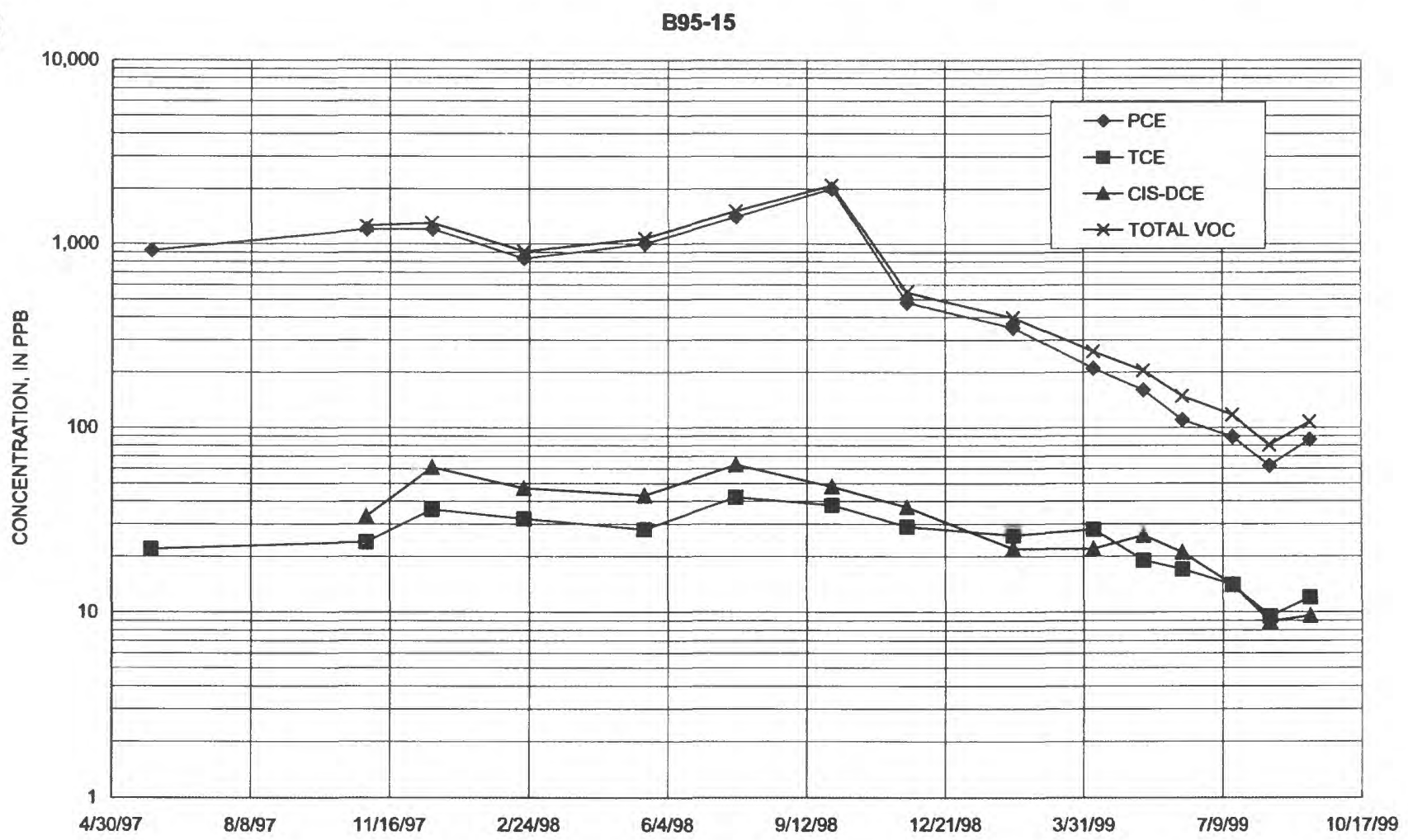

Figure 17. Concentrations of volatile organic compounds (VOC's) tetrachloroethylene (PCE), trichloroethylene (TCE), and cis-1,2-dichloroethane (CIS-DCE), and total VOC's (TOTAL VOC) from diffusion samplers for wells B95-15 and B95-13. (Well locations are shown in figure 3.) 
(A)
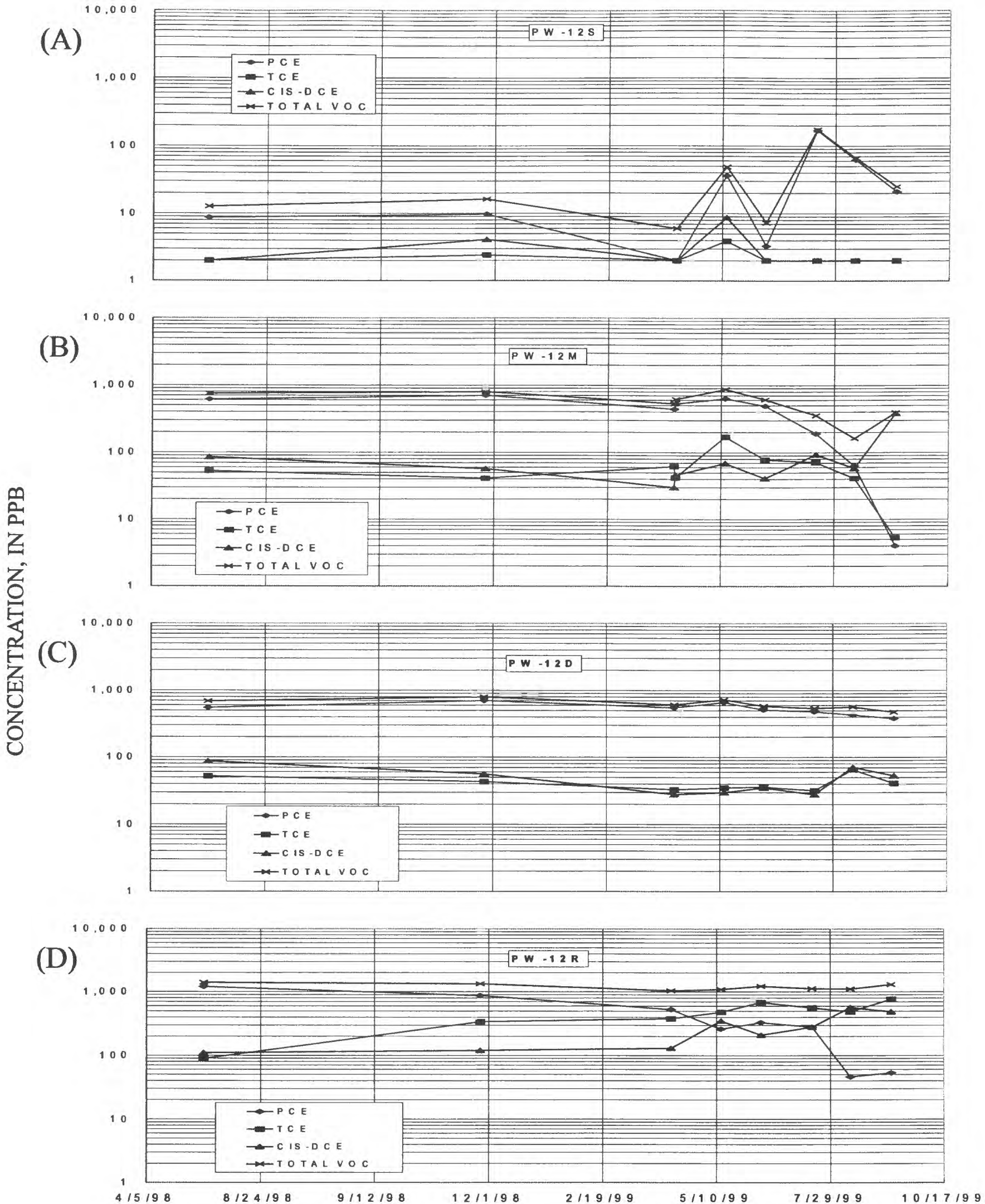

Figure 18. Concentrations of volatile organic compounds (VOC's) tetrachloroethylene (PCE), trichloroethylene (TCE), and cis-1,2-dichloroethane (CIS-DCE), and total VOC's (TOTAL VOC) from diffusion samplers for PW-12 cluster wells. 

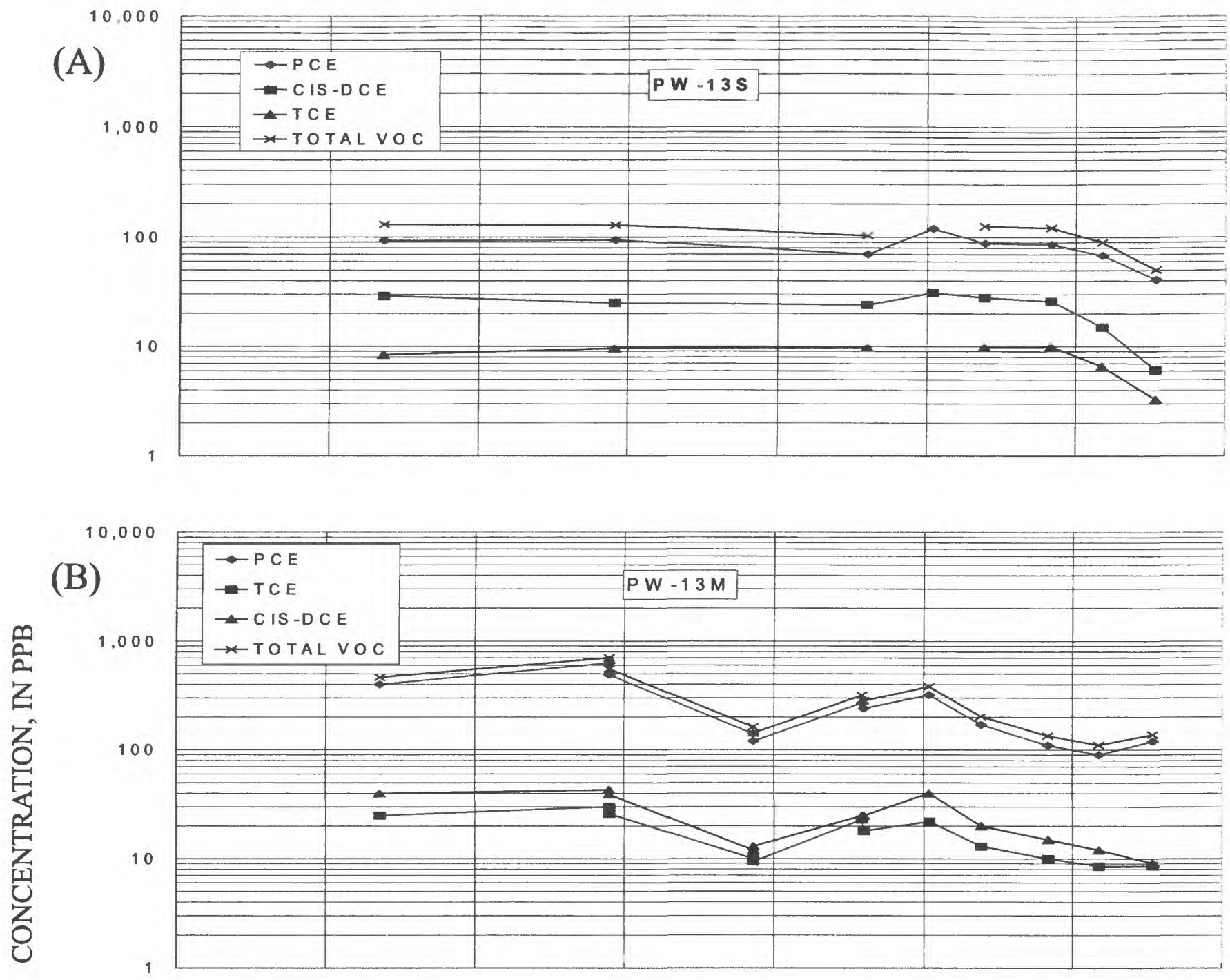

(C)

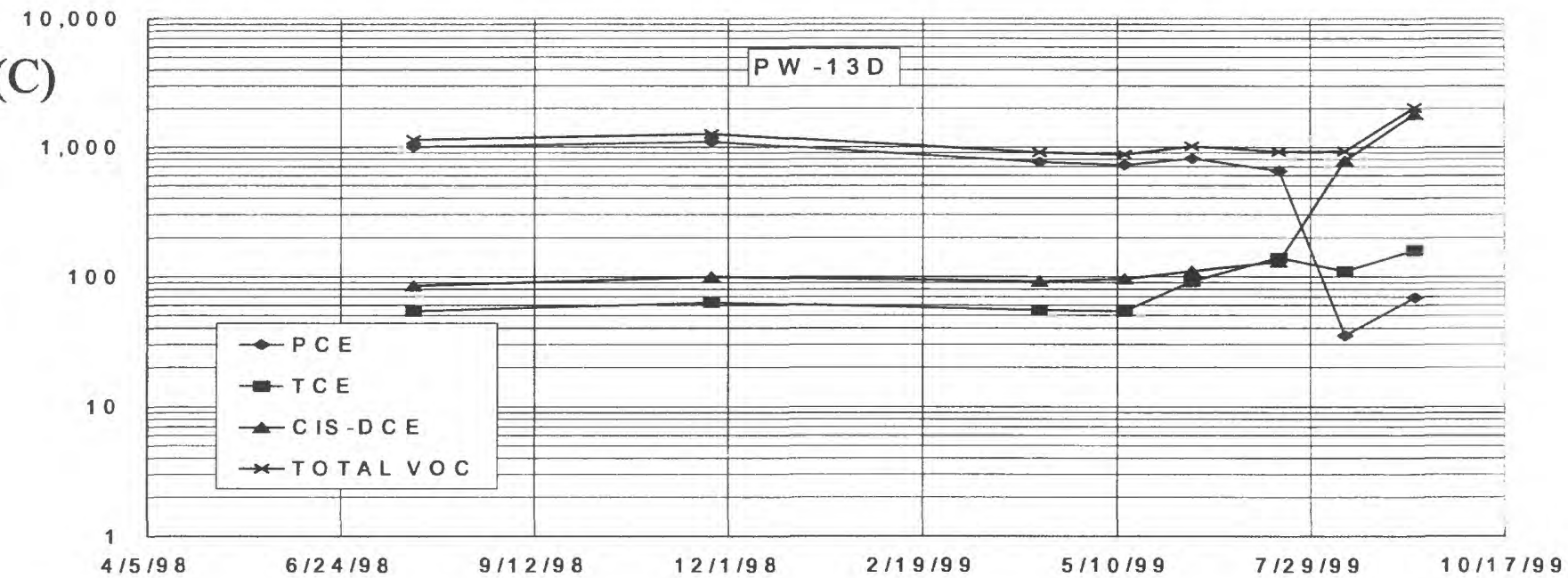

Figure 19. Concentrations of volatile organic compounds (VOC's) tetrachloroethylene (PCE), trichloroethylene (TCE), and cis-1,2-dichloroethane (CIS-DCE), and total VOC's (TOTAL VOC) from diffusion samplers for PW-13 cluster wells. 
(A)
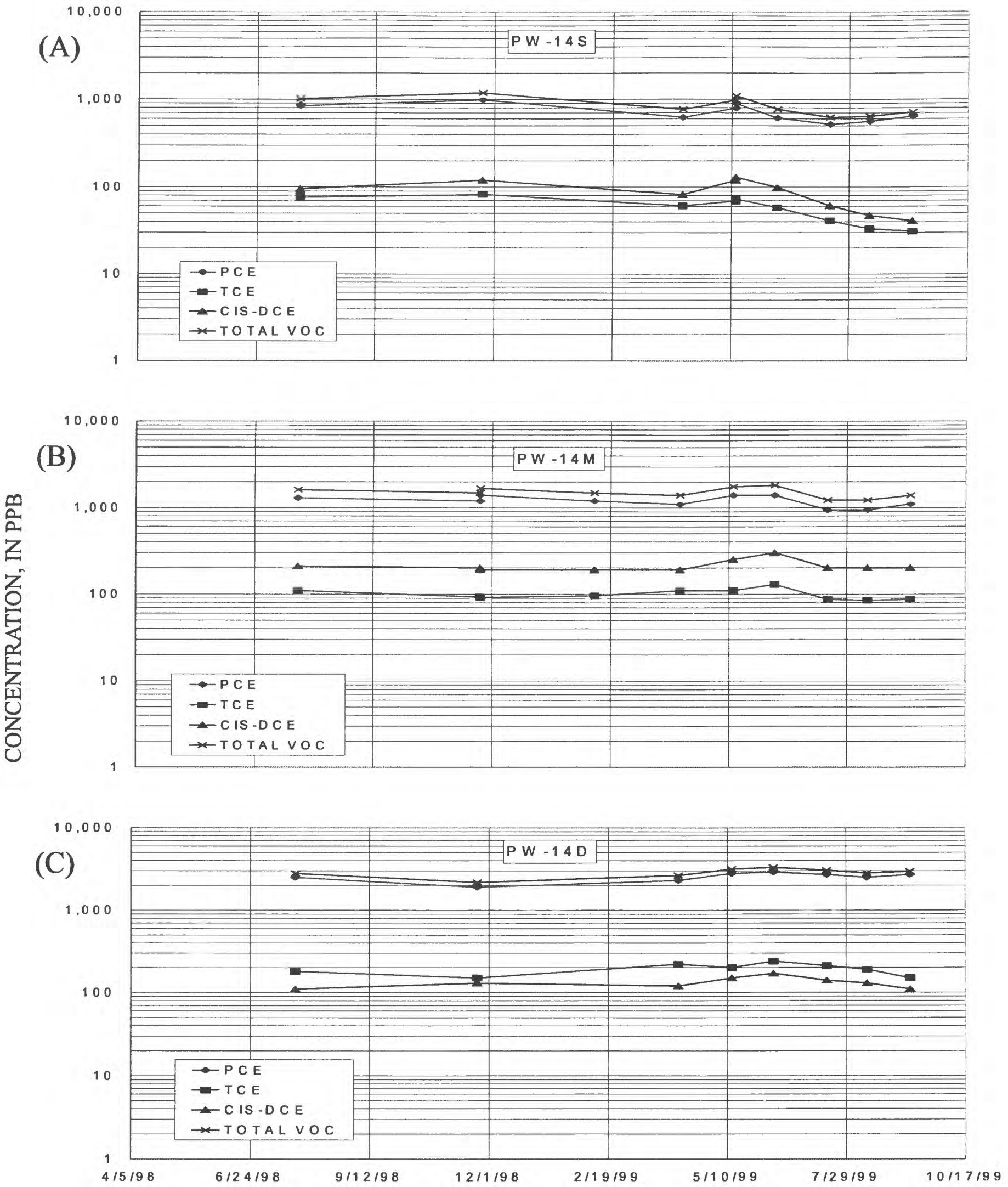

Figure 20. Concentrations of volatile organic compounds (VOC's) tetrachloroethylene (PCE), trichloroethylene (TCE), and cis-1,2-dichloroethane (CIS-DCE), and total VOC's (TOTAL VOC) from diffusion samplers for PW-14 cluster wells. 

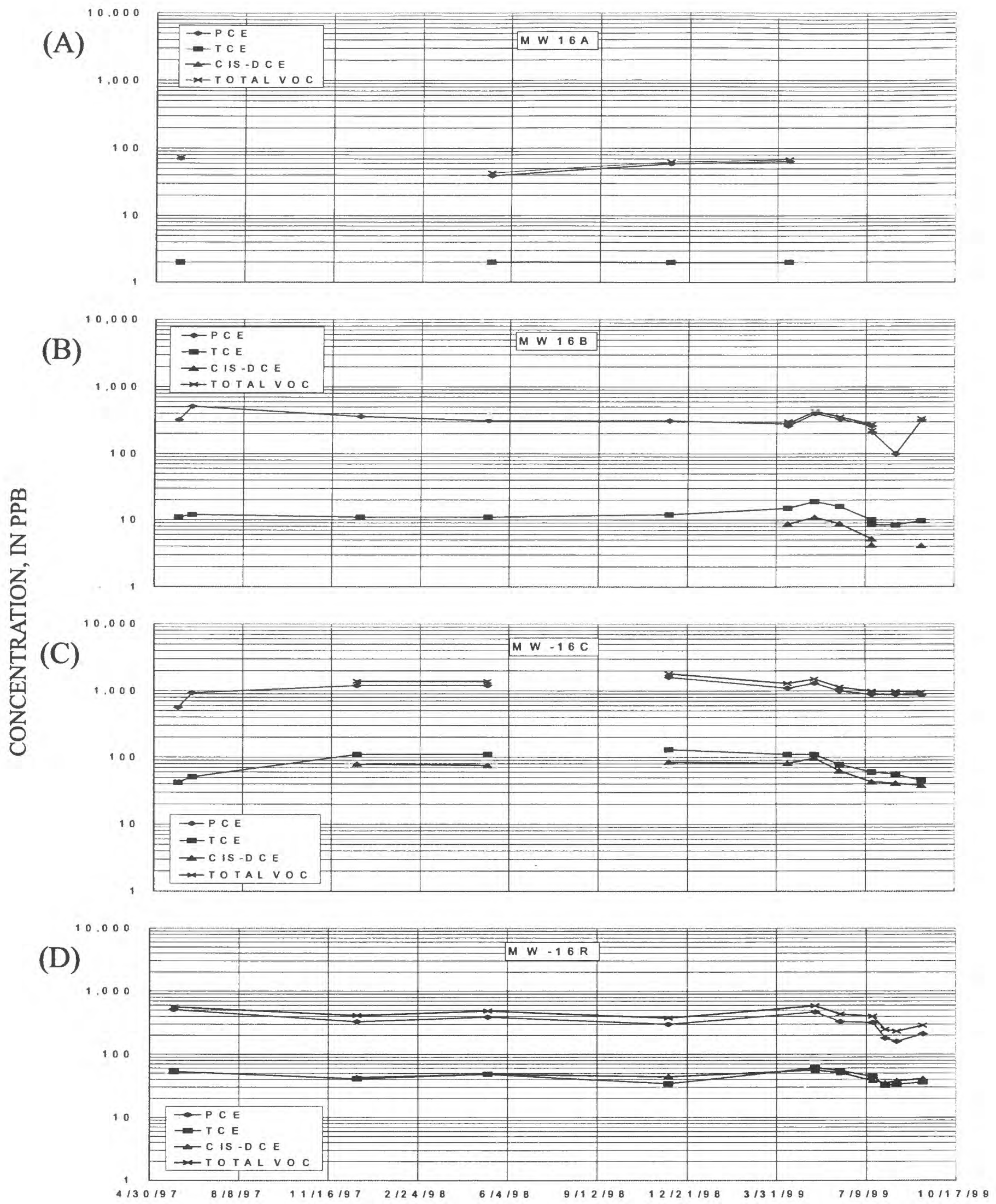

Figure 21. Concentrations of volatile organic compounds (VOC's) tetrachloroethylene (PCE), trichloroethylene (TCE), and cis-1,2-dichloroethane (CIS-DCE), and total VOC's (TOTAL VOC) from diffusion samplers for MW-16 cluster wells. 
treated water is injected back into the aquifer at a rate of approximately $60 \mathrm{gal} / \mathrm{min}$. Many wells show transient rises in PCE in May and September of 1999, which are likely the result of large precipitation events during those months. Large precipitation events, and subsequent recharge to ground water, may help desorb additional contaminants from the aquifer matrix and increase concentrations in the dissolved phase.

Time trends in concentrations of TCE and cis-1,2DCE at most of the sampled wells match the trends in concentrations of PCE. At several wells that had large declines in PCE concentration, however, only small declines occurred in TCE and(or) cis-1,2DCE concentrations. Furthermore, at three wells (wells PW-12M, PW12R, and PW-13D), concentrations of cis-1,2DCE increased while concentrations of PCE decreased. Cis-1,2DCE is primarily formed from the degradation of PCE and TCE and increases in cis-1,2DCE at selected wells suggest spatial and temporal variations in rates of biodegradation. Wells PW-12R and PW-13D are fully and partially set in bedrock, respectively, and some bedrock waters show a tendency of higher daughter-to-parent compound ratios than drift waters. In general, because most wells do not show increases in cis-1,2DCE, biodegradation is evidently occurring only on a local scale. The increase in cis-1,2DCE at three wells since the construction of the barrier wall suggests that the source of PCE probably is isolated by the wall, otherwise PCE concentrations would be higher relative to TCE and cis-1,2DCE concentrations.

At several wells where cis-1,2DCE has increased, sampled waters contain above-background concentrations of methane. The median methane values for contaminated shallow, medium, and deep wells ranged from 3 to $6.1 \mathrm{ppm}$. Well PW-12M, which shows increases of more than 1order of magnitude of cis-1,2DCE, had a methane concentration of 9.0 and $7.7 \mathrm{ppm}$ (appendix $2 \mathrm{~b}$ ).

Methane concentrations have increased over time and coincide with increases in cis-1,2DCE and TCE at wells where high frequency collection of methane occurred (B95-13 and B95-15). The ratio of cis-1,2DCE to PCE and methane $\left(\mathrm{CH}_{4}\right)$ for wells $\mathrm{B} 95-13$ and $\mathrm{B} 95-15$ is shown in figure 22. Methane concentrations have increased from 1997 to maximum levels in November 1998 when the barrier wall was completed. Increases in the ratio of cis-1,2DCE to PCE correspond to increases in methane and suggest an increase in biologic activity and methanogenesis in some zones of the aquifer.

VOC decreases in wells downgradient of the source area probably indicate the success of the barrier-wall construction in preventing the migration of contaminants. The average concentration of PCE and total VOC's (PCE, TCE, and cis-1,2DCE) have decreased since the completion of the barrier wall in November 1998. The average concentration of PCE in wells at the farthest downgradient part of the source area (PW13, PW 14, and MW16 clusters) declined by 23 percent from November 1998 to September 1999; whereas, total VOC's declined by only 5 percent. The slow decline in total VOC's is the result of increases in TCE and cis-1,2DCE at several wells.

A first-order exponential equation (Wiedemeier and others, 1998) was used to quantify observed concentration declines at the downgradient wells:

$$
C=C_{o} \exp ^{-k t}
$$

where

$C$ is concentration at t (time),

$C_{o}$ is initial concentration at time $=0$,

$k$ is the first-order decay constant ( $1 / \mathrm{yr})$, and

$t$ is time (years). 
The average concentration of PCE and total VOC's from sampling rounds in April through October 1999 were divided by average concentrations from November 1998 (the initial concentration, $\mathrm{Co}$ ) and plotted on graphs (fig. 23). An exponential function was fitted by least squares method and is shown as the regression line. The 95-percent confidence level was also plotted to bracket trendlines. The results show that the computed exponential slopes for PCE are steeper than for total VOC's. The computed decay constants (k) are 0.4304/year for PCE and 0.3189 /year for total VOC. After 10 years, the range in C/Co values for PCE is from 0.08 to virtually 0 ; the range in total VOC's is from 0.2 to 0 . As additional data are collected, the exponential trendlines may shift and residual errors also may be reduced, which would result in more representative trends.

The ease of use of diffusion samplers and associated decrease in sampling time allowed for high frequency sampling and detailed analyses of trends, but also allowed for a more instantaneous picture of the plume. For example, depending on the number of wells, it may take 2-3 weeks to sample a round of wells at the site. During that time, sample concentrations can vary because of short-term trends. VOC data collected on July 16, July 30 , and August 12,1999, at well B95-13 (appendix 2c), all at 2-week intervals, show PCE concentrations of 850 ppb, $590 \mathrm{ppb}$, and $520 \mathrm{ppb}$. Thus, the analysis of plume concentrations are less likely to be influenced by errors associated with the length of time required to collect a complete round of data at a site.

\section{SUMMARY AND CONCLUSIONS}

The concentrations of volatile-organic compounds (VOC's), principally tetrachloroethylene (PCE), trichloroethylene (TCE), and cis-1,2-dichloroethane (cis-1,2DCE), in ground-water samples collected with diffusion samplers correlate well with concentrations in samples collected by low-flow purging procedures. Twenty coupled diffusion and peristaltic-pump samples were collected from seven wells completed in glacial drift. Linear regressions of concentrations from diffusion and peristaltic-pump samples produced root-mean squares of 0.966 for PCE, 0.942 for TCE, and 0.979 for cis-1,2DCE. The PCE and cis-1,2DCE regression lines are essentially identical to the 1:1 line. The TCE regression line shows that TCE concentrations in the diffusion samples tend to be greater than concentrations in the peristaltic samples.

The mean concentration of PCE in diffusion samples was 1,152 parts-per-billion (ppb) and the mean from the peristaltic samples was $1,119 \mathrm{ppb}$. The standard deviations also were similar. The mean TCE concentration from diffusion samples $(89.2 \mathrm{ppb})$ was slightly higher than the mean concentration from peristaltic samples (75.4 ppb), whereas the means for cis-1,2DCE with both sample methods were identical. The Relative Percent Differences (RPD) of PCE, TCE, and cis-1,2DCE concentrations between peristaltic-pump and diffusion samples indicate that diffusion samples provide, on average, higher concentrations ( 3 to 16 percent) than peristaltic-pump samples. Compared to duplicate results, which show a small difference in concentration (4 percent on average in samples with positive detects), the differences in concentrations between samples collected by different methods are larger than differences in concentrations associated with analytical inaccuracies.

Trends in VOC's, which were corroborated by both diffusion samples and purged samples following lowflow procedures, indicate that diffusion samplers equilibrate relatively quickly to concentrations of VOC's in the well water at the time of bag retrieval. Declines in PCE concentration in diffusion samples of several hundred parts-per-billion between consecutive coupled sampling periods matched declines in PCE in purged samples and indicate that water concentrations inside the diffusion samplers were equivalent to concentrations in the purged samples collected the same day as bag retrieval.

The use of diffusion samplers in this setting was a cost-effective alternative to more expensive sampling procedures. Diffusion sampling costs less and can be done in one-fifth the time of low-flow sampling, allowing for more frequent data collection, and resulting in the understanding of several contaminant transport conditions at the study site.

The most significant contaminant transport condition identified was the spatial variability in declines of PCE and the small scale increases in TCE and cis-1,2DCE at several wells since a barrier wall was constructed. Rates of PCE decline at wells correspond with variations in sediment lithology at the screen interval and location of the well within the plume. Wells screened in coarse-grained gravel layers along the northern flank of the plume 
showed the largest declines in PCE. At several wells, concentrations of TCE and cis-1,2DCE increased, whereas PCE decreased suggesting that small scale biodegradation is occurring. Most wells that showed concentration increases of TCE or cis-1,2DCE are partially set in the bedrock. Increased methane concentrations following wall construction point to a short-term increase in methanogenesis, which also may help explain the small scale increases in TCE and cis-1,2DCE. Temporary increases in VOC's occurred following recharge events on several occasions, suggesting desorbtion of VOC's from the aquifer matrix.

Vertical variations in VOC's were detected from strings of diffusion samplers installed in one shortscreened (5-ft long) well screened in the glacial drift and one open-hole (38-ft long) bedrock well. Variations in vertical concentrations were as much as 100 percent, much larger than the maximum RPD between duplicates of 11 percent. Preliminary results indicate the technique may be applied as a screening tool to estimate vertical concentrations.

\section{SELECTED REFERENCES}

Camp, Dresser, and McKee, Federal Programs Corporation, 1995, Final report of vertical contaminant profiling, Savage Municipal Supply Well, Superfund Site-OU1, Milford, New Hampshire: Boston, Mass., November 1995, 5 chaps., 5 apps.

Camp, Dresser, and McKee, Inc., 1996, Conceptual remedial design report, volume 1, for OK Tool Source Area, Savage Municipal Supply Well, Superfund Site-OU1, Milford, New Hampshire: Cambridge, Mass., March 1996, 5 chaps.

Chapelle, F.H., 1993, Ground-water microbiology and geochemistry: New York, John Wiley and Sons, Inc., 424 p.

Coakley, M.F., Keirstead, Chandlee, Brown, R.O., and Hilgendorf, G.S., 1997, Water Resources Data New Hampshire and Vermont water year 1996: U.S. Geological Survey Water-Data Report NH-VT-96-1, 189 p.

Crill, P.M., Bartlett, K.B., Wilson, J.O., Sebacher, D.I., 1988, Tropospheric methane from an Amazonian floodplain lake: Journal of Geophysical Research, v. 93, no. D2, p. 1564-1570.

Harte, P.T., Flynn, R.H., Kiah, R.G., Severance, Timothy, and Coakley, M.F., 1997, Information on hydrologic and physical properties of water to assess transient hydrology of the Milford-Souhegan glacial-drift aquifer, Milford, New Hampshire: U.S. Geological Survey Open-File Report 97-414, 96 p.

Harte, P.T., and Mack, T.J., 1992, Geohydrology of, and simulation of ground-water flow in the Milford-Souhegan glacialdrift aquifer, Milford, New Hampshire: U.S. Geological Survey Water-Resources Investigations Report 91-4177, 90 p.

Helsel, D.R., and Hirsch, R.M., 1992, Statistical methods in water resources: Studies in Environmental Science 49, New York, Elsevier Publishers, 522 p.

HMM Associates, Inc., 1989, Draft remedial investigation, Savage well site, Milford, New Hampshire: Concord, Mass., no. $2176 \mathrm{HAZ} / 2880,218 \mathrm{p}$.

1991, Remedial investigation, Savage well site, Milford, New Hampshire: Concord, Mass., no. 2176 HAZ/4814, $800 \mathrm{p}$.

Imbrigiotta, T.E., Gibs, Jacob, Fusillo, T.V., Kish, G.R., and Hochreiter, J.J., 1988, Field evaluation of seven sampling devices for purgeable organic compounds in ground water; Collins, A.G., and Johnson, A.J., eds., in Ground-Water Contamination Field Methods: American Society for Testing and Materials, Philadelphia, ASTM STP 963, p. 258-273.

Johnston, C.M., and Harte, P.T., 1998, Documentation and application example of a simple method to compute the maximum slope and direction of hydraulic head: U.S. Geological Survey Water-Resources Investigations Report 98-4021, 25 p.

McAuliffe, C., 1971, Gas chromatographic determination of solutes by multiple phase equilibrium: Chemical Technology, v. 1, p. 46-51.

McFarlane, I.D., 1996, Low-flow ground-water sampling for manufactured gas plant sites, in Hydrology and Hydrogeology of Urban and Urbanizing Areas, April 1996, Annual meeting, Boston, Mass.: Proceedings, American Institute of Hydrology, p.GWQI23-GWQI24.

Mullaney, J.R., Mondazzi, R.A., and Stone, J.R., 1999, Johnston, C.M., and Harte, P.T., 1998, Hydrogeology and water quality of the Nutmeg Valley Area, Wolcott and Waterbury, Connecticut: U.S. Geological Survey Water-Resources Investigations Report 99-4081, 90 p.

Parsons Engineering Science, Inc., 1999, Technical report for the evaluation of groundwater diffusion samplers: Denver Air Force Center for Environmental Excellence Technology Transfer Division, chaps. 7, appendices 4.

Pohlman, K.F., Icopini, G.A., McArthur, R.D., Rosal, C.G., 1994, Evaluation of sampling and field-filtration methods for the analysis of trace metals in ground water: U.S. Environmental Protection Agency 600/R-94/119, 79 p. 
U.S. Environmental Protection Agency, 1986, RCRA Technical enforcement guidance document: Washington, D.C., Report OSWER-9950.1.

U.S. Environmental Protection Agency, 1996a, Test method for evaluating solid waste, physical/chemical methods, SW-846: Third edition, rev. 2, v. IB, chap. 4, Section 4.3.2, Final update IIl, December 1996, p. 1-86.

Region 1, 1996b, Low stress (low flow) purging and sampling procedure for the collection of ground water samples from monitoring wells: Standard Operating Procedures no. GW0001, rev. 2, p. 13.

U.S. Geological Survey, 1998, National field manual for the collection of water-quality data: U.S. Geological Survey Techniques of Water-Resources Investigations, book 9, chap. A6, variously paginated.

Vroblesky, D.A., Hyde, W.T., 1997, Diffusion samplers as an inexpensive approach to monitoring VOC's in ground water: Ground Water Monitoring and Remediation, Summer 1997, p. 177-184.

Vroblesky, D.A., Robertson, J.F., 1996, Temporal changes in VOC discharge to surface water from a fractured rock aquifer during well installation and operation, Greenville, S.C.: Ground Water Monitoring and Remediation, Summer 1996, p. 196-201.

Wiedemeier, T.H., Swanson, M.A., Moutoux, D.E., Gordon, E.K., Hass, P.E., Miller, R.N., Hansen, J.E., and Chapelle, F.H., 1998, Technical protocol for evaluating natural attenuation of chlorinated solvents in ground water: U.S. Environmental Protection Agency 600/R-99/128, 272 p. 
Appendix 1. Procedures for preparation, installation, and collection of diffusion bag samples in wells.

1) Get trip blank from analyzing laboratory. Trip blank water will remain in $40-\mathrm{mL}$ septum vial and will travel with samplers to the field. Septum viles should be stored in a clean laboratory refrigerator and transported in a cooler with ice.

2) Ensure adequate supply and check quality of $40-\mathrm{mL}$ septum vials to be used in the field.

3) Bag preparation: Cut off a 13 in. length of 2-in.wide, polyethylene 2-mL thick sleeves. When filled, sleeves (bags) are $1.5 \mathrm{in}$. diameter. Seal one end of the sleeve multiple times with a heat-impulse sealer. The last seal and first seal should be approximately 2 in. apart. Rinse the inside of the newly created "bag" with VOC-free water several times. Pour VOC-free water into bag opening, filling to a length of 9 in. (approximately $260 \mathrm{~mL}$ ). Seal open end of bag with heat sealer multiple times with care to minimize air space in the tube. Ideally, the same source of VOC-free water should be used for all blanks and the diffusion bags that will be placed in wells.

4) Create laboratory environment blank. This bag will remain in the laboratory, exposed to ambient laboratory conditions until the next sampling round (the next time diffusion bags are created).

5) Create equipment blank. This diffusion bag will travel with samplers into the field and represents a check of the sampling device as well as the working environment.

6) Create diffusion bags for the wells. Know in advance how many diffusion bags need to be installed. Make two extra bags in case of accidental puncture.

7) Store all bags in a sealed container.

8) Collect laboratory environment sample from previous sampling period by cutting bag open and filling two $40-\mathrm{mL}$ septum vials. This sample has been equilibrating to ambient laboratory conditions for several weeks.

9) Transport all diffusion bags and blanks to the field.

\section{First Time Installation}

Holders and associated equipment for installing bags in wells should be assembled and ready for use before the start of sampling.

Two types of diffusion bag holders (shrouds) can be used. Mesh holders are ideal for cased and screened wells. PVC pipe holders are useful in open- walled rock holes where bag puncture can be an issue. Mesh holders are thick netted flexible devices coated with polyethylene materials and of a minimum diameter of $1.5 \mathrm{in}$. Diffusion bags will fit inside mesh holders. PVC pipe holders are $13 / 8$ in. inner diameter, and 1.5 in. outer diameter, slotted to allow water contact with bag, and pipe material. Diffusion bags will also fit inside PVC pipe holders. Bottom of holders should be fitted with a stainless steel weight. All materials should be properly decontaminated before usage.

Verify well depth by sounding with a measuring tape from known measurement point. Take a water-level measurement from same measurement point and compute height of water column above open interval and potential placement of bag inside well. It is important to fully submerge diffusion bag in water so this step of verifying well 
construction and water levels must be done. For short screens or open holes (less than $5 \mathrm{ft}$ ), diffusion bags are typically installed at the midpoint of well opening. For long screens or open holes ( more than $5 \mathrm{ft}$ ), bags can be installed with several bags in a vertical string (series) up and down opening or at designated locations such as fractures.

Install bag inside holder. Tie a spool of teflon line to one end of holder and lower inside the well to the desired depth. Cut off teflon line so as to set the midpoint of the diffusion bag at desired depth and then secure top part of line to a fixed object such as a padlock anchor.

10) Make a water-level measurement from a known point at monitoring wells.

11) Retrieve samples from all wells by hoisting holders to the surface. Cut open the top part of the diffusion bag with special care not to spill the bag, and fill two $40-\mathrm{mL}$ septum vial's. If duplicates are needed, fill two more vials with remaining water. Otherwise, remaining water can be poured into a small beaker for purposes of recording water temperature with a small temperature probe.

12) Store collected samples in a cooler with ice.

13) Install newly created clean diffusion bags into holder and lower to designated position in well.

14) After last bag is installed, cut open equipment blank diffusion bag and pour contents into two 40-mL septum vials.

15) Fill out chain of custody form and make copies.

16) Transport and submit all samples and blanks to analyzing laboratory. 
Source of Data

DES = New Hampshire Department of Environmental Services

USGS = U.S. Geological Survey

$E P A=$ U.S. Environmental Protection Agency

Sample Collection Method

peri $=$ peristaltic pump

GRAB = grab sample in surface water

$\mathrm{BL}=$ bladder pump

$\mathrm{DB}$ = passive diffusion bag sampler

VOSS $=$ voss bailer pump

Units

$\mathrm{mg} / \mathrm{L}=$ miligrams per liter

$\mathrm{L}=$ liters

$\min =$ minutes

$\mathrm{ft}=$ feet

$\mathrm{cm}=$ centimeter

$\mathrm{mv}=$ milivolts

${ }^{\circ} \mathrm{C}=$ degrees celcius

$\mathrm{NTU}=$ neophlemetirc turbidity unit

Chemical Compounds

$\mathrm{CO}_{2}=$ carbon dioxide

$\mathrm{Fe} 2+=$ iron cation, plus two charge

$\mathrm{S}^{2-}=$ sulfide anion

$\mathrm{NH}_{4}{ }^{+}=$ammonium

$\mathrm{Cl}-=$ chloride anion

$\mathrm{SO}_{4}{ }^{2-}=$ sulfate

$\mathrm{NO}_{3}{ }^{-}=$nitrate

$\mathrm{NO}_{2}{ }^{-}=$nitrite

$\mathrm{PO}_{4}{ }^{3-}=$ total phosphate

$\mathrm{Ca}^{2+}=$ calcium cation

$\mathrm{Fe}($ total $)=$ total iron

$\mathrm{Mg}^{2+}=$ magnesium cation

$\mathrm{Mn}^{2+}=$ manganese cation

$\mathrm{K}^{+}=$potassium cation

$\mathrm{Na}^{+}=$sodium cation

$\mathrm{CH}_{4}=$ methane

TOC $=$ total organic carbon

$\mathrm{Br}$ - = bromide

$\mathrm{CaCO}_{3}=$ alkalinity, measured as total calcium carbonate

$\mathrm{PCE}=$ tetrachloroethene 
TCE $=$ trichloroethe $?$

CIS-DCE $=$ cis- 1,2 dichloroethene

111-Tri $=1,1,1$-trichloroethene

MTBE $=$ methyl-tertiary-butyl-ether

THF = tetrahydrofuran

Meth.Chl = methylene chloride

\section{Other Explanations}

$$
\begin{aligned}
& \text { \# = number } \\
& --=\text { no data } \\
& <\text { less than }
\end{aligned}
$$

CC = field colorimetric chemical test kit

$\mathrm{SC}=$ specific conductance

$\mathrm{DO}=$ dissolved oxygen

hole $=$ downhole measuring device

flowthru $=$ flow-through chamber

Temp $=$ temperature

(d) = duplicate sample

$\mathrm{SC}-\mathrm{lab}=$ specific conductance as measured from sample bottle in the lab

$U$ " $x$ "= undected at a limit of " $x$ " ppb

equip blank = equipment blank

lab blank = laboratory blank

umhos $/ \mathrm{cm}=$ micromhos per centimeter

$\mathrm{Eh}=$ redox potential measurement

river $=$ river sample 


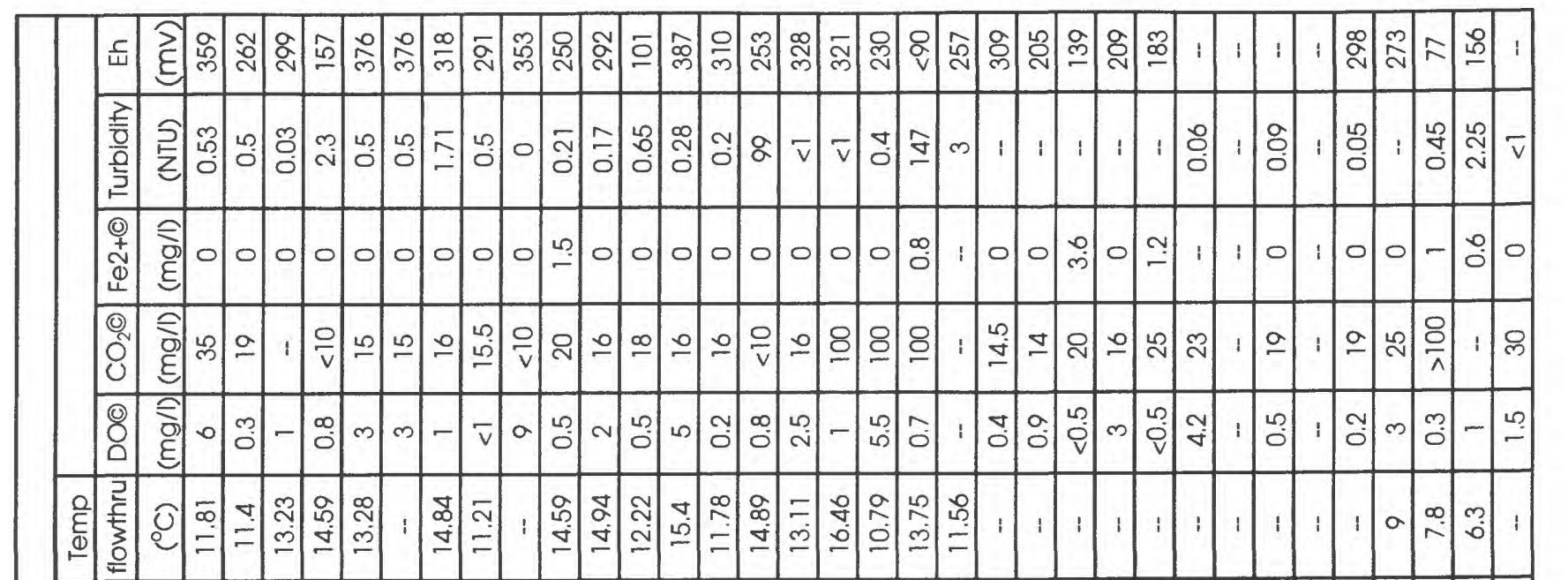

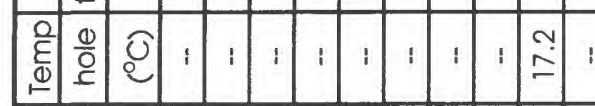

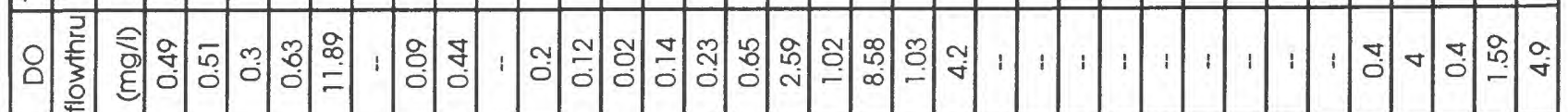

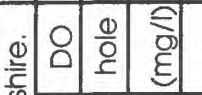

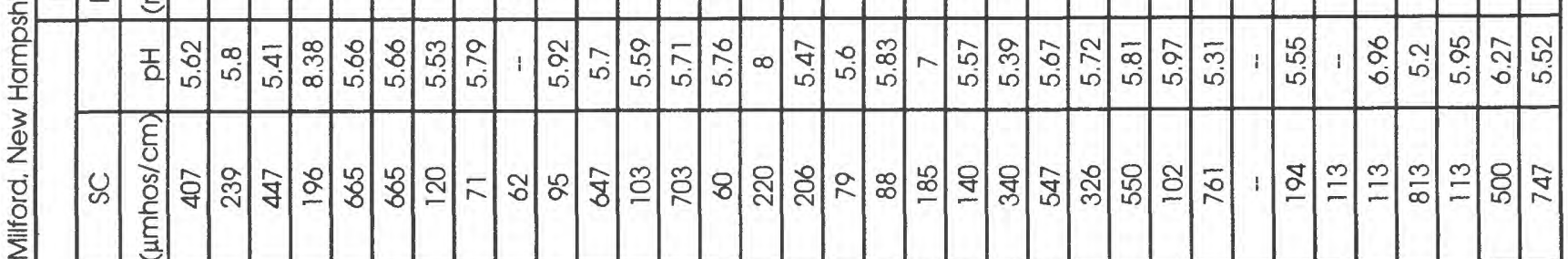

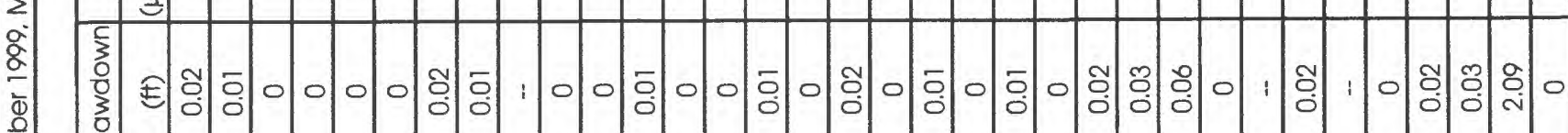

है

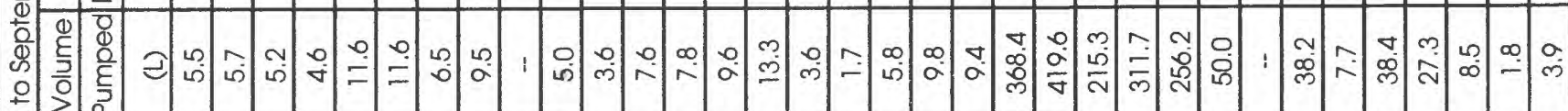

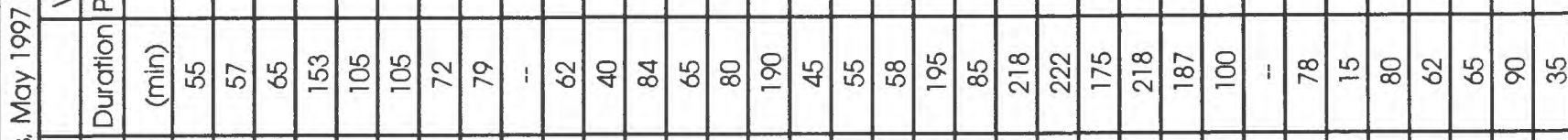

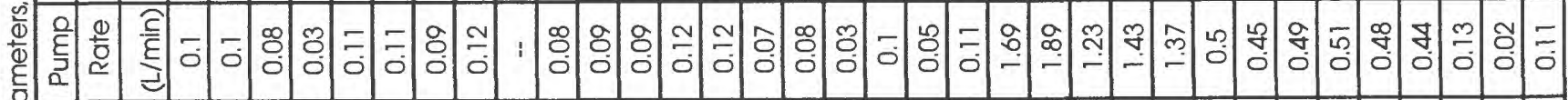

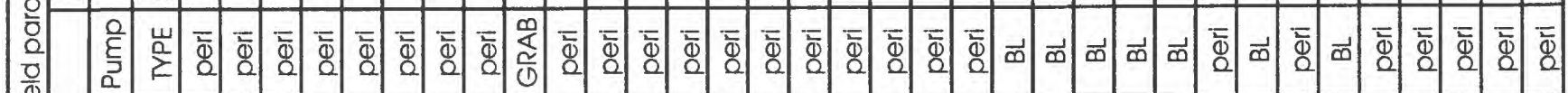

要

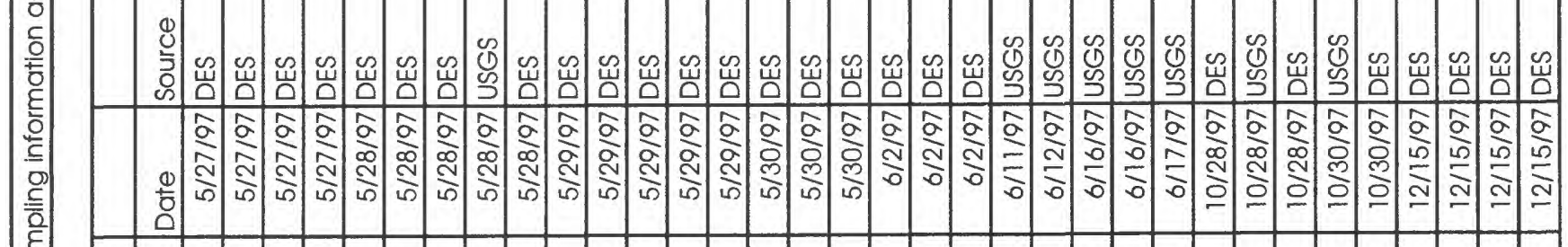

है

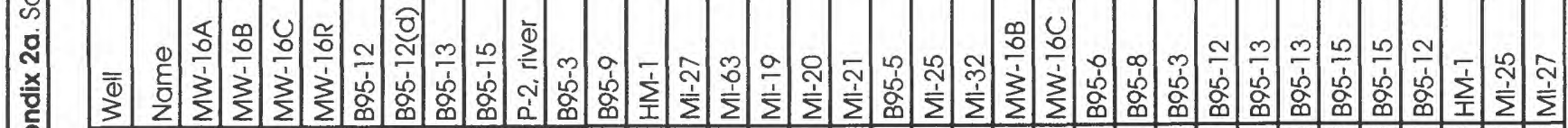

语 


\begin{tabular}{|c|c|c|c|c|c|c|c|c|c|c|c|c|c|c|c|c|c|c|c|c|c|c|c|c|c|c|c|c|c|c|c|c|c|c|}
\hline$\stackrel{ᄃ}{w}$ & है & 1 & 1 & $\overline{\widetilde{N}}$ & $i$ & 1 & 1 & i & i & & ర్లి & ! & & 串 & 의. & & $\circ$ & 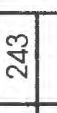 & 1 & ! & ;. & 8 & 总 & $\underset{v}{\mathrm{~J}}$ & $i$ & & 1 & : & 1 & 1 & 1 & & & 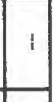 \\
\hline $\begin{array}{l}\frac{7}{1} \\
\frac{0}{0} \\
\frac{5}{5}\end{array}$ & 点 & $\bar{v}$ & $\bar{v}$ & $\bar{v}$ & $\begin{array}{l}\widetilde{\alpha} \\
\alpha \\
\delta\end{array}$ & $\frac{7}{0}$ & ' & $\checkmark$ & $\bar{v}$ & $\bar{v}$ & $\begin{array}{l}- \\
0 \\
0\end{array}$ & $\bar{v}$ & $\begin{array}{l}\circ \\
0 \\
0\end{array}$ & ợ & 号 & & 1 & 12 & $\frac{\infty}{0}$ & ; & 1 & $\hat{\circ}$ & ָ̊) & $\overline{0}$ & i & & $\bar{v} \mathrm{v}$ & $\bar{v}$ & $\frac{\infty}{0}$ & ָ̃ & స̃ & 1 & & 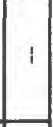 \\
\hline $\begin{array}{l}\text { (1) } \\
+ \\
0 \\
0 \\
4\end{array}$ & है & 0 & 0 & $\left|\begin{array}{l}\infty \\
0\end{array}\right|$ & 0 & 0 & | & 0 & 0 & 0 & -1 & 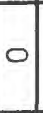 & 잉 & 0 & o) & & 0 & 10 & 0 & : & : & $:$ & 이 & 0 & I & 0.0 & 0. & -0 & $\mid \begin{array}{l}0 \\
\sim\end{array}$ & 0 & 0 & i & 0 & \\
\hline \begin{tabular}{l|}
0 \\
0 \\
0 \\
$\mathcal{U}$
\end{tabular} & ठิ & & : & f & $m$ & f & & مَ & 워 & প্ల & ָ) & $\therefore$ & $:$ & & $\frac{0}{v}$ & $\frac{q}{v}$ & ㅇ & 18 & $\mathrm{~N}$ & i & : & : & $=$ & $\bar{v}$ & 1 & : & : & : & 1 & 1 & 1 & I & 1 & \\
\hline \begin{tabular}{|l|}
8 \\
0 \\
\end{tabular} & Оิ & & $\begin{array}{l}m \\
0\end{array}$ & م & 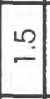 & - & & - & $\sim$ & $m$ & ષे & 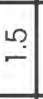 & & ¿ & $\begin{array}{l}a \\
\dot{0}\end{array}$ & $\dot{\mathbb{J}}$ & جمـا & 1 & $m$ & & 1 & & $\hat{0}$ & $\widehat{0}$ & 1 & ১) & c: & $\dot{0}$ & ?. & $\infty$ & $\sim$ & : & - & \\
\hline
\end{tabular}

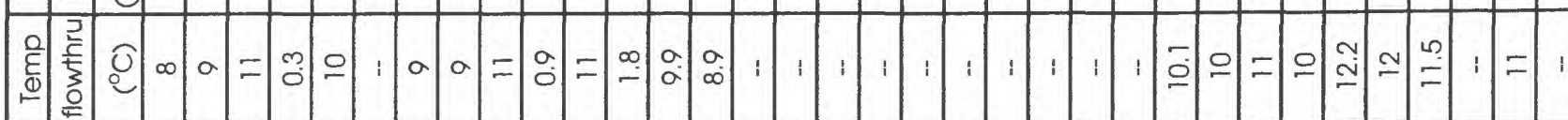

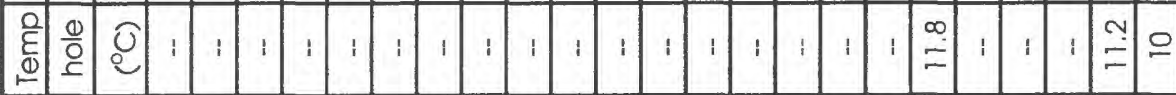

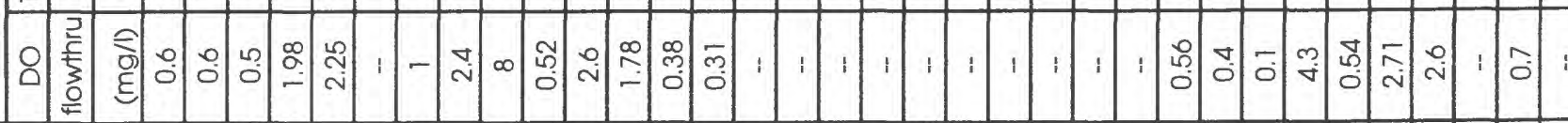

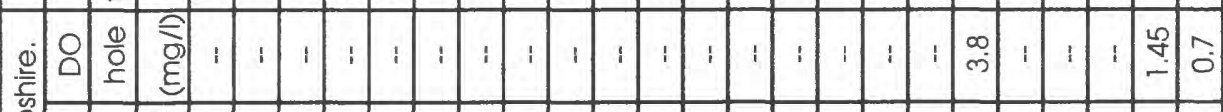

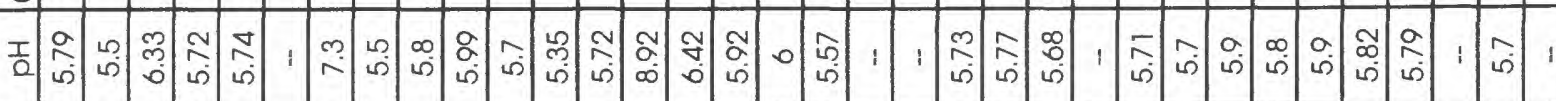

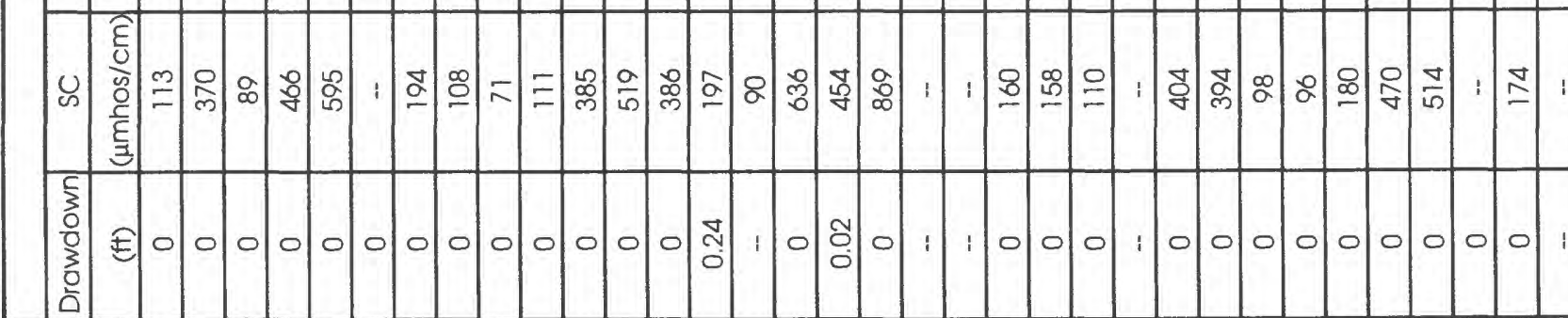

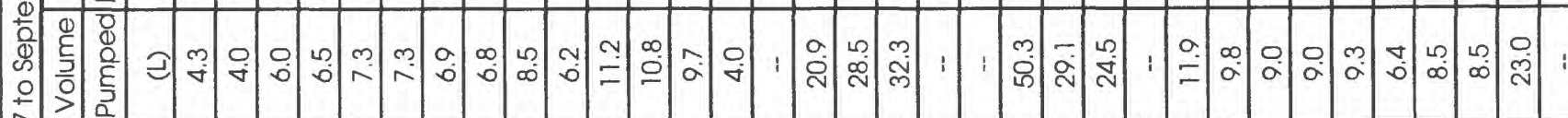

aे

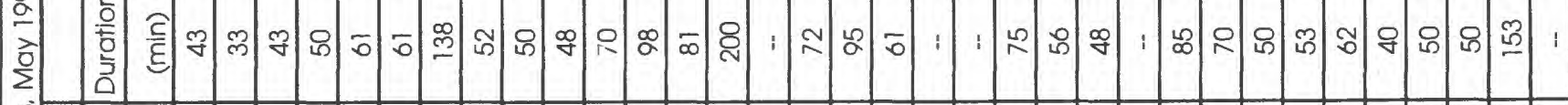

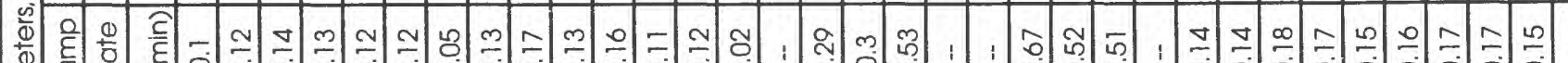
हो

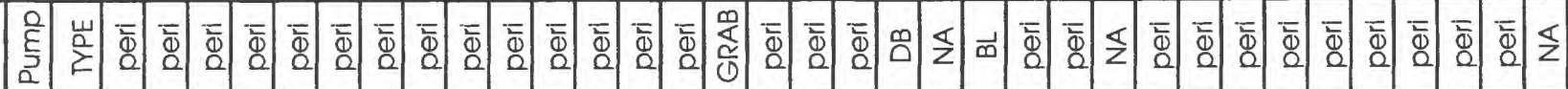

-

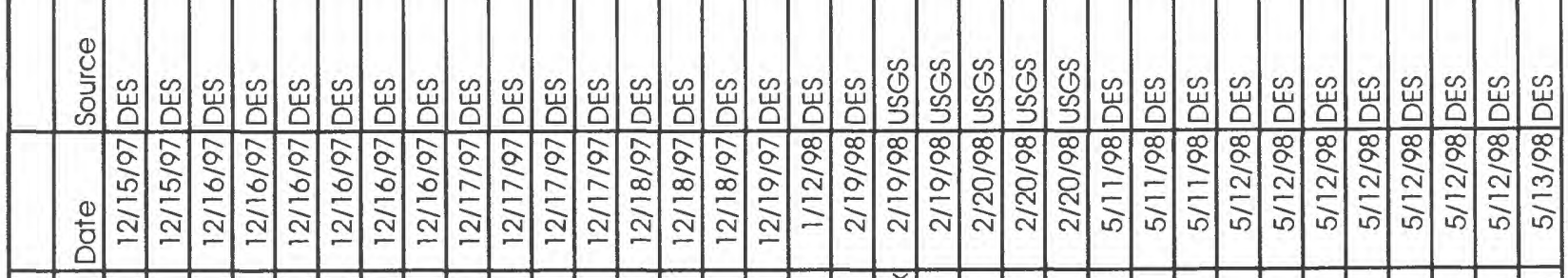

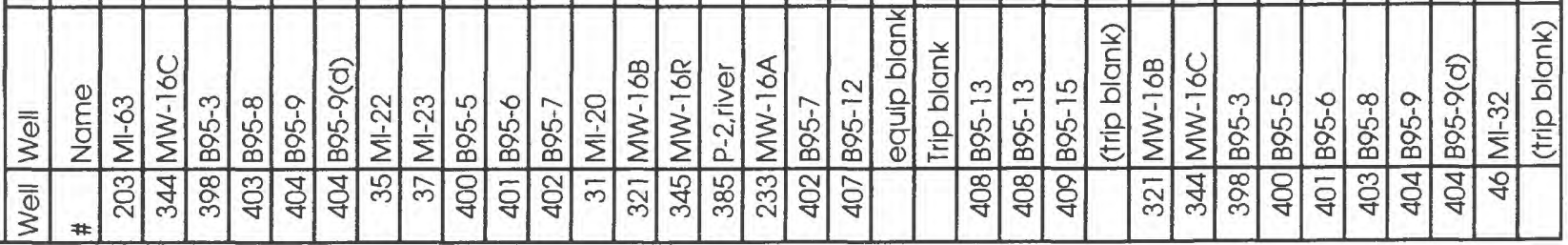




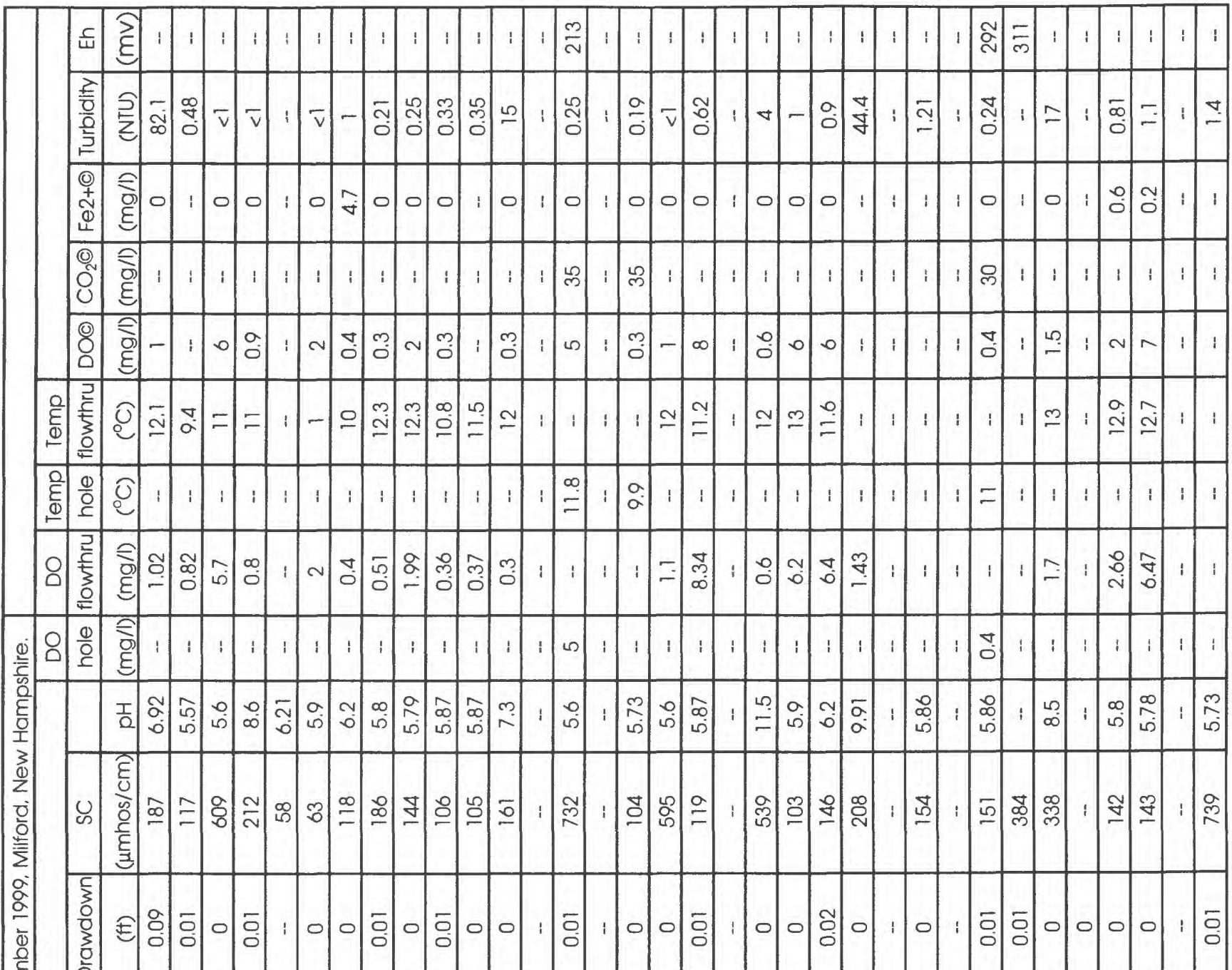

a

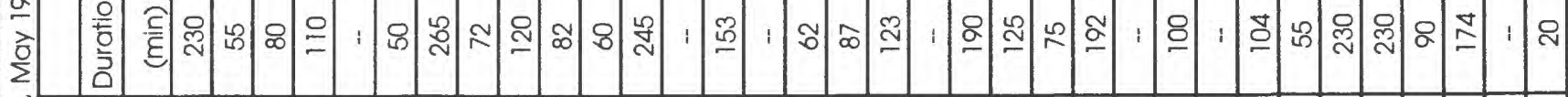
竞

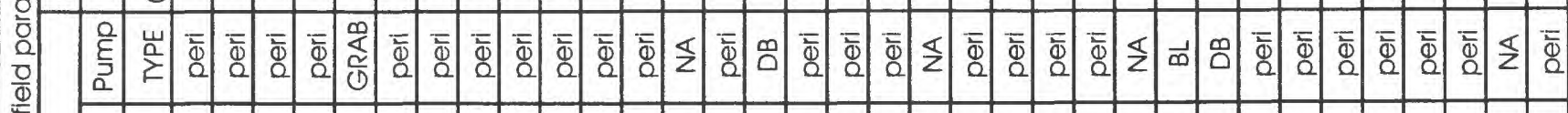

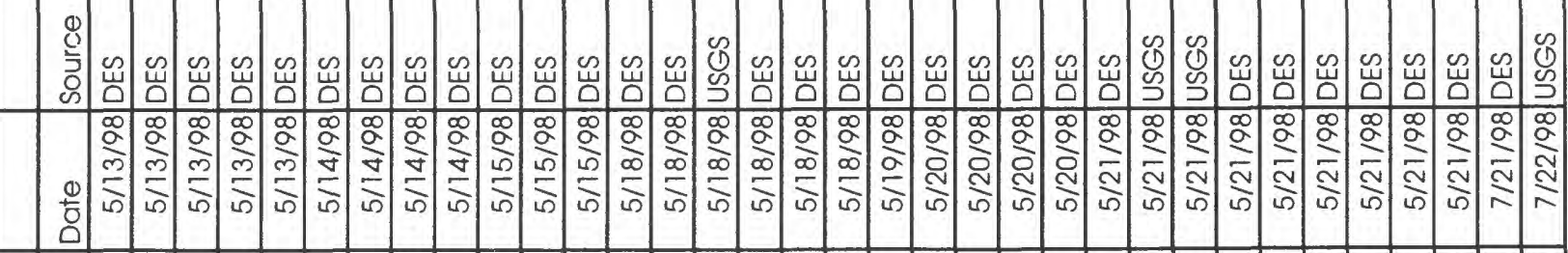

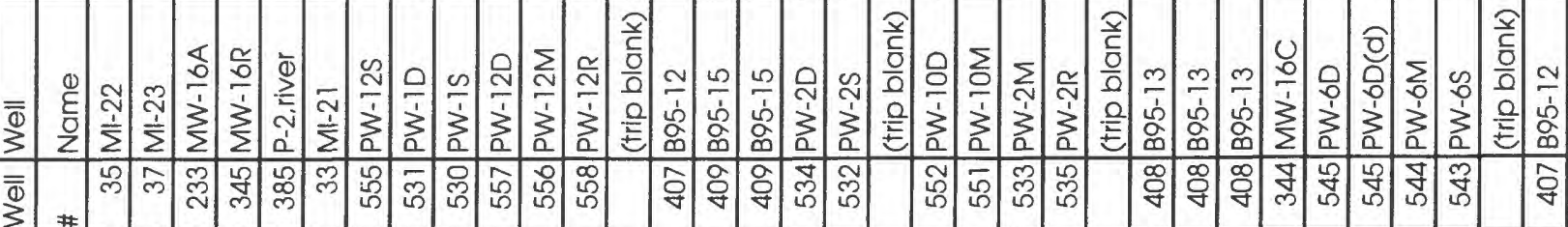




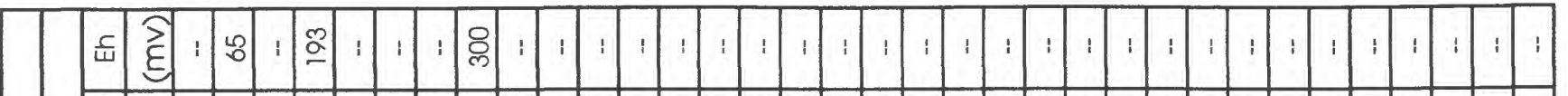

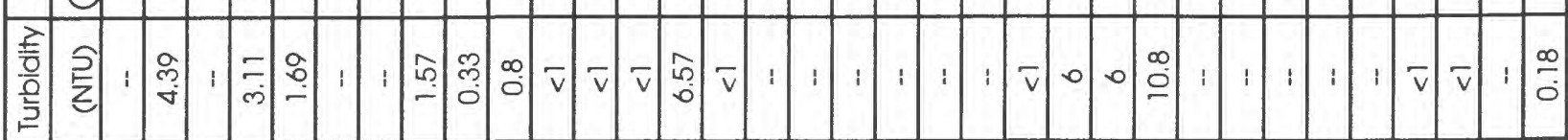

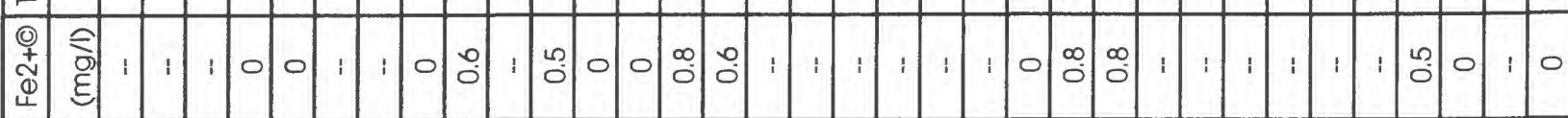

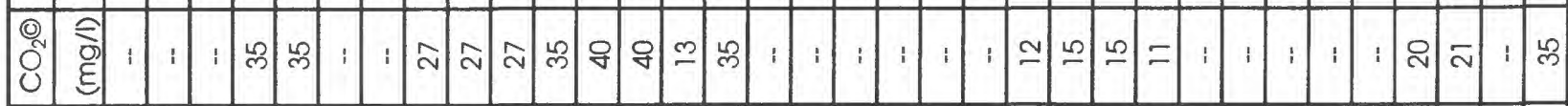
然然

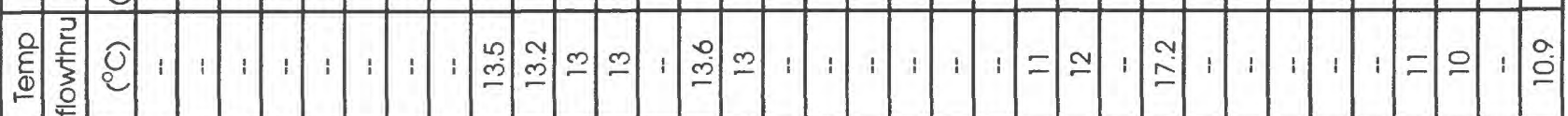

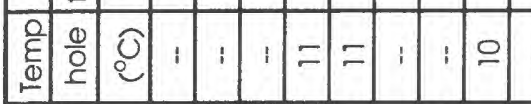

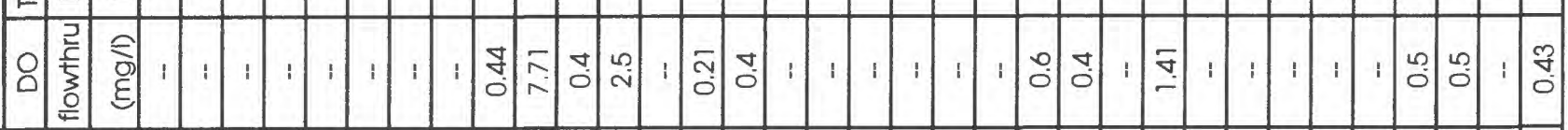

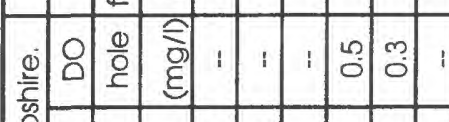

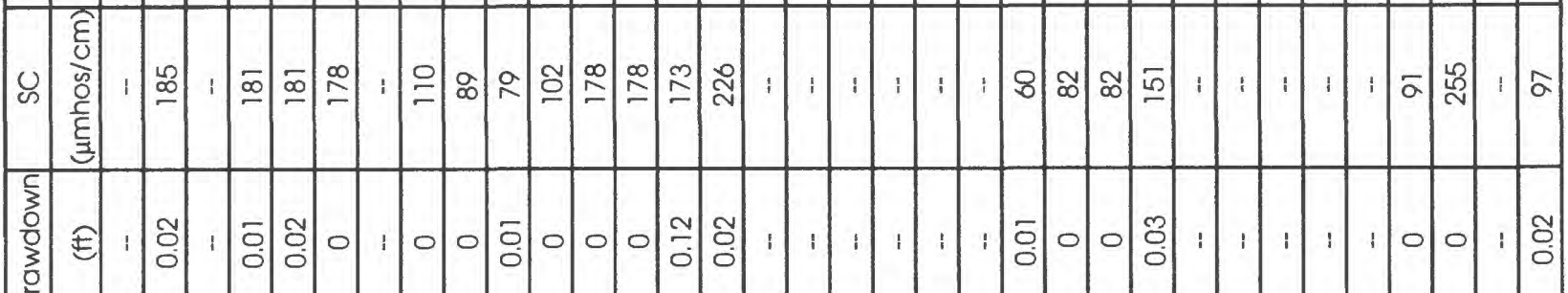

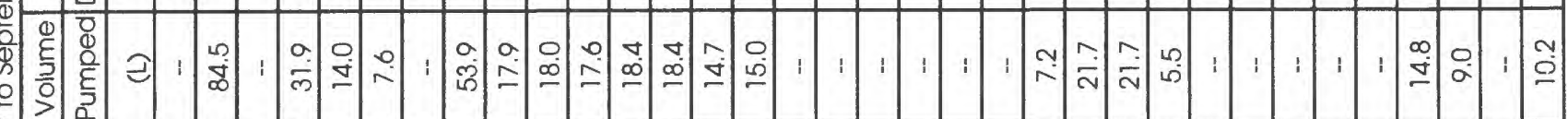

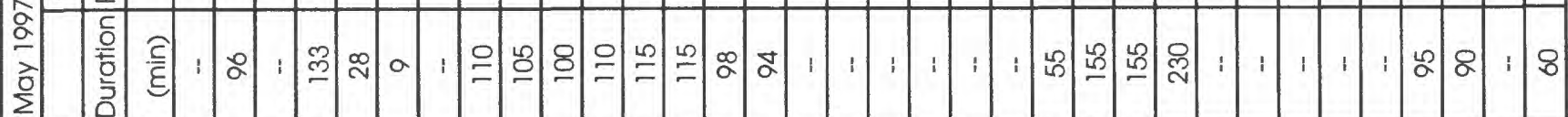

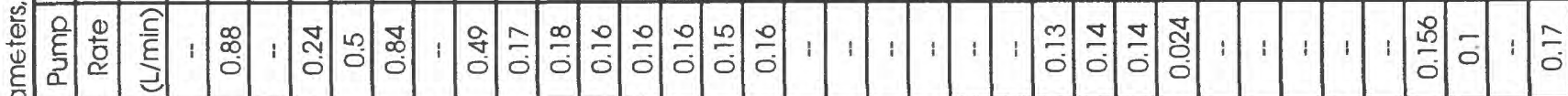

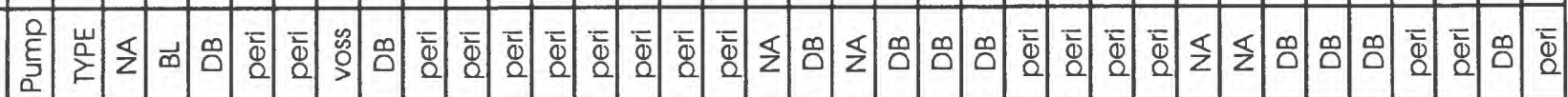

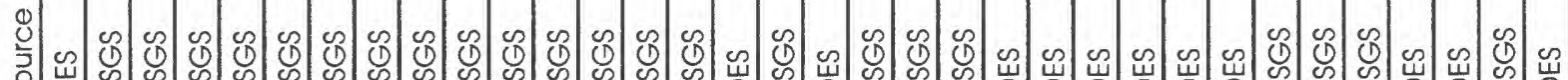

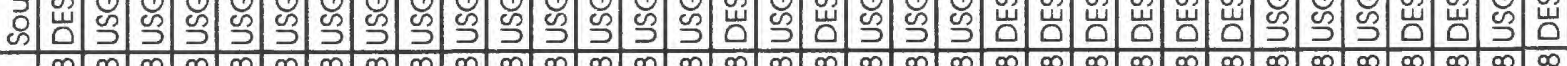

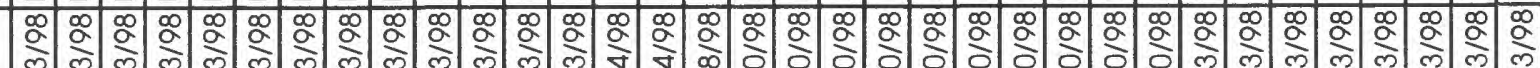

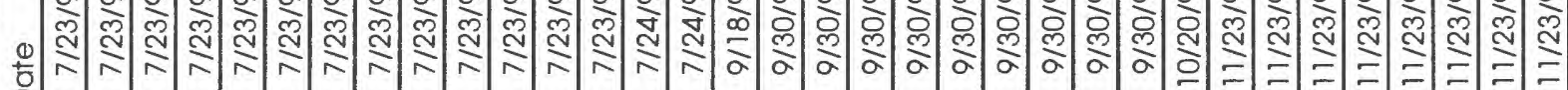
$+$ 章

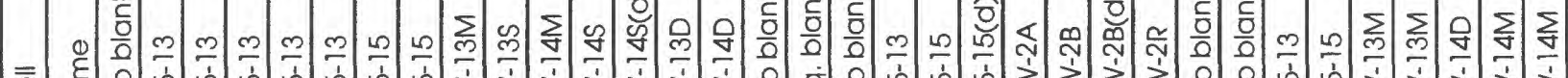

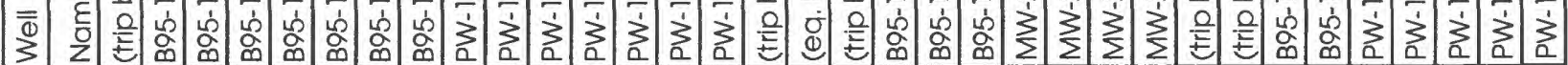

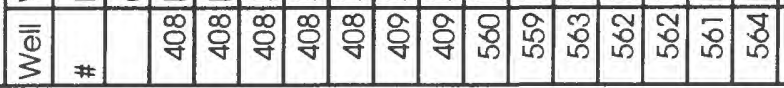

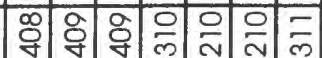

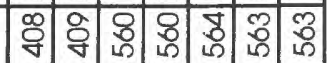




\begin{tabular}{|c|c|c|c|c|c|c|c|c|c|c|c|c|c|c|c|c|c|c|c|c|c|c|c|c|c|c|c|c|c|c|c|}
\hline 古 & $\bar{z}$ & ह & 1 & 1 & 1 & $i$ & $:$ & 1 & 11 & 1 & 1 & 1 & $:$ & 1 & 1 & 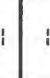 & $1:$ & i & 1 & $:$ & & $\begin{array}{lll} & 1\end{array}$ & $:$ & 1 & & $\begin{array}{llll} & 1\end{array}$ & 1 & i & & & I \\
\hline & 点 & & $\frac{\infty}{0}$ & $\bar{v}$ & $\frac{2}{0}$ & $\bar{v}$ & - & $\bar{v}$ & $\bar{v}$ & $\overline{0}$ & $i$ & $\bar{v}$ & $\bar{v}$ & $\bar{v}$ & $\bar{v}$ & $: \frac{5}{2}$ & $\begin{array}{c}\mathrm{s} \\
\mathrm{s}\end{array}$ & $\frac{\infty}{0}$ & $\bar{v}$ & $\frac{\infty}{0}$ & - & - & $\frac{1}{0}$ & $\bar{v}$ & $\bar{v}$ & $\bar{v} \mid \bar{v}$ & $\bar{v}$ & $m$ & & $\bar{v}$ & 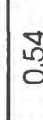 \\
\hline$\stackrel{\varrho}{\omega}$ & ठิ & 0 & 0 & 0 & $\stackrel{a}{i}$ & 0 & 0 & 0 & $=$ & $\sim$ & $:$ & 0 & 0 & 00 & 0 & $: 0$ & 00 & 0 & 0 & $\left.\mid \begin{array}{l}\infty \\
0 \\
0\end{array}\right]$ & $\underset{\forall}{\sim}$ & $\underset{\nabla}{*}$ & 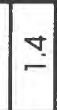 & 0 & 0.0 & 0 & 0 & 0 & & 0 & 0 \\
\hline $\begin{array}{l}\text { (1) } \\
0 \\
0\end{array}$ & & & 요 & $\hat{\curvearrowright}$ & $=$ & 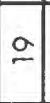 & প্ల & $\stackrel{2}{\sim}$ & $\frac{0}{\mathrm{v}}$ & $\stackrel{\sim}{\sim}$ & $:$ & $\widetilde{\sim}$ & $\bar{N}$ & প్ల) & $\frac{0}{v}$ & : & 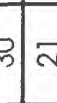 & প্ল & $=$ & 이 & ఇ & . & $\bar{N}$ & $\hat{\sim}$ & $\bar{~}$ & $\bar{N}$ & $\simeq$ & 요 & ผี้ & $\mathrm{v} / \frac{O}{\mathrm{v}}$ & প্ল \\
\hline 8 & & $=0$ & 足 & ¿̀ & $\overline{0}$ & $\sim$ & ঠ் & $\circ$ & $\stackrel{\Delta}{\circ}$ & $\dot{0}$ & : & $\infty$ & 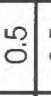 & 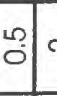 & $\sim$ & c & $\stackrel{D}{b}$ & $\nabla$ & $\infty$ & య & $\begin{array}{llll}\circ & 0\end{array}$ & ○. & $\stackrel{N}{0}$ & a & ১̊ & \begin{tabular}{c|c}
$\Delta$ \\
\end{tabular} & $\nabla$ & $\stackrel{\square}{-}$ & ơ & 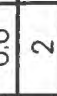 & $\nabla$ \\
\hline 읠 & 0 & 응 & $\equiv$ & 은 & $\stackrel{0}{0}$ & $=$ & ○. & $=$ & $=$ & $\stackrel{\infty}{=}$ & 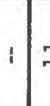 & $=$ & $=$ & $\simeq \simeq$ & 으 & 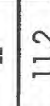 & $=$ & $\stackrel{\infty}{\sim}$ & $\cong$ & $\overline{\mathrm{N}}$ & $=$ & 1 & $\stackrel{m}{\sim}$ & 9 & $=$ & $F=$ & $=$ & $m$ & $\stackrel{a}{\mathrm{i}}$ & $\approx$ & $\widehat{\cong}$ \\
\hline
\end{tabular}

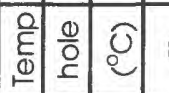

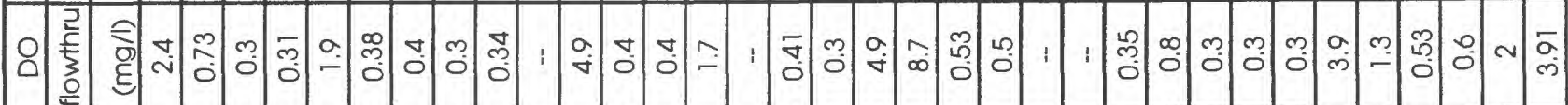

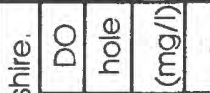

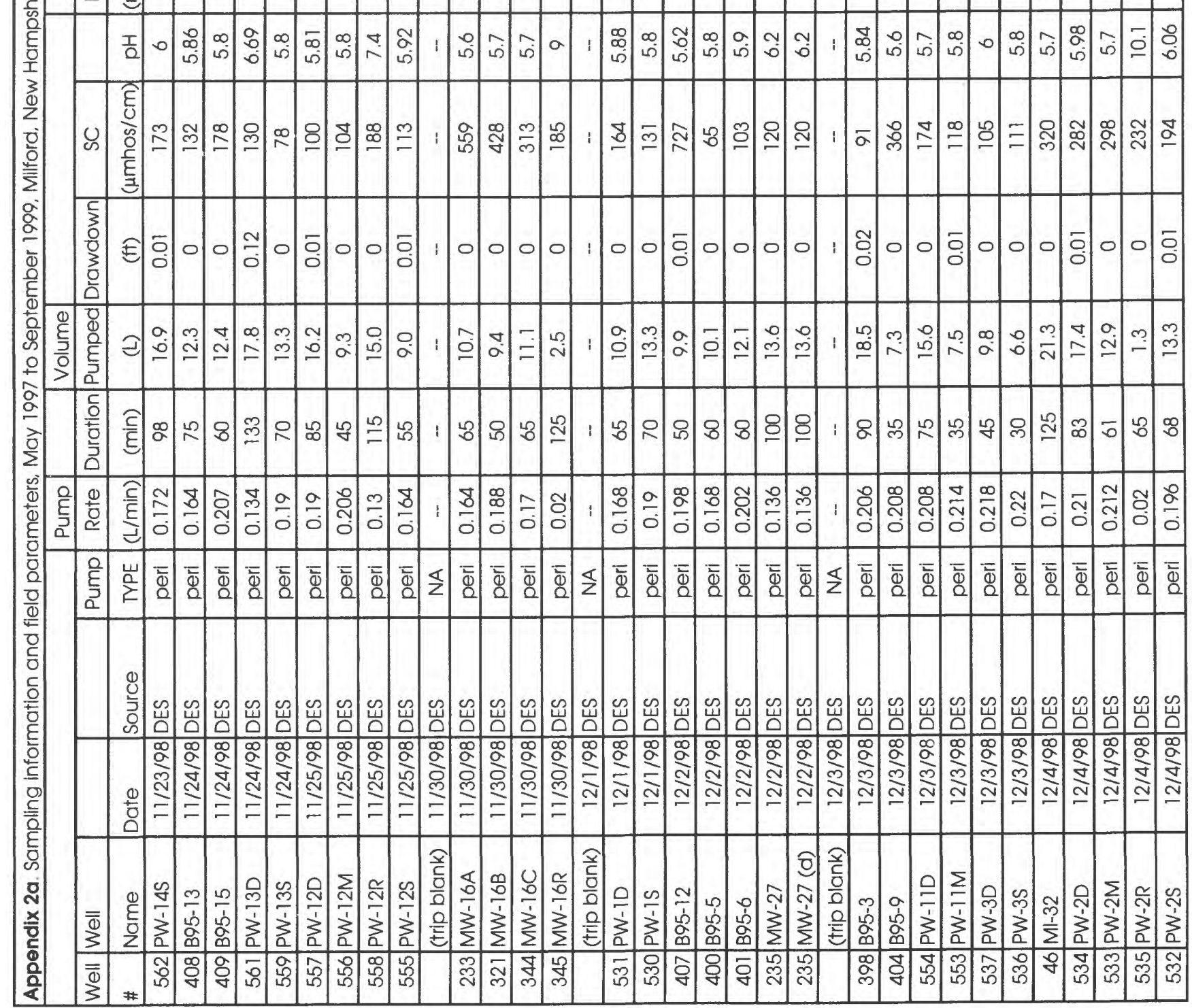




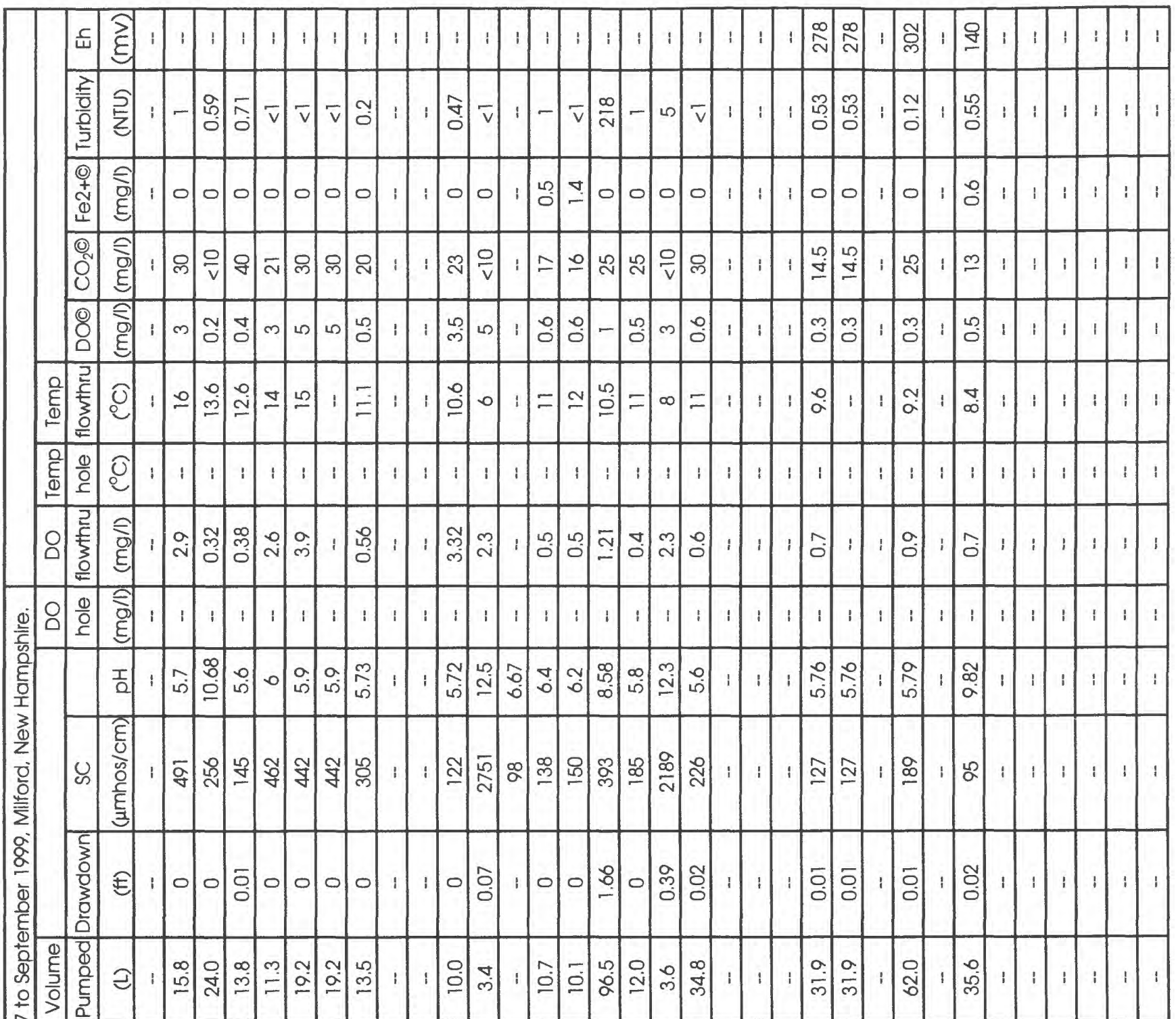

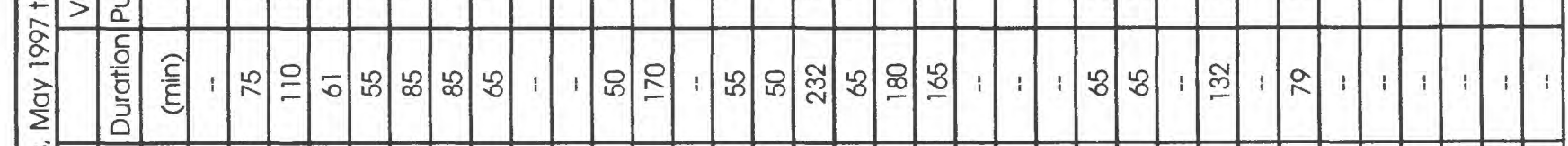

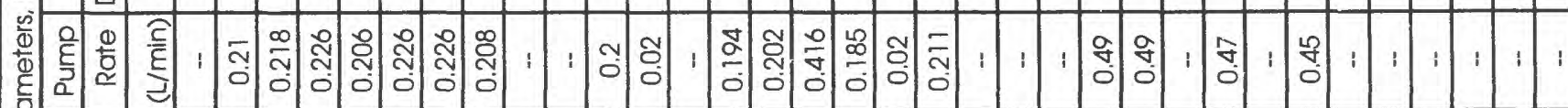

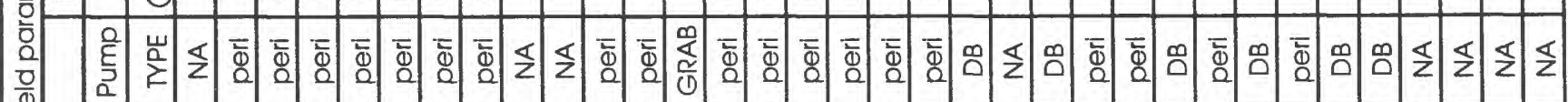

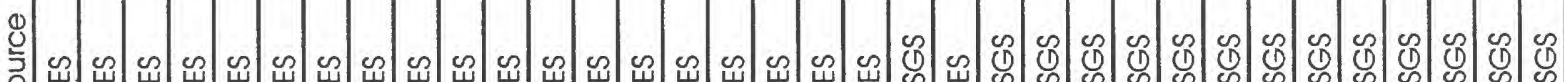

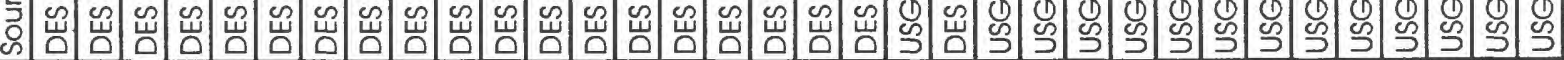

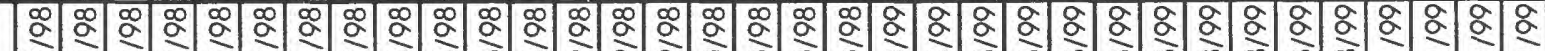

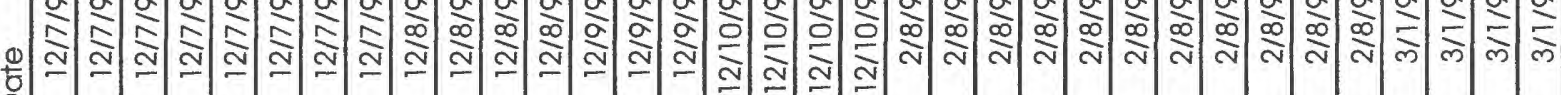

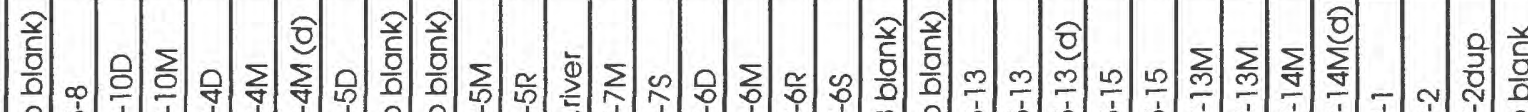

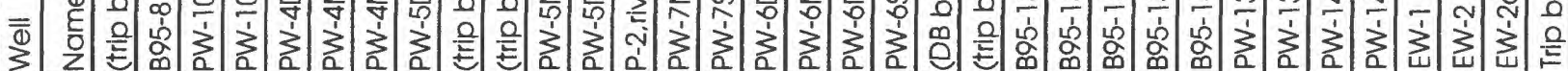
= $\overline{\bar{Q}}$ भิ: 


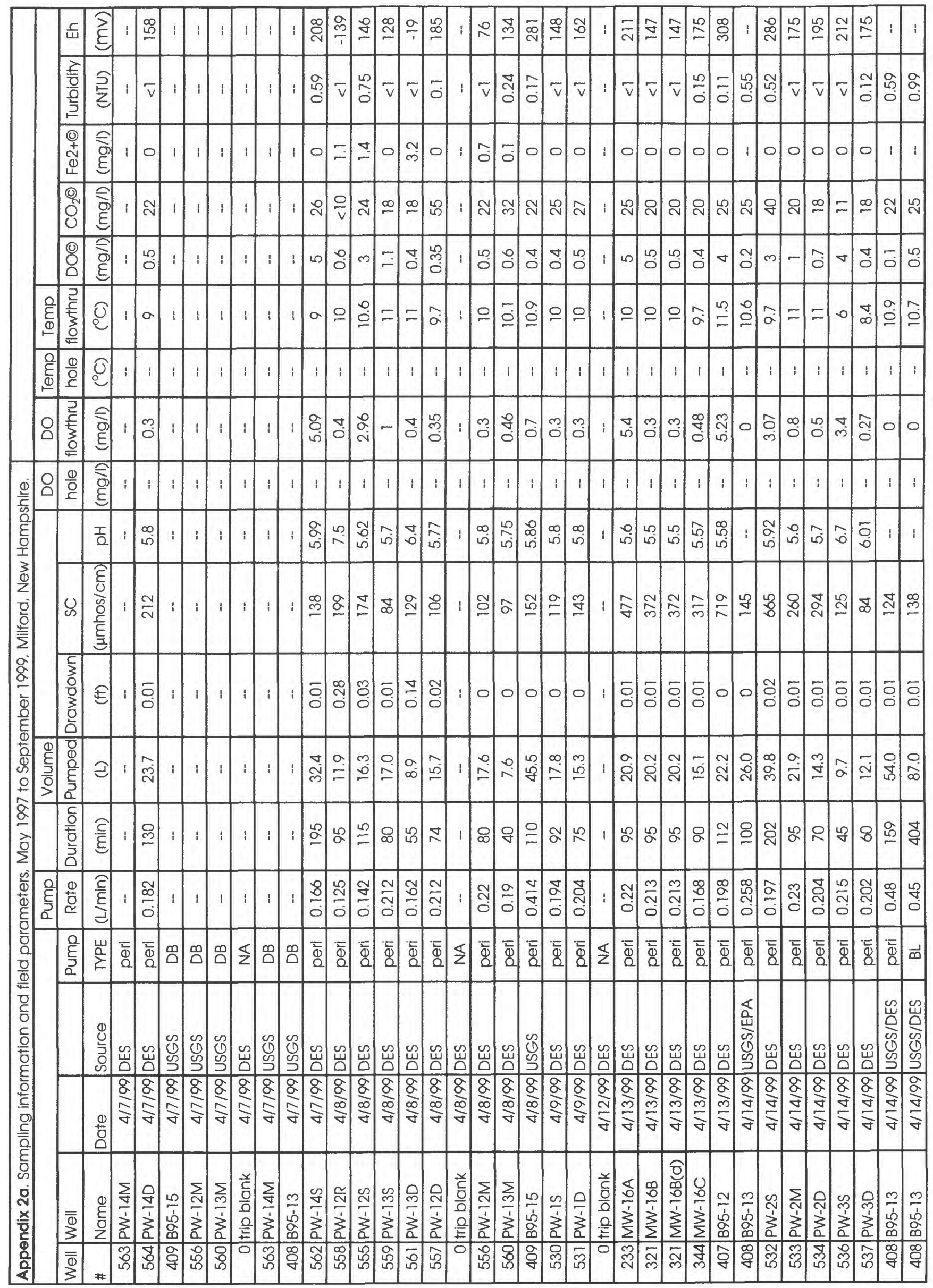




\begin{tabular}{|c|c|c|c|c|c|c|c|c|c|c|c|c|c|c|c|c|c|c|c|c|c|c|c|c|c|c|c|c|c|c|c|c|c|}
\hline & 다 & है & 1 & 1 & if & : & 1 & 1 & 1 & 1 & 1 & 1 & i & $i$ & $:$ & $\widehat{0}$ & $\bar{\Xi}$ & 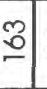 & $\infty$ & : & $:$ c & 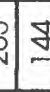 & $\overline{\tilde{N}}$ & 8 & 1 & 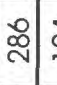 & & 造 & $\stackrel{20}{=}$ & 1 & 1 & $i$ & \\
\hline & $\begin{array}{l}\frac{1}{1} \\
\frac{0}{0} \\
\\
\end{array}$ & 点 & 1 & $\frac{0}{\lambda}$ & $\stackrel{N}{\sim}$ & ర్ల & 1 & . & $\begin{array}{l}\hat{\alpha} \\
\dot{0}\end{array}$ & $i$ & 1 & 1 & ! & 1 & 1 & ○. & $\bar{v}$ & $\bar{v}$ & $\begin{array}{l}0 \\
0 \\
0\end{array}$ & 1 & $1 \frac{3}{c}$ & $\bar{v}$ & $\overline{\widetilde{O}}$ & $\bar{v}$ & 1 & ్ㅟㅇ. & $\bar{v}$ & $\stackrel{\circ}{\circ}$ & $\bar{v}$ & 1 & 1 & 1 & \\
\hline & 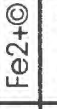 & $\begin{array}{l}\text { के } \\
\text { है }\end{array}$ & 1 & : & 0 & : & 1 & : & : & 1 & : & I & t & : & : & $=$ & 0 & 0 & 兽 & : & $: 0$ & 0 & 0 & 0 & $:$ & $\circ$ & & 00 & 0 & 1 & : & : & \\
\hline & \begin{tabular}{l|} 
(2) \\
0 \\
0 \\
\end{tabular} & $\begin{array}{l}\text { के } \\
\text { है }\end{array}$ & 1 & N & 의 & $\underline{\alpha}$ & 1 & 요 & $\stackrel{\infty}{=}$ & 1 & 1 & ! & ; & : & 1 & ঃి & $=$ & 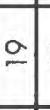 & 이 & i & : & থ & in & $\frac{O}{v}$ & $i$ & "ొ & $\therefore:$ & op & 8 & 1 & 1 & i & \\
\hline & 8 & $\begin{array}{l}\text { वे } \\
\text { है }\end{array}$ & 1 & $\pi$ & $\hat{o}$ & ָָ. & $:$ & O० & ১. & 1 & : & 1 & $!$ & 1 & 1 & ச & $\stackrel{0}{\circ}$ & ○. & (2) & 1 & 15 & $?$ & $\stackrel{\circ}{\circ}$ & ס & $:$ & $N$ & • & $m=$ & $?$ & 1 & $i$ & & \\
\hline $\begin{array}{l}\text { है } \\
\stackrel{0}{-}\end{array}$ & 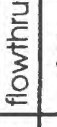 & (0) & : & 0 & $\begin{array}{l}\stackrel{2}{ } \\
\searrow\end{array}$ & $\stackrel{\infty}{a}$ & $\hat{\alpha}$ & 으 & $\stackrel{\infty}{\circ}$ & 1 & ! & : & ; & i & $i$ & $\stackrel{0}{=}$ & 으 & 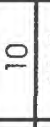 & $\stackrel{0}{=}$ & i & 1 & $=\simeq$ & $\stackrel{a}{=}$ & $\simeq$ & ; & $\stackrel{a}{=}$ & $=7$ & $\underline{E}$ & $a$ & 1 & 1 & ; & \\
\hline 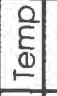 & $\begin{array}{l}\frac{0}{0} \\
\\
\end{array}$ & $\begin{array}{l}0 \\
0 \\
0\end{array}$ & 1 & $i$ & 1 & 1 & 1 & 1 & 1 & 1 & 1 & 1 & ; & 1 & i) & $:$ & $:$ & $i$ & $:$ & 1 & : & 1 & : & 1 & $:$ & $:$ & 1 & : & i & i & i & ; & \\
\hline ○ & $\begin{array}{l}\text { 리 } \\
\text { 表 } \\
0 \\
0\end{array}$ & है & & 0 & 이 & 0 & 0 & 0 & 이 & 1 & $:$ & i & I & 1 & 1 & సิ & ठे & m. & $\frac{10}{0}$ & & $\frac{5}{2}$ & 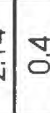 & 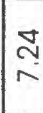 & ב̊ & $:$ & 0 & ১̊) & స̃ & 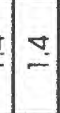 & i & : & ; & \\
\hline
\end{tabular}

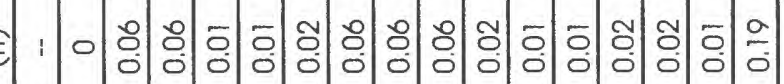

융융훙응

웅훙잉

है

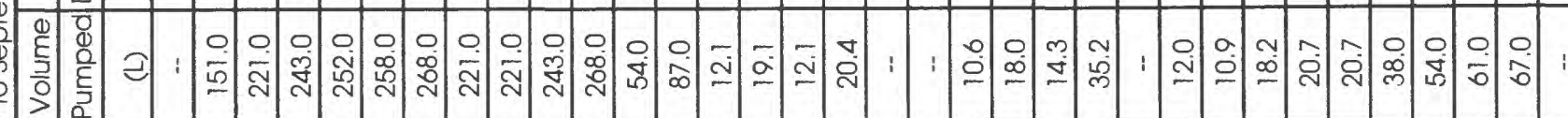

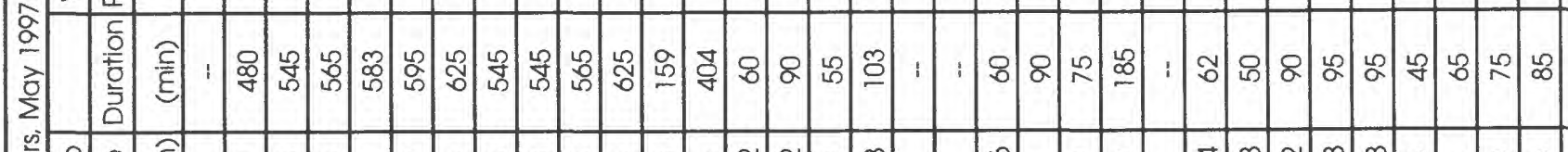

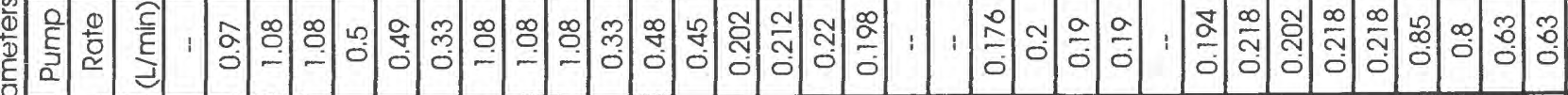

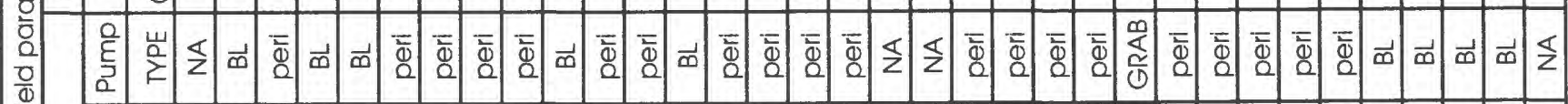

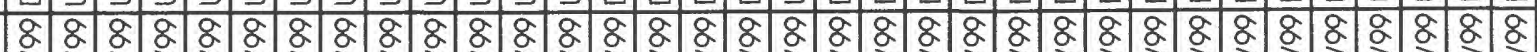

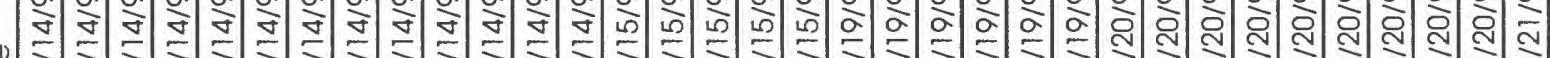

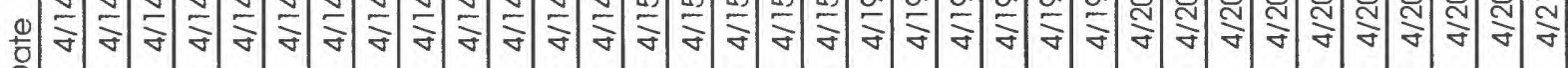

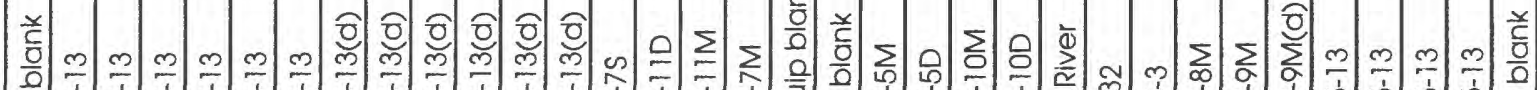

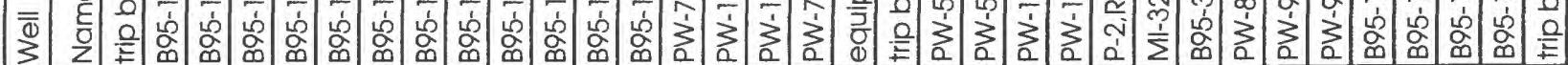
㐫 


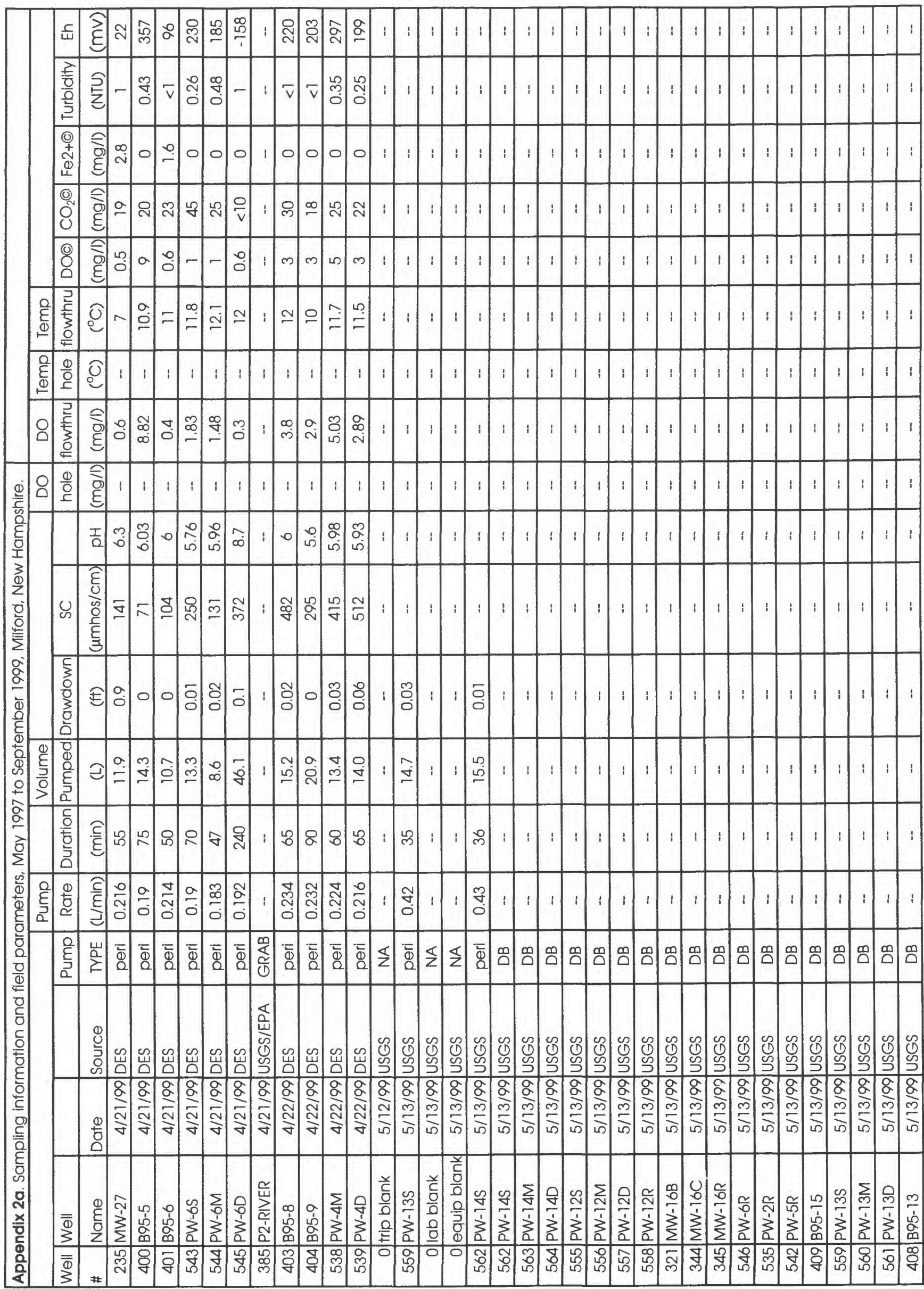




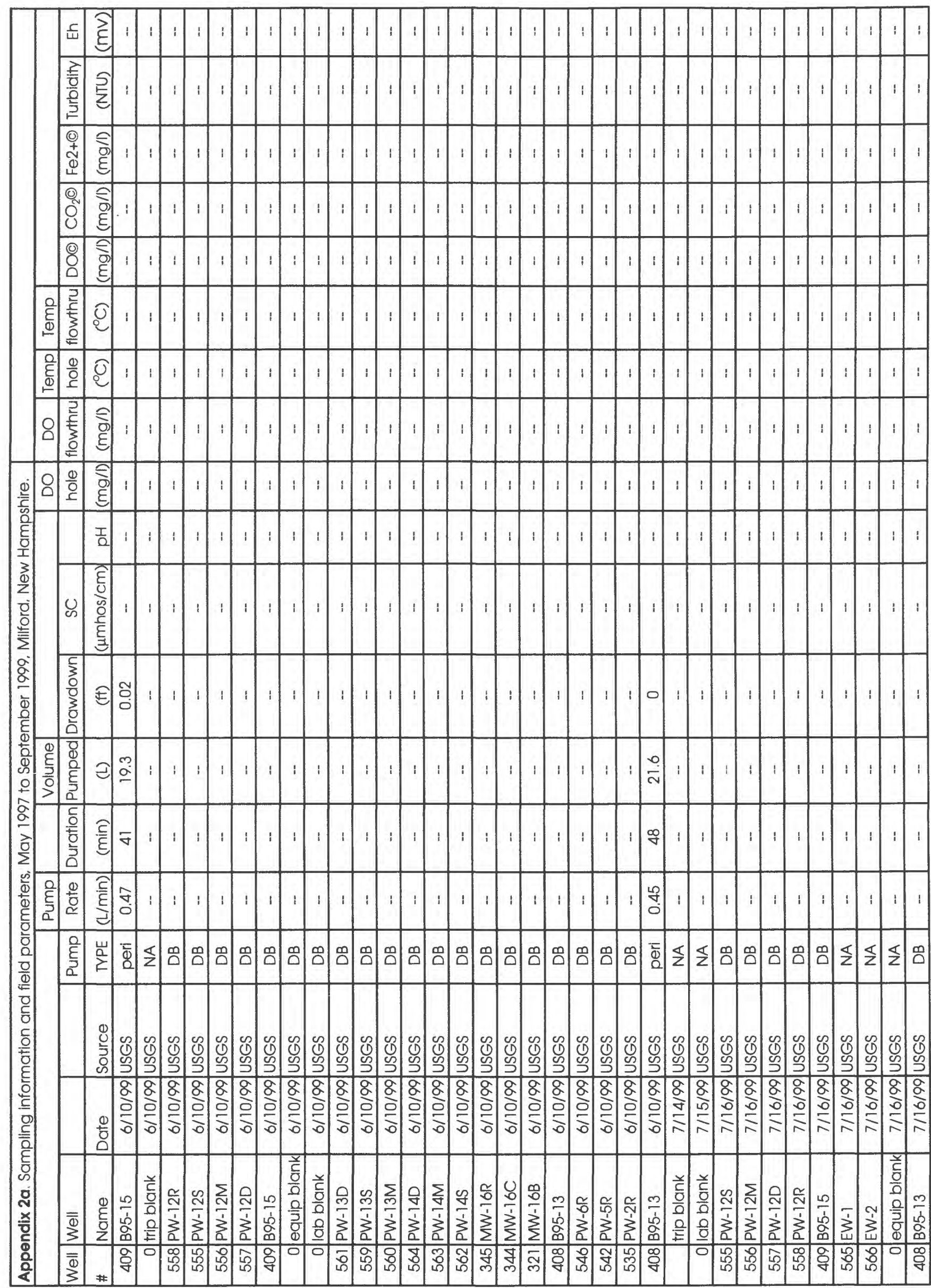




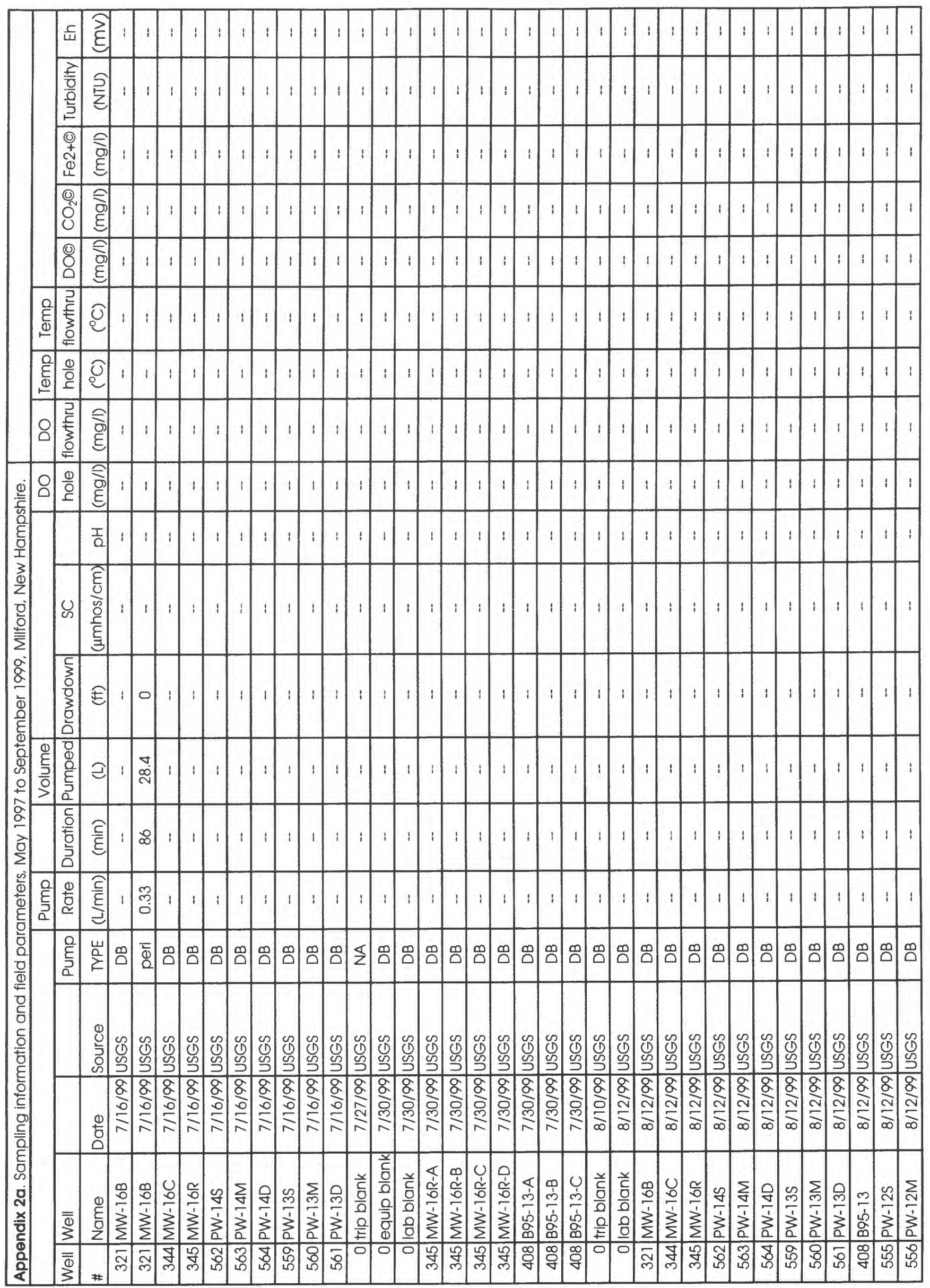




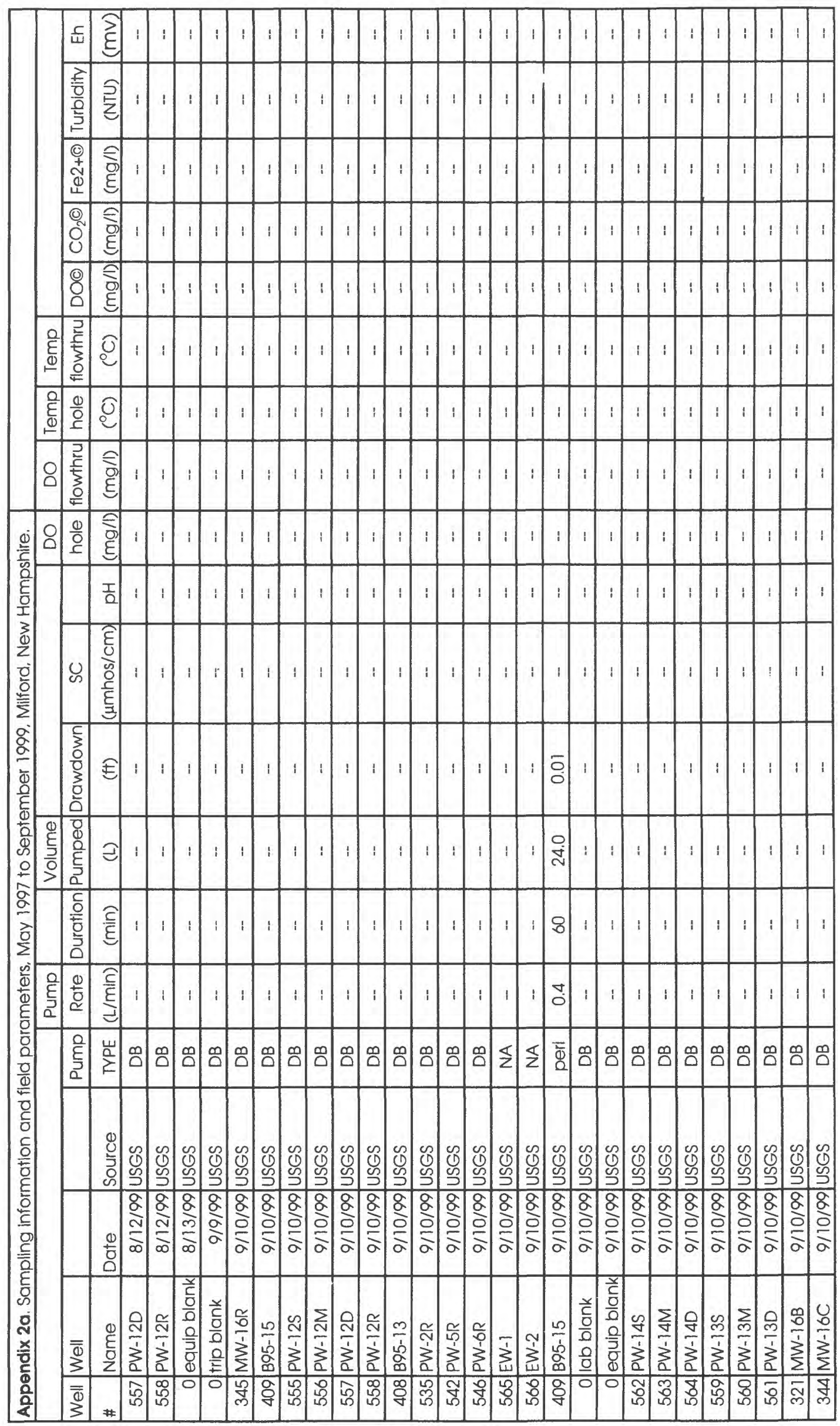




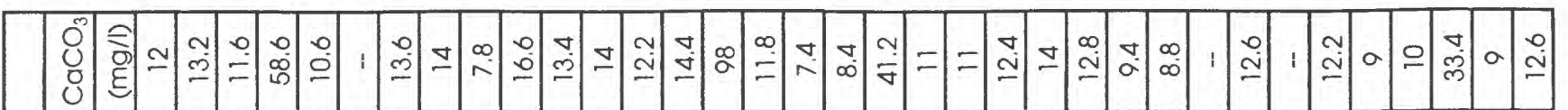

恶

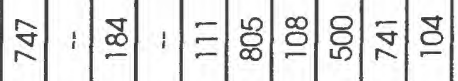

ஸे

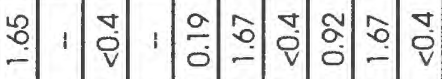

o

志 司

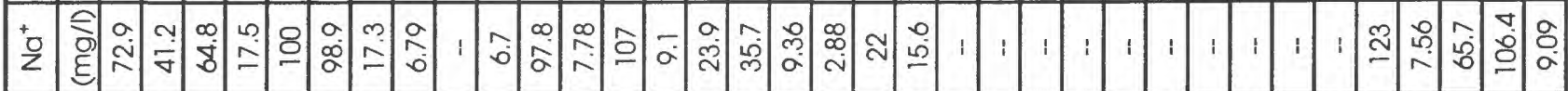

× ही

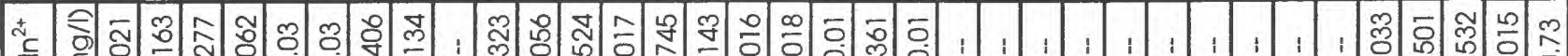

云 है

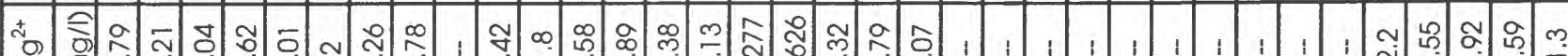

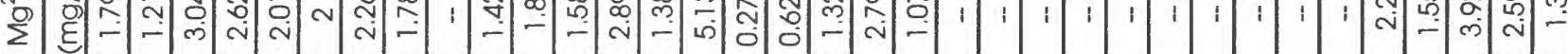

产

है

웧유.

2 ह

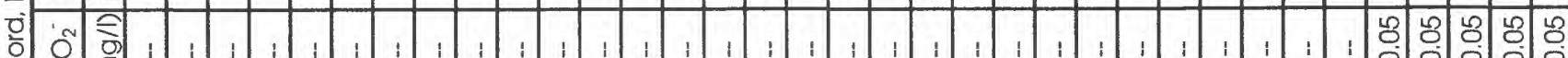

올

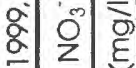

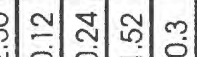

(1)

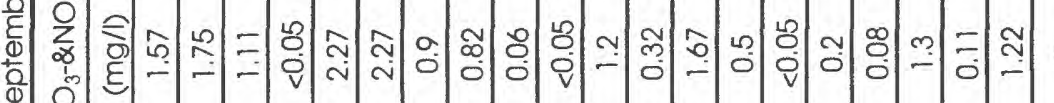

के

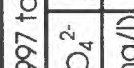

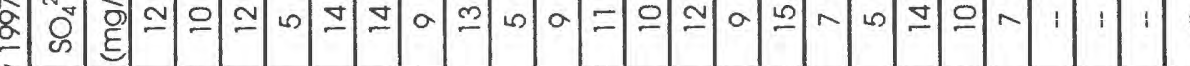

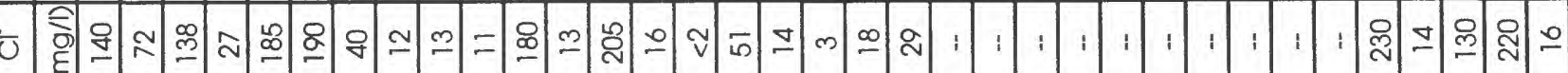

in है

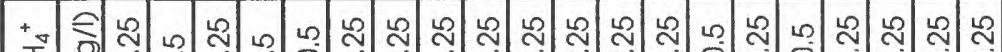

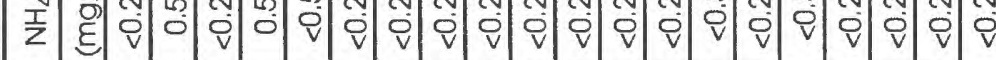

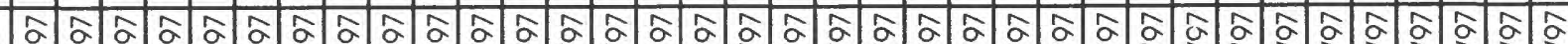

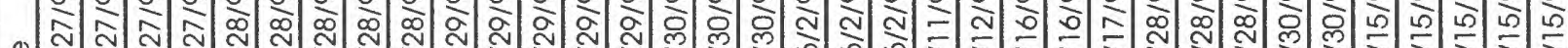

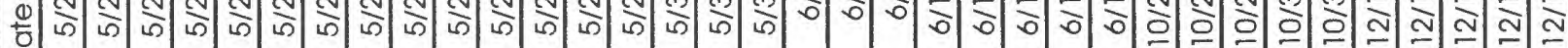

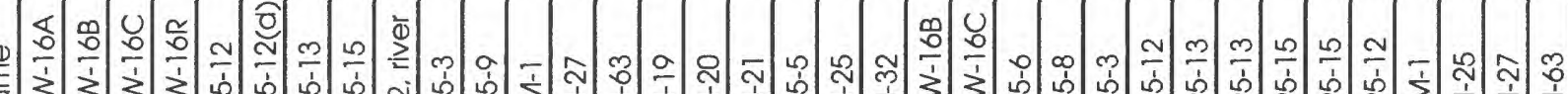

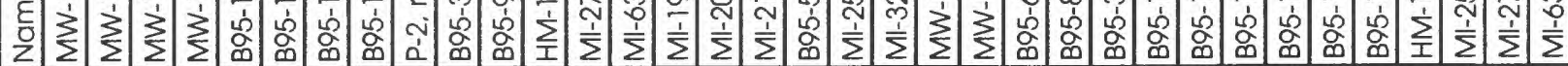

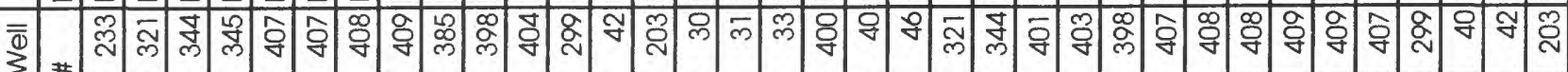




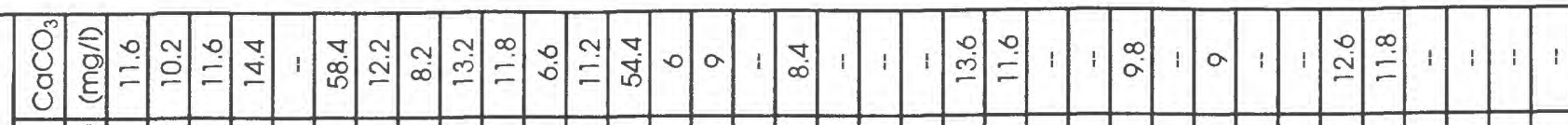

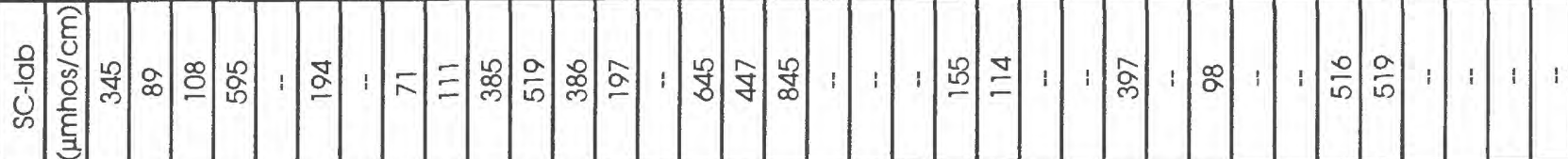

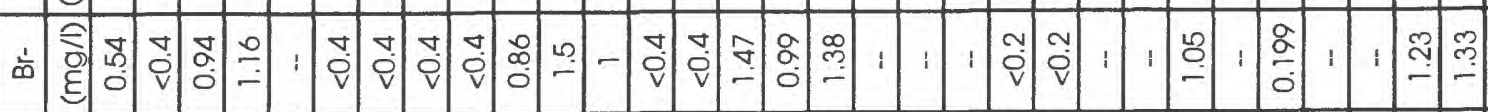

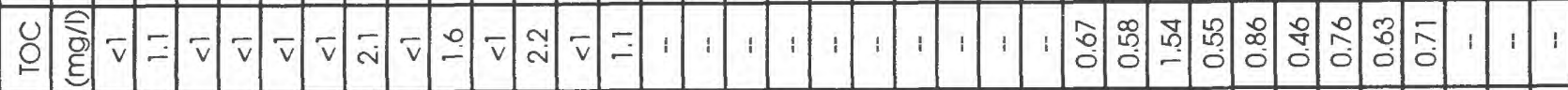

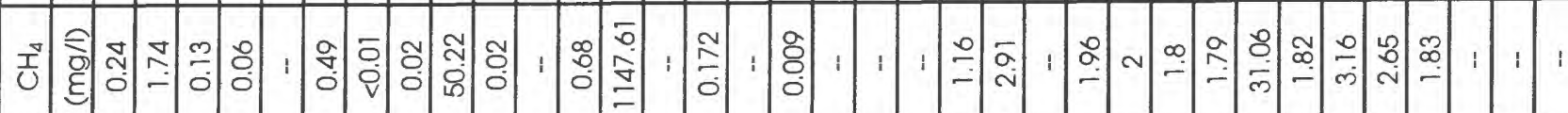

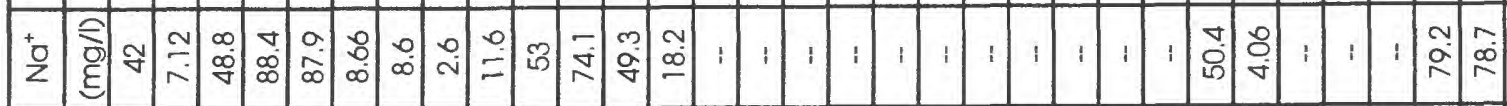

×

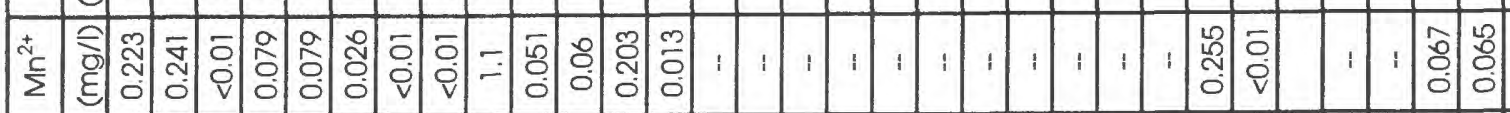

芯

2 ह

产

至

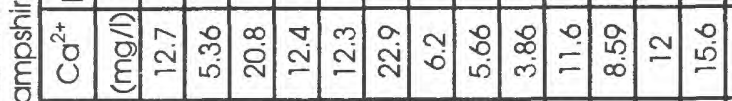

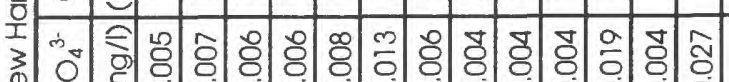

造

○ं

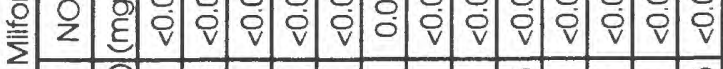

产

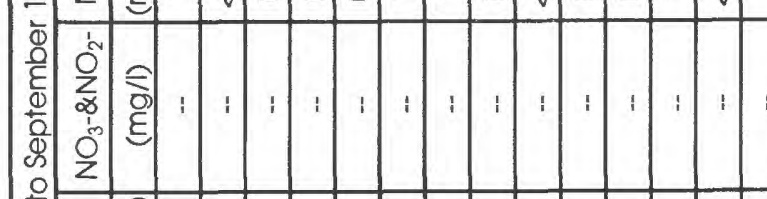

产䗆

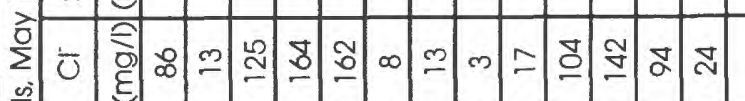

䆑

हे के क्रे

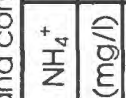

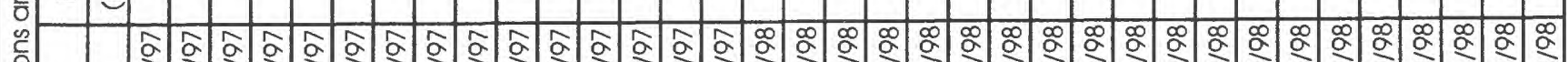

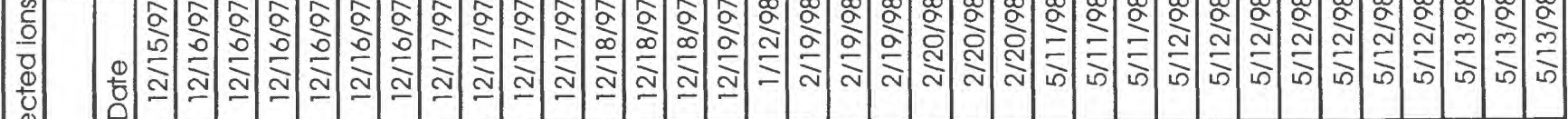

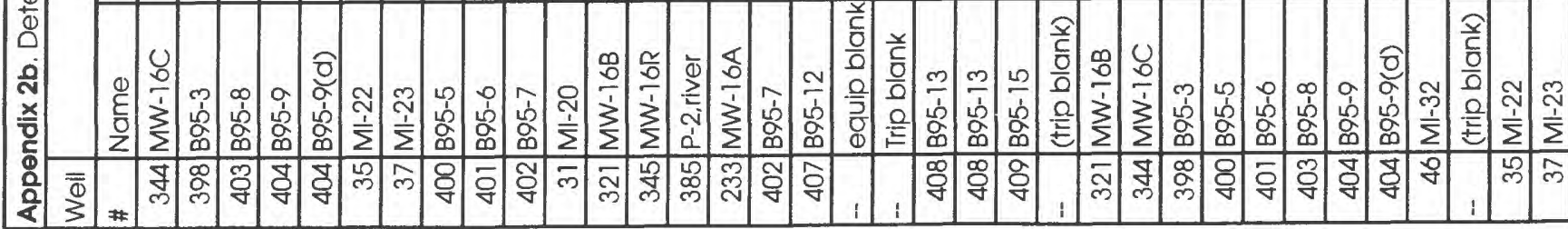




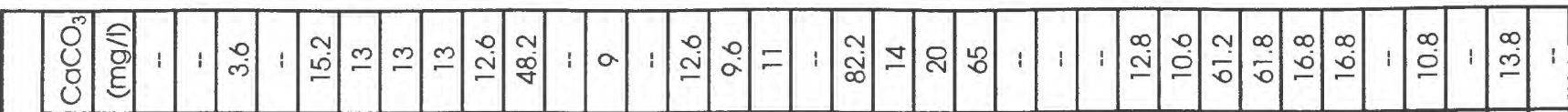

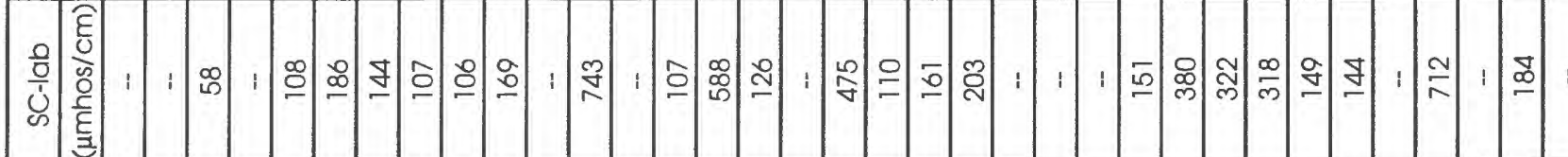

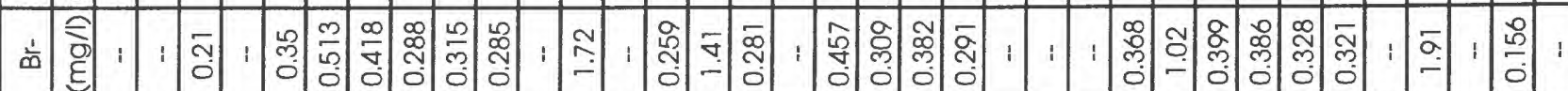

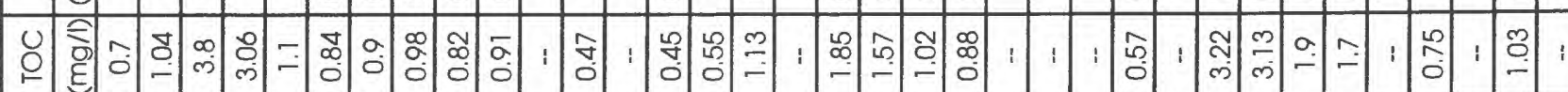

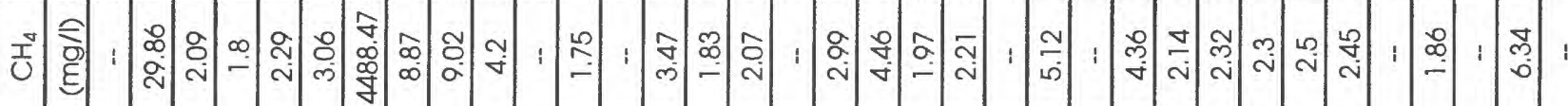

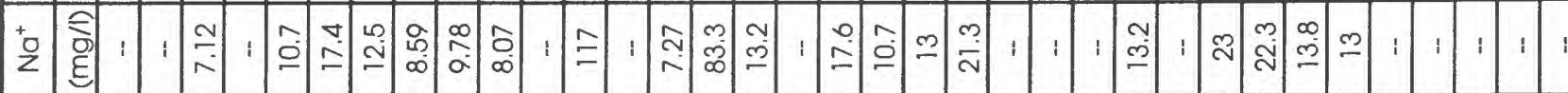

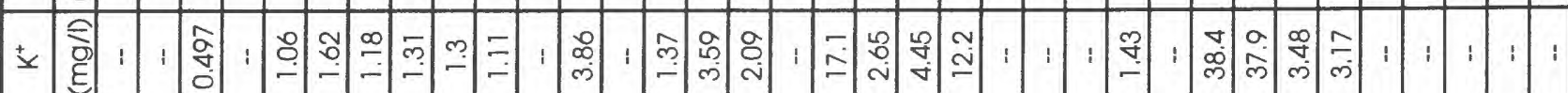

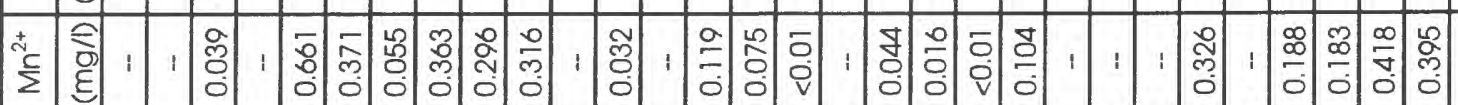

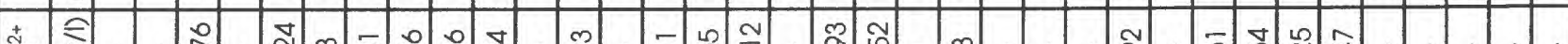

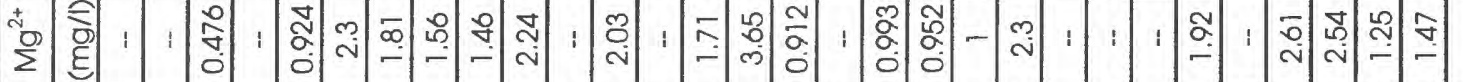

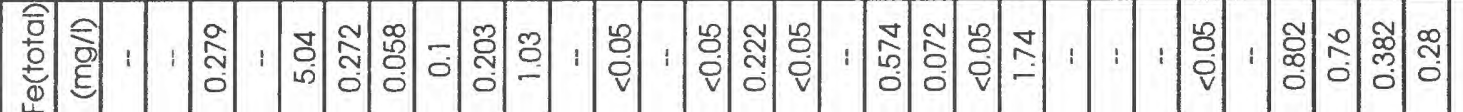

气

왕

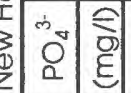

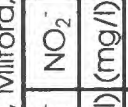

:

हों

t.

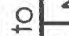

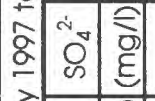

$\sum_{0}^{0} \bar{U}$ :

용

亏े के

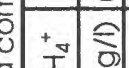

달

ำ

$\frac{1}{0}$

$\frac{1}{4}$ 0.

요

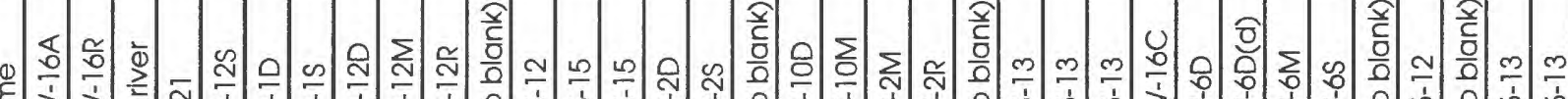

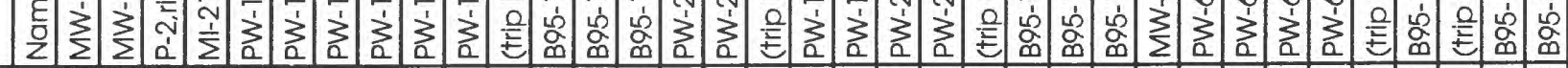

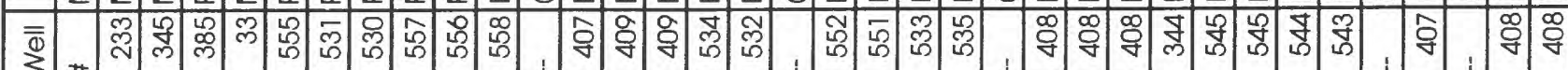




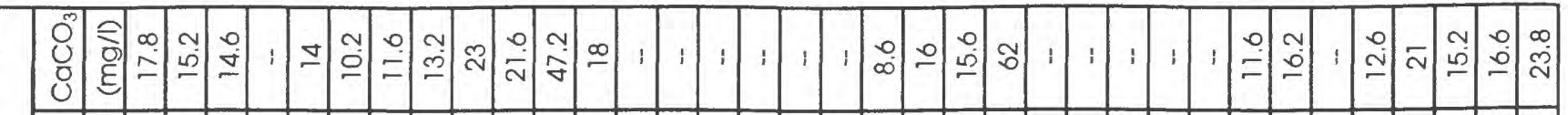

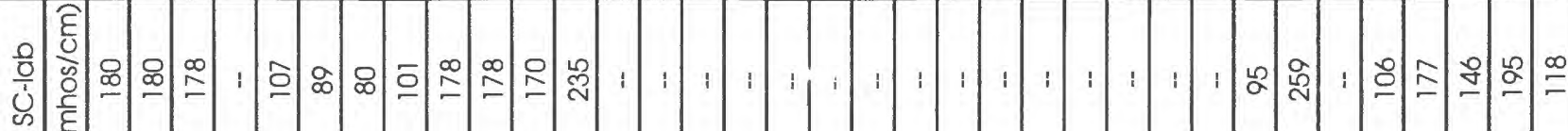

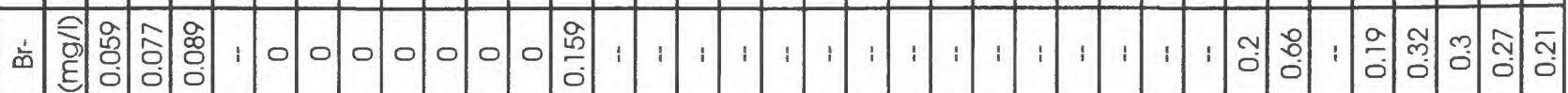

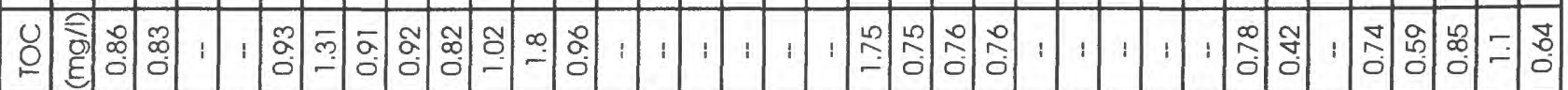

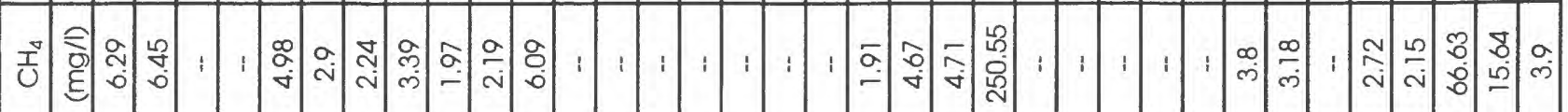

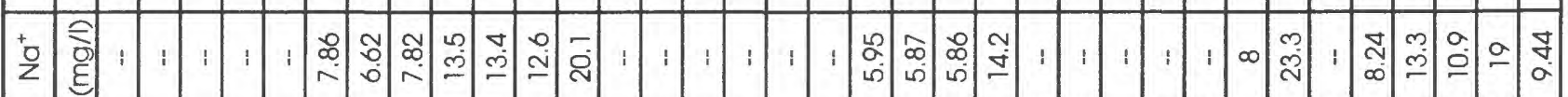

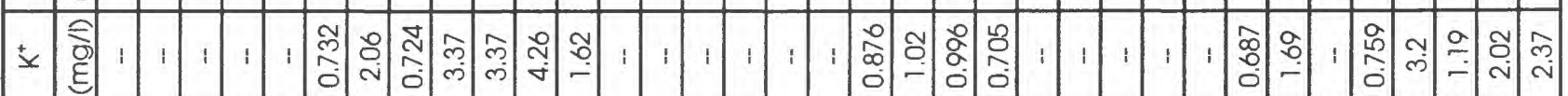

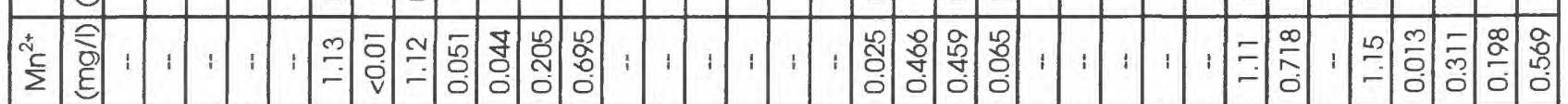

先

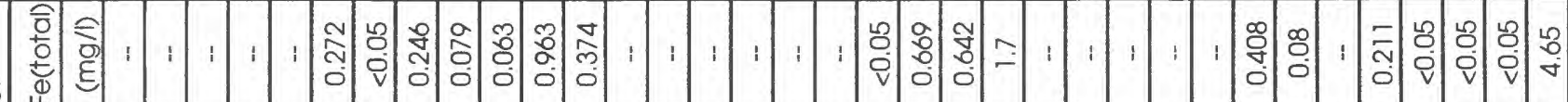

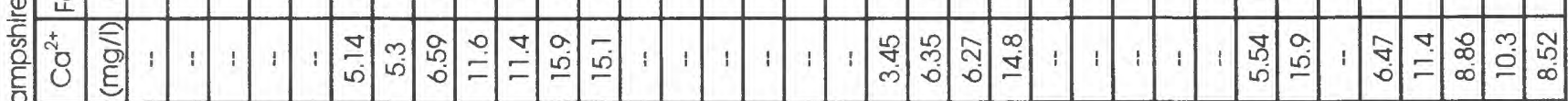

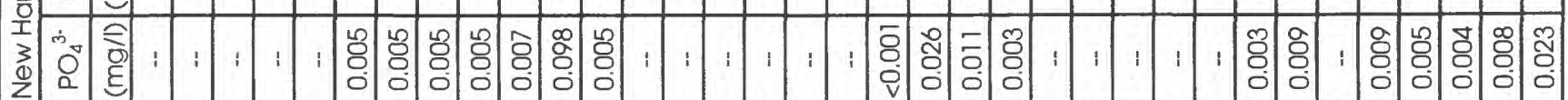

गें ले

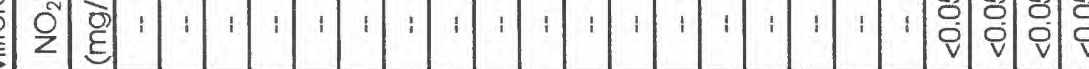

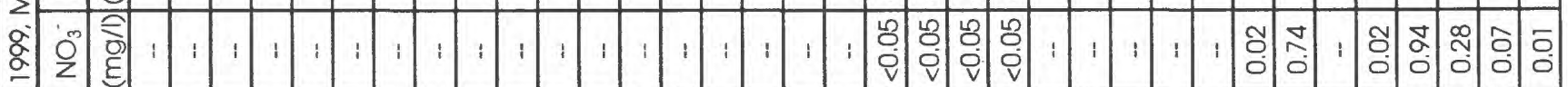

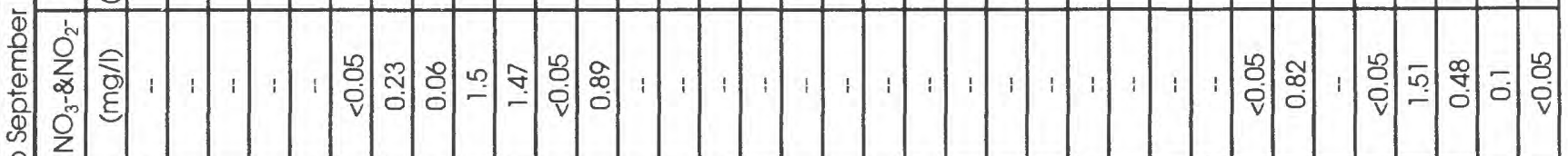

余察

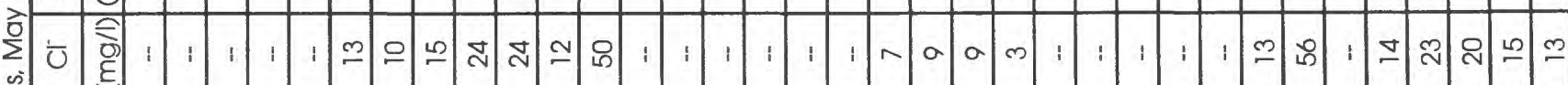

\%

क के

है

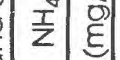

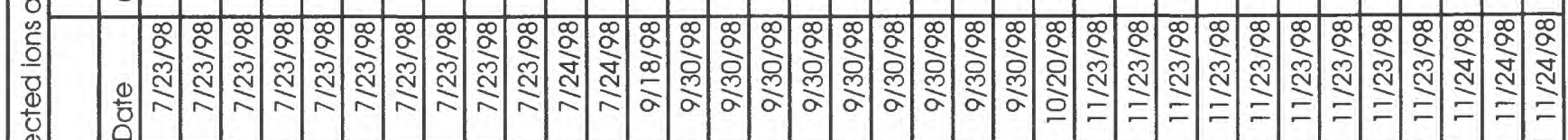

$\frac{0}{2}$

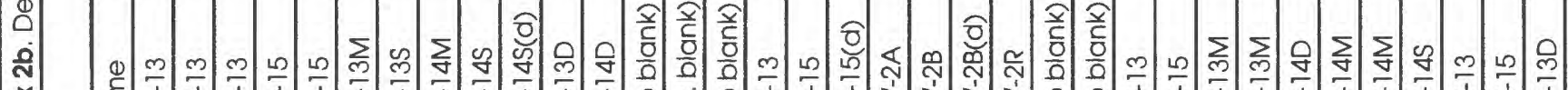

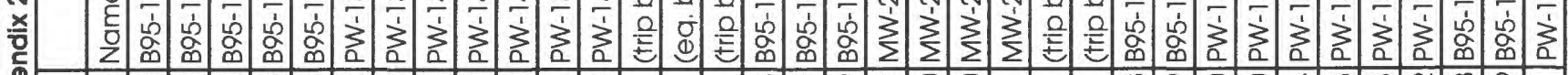

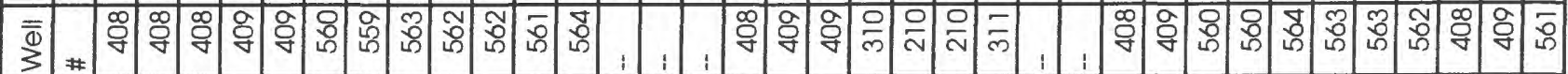




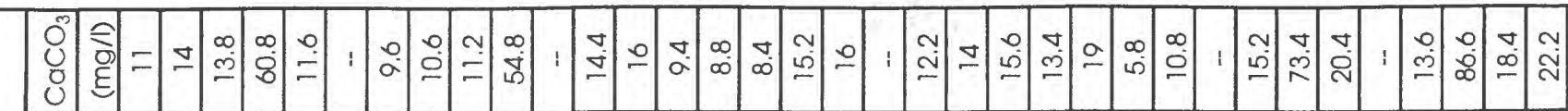

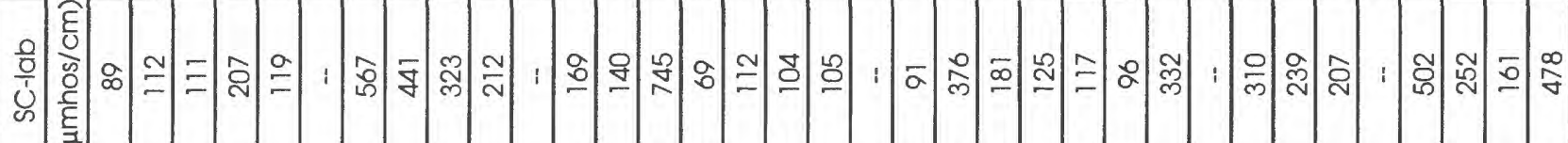

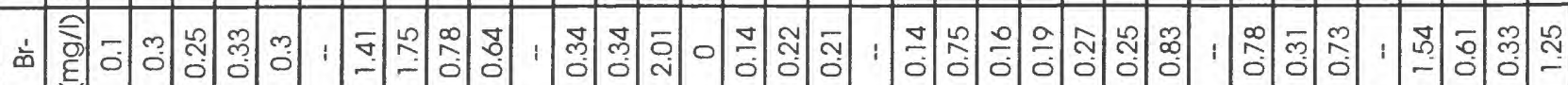

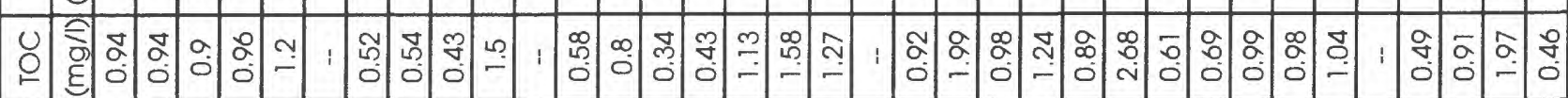

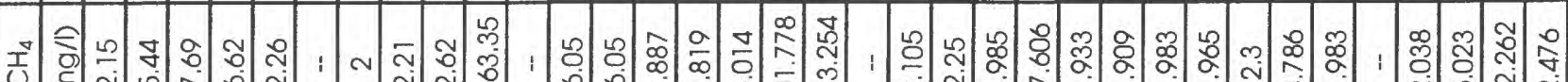

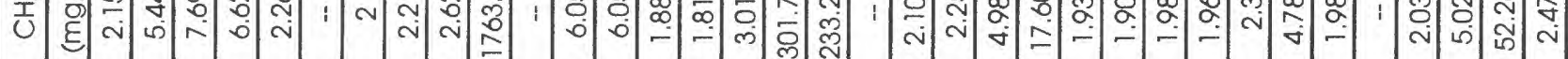

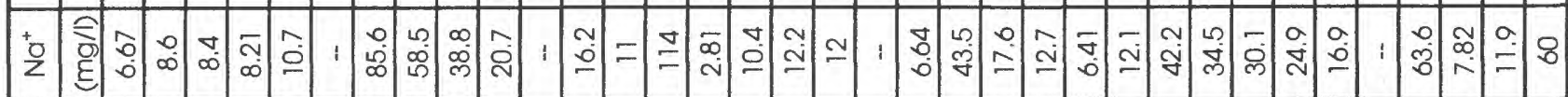

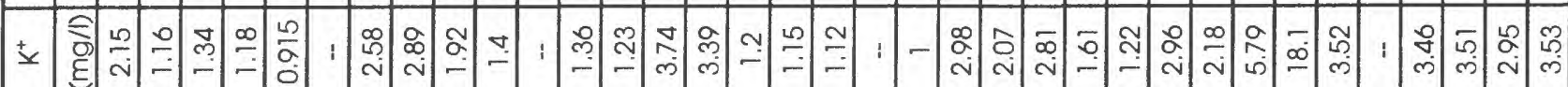

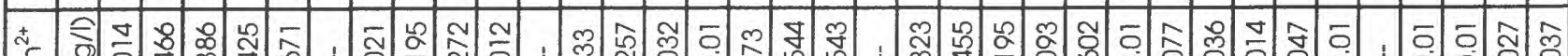

之 है

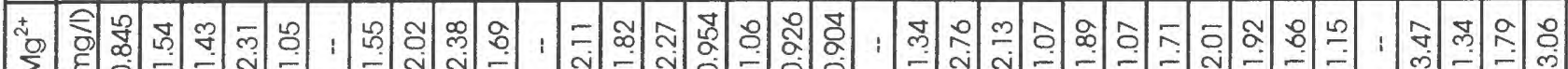

$\sum$ हो

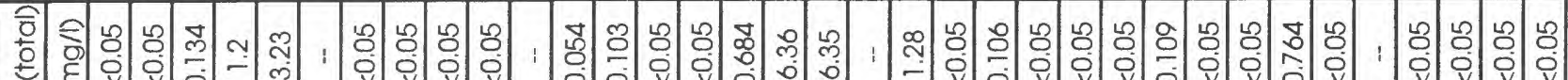
०. है v v 0 m v v v v 0 o v

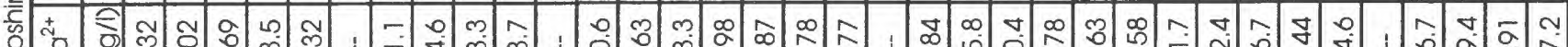

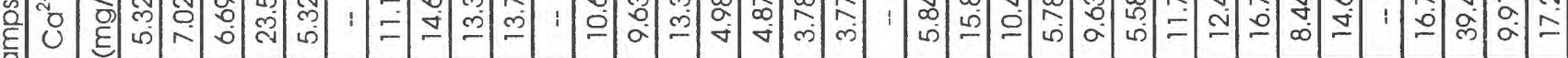
ґ. z

प्रे है

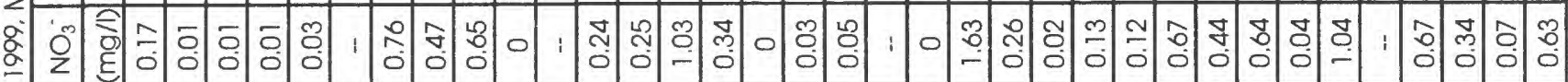

(1)

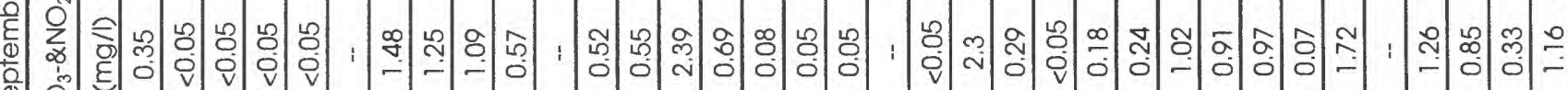

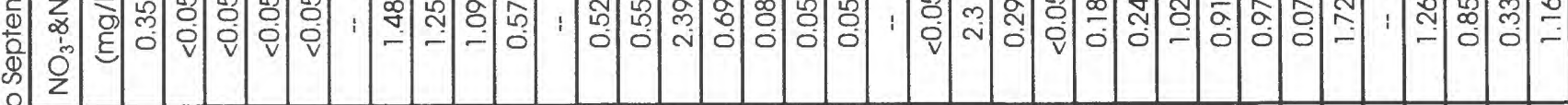

పे

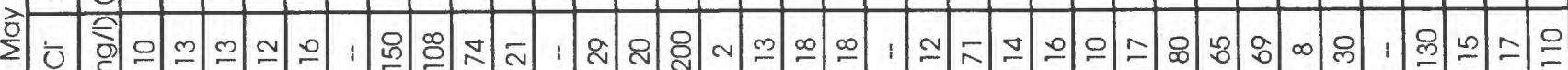
है

in के

+

$\stackrel{\mathrm{I}}{\mathrm{z}}$ हे

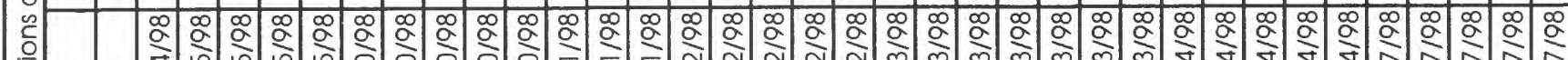

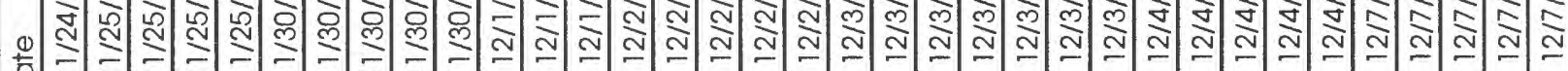

흘 $==\equiv=\equiv=\equiv=0$

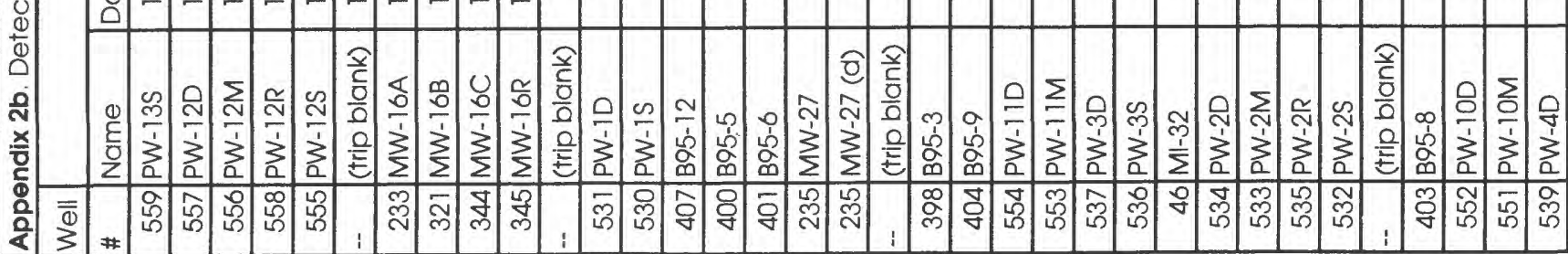




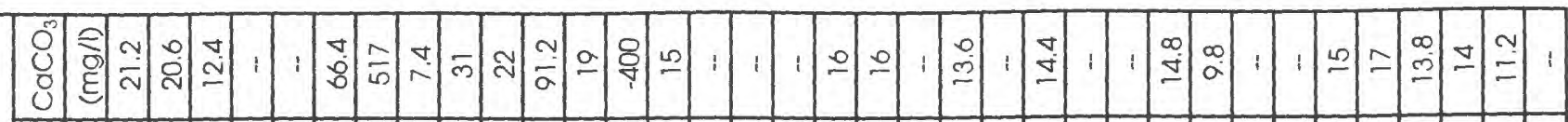

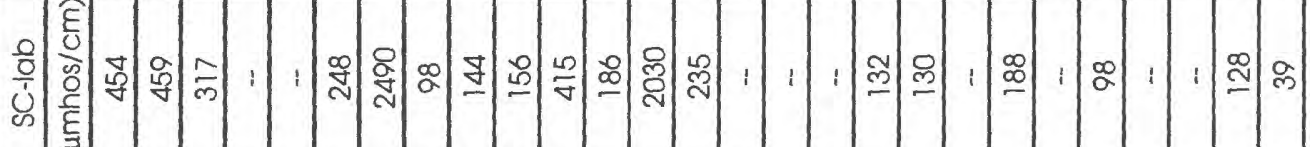

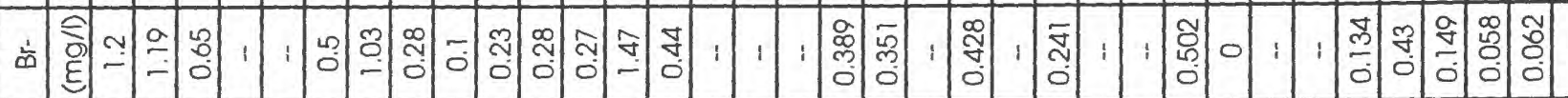

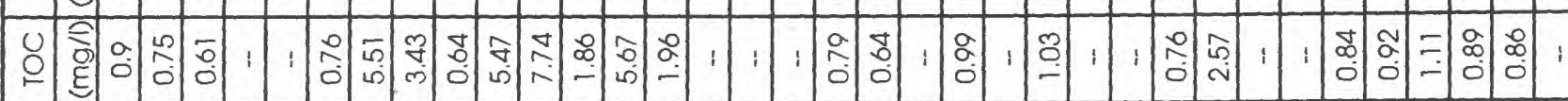

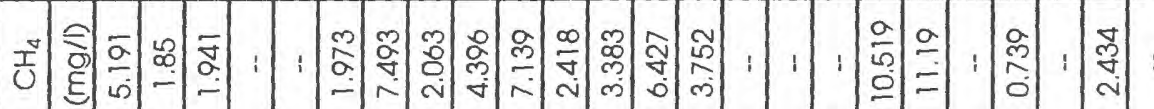

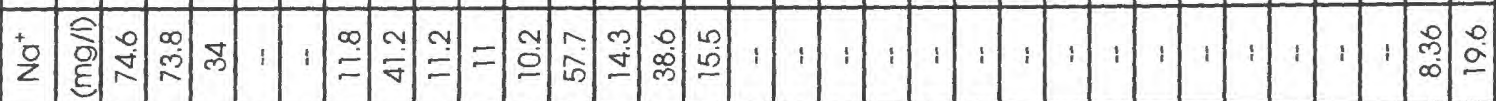

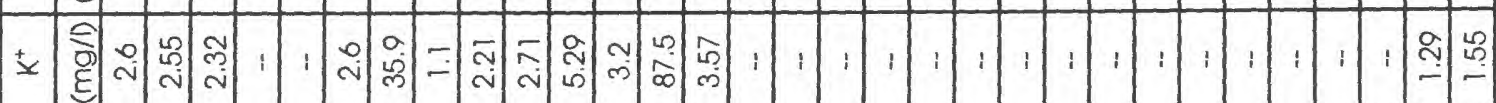

ํㅗㄴ

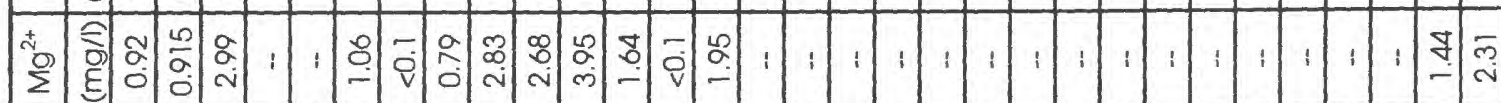

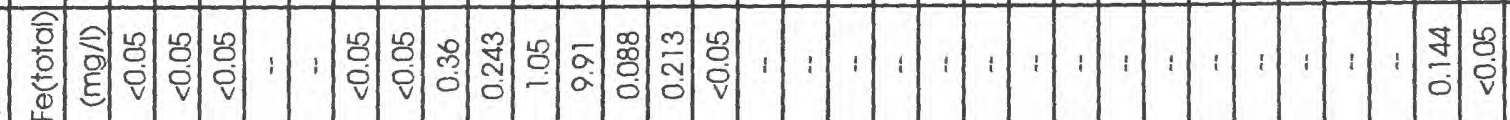

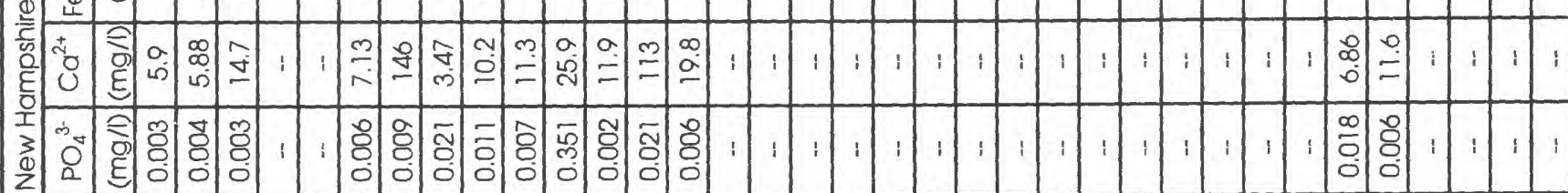

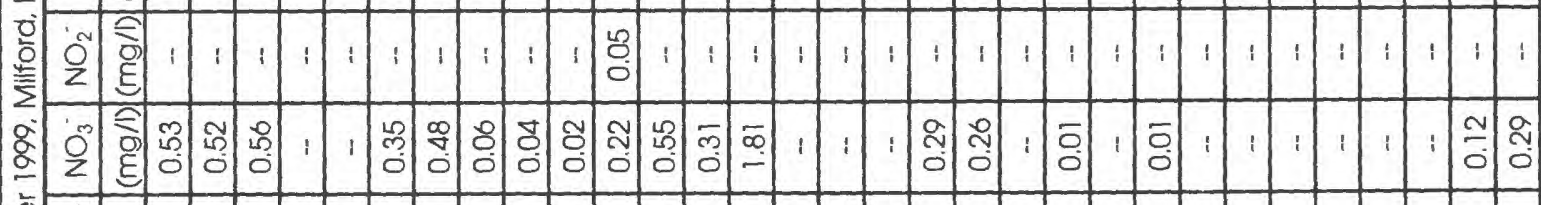

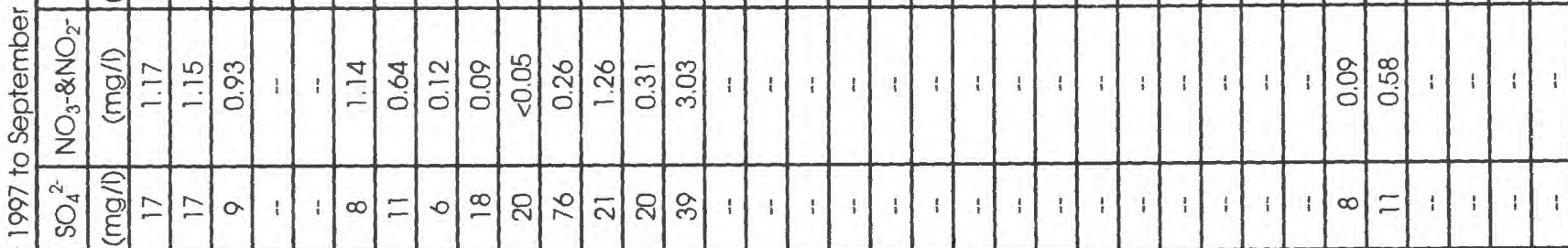

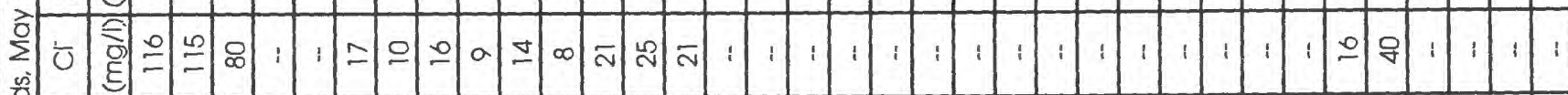

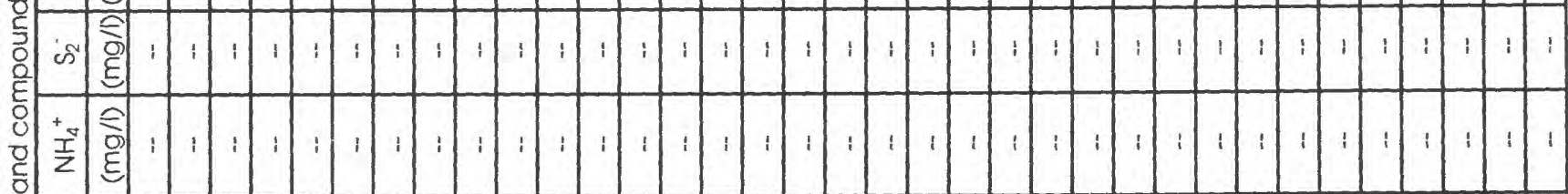

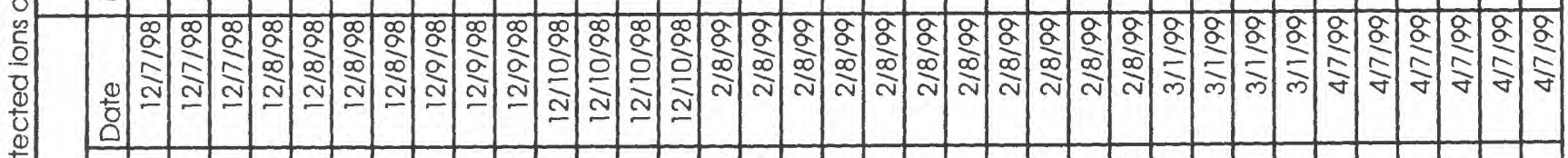

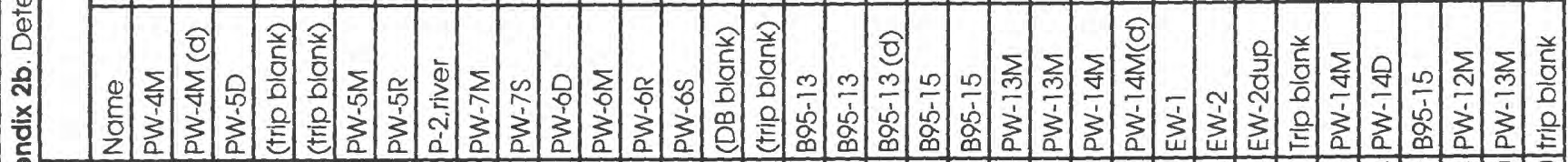

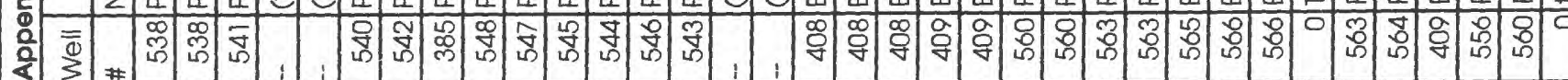




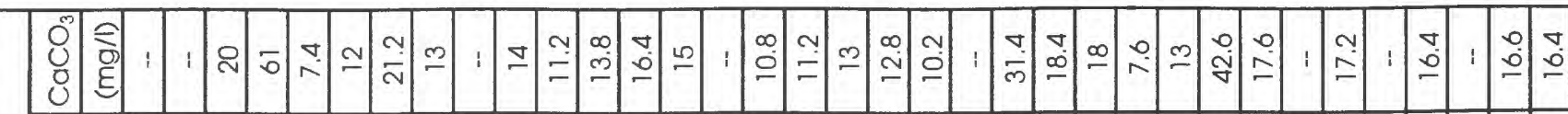

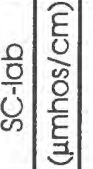

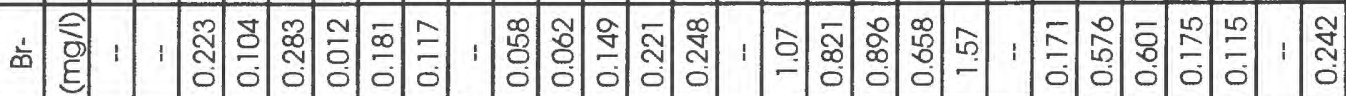

岁

ปे

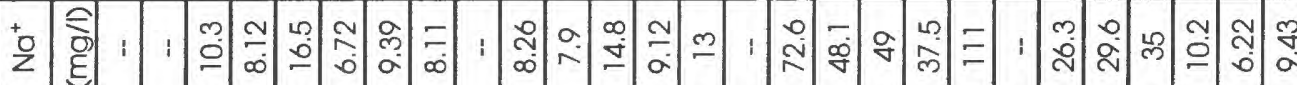

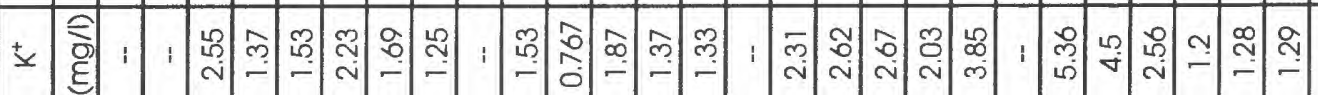

先

离

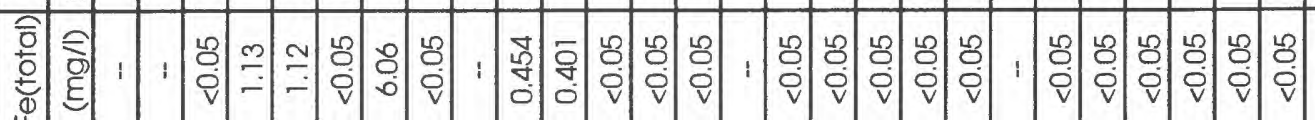

일

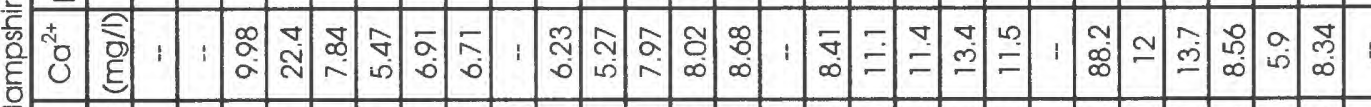

䍃官

产

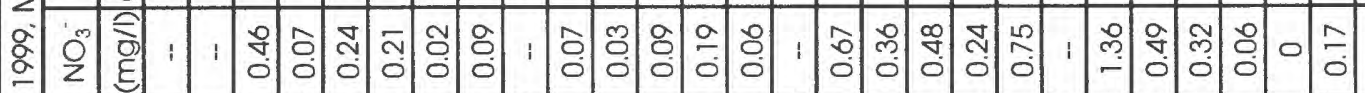

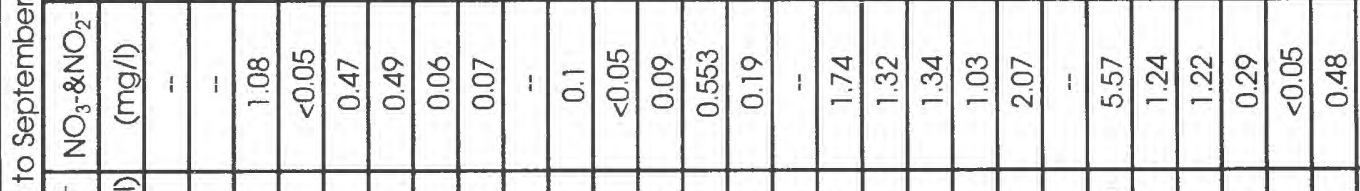

产的

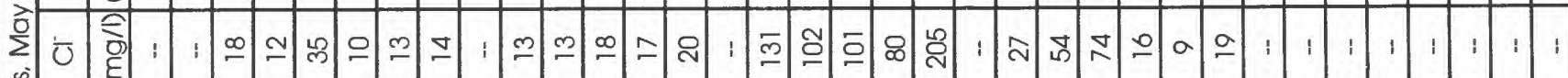

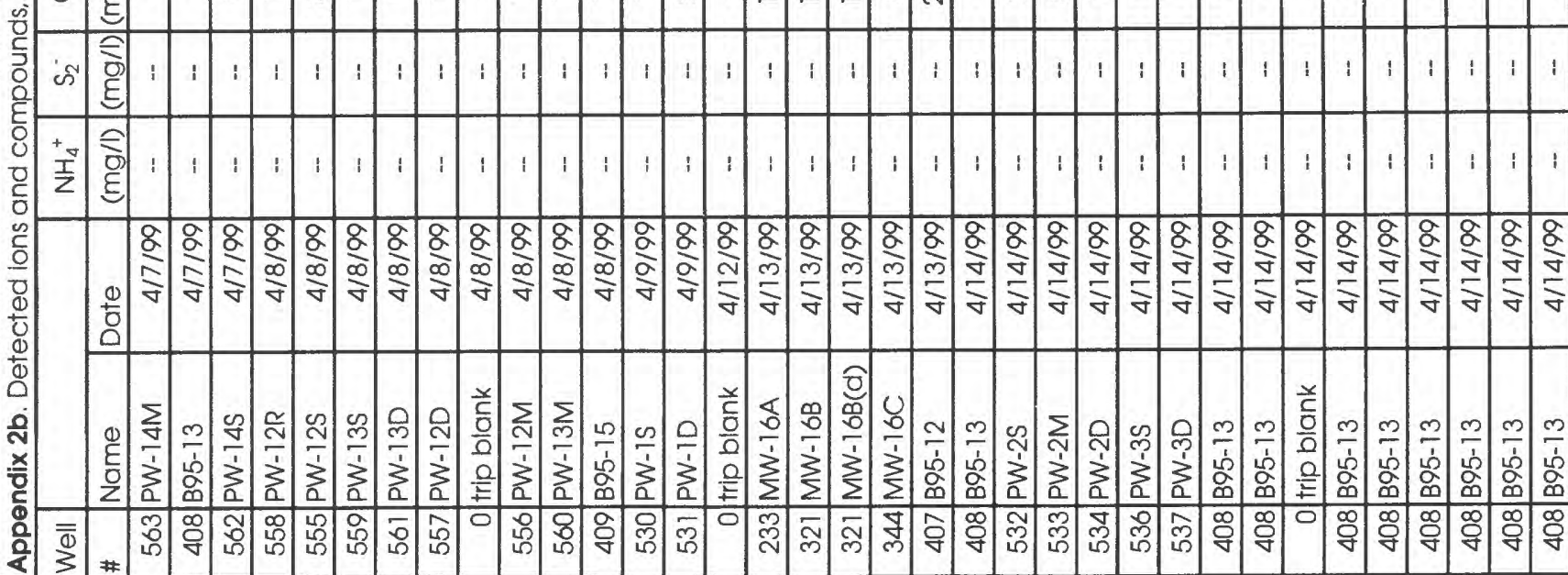




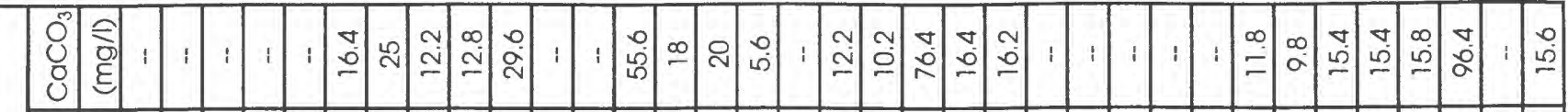

을

फ)

㐫

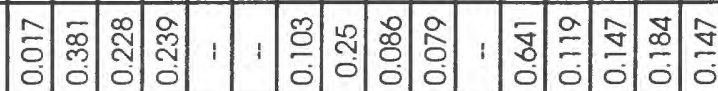

₹ิ

은

गे ठิ

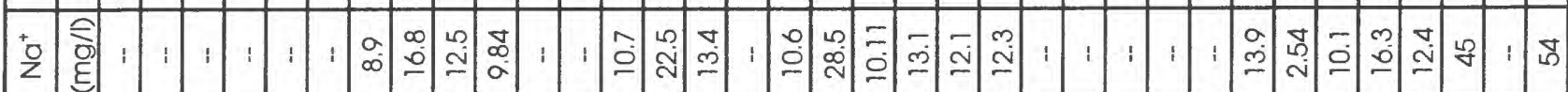

×

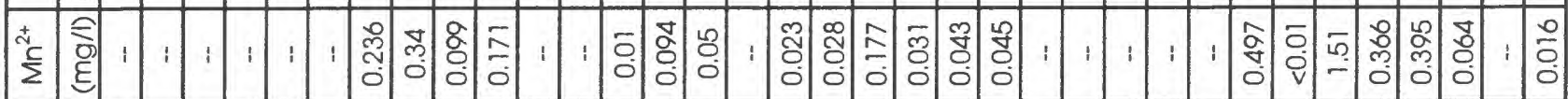

茎产:

产产帝

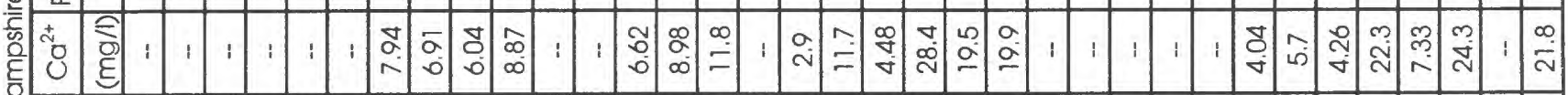

गें के

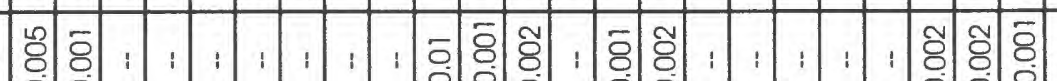

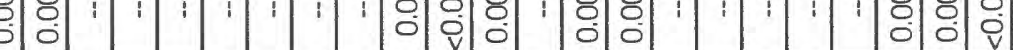

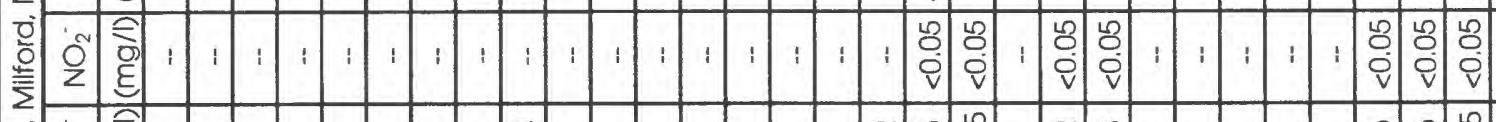

\%

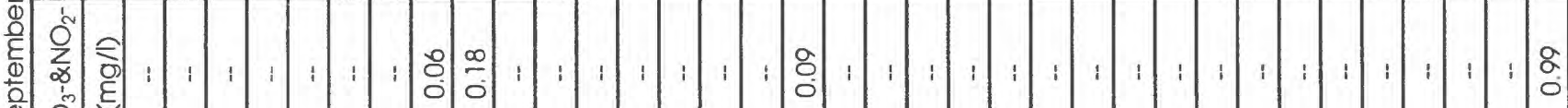

와

बें

:

(8)

ठ

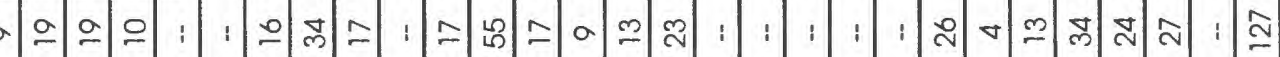

기요

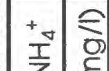

등 है

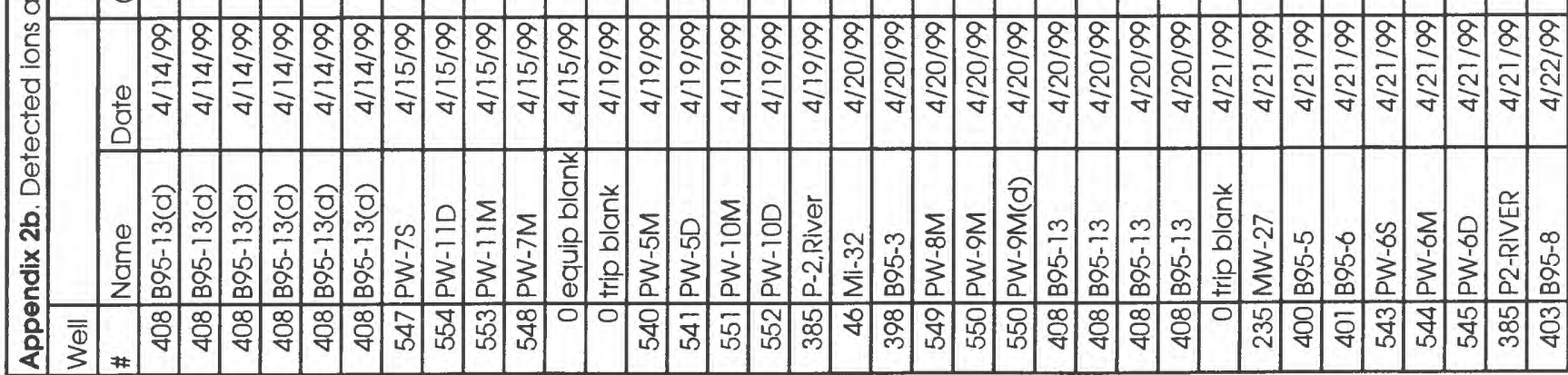




\begin{tabular}{|c|c|c|c|c|c|c|c|c|c|c|c|c|c|c|c|c|c|c|c|c|c|c|c|c|c|c|c|c|c|c|c|c|c|c|c|c|}
\hline & $\begin{array}{l}0 \\
0 \\
0 \\
0\end{array}$ & 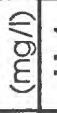 & $\stackrel{\square}{=}$ & 㴅 & $\begin{array}{l}\tilde{N} \\
\omega \\
-\end{array}$ & $:$ & i & ! & 1 & $i$ & $:$ & $!$ & 1 & 11 & 11 & $:$ & 1 & $:$ & 1 & 11 & 11 & & 1 & 1 & 1 & & : & & 1 & & : & 1 & 1 & 1 & $i$ & 1 \\
\hline & $\begin{array}{l}\frac{0}{0} \\
\frac{0}{\dot{u}} \\
\infty\end{array}$ & 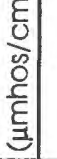 & 1 & 1 & 1 & 1 & 1 & 1 & 1 & $:$ & 1 & 1 & 11 & 1 & 11 & 1 & 1 & 11 & 11 & 11 & 11 & & $i$ & & 1 & 1 & 1 & 11 & i) & & & $:$ & 11 & : & & I \\
\hline & $\frac{1}{\infty}$ & ఫ్ & $\begin{array}{l}\text { Jे. } \\
\text { ले. }\end{array}$ & ले & $\stackrel{0}{-}$ & 1 & 1 & $:$ & 1 & 1 & i & 1 & $:$ & 1 & 1 & 1 & 1 & 1 & 1 & $:$ & 1 & i & 1 & i & 1 & & $:$ & 11 & 11 & & : & 1 & 1 & 1 & 1 & i \\
\hline & $\begin{array}{l}0 \\
\bigcirc\end{array}$ & $\begin{array}{l}\text { क् } \\
\text { है }\end{array}$ & & 1 & 1 & 1 & 1 & 1 & 1 & 1 & 1 & 1 & 1 & : & 11 & 1 & 1 & 1 & $i$ & 1 & $:$ & $i$ & 1 & : & 1 & 1 & 1 & 11 & : & 1 & 11 & $:$ & 1 & 1 & 1 & 1 \\
\hline & $\frac{I^{J}}{U}$ & ఫิ & & 1 & 1 & $i$ & 1 & $:$ & $:$ & 1 & 1 & 1 & 1 & 1 & 1 & $i$ & 1 & 1 & 1 & 11 & 11 & 1 & $:$ & i & 1 & 1 & $:$ & 1 & : & & ! & 1 & 11 & i & $i$ & 1 \\
\hline & ${ }^{+} 0$ & क्ञे & $\begin{array}{l}0 \\
\tilde{m} \\
m\end{array}$ & $\begin{array}{l}0 \\
0 \\
0\end{array} \mid$ & $\approx$ & 1 & 1 & $i$ & $i$ & 1 & 1 & $:$ & 1 & 1 & 1 & 1 & 1 & 1 & 1 & 1 & $:$ & 1 & $:$ & 1 & 1 & 1 & 1 & 1 & 1 & 1 & : & 1 & 1 & 1 & 4 & $:$ \\
\hline & \pm & क्री & & ন্ & $\begin{array}{l}0 \\
0 \\
\dot{j}\end{array} \mid$ & 1 & $:$ & 1 & 1 & 1 & $:$ & 1 & $:$ & 1 & 1 & $:$ & 1 & 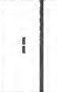 & 1 & 1 & 1 & 1 & : & 1 & : & 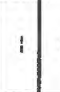 & 1 & & ; & 1 & 11 & 1 & 1 & 1 & 1 & 1 \\
\hline & 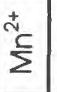 & है: & $\frac{\widehat{N}}{0}$ & $\begin{array}{l}\mathrm{J} \\
\text { 어 } \\
\end{array}$ & $\begin{array}{l}8 \\
0 \\
0\end{array}$ & 1 & $:$ & 1 & 1 & 1 & : & 11 & $i$ & 1 & 1 & $i$ & 1 & 1 & $i$ & 11 & 1 & 1 & 1 & $i$ & 1 & 1 & 1 & & : & 1 & 1 & 1 & 1 & 1 & 1 & 1 \\
\hline & $\stackrel{+}{+}$ & $\begin{array}{l}\text { के } \\
\text { है }\end{array}$ & సু & $\stackrel{8}{-}$ & ๙ & $:$ & $i$ & $i$ & $i$ & 1 & 1 & 1 & 1 & 1 & 1 & 1 & 1 & 1 & 1 & 1 & 1 & 1 & 1 & : & $i$ & 1 & 1 & & : & 1 & : & 1 & 1 & 1 & : & 1 \\
\hline & $\begin{array}{l}\text { 흐. } \\
\overline{0} \\
\Phi \\
4\end{array}$ & के & $\begin{array}{l}\overline{0} \\
0 \\
0\end{array}$ & $\begin{array}{l}2 \\
0 \\
0 \\
v\end{array}$ & $\begin{array}{l}0 \\
0 \\
0 \\
0\end{array}$ & $:$ & $:$ & 1 & 1 & 1 & : & 1 & $:$ & 1 & 1 & 1 & 1 & 1 & 1 & $:$ & 1 & i) & 1 & 1 & 11 & 1 & 1 & & : & 1 & i] & : & $:$ & $:$ & : & \\
\hline $\begin{array}{l}\text { है } \\
\text { है } \\
\text { है }\end{array}$ & 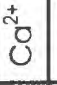 & है & $\begin{array}{ll}0 \\
\stackrel{2}{-}\end{array}$ & $\begin{array}{l}\infty \\
\alpha \\
0\end{array}$ & 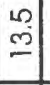 & 1 & 1 & $i$ & 1 & 1 & 1 & $i$ & 1 & $: 1$ & 1 & 1 & $:$ & & $:$ & 1 & 1 & $:$ & 1 & 1 & i & $i$ & $i$ & : & 1 & : & : & 1 & 1 & $:$ & 1 & \\
\hline $\begin{array}{l}\frac{1}{3} \\
\frac{1}{2}\end{array}$ & $\begin{array}{l}m^{\prime} \\
0 \\
a^{\prime}\end{array}$ & है & ర్ & $\overline{0}$ & 힝. & 1 & 1 & $:$ & $:$ & : & $:$ & $i$ & $:$ & 1 & $:$ & $i$ & : & $:$ & $i$ & 1 & $:$ & $i$ & 1 & : & : & 1 & $i$ & $i$ & 1 & 1 & : & $i$ & 1 & 1 & 1 & \\
\hline 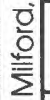 & $\tilde{O}$ & है & & 1 & 1 & 1 & 1 & 1 & $:$ & 1 & $:$ & $:$ & 1 & $:$ & 1 & $:$ & 1 & 1 & 1 & 11 & $:$ & 1 & $:$ & 1 & 1 & 1 & $i$ & & i & 1 & i & 1 & 1 & 1 & i & 1 \\
\hline 查 & $\begin{array}{l}\infty \\
2\end{array}$ & है & 1 & 1 & 1 & $i$ & $i$ & $i$ & 1 & 1 & 1 & 1 & 1 & 1 & 1 & 1 & 1 & 1 & 1 & 1 & 1 & 1 & 1 & 1 & 1 & 11 & 1 & & 1 & 1 & : & $i$ & 1 & 1 & & $:$ \\
\hline $\begin{array}{l}0 \\
\frac{0}{2} \\
\frac{0}{0} \\
\frac{0}{0} \\
0 \\
0 \\
0\end{array}$ & $\begin{array}{l}1 \\
0 \\
2 \\
\alpha \\
1 \\
0 \\
2 \\
2\end{array}$ & है & & $=$ & $\begin{array}{l}\mathbb{N} \\
\hat{0}\end{array}$ & 1 & $i$ & 1 & 1 & 1 & 1 & 1 & 1 & 1 & 1 & $:$ & 1 & 1 & $i$ & 1 & 1 & 1 & 1 & 1 & 1 & 1 & 1 & $i$ & i & 1 & i & : & 11 & $i$ & : & 1 \\
\hline$\underline{\alpha}$ & \begin{tabular}{c}
10 \\
\hdashline \\
\hdashline
\end{tabular} & है। & $\curvearrowright$ & $\simeq$ & $\cong$ & 1 & 1 & 1 & $i$ & $:$ & 1 & $:$ & $:$ & 1 & 1 & $:$ & $:$ & 1 & : & 1 & $:$ & $:$ & $!$ & : & $:$ & 1 & 1 & 1 & 1 & 1 & 1 & : & 1 & 1 & ! & 1 \\
\hline$\sum_{0=0}^{0}$ & $\dot{U}$ & है & $\approx$ & 으 & $\bar{\nabla}$ & : & $i$ & 1 & 1 & : & $i$ & $i$ & 1 & $:$ & 1 & $i$ & 11 & 1 & 1 & i & $\vdots$ & 1 & 1 & 1 & 1 & 1 & 1 & 1 & $:$ & 1 & : & : & 1 & 1 & : & : \\
\hline $\begin{array}{l}\text { 들 } \\
\text { है }\end{array}$ & का & है & & 1 & 1 & $i$ & 1 & 1 & 1 & 1 & $:$ & 1 & 1 & 1 & 1 & $i$ & 1 & $i$ & 1 & 1 & 1 & $:$ & 1 & 1 & 1 & 1 & $i$ & 1 & 1 & 1 & 1 & 1 & 1 & 1 & i & $:$ \\
\hline $\begin{array}{l}8 \\
0 \\
0 \\
0 \\
0\end{array}$ & $\begin{array}{l}+ \\
\frac{+}{z}\end{array}$ & क्ञ & & $i$ & 1 & $i$ & : & $i$ & 1 & 1 & 1 & 1 & 1 & 1 & $:$ & 1 & $:$ & 1 & 1 & 1 & 11 & $:$ & 1 & 1 & $:$ & $:$ & : & 1 & 1 & 1 & 1 & i & 1 & i & 1 & 1 \\
\hline $\begin{array}{l}\frac{2}{0} \\
\frac{0}{0} \\
\frac{\Phi}{0} \\
\Phi\end{array}$ & & . & 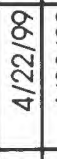 & 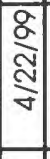 & \begin{tabular}{l}
\multirow{2}{\alpha}{} \\
$\underset{\mathrm{N}}{\mathrm{v}}$ \\
$\mathrm{v}$
\end{tabular} & $\begin{array}{l}\frac{9}{2} \\
\frac{10}{10} \\
\end{array}$ & \begin{tabular}{|l|}
$\frac{9}{2}$ \\
$\frac{m}{6}$ \\
\end{tabular} & $\begin{array}{l}\frac{g}{2} \\
\frac{m}{2}\end{array}$ & \begin{tabular}{l|}
$\frac{a}{2}$ \\
$\frac{m}{n}$ \\
\end{tabular} & \begin{tabular}{|l|}
$\frac{a}{2}$ \\
$\frac{m}{6}$ \\
\end{tabular} & $\frac{g}{\frac{g}{m}} \frac{}{10}$ & $\begin{array}{l}\frac{8}{2} \\
\frac{2}{6}\end{array}$ & $\begin{array}{l}\frac{2}{2} \\
\frac{2}{i n}\end{array}$ & \begin{tabular}{l|}
$\frac{\alpha}{\alpha}$ \\
$\frac{m}{10}$
\end{tabular} & \begin{tabular}{|l|}
$\frac{a}{2}$ \\
$\frac{m}{6}$ \\
\end{tabular} & \begin{tabular}{|l|}
$\frac{9}{m}$ \\
$\frac{m}{15}$ \\
\end{tabular} & \begin{tabular}{|c|}
$\begin{array}{c}0 \\
0 \\
\frac{m}{6} \\
\end{array}$ \\
\end{tabular} & $\begin{array}{l}\frac{g}{\alpha} \\
\frac{m}{i}\end{array}$ & $\begin{array}{l}\frac{a}{\alpha} \\
\frac{m}{n}\end{array}$ & \begin{tabular}{c|}
$\frac{9}{2}$ \\
$\frac{2}{6}$ \\
\end{tabular} & 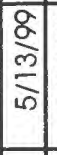 & \begin{tabular}{|c|}
$\alpha$ \\
0 \\
$\frac{m}{i n}$ \\
\end{tabular} & $\begin{array}{l}\frac{a}{a} \\
\frac{m}{i} \\
0\end{array}$ & 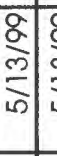 & $\frac{a}{\frac{2}{m}}$ & 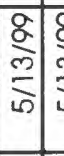 & 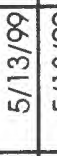 & 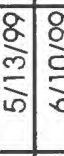 & \begin{tabular}{l|l}
8 \\
0 \\
0 \\
\end{tabular} & $\begin{array}{lll}8 & 8 \\
0 & 9 \\
2 & 3\end{array}$ & $\frac{0}{0}$ & $\frac{\frac{\alpha}{2}}{\partial}$ & $\frac{2}{2}$ & $\frac{g}{\frac{g}{0}}$ & & $\begin{array}{l}\text { a } \\
0 \\
0\end{array}$ \\
\hline 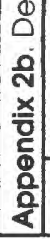 & $\begin{array}{c}\overline{\overline{0}} \\
3\end{array}$ & $\begin{array}{l}0 \\
\text { है } \\
0 \\
2\end{array}$ & 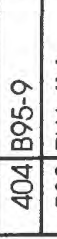 & 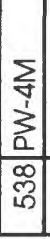 & 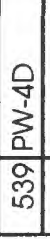 & $\begin{array}{l}\frac{\overrightarrow{0}}{0} \\
\frac{0}{0} \\
\text { 은 } \\
0\end{array}$ & 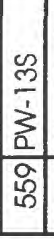 & $\begin{array}{l}\text { 들 } \\
\frac{0}{0} \\
\text { 응 } \\
0\end{array}$ & 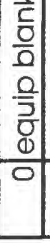 & $\frac{\frac{0}{3}}{\frac{0}{2}}$ & 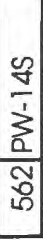 & 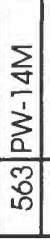 & \begin{tabular}{|c|}
$\frac{0}{2}$ \\
$\vdots$ \\
$\vdots$ \\
\end{tabular} & 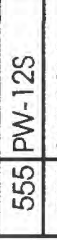 & 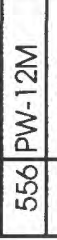 & 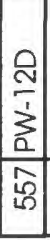 & 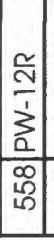 & 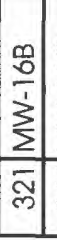 & 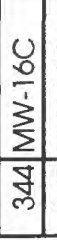 & 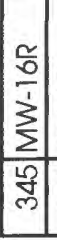 & \begin{tabular}{|l|}
\multicolumn{2}{c}{} \\
\\
$\vdots$ \\
$\vdots$ \\
0 \\
0 \\
0 \\
\end{tabular} & 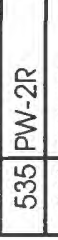 & 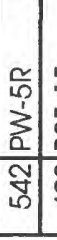 & 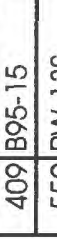 & 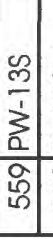 & 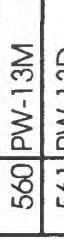 & 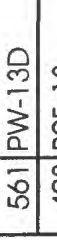 & 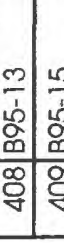 & 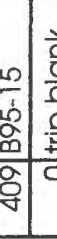 & 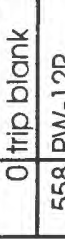 & 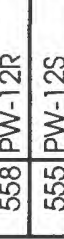 & 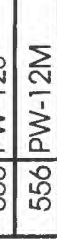 & 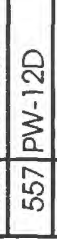 & 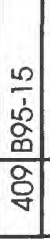 & 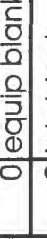 & $\begin{array}{l}\text { 들 } \\
\text { 음 } \\
\text { 의 } \\
0\end{array}$ \\
\hline
\end{tabular}




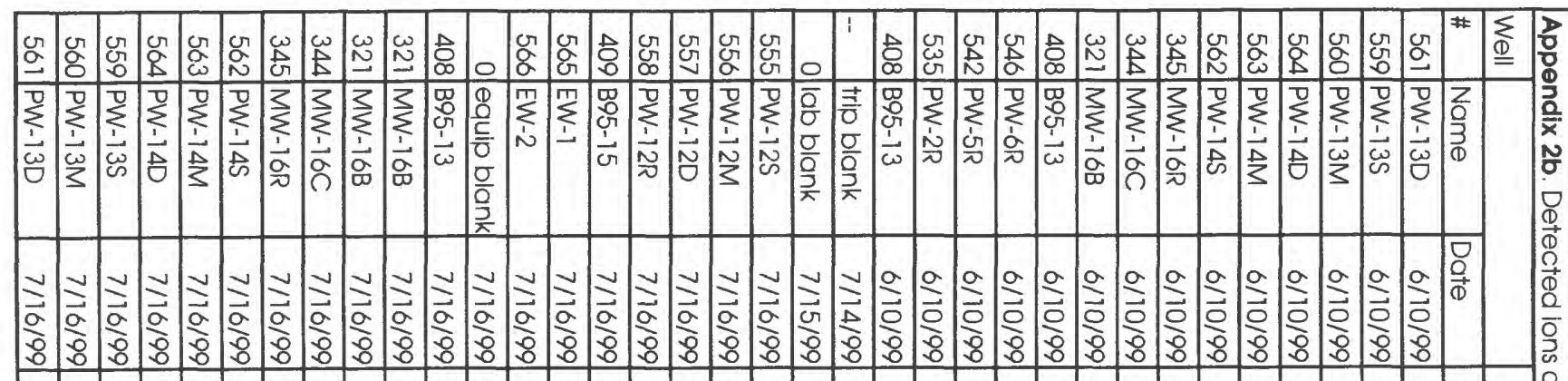

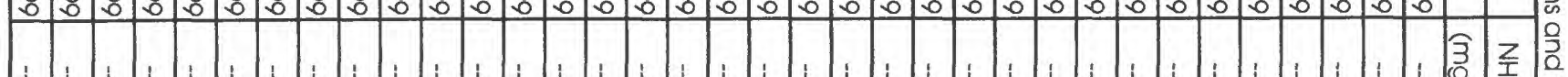

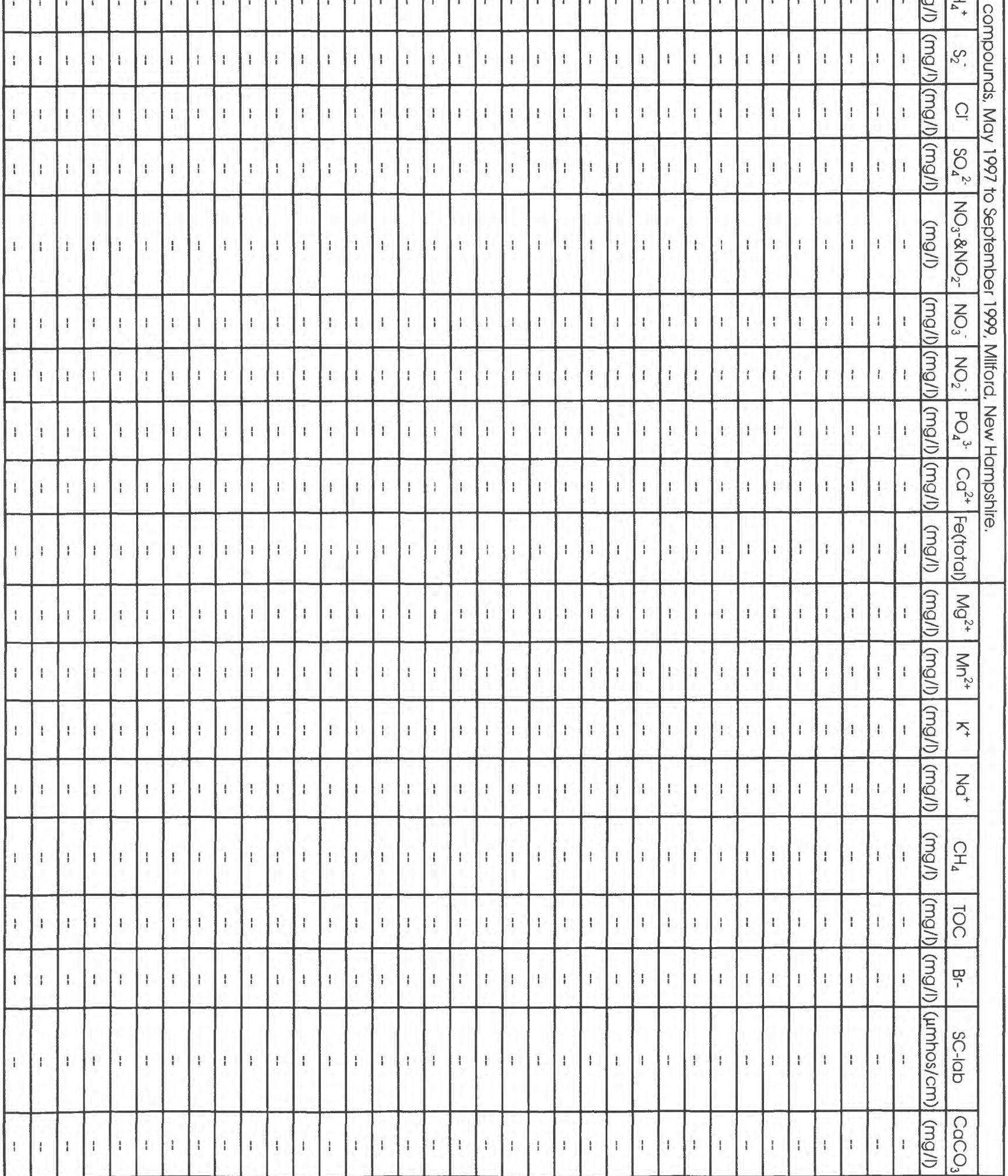




\begin{tabular}{|c|c|c|c|c|c|c|c|c|c|c|c|c|c|c|c|c|c|c|c|c|c|c|c|c|c|c|c|c|c|c|c|c|c|c|c|c|}
\hline & $\begin{array}{l}0 \\
0 \\
0 \\
0\end{array}$ & के & & 1 & 1 & ! & 1 & 1 & 1 & 1 & : & 1 & 1 & i & 1 & 1 & 1 & 1 & ! & 1 & 1 & 1 & : & $:$ & 1 & i & 1 & 1 & 1 & & i & ; & : 1 & ' & 1 & 1 \\
\hline & $\begin{array}{l}\text { 욤 } \\
\frac{0}{\dot{0}} \\
\infty\end{array}$ & 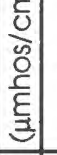 & & ! & ! & 1 & & & 11 & 1 & 1 & 1 & 11 & 1 & : & 1 & 1 & 1 & 11 & 11 & $1:$ & & 1 & 11 & $:$ & : & 1 & : & & & & & 1 & 1 & 1 & i \\
\hline & $\frac{1}{\Phi}$ & क् & & : & : & 1 & $\because$ & $i$ & $:$ & 1 & 1 & 1 & 1 & 1 & 1 & 1 & 1 & 1 & $:$ & 1 & : & 1 & $:$ & 1 & 1 & $:$ & 1 & 1 & & & & i & : & ! & i & $i$ \\
\hline & O) & क्ञे & & 1 & 1 & 1 & 1 & 1 & $:$ & 1 & : & $:$ & $:$ & 1 & 1 & 1 & 1 & 1 & 1 & 1 & 1 & 1 & 11 & 1 & 1 & 1 & 1 & 1 & & & i & : & 1 & 1 & 1 & 1 \\
\hline & $\frac{I^{J}}{U}$ & స్ & & 1 & 1 & 1 & 1 & 1 & 1 & 1 & 1 & 1 & 1 & 1 & 1 & 1 & 1 & 1 & 1 & 1 & 1 & 1 & 4 & 1 & 1 & 1 & 1 & 1 & i & 1 & : & i & \begin{tabular}{l|l}
1 & 1
\end{tabular} & : & 1 & 1 \\
\hline & $\stackrel{+}{0}$ & है। & & 1 & 1 & 1 & 1 & $:$ & $:$ & 1 & 1 & : & 1 & 1 & 1 & 1 & $:$ & $:$ & 1 & 1 & 1 & 1 & $:$ & 1 & 1 & 1 & $i$ & : & $\begin{array}{lll} & 1\end{array}$ & & i & I & : & 1 & 1 & 1 \\
\hline & \pm & क्ञे & & $i$ & : & ! & ! & 1 & 1 & 1 & : & : & 1 & 1 & ! & ! & 1 & 1 & 1 & 1 & 1 & 1 & i & : & i & i & : & 1 & & & & 1 & 1 & & 1 & 1 \\
\hline & 䓠 & के & & 1 & : & 1 & : & 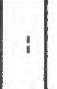 & $: 1$ & 1 & 1 & 1 & 1 & $i$ & $:$ & $:$ & $:$ & 1 & 1 & : & $:$ & 11 & 1 & : & 1 & $:$ & 1 & i & & 4 & ; & : & 1 & 1 & 1 & 1 \\
\hline & $\stackrel{+}{ \pm}$ & क् & & : & : & 1 & $:$ & $i$ & $:$ & 1 & 1 & 1 & 1 & $:$ & $:$ & : & 1 & 1 & 1 & 1 & 1 & 1 & 1 & 1 & 1 & i & : & : & i & : & ; & : & i & 1 & 1 & 1 \\
\hline$\stackrel{\Omega}{g}$ & $\begin{array}{l}\text { 흠 } \\
\frac{0}{0} \\
\frac{1}{4} \\
\end{array}$ & के & & : & 1 & 1 & $i$ & 1 & $:$ & 1 & i & : & 11 & 1 & 1 & : & : & $: 1$ & 1 & 1 & 11 & 1 & 1 & : & $:$ & : & 1 & : & : & 1 & ' & 1 & i & 1 & 1 & 1 \\
\hline $\begin{array}{l}\text { है } \\
\text { है } \\
\text { है }\end{array}$ & 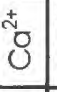 & ठิ & 1 & 1 & 1 & 1 & 1 & 1 & $:$ & $:$ & 1 & 1 & 4 & 1 & 1 & 1 & 1 & 1 & 1 & 1 & 11 & 1 & $i$ & 4 & $:$ & : & 1 & $!$ & & & i & ; & : & : & 1 & 1 \\
\hline$\frac{1}{3}$ & 品 & है। & & ; & i & 1 & $:$ & 1 & $:$ & 1 & : & : & & $:$ & $!$ & : & 1 & & 1 & 1 & i & : & & 1 & 1 & 1 & : & : & & & & & 1 & : & 1 & 1 \\
\hline$\frac{0}{\overline{3}}$ & ¿ & ธ్ & : & : & I & 1 & $:$ & 1 & $:$ & $:$ & : & : & 1 & 1 & 1 & : & $:$ & $:$ & 1 & ! & 1 & 1 & $i$ & $:$ & $:$ & : & 1 & $:$ & 1 & : & $:$ & I & : & : & : & 1 \\
\hline \& & $\stackrel{0}{2}$ & है & & ; & i & $:$ & 1 & 1 & $:$ & 1 & $:$ & 1 & 1 & 1 & $i$ & $i$ & 1 & $:$ & 1 & 1 & 1 & 1 & 1 & 1 & 1 & 1 & 1 & 1 & 1 & 1 & 1 & I & I & 1 & 1 & 1 \\
\hline $\begin{array}{l}8 \\
d \\
d \\
d \\
c\end{array}$ & 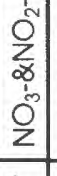 & के & & $i$ & 1 & $i$ & : & : & : & 11 & 1 & 1 & 1 & 1 & 1 & 1 & $:$ & $:$ & $:$ & i & i & 1 & i & : & $: 1$ & 1 & $i$ & i & & $!$ & i & i & 1 & $:$ & : & : \\
\hline 8 & $\begin{array}{l}\tilde{\sim}^{\prime} \\
0 \\
\infty\end{array}$ & $\begin{array}{l}\text { Оे } \\
\text { है }\end{array}$ & & $i$ & 1 & 1 & 1 & 1 & 1 & 11 & 1 & $i$ & 1 & 1 & 1 & 1 & $i$ & $:$ & $i$ & 1 & : & $i$ & 1 & $:$ & 1 & $i$ & $i$ & i & 1 & 1 & 1 & i & i & 1 & $:$ & $:$ \\
\hline$\sum_{0}^{0}$ & $\overline{\mathrm{U}}$ & $\begin{array}{l}\text { Оे } \\
\text { है }\end{array}$ & & $i$ & 1 & 1 & 1 & $:$ & 1 & 1 & : & : & 1 & 1 & : & 1 & : & 1 & 1 & 1 & 1 & $i$ & i & 1 & 1 & 1 & 1 & 1 & & : & 1 & ! & ; & i & : & 1 \\
\hline d & in & क्षे & & 1 & 1 & : & $i$ & 1 & $:$ & $:$ & 1 & : & 1 & $:$ & 1 & 1 & $:$ & 1 & 1 & 1 & 1 & 1 & 1 & 1 & 1 & 1 & $i$ & : & $:$ & $i$ & : & : & i & $i$ & 1 & 1 \\
\hline $\begin{array}{l}\overline{0} \\
0 \\
\text { 믕 }\end{array}$ & 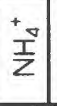 & 今ે & & i & : & 1 & 1 & 1 & 1 & 1 & 1 & $:$ & 1 & 1 & 1 & 1 & $:$ & $:$ & : & : & 1 & 1 & : & 1 & $:$ & 1 & : & : & : & 1 & $:$ & : & ! & ! & 1 & 1 \\
\hline $\begin{array}{l}2 \\
\frac{0}{0} \\
0 \\
\frac{d}{0} \\
d\end{array}$ & & $\frac{0}{0}$ & 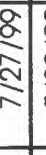 & $\begin{array}{l} \\
\\
\\
0 \\
\end{array}$ & 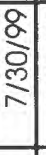 & 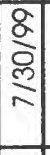 & $\begin{array}{l} \\
\\
0 \\
2 \\
2\end{array}$ & 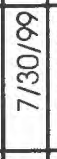 & 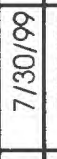 & \begin{tabular}{|l|} 
\\
\\
\end{tabular} & 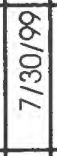 & 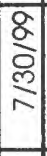 & 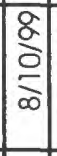 & \begin{tabular}{|l|}
\multirow{2}{*}{} \\
$\frac{1}{\infty}$ \\
\end{tabular} & 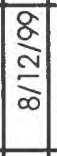 & $\mid \begin{array}{c}\frac{8}{2} \\
\frac{1}{\infty} \\
\infty\end{array}$ & $\begin{array}{l}\frac{g}{i} \\
\frac{a}{\infty} \\
\infty\end{array}$ & \begin{tabular}{|l|}
\multirow{2}{*}{} \\
$\stackrel{\infty}{\infty}$ \\
\end{tabular} & 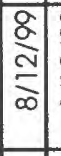 & 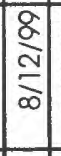 & 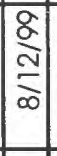 & \begin{tabular}{|c|}
\multirow{2}{a}{} \\
$\stackrel{-}{\infty}$ \\
\end{tabular} & \begin{tabular}{l|} 
\\
$\hat{a}$ \\
$\frac{1}{\infty}$
\end{tabular} & 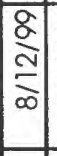 & $\left|\begin{array}{c}\stackrel{2}{\alpha} \\
\stackrel{\infty}{\infty} \\
\infty\end{array}\right|$ & \begin{tabular}{|l} 
\\
$\stackrel{2}{2}$ \\
$\stackrel{\infty}{\infty}$
\end{tabular} & $\left|\begin{array}{l}\frac{1}{2} \\
\frac{2}{\infty} \\
\infty\end{array}\right|$ & 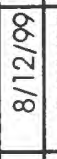 & 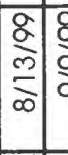 & \begin{tabular}{l|l}
$\frac{\alpha}{\alpha}$ \\
$\frac{\alpha}{\alpha}$
\end{tabular} & $\begin{array}{l}8 \\
0 \\
0 \\
0\end{array}$ & $\begin{array}{lll}0 \\
0 \\
0\end{array}$ & $=\frac{8}{\frac{8}{2}}$ & $\frac{\frac{\sigma}{2}}{\frac{\partial}{\alpha}}$ & $\frac{2}{\partial}$ & $\frac{\alpha}{\frac{\alpha}{\alpha}}$ \\
\hline 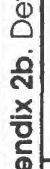 & & $\begin{array}{l}0 \\
\text { है } \\
\text { ¿ }\end{array}$ & $\begin{array}{l}\text { - } \\
\text { 을 } \\
\text { 읠 } \\
\end{array}$ & 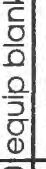 & 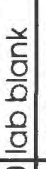 & $\begin{array}{l}\frac{1}{2} \\
\frac{1}{0} \\
\frac{1}{3} \\
\sum \\
\end{array}$ & 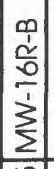 & \begin{tabular}{|c|c}
0 \\
1 \\
$\vdots$ \\
0 \\
$\vdots$ \\
$\vdots$ \\
$\vdots$ \\
\end{tabular} & $\begin{array}{l}0 \\
0 \\
\frac{1}{0} \\
\vdots \\
\vdots \\
\vdots \\
\end{array}$ & 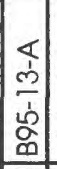 & 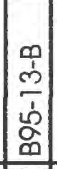 & 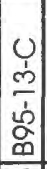 & \begin{tabular}{|l|} 
들 \\
응 \\
은 \\
\end{tabular} & \begin{tabular}{|l|}
\multicolumn{2}{c}{} \\
응 \\
o \\
\end{tabular} & 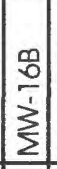 & $\mid \begin{array}{c}0 \\
0 \\
\vdots \\
\vdots \\
\Sigma \\
\end{array}$ & $\frac{0}{3}$ & \begin{tabular}{|c|}
0 \\
7 \\
$\vdots$ \\
$\vdots$ \\
$\vdots$
\end{tabular} & \begin{tabular}{|c|} 
\\
$\vdots$ \\
$\vdots$ \\
$\vdots$ \\
0
\end{tabular} & 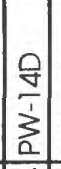 & \begin{tabular}{|c|c|} 
\\
0 \\
$\vdots$ \\
$\vdots$ \\
$\vdots$ \\
\end{tabular} & 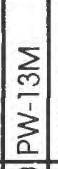 & $\begin{array}{l}0 \\
\text { p } \\
\vdots \\
\vdots \\
\vdots\end{array}$ & 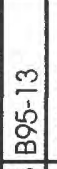 & \begin{tabular}{|l|}
2 \\
$\frac{1}{1}$ \\
$\vdots$ \\
$\vdots$ \\
2
\end{tabular} & 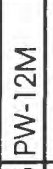 & 忿 & \begin{tabular}{|l}
$\stackrel{2}{\sim}$ \\
$\vdots$ \\
$\vdots$ \\
$a$
\end{tabular} & 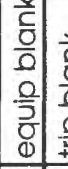 & $\begin{array}{l}\text { c) } \\
\text { 응 } \\
\text { 을 }\end{array}$ & 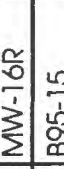 & : & $\frac{1}{3} \frac{\sum_{n}^{n}}{3}$ & 空 & 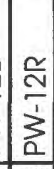 & 号 \\
\hline$\frac{0}{0}$ & $\begin{array}{l}\overline{\overline{0}} \\
3\end{array}$ & $\#$ & & 9 & 9 & "్ & & 年 & 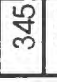 & & & $\begin{array}{l}0 \\
q \\
\end{array}$ & & & స్ল & & f & & & 苚 & \begin{tabular}{|c|}
0 \\
号
\end{tabular} & & & 号 & \begin{tabular}{|l|l|} 
㞻 \\
\end{tabular} & 员 & 命 & \begin{tabular}{|l|} 
\\
\\
0 \\
0
\end{tabular} & 00 & 9 & & 8 & $\begin{array}{ll}0 \\
6\end{array}$ & 点 & 足 & $\stackrel{\infty}{\forall}$ \\
\hline
\end{tabular}




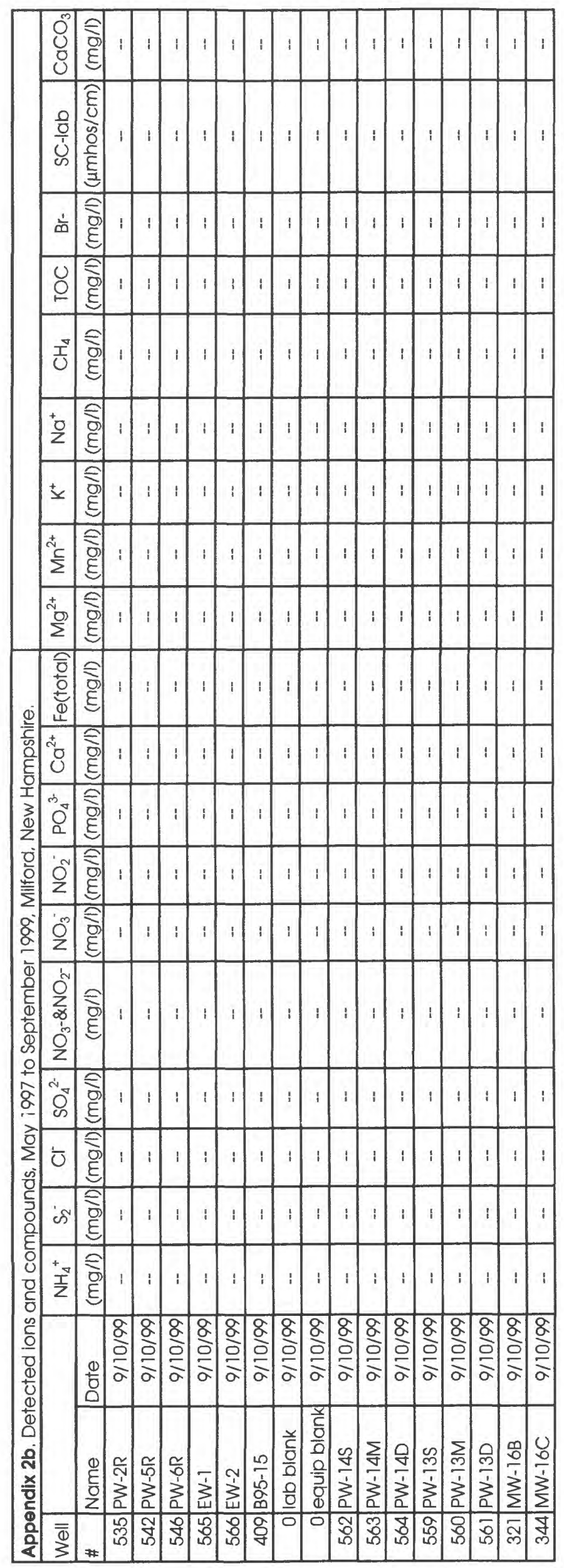




\begin{tabular}{|c|c|c|c|c|c|c|c|c|c|c|}
\hline Appe & endix 2c. M & jor detectec & d volatil & organ & compc & nds (VOC & s), May 1 & 297 to $S e$ & ptemker 1 & 999, Milford, New Hampshire. \\
\hline Well & & & Pump & & & & & & & Vinyl \\
\hline \# & Name & Date & TYPE & PCE & TCE & CIS-DCE & 111-Tri & MTBE & Acetone & Chloride Comments \\
\hline 233 & MW-16A & $5 / 27 / 97$ & peri & 71 & U2 & - & U2 & 2.7 & U 10 & U2 \\
\hline 321 & $M W-16 B$ & $5 / 27 / 97$ & peri & 320 & 11 & - & 3.3 & U2 & U 10 & U2 \\
\hline 344 & $M W-16 C$ & $5 / 27 / 97$ & peri & 560 & 42 & - & 5.5 & 2.2 & U 10 & U2 \\
\hline 345 & $M W-16 R$ & $5 / 27 / 97$ & peri & 510 & 53 & - & U2 & 3.9 & 11 & U2 \\
\hline 407 & B95-12 & $5 / 28 / 97$ & peri & U2 & U2 & - & U2 & U2 & U 10 & U2 \\
\hline 407 & B95-12(d) & $5 / 28 / 97$ & peri & U2 & U2 & - & U2 & U2 & 12 & U2 \\
\hline 408 & B95-13 & $5 / 28 / 97$ & peri & 2000 & 180 & - & 11 & U 2 & U 10 & U2 \\
\hline 409 & B95-15 & $5 / 28 / 97$ & peri & 920 & 22 & - & U2 & U2 & U 10 & U2 \\
\hline 385 & $P-2$, river & $5 / 28 / 97$ & GRAB & - & - & - & - & - & - & -- \\
\hline 398 & B95-3 & $5 / 29 / 97$ & peri & $\cup 2$ & U2 & - & $\cup 2$ & U2 & U 10 & U2 \\
\hline 404 & $895-9$ & $5 / 29 / 97$ & peri & 52 & 2.1 & -- & U2 & 17 & U 10 & U2 \\
\hline 299 & $\mathrm{HM}-1$ & $5 / 29 / 97$ & peri & 670 & 66 & - & U2 & U2 & U 10 & U2 \\
\hline 42 & $\mathrm{MI}-27$ & $5 / 29 / 97$ & peri & U2 & U2 & - & U2 & U2 & U 10 & U2 \\
\hline 203 & MI-63 & $5 / 29 / 97$ & peri & 2100 & 130 & - & 2.7 & U2 & U 10 & 4.1 \\
\hline 30 & MI-19 & $5 / 30 / 97$ & peri & U2 & U2 & -- & U 2 & U2 & U 10 & U2 \\
\hline 31 & MI-20 & $5 / 30 / 97$ & peri & U2 & U2 & - & U2 & U2 & U 10 & U2 \\
\hline 33 & $M I-21$ & $5 / 30 / 97$ & peri & U2 & U2 & - & U2 & U2 & U 10 & U2 \\
\hline 400 & B95-5 & $6 / 2 / 97$ & peri & U2 & U2 & - & U2 & U2 & U 10 & U2 \\
\hline 40 & $\mathrm{Ml}-25$ & $6 / 2 / 97$ & peri & 85 & 18 & - & U2 & U2 & U 10 & 25 \\
\hline 46 & MI-32 & $6 / 2 / 97$ & peri & 1000 & 79 & - & 59 & U2 & U 10 & U2 \\
\hline 321 & $M W-16 B$ & $6 / 11 / 97$ & $B L$ & 510 & 12 & - & U2 & U 2 & U 10 & U2 \\
\hline 344 & $M W-16 C$ & $6 / 12 / 97$ & $B L$ & 930 & 51 & - & U2 & U2 & U 10 & U2 \\
\hline 401 & B95-6 & $6 / 16 / 97$ & $\mathrm{BL}$ & U 2 & U2 & - & U2 & U2 & U 10 & U2 \\
\hline 403 & B95-8 & $6 / 16 / 97$ & $B L$ & 9.3 & U2 & - & U2 & 2.5 & U 10 & U2 \\
\hline 398 & B95-3 & $6 / 17 / 97$ & $B L$ & U 2 & U2 & - & U2 & U2 & U 10 & U2 \\
\hline 407. & B95-12 & $10 / 28 / 97$ & peri & U2 & U2 & U2 & U2 & U2 & U 10 & U2 \\
\hline 408 & B95-13 & $10 / 28 / 97$ & $B L$ & - & - & - & - & - & - & - \\
\hline 408 & B95-13 & $10 / 28 / 97$ & peri & 3100 & 270 & 150 & $\cup 40$ & $\cup 40$ & U 200 & $\cup 40$ \\
\hline 409 & B95-15 & $10 / 30 / 97$ & $B L$ & -- & -- & - & - & -- & - & - \\
\hline 409 & B95-15 & $10 / 30 / 97$ & peri & 1200 & 24 & 33 & U 20 & U 20 & $\cup 100$ & U 20 \\
\hline 407 & B95-12 & $12 / 15 / 97$ & peri & U2 & U2 & U2 & U2 & U2 & U 10 & U2 \\
\hline 299 & $\mathrm{HM}-1$ & $12 / 15 / 97$ & peri & 500 & 120 & 70 & U 10 & U 10 & U 50 & U 10 \\
\hline 40 & $\mathrm{MI}-25$ & $12 / 15 / 97$ & peri & 13 & 4.7 & 6.2 & U2 & U2 & U 10 & 4.5 \\
\hline 42. & MI-27 & $12 / 15 / 97$ & peri & U2 & U2 & $\cup 2$ & U2 & 3.2 & U 10 & U2 \\
\hline $203:$ & MI-63 & $12 / 15 / 97$ & peri & 1700 & 120 & 170 & U 28.6 & U 28.6 & U 143 & U 28.6 \\
\hline 344 & $M W-16 C$ & $12 / 15 / 97$ & peri & 1200 & 110 & 79 & 22 & U 10 & U 50 & U 10 \\
\hline 398 & B95-3 & $12 / 16 / 97$ & peri & U2 & U2 & U 2 & U2 & U2 & U 10 & U2 \\
\hline 403 & B95-8 & $12 / 16 / 97$ & peri & 240 & 2.6 & 6.4 & U2 & 2.4 & U 10 & U2 \\
\hline 404 & B95-9 & $12 / 16 / 97$ & peri & 140 & 3.8 & U2 & U 2 & 6.5 & U 10 & U2 \\
\hline 404 & B95-9(d) & $12 / 16 / 97$ & peri & 140 & 3.5 & U 2 & U2 & 6.5 & U 10 & U2 \\
\hline 35 & $\mathrm{MI}-22$ & $12 / 16 / 97$ & peri & 3400 & 160 & 57 & U 50 & U 50 & U 250 & U 50 \\
\hline 37 & Ml-23 & $12 / 16 / 97$ & peri & 340 & 61 & 320 & U 6.66 & U6.66 & U 33.3 & U 6.66 \\
\hline 400 & B95-5 & $12 / 17 / 97$ & peri & U2 & U 2 & U2 & U2 & U2 & U 10 & U2 \\
\hline 401 & B95-6 & $12 / 17 / 97$ & peri & U2 & U2 & U 2 & U2 & U2 & U 10 & U2 \\
\hline 402 & B95-7 & $12 / 17 / 97$ & peri & 15 & 2.1 & U 2 & U2 & 3.8 & U 10 & U2 \\
\hline 31 & MI-20 & $12 / 17 / 97$ & peri & U2 & U2 & U 2 & U2 & U2 & U 10 & U2 \\
\hline 321 & $M W-16 B$ & $12 / 18 / 97$ & peri & 360 & 11 & U 10 & U 10 & U 10 & U 50 & U 10 \\
\hline 345 & $M W-16 R$ & $12 / 18 / 97$ & peri & 330 & 41 & 43 & U 10 & U 10 & U 50 & U 10 \\
\hline
\end{tabular}




\begin{tabular}{|c|c|c|c|c|c|c|c|c|c|c|c|}
\hline \multicolumn{12}{|c|}{ Appendix 2c. Major detected volatile organic compounds (VOCs). May 1997 to September 1999. Milford, New Hampshire. } \\
\hline \multirow{2}{*}{$\begin{array}{l}\text { Well } \\
\#\end{array}$} & \multirow[b]{2}{*}{ Name } & \multirow[b]{2}{*}{ Date } & \multicolumn{5}{|c|}{ Pump } & \multicolumn{4}{|c|}{ Vinyl } \\
\hline & & & TYPE & PCE & TCE & CIS-DCE & $111-T r i$ & MTBE & Acetone & Chloride Comments & \\
\hline 385 & P-2,river & $12 / 18 / 97$ & GRAB & - & - & -- & - & - & -- & - & \\
\hline 233 & $M W-16 A$ & $12 / 19 / 97$ & peri & - & - & - & -- & -- & - & -- & \\
\hline 402 & B95-7 & $1 / 12 / 98$ & peri & - & - & - & - & - & - & - & \\
\hline \multirow[t]{3}{*}{407} & B95-12 & $2 / 19 / 98$ & peri & U2 & U2 & U2 & U2 & U2 & U 10 & U 2 & \\
\hline & equip blank & $2 / 19 / 98$ & DB & 3.5 & U2 & U2 & U2 & U2 & U 10 & U2 & \\
\hline & Trip blank & $2 / 19 / 98$ & NA & U2 & U2 & U2 & U2 & U2 & U 10 & U2 & \\
\hline 408 & B95-13 & $2 / 20 / 98$ & $\mathrm{BL}$ & 4100 & 290 & 150 & U 100 & U 100 & U 500 & U 100 & \\
\hline 408 & B95-13 & $2 / 20 / 98$ & peri & 3700 & 280 & 150 & U 100 & U 100 & U 500 & U 100 & \\
\hline 409 & B95-15 & $2 / 20 / 98$ & peri & 830 & 32 & 47 & U 20 & U 20 & U 100 & U 20 & \\
\hline & (trip blank) & $5 / 11 / 98$ & NA & U2 & U2 & U2 & U2 & U 2 & U 10 & U 2 & \\
\hline 321 & $M W-16 B$ & $5 / 11 / 98$ & peri & 310 & 11 & U5 & U 5 & U 5 & U 25 & U5 & \\
\hline 344 & $M W-16 C$ & $5 / 11 / 98$ & peri & 1200 & 110 & 75 & U 20 & U 20 & U 100 & U 20 & \\
\hline 398 & B95-3 & $5 / 12 / 98$ & peri & U2 & U 2 & U 2 & U2 & U 2 & U 10 & U 2 & \\
\hline 400 & B95-5 & $5 / 12 / 98$ & peri & U2 & U2 & $\cup 2$ & U2 & U2 & U 10 & U2 & \\
\hline 401 & B95-6 & $5 / 12 / 98$ & peri & U2 & U2 & U2 & U2 & U2 & U 10 & U2 & \\
\hline 403 & B95-8 & $5 / 12 / 98$ & peri & 34 & 2.5 & 3 & U 2 & 8.2 & U 10 & U2 & \\
\hline 404 & B95-9 & $5 / 12 / 98$ & peri & 120 & 2.6 & U2 & U2 & 4.4 & U 10 & U2 & \\
\hline 404 & B95-9(d) & $5 / 12 / 98$ & peri & 120 & 2.9 & U2 & U2 & 5.2 & U 10 & U2 & \\
\hline 46 & Ml-32 & $5 / 12 / 98$ & peri & 1100 & 65 & 44 & 39 & U 20 & U 100 & U 20 & \\
\hline & (trip blank) & $5 / 13 / 98$ & NA & U 2 & U2 & U2 & U 2 & U2 & U 10 & U2 & \\
\hline 35 & MI-22 & $5 / 13 / 98$ & peri & 2400 & 130 & U 40 & U 40 & U 40 & U 200 & U 40 & \\
\hline 37 & $\mathrm{Ml}-23$ & $5 / 13 / 98$ & peri & 180 & 68 & 140 & U2 & U 2 & U 10 & U 2 & \\
\hline 233 & $M W-16 A$ & $5 / 13 / 98$ & peri & 39 & U 2 & U 2 & U 2 & 13 & U 10 & U2 & \\
\hline 345 & $M W-16 R$ & $5 / 13 / 98$ & peri & 390 & 48 & 48 & U 10 & U 10 & U 50 & U 10 & \\
\hline 385 & P-2,river & $5 / 13 / 98$ & GRAB & - & - & - & - & - & - & -- & \\
\hline 33 & Ml-21 & $5 / 14 / 98$ & peri & U 2 & U 2 & U 2 & U2 & U2 & U 10 & U2 & \\
\hline 555 & PW-12S & $5 / 14 / 98$ & peri & 8.7 & U 2 & U 2 & U2 & U2 & U 10 & U2 & \\
\hline 531 & PW-1D & $5 / 14 / 98$ & peri & 2600 & 220 & 130 & U 40 & U 40 & U 200 & U 40 & \\
\hline 530 & PW-1S & $5 / 14 / 98$ & peri & 3400 & 250 & 160 & U 50 & U 50 & U 250 & U 50 & \\
\hline 557 & $P W-12 D$ & $5 / 15 / 98$ & peri & 550 & 52 & 87 & U 10 & U 10 & U 50 & U 10 & \\
\hline 556 & PW-12M & $5 / 15 / 98$ & peri & 610 & 53 & 85 & U 10 & U 10 & U 50 & U 10 & \\
\hline 558 & $P W-12 R$ & $5 / 15 / 98$ & peri & 1200 & 89 & 110 & U 20 & U 20 & U 100 & U 20 & \\
\hline & (trip blank) & $5 / 18 / 98$ & NA & U2 & U2 & U2 & U 2 & U 2 & U 10 & U 2 & \\
\hline 407 & B95-12 & $5 / 18 / 98$ & peri & U2 & U 2 & U2 & U2 & 3.3 & U 10 & U2 & \\
\hline 409 & B95-15 & $5 / 18 / 98$ & DB & 1000 & 28 & 43 & U 20 & U 20 & U 100 & U 20 & \\
\hline 409 & B95-15 & $5 / 18 / 98$ & peri & 890 & 27 & 45 & U 10 & U 10 & U 50 & U 10 & \\
\hline 534 & PW-2D & $5 / 18 / 98$ & peri & 170 & 9.4 & 4.7 & U2 & 3.8 & U 10 & U 2 & \\
\hline 532 & PW-2S & $5 / 18 / 98$ & peri & 830 & 120 & 110 & 43 & U 20 & U 100 & U 20 & \\
\hline & (trip blank) & $5 / 19 / 98$ & NA & U2 & U 2 & U 2 & U2 & U 2 & U 10 & U2 & \\
\hline 552 & PW-10D & $5 / 20 / 98$ & peri & 2200 & 80 & U 40 & $\cup 40$ & $\cup 40$ & U 200 & U 40 & \\
\hline 551 & PW-10M & $5 / 20 / 98$ & peri & 130 & 30 & 130 & U2 & U 2 & U 10 & U 2 & \\
\hline 533 & PW-2M & $5 / 20 / 98$ & peri & 1100 & 190 & 180 & 120 & U 20 & U 100 & U 20 & \\
\hline 535 & $P W-2 R$ & $5 / 20 / 98$ & peri & 36 & 6.2 & 2.1 & U 2 & U2 & U 10 & U2 & \\
\hline & (trip blank) & $5 / 21 / 98$ & NA & U2 & U2 & U2 & U 2 & U 2 & U 10 & U2 & \\
\hline 408 & B95-13 & $5 / 21 / 98$ & $\mathrm{BL}$ & 4100 & 270 & 160 & U 100 & U 100 & U 500 & U 100 & \\
\hline 408 & B95-13 & $5 / 21 / 98$ & DB & 3200 & 250 & 150 & U 100 & U 100 & U 500 & U 100 & \\
\hline 408 & B95-13 & $5 / 21 / 98$ & peri & 3300 & 230 & 160 & $\cup 40$ & $\cup 40$ & U 200 & U 40 & \\
\hline 344 & $M W-16 C$ & $5 / 21 / 98$ & peri & - & -- & - & - & -- & - & - & \\
\hline
\end{tabular}




\begin{tabular}{|c|c|c|c|c|c|c|c|c|c|c|}
\hline \multicolumn{11}{|c|}{ Appendix 2c. Major detected volatile organic compounds (VOCs), May 1997 to September 1999. Milford, New Hampshire. } \\
\hline \multicolumn{3}{|c|}{ Well } & \multicolumn{4}{|c|}{ Pump } & \multicolumn{4}{|c|}{ Vinyi } \\
\hline \# & Name & Date & TYPE & PCE & TCE & CIS-DCE & $111-T_{i} i$ & MTBE & Acetone & Chloride Comments \\
\hline 545 & $5 P W-6 D$ & $5 / 21 / 98$ & peri & 4900 & U 100 & U 100 & U 100 & U 100 & U 500 & U 100 \\
\hline 545 & 5 PW-6D(d) & $5 / 21 / 98$ & peri & 4800 & U 100 & U 100 & U 100 & U 100 & U 500 & U 100 \\
\hline 544 & 4 PW-6M & $5 / 21 / 98$ & peri & 3300 & 1300 & 800 & U 66 & U 66 & U 330 & U 66 \\
\hline 543 & PW-6S & $5 / 21 / 98$ & peri & 1700 & 1400 & 1100 & U 50 & U 50 & U 250 & U 50 \\
\hline & (trip blank) & $7 / 21 / 98^{+}$ & NA & U2 & U 2 & U2 & U 2 & U2 & U 10 & U2 \\
\hline 407 & B95-12 & $7 / 22 / 98$ & peri & - & -- & - & - & - & - & -- \\
\hline & (trip blank) & $7 / 23 / 98^{\circ}$ & NA & U 2 & U2 & U 2 & U2 & U2 & U 10 & U2 \\
\hline 408 & B95-13 & $7 / 23 / 98$ & $\mathrm{BL}$ & 3900 & 230 & 150 & U 50 & U 50 & U 250 & U 50 \\
\hline 408 & B95-13 & $7 / 23 / 98$ & DB & 3100 & 220 & 150 & U 50 & U 50 & $\cup 250$ & U 50 \\
\hline 408 & B95-13 & $7 / 23 / 98$ & peri & 2800 & 190 & 140 & U 50 & U 50 & U 250 & U 50 \\
\hline 408 & B95-13 & $7 / 23 / 98$ & peri & 3400 & 210 & 150 & U 50 & U 50 & U 250 & U 50 \\
\hline 408 & B95-13 & $7 / 23 / 98$ & voss & 3100 & 200 & 140 & U 50 & U 50 & U 250 & U 50 \\
\hline 409 & B95-15 & $7 / 23 / 98$ & $D B$ & 1400 & 42 & 63 & $\cup 20$ & U 20 & U 100 & U 20 \\
\hline 409 & B95-15 & $7 / 23 / 98$ & peri & 1200 & 39 & 68 & U 20 & U 20 & U 100 & U 20 \\
\hline 560 & $P W-13 M$ & $7 / 23 / 98$ & peri & 400 & 25 & 40 & U 2 & U2 & U 10 & U 2 \\
\hline 559 & PW-13S & $7 / 23 / 98$ & peri & 93 & 8.4 & 29 & U2 & U2 & U 10 & U 2 \\
\hline 563 & PW-14M & $7 / 23 / 98$ & peri & 1300 & 110 & 210 & 5.5 & U 2 & U 10 & 2.8 \\
\hline 562 & PW-14S & $7 / 23 / 98$ & peri & 840 & 76 & 95 & 12 & U2 & U 10 & U2 \\
\hline 562 & PW-14S(d) & $7 / 23 / 98$ & peri & 870 & 75 & 91 & 12 & U 2 & U 10 & U2 \\
\hline 561 & PW-13D & $7 / 24 / 98$ & peri & 1000 & 54 & 85 & U2 & U 2 & U 10 & 2 \\
\hline 564 & $P W-14 D$ & $7 / 24 / 98$ & peri & 2500 & 180 & 110 & 8.4 & U2 & U 10 & U 2 \\
\hline & (eq. blank) & $9 / 30 / 98$ & $\mathrm{DB}$ & U2 & U2 & U2 & U2 & U2 & 60 & U2 \\
\hline & (trip blank) & $9 / 29 / 98$ & NA & U 2 & U2 & U2 & U2 & U2 & U 10 & U2 \\
\hline 408 & B95-13 & 9/30/98 & $\mathrm{DB}$ & 1900 & 170 & 140 & U 50 & U 50 & U 250 & U 50 \\
\hline 409 & B95-15 & 9/30/98 & DB & 2000 & 38 & 48 & U 50 & $\cup 50$ & U 250 & U 50 \\
\hline 409 & $B 95-15(d)$ & $9 / 30 / 98$ & $\mathrm{DB}$ & 1900 & U 50 & 46 & U 50 & U 50 & U 250 & U 50 \\
\hline 310 & $M W-2 A$ & $9 / 30 / 98$ & peri & U 2 & U2 & U 2 & U2 & U2 & U 10 & U2 \\
\hline 210 & $M W-2 B$ & 9/30/98 & peri & U2 & U2 & U2 & U2 & U2 & U 10 & U 2 \\
\hline 210 & $M W-2 B(d)$ & $9 / 30 / 98$ & peri & U 2 & U2 & U2 & U2 & U 2 & U 10 & U2 \\
\hline 311 & $M W-2 R$ & $9 / 30 / 98$ & peri & 26 & 5.9 & U 2 & U 2 & U 2 & U 10 & U2 \\
\hline & (trip blank) & $10 / 20 / 98$ & NA & U 0.5 & บ 0.5 & บ 0.5 & U 0.5 & บ 0.5 & U 10 & บ 0.5 \\
\hline & (trip blank) & $11 / 23 / 98$ & NA & U 2 & U 2 & U 2 & U2 & U 2 & U 10 & U 2 \\
\hline 408 & B95-13 & $11 / 23 / 98$ & $\mathrm{DB}$ & 1900 & 170 & 140 & U 40 & U 40 & U 200 & $\cup 40$ \\
\hline 409 & B95-15 & $11 / 23 / 98$ & $\mathrm{DB}$ & 480 & 29 & 37 & U 20 & $\cup 20$ & U 100 & $\cup 20$ \\
\hline 560 & PW-13M & $11 / 23 / 98$ & $\mathrm{DB}$ & 630 & 30 & 43 & U 10 & U 10 & U 50 & U 10 \\
\hline 560 & $P W-13 M$ & $11 / 23 / 98$ & peri & 490 & 26 & 39 & $\cup 10$ & U 10 & U 50 & U 10 \\
\hline 564 & PW-14D & $11 / 23 / 98$ & peri & 1900 & 150 & 130 & U 40 & U 40 & U 200 & U 40 \\
\hline 563 & $P W-14 M$ & $11 / 23 / 98$ & $\mathrm{DB}$ & 1400 & 92 & 190 & U 40 & U 40 & U 200 & U 40 \\
\hline 563 & PW-14M & $11 / 23 / 98$ & peri & 1200 & 93 & 200 & U 40 & บ 40 & U 200 & U 40 \\
\hline 562 & PW-14S & $11 / 23 / 98$ & peri & 990 & 82 & 120 & U 20 & U 20 & U 100 & U 20 \\
\hline 408 & B95-13 & $11 / 24 / 98$ & peri & 2100 & 130 & 140 & U 40 & U 40 & U 200 & $\cup 40$ \\
\hline 409 & B95-15 & $11 / 24 / 98$ & peri & 350 & 26 & 36 & U 20 & U 20 & U 100 & U 20 \\
\hline 561 & $P W-13 D$ & $11 / 24 / 98$ & peri & 1100 & 63 & 100 & U 20 & U 20 & U 100 & U 20 \\
\hline 559 & PW-13S & $11 / 24 / 98$ & peri & 94 & 9.6 & 25 & U2 & U2 & U 10 & U 2 \\
\hline 557 & $P W-12 D$ & $11 / 25 / 98$ & peri & 700 & 43 & 56 & U 2 & U2 & U 10 & U 2 \\
\hline 556 & $P W-12 M$ & $11 / 25 / 98$ & peri & 700 & 41 & 57 & U2 & U2 & U 10 & U2 \\
\hline 558 & $P W-12 R$ & $11 / 25 / 98$ & peri & 870 & 340 & 120 & U2 & U2 & U 10 & U2 \\
\hline 555 & $P W-12 S$ & $11 / 25 / 98$ & peri & 9.7 & 2.4 & 4.1 & U 2 & U 2 & U 10 & U 2 \\
\hline
\end{tabular}




\begin{tabular}{|c|c|c|c|c|c|c|c|c|c|c|c|}
\hline \multicolumn{12}{|c|}{ Appendix 2c. Major detected volatile organic compounds (VOCs), May 1997 to September 1999, Milford, New Hampshire. } \\
\hline Well & & & Pump & & & & & & & Vinyl & \\
\hline \# & Name & Date & TYPE & PCE & TCE & CIS-DCE & $111-\mathrm{Tr}_{\mathrm{i}}$ & MTBE & Acetone & Chloride & Comments \\
\hline & (trip blank) & $11 / 30 / 98$ & NA & $\cup 2$ & U2 & U2 & U2 & U2 & U 10 & $\cup 2$ & \\
\hline 233 & $3 \mathrm{MW}-16 \mathrm{~A}$ & $11 / 30 / 98$ & peri & 59 & U2 & U2 & U2 & 4 & U 10 & U2 & \\
\hline 321 & $M W-16 B$ & $11 / 30 / 98$ & peri & 310 & 12 & U 10 & U 10 & $\cup 10$ & U 50 & U10 & \\
\hline 344 & $4 \mathrm{MW}-16 \mathrm{C}$ & $11 / 30 / 98$ & peri & 1600 & 130 & 85 & 23 & U 20 & U 100 & U 20 & \\
\hline 345 & $5 \mathrm{MW}-16 \mathrm{R}$ & $11 / 30 / 98$ & peri & 300 & 34 & 44 & U 10 & U 10 & U 50 & $\cup 10$ & \\
\hline & (trip blank) & $12 / 1 / 98$ & NA & U2 & U2 & U2 & U2 & U2 & U 10 & U2 & \\
\hline 531 & PW-ID & $12 / 1 / 98$ & peri & 2400 & 160 & 110 & $\cup 40$ & $\cup 40$ & U 200 & U 40 & \\
\hline 530 & PW-1S & $12 / 1 / 98$ & peri & 3000 & 170 & 190 & $\cup 40$ & U 40 & U 200 & U 40 & \\
\hline 407 & B95-12 & $12 / 2 / 98$ & peri & U2 & U2 & U2 & $\cup 2$ & 3.2 & U 10 & U 2 & \\
\hline 400 & B95-5 & $12 / 2 / 98$ & peri & U2 & U2 & U2 & U2 & U2 & U 10 & U2 & \\
\hline 401 & B95-6 & $12 / 2 / 98$ & peri & U2 & U2 & U 2 & U 2 & U2 & $\cup 10$ & U2 & \\
\hline 235 & $\mathrm{MW}-27$ & $12 / 2 / 98$ & peri & $\cup 2$ & $\cup 2$ & U2 & U2 & U2 & U 10 & U2 & \\
\hline 235 & $M W-27$ (d) & $12 / 2 / 98$ & peri & U2 & U2 & U2 & U2 & U 2 & U 10 & U2 & \\
\hline & (trip blank) & $12 / 3 / 98$ & NA & U2 & U2 & U2 & U2 & U2 & U 10 & U2 & \\
\hline 398 & B95-3 & $12 / 3 / 98$ & peri & 2.1 & $\cup 2$ & $\cup 2$ & U2 & U2 & U 10 & U2 & \\
\hline 404 & B95-9 & $12 / 3 / 98$ & peri & 610 & U 6.6 & U 6.6 & U 6.6 & U 6.6 & U 33.3 & U 6.6 & \\
\hline 554 & PW-11D & $12 / 3 / 98$ & peri & 1200 & 44 & $\cup 20$ & U 20 & $\cup 20$ & U 100 & U 20 & \\
\hline 553 & PW-11M & $12 / 3 / 98$ & peri & 45 & 13 & 26 & U2 & U2 & U 10 & $\cup 2$ & \\
\hline 537 & PW-3D & $12 / 3 / 98$ & peri & $\cup 2$ & U2 & U 2 & U2 & U2 & U 10 & U2 & \\
\hline 536 & $P W-3 S$ & $12 / 3 / 98$ & peri & 2.1 & U2 & $\cup 2$ & U2 & U 2 & U 10 & U2 & \\
\hline 46 & Ml-32 & $12 / 4 / 98$ & peri & 700 & 38 & 19 & 17 & U 10 & U 50 & U 10 & \\
\hline 534 & PW-2D & $12 / 4 / 98$ & peri & 1700 & 170 & 91 & 20 & U 20 & U 100 & U 20 & \\
\hline 533 & PW-2M & $12 / 4 / 98$ & peri & 1600 & 130 & 68 & 23 & U 20 & U 100 & U 20 & \\
\hline 535 & $P W-2 R$ & $12 / 4 / 98$ & peri & 20 & 3.6 & U 2 & U 2 & U 2 & U 10 & U 2 & 27 THF, 5.1 Carbon disulfide \\
\hline 532 & PW-2S & $12 / 4 / 98$ & peri & 1400 & 140 & 110 & 65 & U 20 & U 100 & U 20 & \\
\hline & (trip blank) & $12 / 7 / 98$ & NA & U 2 & U 2 & U 2 & U 2 & U 2 & U 10 & U 2 & \\
\hline 403 & B95-8 & $12 / 7 / 98$ & peri & 65 & U2 & U2 & U2 & 5.2 & U 10 & $\cup 2$ & \\
\hline 552 & PW-10D & $12 / 7 / 98$ & peri & 6300 & U 100 & U 100 & U 100 & U 100 & U 500 & U 100 & \\
\hline 551 & PW-10M & $12 / 7 / 98$ & peri & 140 & 32 & 110 & U2 & U 2 & U 10 & 3.3 & \\
\hline 539 & PW-4D & $12 / 7 / 98$ & peri & 38 & 5.9 & U 2 & U2 & 4.2 & U 10 & U 2 & \\
\hline 538 & PW-4M & $12 / 7 / 98$ & peri & 2.1 & $\cup 2$ & U2 & U2 & U2 & U 10 & $\cup 2$ & . \\
\hline 538 & PW-4M (d) & $12 / 7 / 98$ & peri & $\cup 2$ & U2 & U 2 & U2 & U2 & U 10 & U 2 & \\
\hline 541 & PW-5D & $12 / 7 / 98$ & peri & 1500 & 190 & 100 & U 20 & U 20 & U 100 & U 20 & \\
\hline & (trip blank) & $12 / 8 / 98$ & NA & U 2 & U 2 & U2 & U 2 & U 2 & U 10 & U2 & + \\
\hline & (trip blank) & $12 / 8 / 98$ & NA & U2 & U2 & U2 & U2 & U2 & U 10 & U2 & \\
\hline 540 & PW-5M & $12 / 8 / 98$ & peri & 1400 & 160 & 120 & 57 & U 20 & U 100 & $\cup 20$ & \\
\hline 542 & PW-5R & $12 / 8 / 98$ & peri & 95 & 14 & 9.6 & 4.5 & U 2 & 28 & U2 & 2.9 Toluene \\
\hline 385 & P-2,river & $12 / 9 / 98$ & GRAB & - & - & - & - & - & - & - & \\
\hline 548 & PW-7M & $12 / 9 / 98$ & peri & 12 & 2.3 & U2 & $\cup 2$ & U2 & U 10 & U 2 & \\
\hline 547 & PW-7S & $12 / 9 / 98$ & peri & 40 & 2.5 & U2 & U2 & U2 & U 10 & U2 & \\
\hline 545 & PW-6D & $12 / 10 / 98$ & peri & 610 & U 10 & U 10 & U 10 & U 10 & U 50 & U 10 & \\
\hline 544 & PW-6M & $12 / 10 / 98$ & peri & 3600 & 1300 & 650 & U 40 & U 40 & U 200 & U 40 & \\
\hline 546 & PW-6R & $12 / 10 / 98$ & peri & 940 & 43 & U 20 & $\cup 20$ & U 20 & U 100 & $\cup 20$ & \\
\hline 543 & PW-6S & $12 / 10 / 98$ & peri & 3100 & 1600 & 850 & $\cup 40$ & U 40 & U 200 & U 40 & \\
\hline & (DB blank) & $2 / 8 / 99$ & DB & U2 & U 2 & U 2 & U2 & U 2 & 52 & U 2 & \\
\hline & (trip blank) & $2 / 8 / 99$ & NA & U 2 & U2 & $\cup 2$ & U2 & $\cup 2$ & U 10 & U2 & \\
\hline 408 & B95-13 & $2 / 8 / 99$ & DB & 1400 & 130 & 170 & U 25 & U 25 & U 125 & $\cup 25$ & \\
\hline 408 & B95-13 & $2 / 8 / 99$ & peri & 1500 & 97 & 180 & $\cup 40$ & U 40 & U 200 & U 40 & \\
\hline
\end{tabular}




\begin{tabular}{|c|c|c|c|c|c|c|c|c|c|c|c|}
\hline \multicolumn{12}{|c|}{ Appendix 2c. Major detected volatile organic compounds (VOCs), May 1997 to September 1999. Milford. New Hampshire. } \\
\hline Well & & & Pump & & & & & & & Vinyl & \\
\hline \# & Name & Date & TYPE & PCE & TCE & CIS-DCE & $111-\mathrm{Tri}$ & MTBE & Acetone & Chloride & Comments \\
\hline 408 & B95-13 (d) & $2 / 8 / 99$ & peri & 1600 & 100 & 190 & U 40 & U 40 & U 200 & U 40 & \\
\hline 409 & B95-15 & $2 / 8 / 99$ & DB & 350 & 26 & 22 & U 4 & U4 & U 20 & $\cup 4$ & \\
\hline 409 & B95-15 & $2 / 8 / 99$ & peri & 310 & 27 & 22 & U4 & U 4 & U 20 & U4 & \\
\hline 560 & PW-13M & $2 / 8 / 99$ & $\mathrm{DB}$ & 140 & 10 & 12 & U 2 & U2 & U 10 & U 2 & \\
\hline 560 & PW-13M & $2 / 8 / 99$ & peri & 120 & 9.4 & 13 & U2 & U2 & U 10 & U 2 & 2.7. carbon disulfide \\
\hline 563 & PW-14M & $2 / 8 / 99$ & DB & 1200 & 96 & 190 & $\cup 20$ & U 20 & U 100 & $\cup 20$ & \\
\hline 563 & PW-14M(d) & $2 / 8 / 99$ & DB & 1200 & 91 & 180 & $\cup 20$ & $\cup 20$ & U 100 & $\cup 20$ & \\
\hline 565 & EW-1 & $3 / 1 / 99$ & NA & 2500 & 160 & U 100 & U 100 & U 100 & U 500 & U 100 & \\
\hline 566 & EW-2 & $3 / 1 / 99$ & NA & 10 & U2 & U 2 & U2 & U2 & 34 & U 2 & \\
\hline 566 & EW-2dup & $3 / 1 / 99$ & NA & 11 & U 2 & U 2 & U 2 & U2 & 44 & U2 & \\
\hline 0 & Trip blank & $3 / 1 / 99$ & NA & U2 & U2 & U2 & U 2 & U2 & U 10 & U2 & \\
\hline 563 & PW-14M & $4 / 7 / 99$ & peri & 760 & 92 & 160 & 12 & U 10 & U 50 & U 10 & \\
\hline 564 & PW-14D & $4 / 7 / 99$ & peri & 2300 & 220 & 120 & $\cup 40$ & $\cup 40$ & U 200 & U 40 & \\
\hline 409 & B95-15 & $4 / 7 / 99$ & $\mathrm{DB}$ & 210 & 28 & 22 & U 4 & U 4 & U 20 & U4 & \\
\hline 556 & $P W-12 M$ & $4 / 7 / 99$ & DB & 440 & 62 & 30 & U 10 & U 10 & U 10 & U 10 & \\
\hline 560 & $P W-13 M$ & $4 / 7 / 99$ & DB & 270 & 23 & 25 & U4 & U 4 & U 20 & U 4 & \\
\hline 0 & trip blank & $4 / 7 / 99$ & NA & U2 & U2 & U2 & U2 & U2 & U 10 & U2 & \\
\hline 563 & $P W-14 M$ & 4/7/99. & DB & 1100 & 110 & 190 & U 20 & U 20 & U 100 & U 20 & \\
\hline 408 & B95-13 & $4 / 7 / 99$ & $\mathrm{DB}$ & 950 & 200 & 160 & U 20 & U 20 & U 100 & $\cup 20$ & \\
\hline 562 & PW-14S & $4 / 7 / 99$ & peri & 620 & 61 & 82 & U 20 & U 20 & U 100 & $\cup 20$ & \\
\hline 558 & $P W-12 R$ & $4 / 8 / 99$ & peri & 530 & 380 & 130 & U 10 & U 10 & U 50 & U 10 & \\
\hline 555 & $P W-12 S$ & $4 / 8 / 99$ & peri & U2 & U 2 & U2 & U 2 & U 2 & $\cup 10$ & U2 & \\
\hline 559 & PW-13S & $4 / 8 / 99$ & peri & 70 & 9.8 & 24 & U2 & U2 & U 10 & U 2 & \\
\hline 561 & PW-13D & $4 / 8 / 99$ & peri & 760 & 55 & 92 & U 20 & U 20 & U 100 & U 20 & \\
\hline 557 & $P W-12 D$ & $4 / 8 / 99$ & peri & 550 & 33 & 28 & U 10 & U 10 & U 50 & U 10 & \\
\hline 0 & trip blank & $4 / 8 / 99$ & NA & U 2 & U 2 & U2 & U 2 & U 2 & U 10 & U 2 & \\
\hline 556 & $P W-12 M$ & $4 / 8 / 99$ & peri & 530 & 42 & 46 & 27 & U 10 & U 50 & U 10 & \\
\hline 560 & PW-13M & $4 / 8 / 99$ & peri & 240 & 18 & 25 & U4 & U4 & U 20 & U 4 & \\
\hline 409 & B95-15 & $4 / 8 / 99$ & peri & 91 & 14 & 22 & U2 & U 2 & U 10 & U 2 & \\
\hline 530 . & PW-1S & $4 / 9 / 99$ & peri & 1200 & 87 & 200 & $\cup 40$ & $\cup 40$ & U 200 & $\cup 40$ & \\
\hline 531 & PW-1D & $4 / 9 / 99$ & peri & 940 & 80 & 65 & U 40 & $\cup 40$ & U 200 & U 40 & \\
\hline 0 & trip blank & $4 / 12 / 99$ & NA & U2 & U 2 & U2 & U2 & U2 & U 10 & U 2 & \\
\hline 233 & MW-16A & $4 / 13 / 99$ & peri & 64 & U 2 & U2 & $\cup 2$ & 2.8 & U 10 & U2 & \\
\hline 321 & $M W-16 B$ & $4 / 13 / 99$ & peri & 280 & 15 & 8.7 & 7.2 & U 4 & U 20 & U 4 & \\
\hline 321 & $M W-16 B(d)$ & $4 / 13 / 99$ & peri & 260 & 15 & 8.6 & U4 & U4 & U 20 & U4 & \\
\hline 344 & $M W-16 C$ & $4 / 13 / 99$ & peri & 1100 & 110 & 81 & $\cup 20$ & U 20 & U 100 & U 20 & \\
\hline 407 & B95-12 & $4 / 13 / 99$ & peri & U 2 & U 2 & U2 & U 2 & 3.7 & U 10 & U2 & \\
\hline 532 & PW-2S & $4 / 14 / 99$ & peri & 530 & 73 & 63 & 27 & U 20 & U 100 & U 20 & \\
\hline 533 & $P W-2 M$ & $4 / 14 / 99$ & peri & 950 & 110 & 89 & 26 & U 20 & U 100 & U 20 & \\
\hline 534 & $P W-2 D$ & $4 / 14 / 99$ & peri & 1000 & 140 & 88 & $\cup 20$ & U 20 & U 100 & U 20 & \\
\hline 536 & PW-3S & $4 / 14 / 99$ & peri & 2 & U 2 & U2 & U 2 & U2 & U 10 & U 2 & \\
\hline 537 & PW-3D & $4 / 14 / 99$ & peri & U 2 & U 2 & U2 & U 2 & U2 & U 10 & U2 & \\
\hline 0 & trip blank & 4/14/99 & NA & U 2 & U 2 & U 2 & U 2 & U 2 & U 10 & U 2 & \\
\hline 408 & B95-13 & $4 / 14 / 99$ & peri & 1400 & 110 & 180 & U 20 & U 20 & U 100 & U 20 & (split with p.48f) \\
\hline 408 & B95-13 & $4 / 14 / 99$ & $\mathrm{BL}$ & 1700 & 120 & 190 & U 50 & U 50 & U 250 & U 50 & (split with b.45f) \\
\hline 408 & B95-13 & $4 / 14 / 99$ & peri & 1685 & 100 & - & - & - & - & - & name $=p .25 f$ \\
\hline 408 & B95-13 & $4 / 14 / 99$ & peri & 1717 & 96 & - & - & - & - & - & name $=p .48 f$ \\
\hline 408 & B95-13 & $4 / 14 / 99$ & $\mathrm{BL}$ & 2010 & 101 & - & - & - & - & - & name $=b .45 \mathrm{f}$ \\
\hline
\end{tabular}




\begin{tabular}{|c|c|c|c|c|c|c|c|c|c|c|c|}
\hline \multicolumn{12}{|c|}{ Appendix 2c. Major detected volatile organic compounds (VOCs), May 1997 to September 1999, Milford, New Hampshire. } \\
\hline Well & \multirow{2}{*}{ Name } & \multirow[b]{2}{*}{ Date } & \multicolumn{2}{|c|}{ Pump } & \multirow[b]{2}{*}{ TCE } & \multirow[b]{2}{*}{ CIS-DCE } & \multirow[b]{2}{*}{$111-\operatorname{Tri}$} & \multirow[b]{2}{*}{ MTBE } & \multirow[b]{2}{*}{ Acetone } & \multirow{2}{*}{$\begin{array}{c}\text { Vinyl } \\
\text { Chloride }\end{array}$} & \multirow{2}{*}{ Comments } \\
\hline \# & & & TYPE & PCE & & & & & & & \\
\hline 408 & B95-13 & $4 / 14 / 99$ & $\mathrm{BL}$ & 2006 & 99 & - & - & - & - & - & name $=b .97 f$ \\
\hline 408 & $895-13$ & $4 / 14 / 99$ & peri & 1877 & 113 & - & - & - & - & - & name $=p .1+$ \\
\hline 408 & B95-13 & $4 / 14 / 99$ & $B L$ & 2032 & 118 & - & - & - & - & - & name = b. $1+$ \\
\hline 408 & 3 B95-13 & $4 / 14 / 99$ & $\mathrm{BL}$ & 1738 & 105 & - & - & - & - & - & name $=b .5 r 2$ \\
\hline 408 & B95-13 & $4 / 14 / 99$ & peri & 1841 & 98 & - & - & - & - & - & name $=p .49 r 2$ \\
\hline 408 & B95-13 & $4 / 14 / 99$ & peri & 1783 & 104 & - & - & - & - & - & name $=p .33 r$ \\
\hline 408 & B95-13(d) & $4 / 14 / 99$ & peri & 1945 & 101 & - & - & - & - & - & (duplicate with p.25f) \\
\hline 408 & B95-13(d) & $4 / 14 / 99$ & peri & 1963 & 103 & - & - & - & - & - & (duplicate with p.48f) \\
\hline 408 & $B 95-13(d)$ & $4 / 14 / 99$ & $\mathrm{BL}$ & 2052 & 116 & - & - & - & -- & - & (duplicate with b.45f) \\
\hline 408 & $B 95-13(d)$ & $4 / 14 / 99$ & peri & 2010 & 99 & - & - & - & - & - & (duplicate with p.49r2) \\
\hline 547 & PW-7S & $4 / 15 / 99$ & peri & 8.5 & U 2 & U 2 & U 2 & U 2 & U 10 & U 2 & \\
\hline 554 & PW-11D & $4 / 15 / 99$ & peri & 330 & 41 & 20 & U 20 & U 20 & U 100 & U 20 & \\
\hline 553 & PW-11M & $4 / 15 / 99$ & peri & 8.6 & 3.2 & 3.8 & U 2 & U 2 & U 10 & U 2 & \\
\hline 548 & PW-7M & $4 / 15 / 99$ & peri & 5.8 & U 2 & U 2 & U2 & U 2 & U 10 & U 2 & \\
\hline 0 & equip blank & $4 / 15 / 99$ & NA & U2 & U 2 & U 2 & U2 & U2 & 25 & U2 & \\
\hline 0 & trip blank & $4 / 19 / 99$ & NA & U 2 & U 2 & U2 & U2 & U 2 & U 10 & U 2 & \\
\hline 540 & PW-5M & $4 / 19 / 99$ & peri & 520 & 98 & 150 & 21 & U 10 & U 50 & U 10 & \\
\hline 541 & PW-5D & $4 / 19 / 99$ & peri & 770 & 100 & 97 & U 20 & U 20 & U 100 & U 20 & \\
\hline 551 & PW-10M & $4 / 19 / 99$ & peri & 66 & 22 & 82 & U 2 & U2 & U 10 & 2.3 & \\
\hline 552 & PW-10D & $4 / 19 / 99$ & peri & 1800 & 62 & 45 & $\cup 40$ & U 40 & U 200 & $\cup 40$ & \\
\hline 385 & P-2, River & $4 / 19 / 99$ & GRAB & - & - & - & -- & - & - & - & \\
\hline 46 & MI-32 & $4 / 20 / 99$ & peri & 550 & 41 & 29 & 21 & U 10 & U 50 & U 10 & \\
\hline 398 & B95-3 & $4 / 20 / 99$ & peri & 20 & 7.2 & 6 & U 2 & U 2 & U 10 & U 2 & \\
\hline 549 & PW-8M & $4 / 20 / 99$ & peri & 540 & 12 & U 10 & U 10 & U 10 & U 50 & U 10 & \\
\hline 550 & PW-9M & $4 / 20 / 99$ & peri & 2.9 & U 2 & U 2 & U 2 & U 2 & U 10 & U 2 & \\
\hline 550 & PW-9M(d) & $4 / 20 / 99$ & peri & 2.6 & U 2 & U 2 & U2 & U 2 & U 10 & U 2 & \\
\hline 408 & B95-13 & $4 / 20 / 99$ & $B L$ & 1608 & 86 & - & - & - & - & - & \\
\hline 408 & B95-13 & $4 / 20 / 99$ & $\mathrm{BL}$ & 1702 & 91 & - & - & - & - & - & \\
\hline 408 & B95-13 & $4 / 20 / 99$ & $B L$ & 1750 & 92 & - & - & - & - & - & \\
\hline 408 & B95-13 & $4 / 20 / 99$ & $B L$ & 1674 & 89 & - & - & - & - & - & \\
\hline 0 & trip blank & $4 / 21 / 99$ & NA & U 2 & U2 & U2 & U 2 & U 2 & U 10 & U 2 & \\
\hline 235 & $M W-27$ & $4 / 21 / 99$ & peri & U 2 & U2 & U 2 & U 2 & U 2 & U 10 & U 2 & \\
\hline 400 & B95-5 & $4 / 21 / 99$ & peri & U 2 & U2 & U 2 & U2 & U 2 & U 10 & U 2 & \\
\hline 401 & B95-6 & $4 / 21 / 99$ & peri & U 2 & U 2 & U 2 & U 2 & U 2 & U 10 & U 2 & \\
\hline 543 & PW-6S & $4 / 21 / 99$ & peri & 4000 & 2000 & 1400 & U 50 & U 50 & U 250 & U 50 & \\
\hline 544 & PW-6M & $4 / 21 / 99$ & peri & 2300 & 390 & 240 & U 50 & U 50 & U 250 & U 50 & \\
\hline 545 & PW-6D & $4 / 21 / 99$ & peri & 3600 & U 100 & U 100 & U 100 & U 100 & U 500 & U. 100 & \\
\hline 385 & P2-RIVER & $4 / 21 / 99$ & GRAB & U 0.2 & U 0.2 & U 0.2 & U 0.2 & U 0.2 & U 1 & U 0.2 & \\
\hline 403 & B95-8 & $4 / 22 / 99$ & peri & 79 & 3.6 & U 2 & U 2 & 7 & U 10 & U 2 & \\
\hline 404 & B95-9 & $4 / 22 / 99$ & peri & 440 & U 10 & U 10 & U 10 & U 10 & U 50 & U 10 & \\
\hline 538 & PW-4M & $4 / 22 / 99$ & peri & U 2 & U 2 & U 2 & U 2 & U2 & U 10 & U 2 & \\
\hline 539 & $P W-4 D$ & $4 / 22 / 99$ & peri & U 2 & U2 & U 2 & U 2 & 6.1 & U 10 & U2 & \\
\hline 01 & trip blank & $5 / 12 / 99$ & NA & U 2 & U2 & U 2 & U2 & U 2 & U 10 & U2 & \\
\hline 559 & PW-13S & $5 / 13 / 99$ & peri & 78 & 8.4 & 27 & U 2 & U 2 & U 10 & U2 & \\
\hline 01 & lab blank & $5 / 13 / 99$ & NA & U 2 & U 2 & U2 & U2 & U 2 & U 10 & U2 & \\
\hline 0 & equip blank & $5 / 13 / 99$ & NA & U2 & $\cup 2$ & U 2 & U2 & U 2 & U 10 & U 2 & \\
\hline 562 & PW-14S & $5 / 13 / 99$ & peri & 890 & 73 & 130 & U 20 & U 20 & U 100 & U 20 & \\
\hline 562 & PW-14S & $5 / 13 / 99$ & DB & 790 & 69 & 120 & U 20 & U 20 & U 100 & $\cup 20$ & \\
\hline
\end{tabular}




\begin{tabular}{|c|c|c|c|c|c|c|c|c|c|c|c|}
\hline \multicolumn{12}{|c|}{ Appendix 2c. Major detected volatile organic compounds (VOCs), May 1997 to September 1999, Milford, New Hampshire. } \\
\hline \multirow{2}{*}{$\begin{array}{l}\text { Well } \\
\#\end{array}$} & \multirow{2}{*}{ Name } & \multirow[b]{2}{*}{ Date } & \multicolumn{3}{|c|}{ Pump } & \multirow[b]{2}{*}{ CIS-DCE } & \multirow[b]{2}{*}{ 111-Tri } & \multirow[b]{2}{*}{ MTBE } & \multicolumn{3}{|c|}{ Vinyl } \\
\hline & & & TYPE & PCE & TCE & & & & Acetone & Chloride & Comments \\
\hline 563 & PW-14M & $5 / 13 / 99$ & $\mathrm{DB}$ & 1400 & 110 & 250 & U 20 & U 20 & U 100 & U 20 & \\
\hline 564 & PW-14D & $5 / 13 / 99$ & DB & 2800 & 200 & 150 & $\cup 40$ & U 40 & U 200 & U 40 & \\
\hline 555 & $P W-12 S$ & $5 / 13 / 99$ & DB & 36 & 3.9 & 8.7 & U2 & U2 & U 10 & U2 & \\
\hline 556 & $P W-12 M$ & $5 / 13 / 99$ & DB & 630 & 170 & 69 & $\cup 10$ & $\cup 10$ & U 50 & U 10 & \\
\hline 557 & $P W-12 D$ & $5 / 13 / 99$ & DB & 660 & 35 & 30 & $\cup 10$ & U 10 & U 50 & U 10 & \\
\hline 558 & $P W-12 R$ & $5 / 13 / 99$ & DB & 260 & 480 & 350 & U 20 & $\cup 20$ & U 100 & U 20 & \\
\hline 321 & $M W-16 B$ & $5 / 13 / 99$ & DB & 400 & 19 & 11 & U 5 & U5 & U 25 & U 5 & \\
\hline 344 & $M W-16 C$ & $5 / 13 / 99$ & DB & 1300 & 110 & 97 & 22 & U 20 & U 100 & U 20 & \\
\hline 345 & $M W-16 R$ & $5 / 13 / 99$ & DB & 470 & 61 & 56 & U 5 & U 5 & U 25 & U5 & \\
\hline 546 & PW-6R & $5 / 13 / 99$ & DB & 1200 & 62 & 30 & U 20 & U 20 & U 100 & U 20 & \\
\hline 535 & PW-2R & $5 / 13 / 99$ & DB & 29 & 4.4 & U2 & U2 & U2 & 410 & $\mathrm{U}_{2}$ & 15.THF \\
\hline 542 & $P W-5 R$ & $5 / 13 / 99$ & DB & 170 & 21 & 15 & 6.5 & U2 & U 10 & U2 & 3.9. Toluene \\
\hline 409 & B95-15 & $5 / 13 / 99$ & DB & 160 & 19 & 26 & U 3.34 & U 3.34 & U 16.7 & U 3.34 & \\
\hline 559 & PW-13S & $5 / 13 / 99$ & DB & 120 & U 20 & 31 & U 20 & U 20 & U 100 & U 20 & \\
\hline 560 & PW-13M & $5 / 13 / 99$ & DB & 320 & 22 & 40 & $\cup 10$ & U 10 & U 50 & U 10 & \\
\hline 561 & PW-13D & $5 / 13 / 99$ & DB & 720 & 54 & 96 & U 20 & U 20 & U 100 & U 20 & \\
\hline 408 & $895-13$ & $5 / 13 / 99$ & DB & 1700 & 97 & 190 & U 20 & $\cup 20$ & U 100 & U 20 & \\
\hline 409 & B95-15 & $6 / 10 / 99$ & peri & 93 & 13 & 14 & U 2 & U 2 & U 10 & U2 & \\
\hline & trip blank & $6 / 10 / 99$ & NA & U2 & U2 & U2 & U2 & U2 & $\cup 10$ & U 2 & \\
\hline 558 & $P W-12 R$ & $6 / 10 / 99$ & DB & 330 & 680 & 210 & U 10 & U 10 & U 50 & U 10 & \\
\hline 555 & $P W-12 S$ & $6 / 10 / 99$ & DB & 3.3 & U 2 & U 2 & U 2 & U 2 & U 10 & U 2 & \\
\hline 556 & $P W-12 M$ & $6 / 10 / 99$ & DB & 490 & 78 & 41 & U 10 & U 10 & U 50 & U 10 & \\
\hline 557 & $P W-12 D$ & $6 / 10 / 99$ & DB & 510 & 36 & 35 & U 10 & U 10 & U 50 & U 10 & \\
\hline 409 . & B95-15 & $6 / 10 / 99$ & DB & 110 & 17 & 21 & U5 & U5 & U 25 & U5 & \\
\hline & equip blank & $6 / 10 / 99$ & DB & U2 & U2 & U2 & U2 & U2 & U 10 & U2 & \\
\hline & lab blank & $6 / 10 / 99$ & DB & U2 & U 2 & U 2 & U2 & U2 & U 10 & U2 & \\
\hline 561 & PW-13D & $6 / 10 / 99$ & DB & 810 & 92 & 110 & U 20 & U 20 & U 100 & U 20 & \\
\hline 559 & PW-13S & $6 / 10 / 99$ & DB & 88 & 9.9 & 28 & U 2 & U2 & U 10 & U2 & \\
\hline 560 & PW-13M & $6 / 10 / 99$ & DB & 170 & 13 & 20 & U4 & U 4 & U 20 & U 4 & \\
\hline 564 & $P W-14 D$ & $6 / 10 / 99$ & DB & 2900 & 240 & 170 & $\cup 40$ & $\cup 40$ & U 200 & U 40 & \\
\hline 563 & PW-14M & $6 / 10 / 99$ & DB & 1400 & 130 & 300 & U 20 & U 20 & U 100 & $\cup 20$ & 21. methylene chloride \\
\hline 562 & $P W-14 S$ & $6 / 10 / 99$ & DB & 610 & 58 & 99 & 8.1 & U 6.66 & U 33.33 & U 6.66 & \\
\hline 345 & $M W-16 R$ & $6 / 10 / 99$ & DB & 330 & 55 & 51 & U 3.34 & U 3.34 & U 16.67 & U 3.34 & \\
\hline 344 & $M W-16 C$ & $6 / 10 / 99$ & DB & 1000 & 78 & 63 & U20 & U 20 & U 100 & U 20 & \\
\hline 321 & $M W-16 B$ & $6 / 10 / 99$ & DB & 330 & 16 & 8.8 & U4 & U 4 & U 20 & U4 & \\
\hline 408 & B95-13 & $6 / 10 / 99$ & DB & 1400 & 92 & 180 & U 20 & U 20 & U 100 & U 20 & 21. methylene chloride \\
\hline 546 & $P W-6 R$ & $6 / 10 / 99$ & DB & 1600 & 64 & U 20 & U 20 & U 20 & U 100 & U 20 & \\
\hline 542 & $P W-5 R$ & $6 / 10 / 99$ & DB & 170 & 24 & 16 & 7 & U 2 & U 10 & U2 & 2.1.Xylene: 4.3.Toluene \\
\hline 535 & $P W-2 R$ & $6 / 10 / 99$ & $\mathrm{DB}$ & 28 & 5.1 & U2 & U2 & U2 & U 10 & U2 & 11, THF \\
\hline 408 & B95-13 & $6 / 10 / 99$ & peri & 1200 & 85 & 170 & U 20 & U 20 & U 100 & $\cup 20$ & \\
\hline & trip blank & $7 / 14 / 99$ & NA & U2 & U2 & U2 & U2 & U 2 & U 10 & U2 & \\
\hline & lab blank & $7 / 15 / 99$ & NA & U2 & U2 & U2 & U2 & U2 & U 10 & U2 & \\
\hline 555 & $P W-12 S$ & $7 / 16 / 99$ & DB & 170 & U2 & U2 & U2 & U2 & U 10 & U 2 & \\
\hline 556 & $P W-12 M$ & $7 / 16 / 99$ & DB & 190 & 71 & 93 & U 10 & $\cup 10$ & U 50 & U 10 & \\
\hline 557 & $P W-12 D$ & $7 / 16 / 99$ & DB & 480 & 32 & 28 & U 10 & U 10 & U 50 & U 10 & \\
\hline 558 & $P W-12 R$ & $7 / 16 / 99$ & DB & 280 & 560 & 280 & U 10 & U 10 & U 50 & U 10 & \\
\hline 409 & B95-15 & $7 / 16 / 99$ & DB & 89 & 14 & 14 & U2 & U2 & U 10 & U2 & \\
\hline 565 & EW-1 & $7 / 16 / 99$ & NA & 880 & 59 & 75 & U 20 & $\cup 20$ & $\cup 100$ & $\cup 20$ & \\
\hline
\end{tabular}




\begin{tabular}{|c|c|c|c|c|c|c|c|c|c|c|c|}
\hline Appe & endix 2c. Maj & jor detectec & d volati & organ & compc & unds VOC & 5), May 1 & 997 to $S e$ & ptember I & 999, Milfor & ord. New Hampshire. \\
\hline Well & & & Pump & & & & & & & Vinyl & \\
\hline \# & Name & Date & TYPE & PCE & TCE & CIS-DCE & 111-Tri & MTBE & Acetone & Chloride & Comments \\
\hline 566 & EW-2 & $7 / 16 / 99$ & NA & 520 & 89 & 54 & 8.7 & U 6.67 & U 33.33 & U 6.67 & \\
\hline 0 & equip blank & $7 / 16 / 99$ & NA & U2 & U2 & U2 & U2 & U2 & U 10 & U 2 & \\
\hline 408 & B95-13 & $7 / 16 / 99$ & DB & 850 & 51 & 110 & U 20 & U 20 & U 100 & U 20 & \\
\hline 321 & $M W-16 B$ & $7 / 16 / 99$ & DB & 260 & 10 & 5.2 & U 5 & U5 & U 25 & U 5 & \\
\hline 321 & MW-16B & $7 / 16 / 99$ & peri & 210 & 8.5 & 4.2 & U 4 & $\cup 4$ & $\cup 20$ & U 4 & \\
\hline 344 & $M W-16 C$ & $7 / 16 / 99$ & DB & 880 & 60 & 43 & U 20 & U 20 & U 100 & U 20 & \\
\hline 345 & $M W-16 R$ & $7 / 16 / 99$ & DB & 320 & 44 & 38 & U 4 & U 4 & U २० & U 4 & \\
\hline 562 & PW-14S & $7 / 16 / 99$ & DB & 520 & 41 & 61 & U 10 & U 10 & U 50 & U 10 & \\
\hline 563 & PW-14M & $7 / 16 / 99$ & DB & 940 & 87 & 200 & U 20 & U 20 & U 100 & U 20 & \\
\hline 564 & PW-14D & $7 / 16 / 99$ & DB & 2700 & 210 & 140 & U 40 & U 40 & U 200 & $\cup 40$ & \\
\hline 559 & PW-13S & $7 / 16 / 99$ & DB & 86 & 10 & 26 & U 2 & U 2 & $\cup 10$ & U 2 & \\
\hline 560 & PW-13M & $7 / 16 / 99$ & DB & 110 & 10 & 15 & U2 & U2 & U 10 & U2 & \\
\hline 561 & PW-13D & $7 / 16 / 99$ & DB & 650 & 140 & 130 & U 10 & U 10 & U 50 & U 10 & \\
\hline 0 & trip blank & $7 / 27 / 99$ & NA & U2 & U2 & U2 & U 2 & U2 & U 10 & U 2 & \\
\hline 0 & equip blank & $7 / 30 / 99$ & DB & U2 & U2 & U2 & U2 & U2 & U 10 & U 2 & \\
\hline 0 & lab blank & $7 / 30 / 99$ & DB & U 2 & U 2 & U2 & U 2 & U2 & $\cup 10$ & U2 & \\
\hline 345 & MW-16R-A & $7 / 30 / 99$ & DB & 78 & 25 & 32 & U2 & U2 & U 10 & U2 & \\
\hline 345 & MW-16R-B & $7 / 30 / 99$ & DB & 110 & 29 & 38 & U 5 & U 5 & U 25 & U 5 & \\
\hline 345 & MW-16R-C & $7 / 30 / 99$ & DB & 180 & 32 & 35 & U 4 & U4 & U 20 & U 4 & \\
\hline 345 & MW-16R-D & $7 / 30 / 99$ & DB & 110 & 49 & 110 & U 5 & U5 & U 25 & U 5 & \\
\hline 408 & B95-13-A & $7 / 30 / 99$ & DB & 290 & 40 & 100 & $\cup 5$ & U 5 & U 25 & U 5 & \\
\hline 408 & B95-13-B & $7 / 30 / 99$ & DB & 590 & 40 & 100 & U 20 & $\cup 20$ & U 100 & U 20 & \\
\hline 408 & B95-13-C & $7 / 30 / 99$ & DB & 590 & 40 & 100 & U 20 & U 20 & U 100 & U 20 & \\
\hline 0 & trip blank & $8 / 10 / 99$ & DB & U 2 & U 2 & U 2 & U 2 & U 2 & U 10 & U 2 & \\
\hline 0 & lab blank & $8 / 12 / 99$ & DB & U2 & U2 & U 2 & U2 & U 2 & U 10 & U2 & \\
\hline 321 & $M W-16 B$ & $8 / 12 / 99$ & DB & 100 & 8.4 & U5 & U 5 & U5 & $\cup 25$ & U 5 & \\
\hline 344 & $M W-16 C$ & $8 / 12 / 99$ & DB & 880 & 56 & 41 & U 20 & U 20 & U 100 & U 20 & \\
\hline 345 & MW-16R & $8 / 12 / 99$ & DB & 160 & 33 & 38 & U5 & U 5 & U 25 & U 5 & \\
\hline 562 & PW-14S & $8 / 12 / 99$ & DB & 560 & 33 & 47 & U 10 & $\cup 10$ & U 50 & U 10 & \\
\hline 563. & PW-14M & $8 / 12 / 99$ & DB & 940 & 85 & 200 & U 20 & U 20 & U 100 & U 20 & 25.Meth.Chl:76,Benzene;200.THF \\
\hline 564 & PW-14D & $8 / 12 / 99$ & DB & 2500 & 190 & 130 & U 40 & $\cup 40$ & U 200 & $\cup 40$ & \\
\hline 559 & PW-13S & $8 / 12 / 99$ & DB & 68 & 6.6 & 15 & U2 & U 2 & U 10 & U2 & \\
\hline 560 & PW-13M & $8 / 12 / 99$ & DB & 90 & 8.5 & 12 & $\cup 2$ & U 2 & $\cup 10$ & U2 & \\
\hline 561 & PW-13D & $8 / 12 / 99$ & DB & 35 & 110 & 780 & $\cup 10$ & U 10 & U 50 & U 10 & \\
\hline 408 & B95-13 & $8 / 12 / 99$ & DB & 520 & 35 & 95 & $\cup 10$ & $\cup 10$ & U 50 & U 10 & \\
\hline 555 & PW-12S & $8 / 12 / 99$ & DB & 62 & U 2 & U 2 & $\cup 2$ & U2 & U 10 & U2 & \\
\hline 556 & PW-12M & $8 / 12 / 99$ & DB & 63 & 41 & 58 & U 2 & U2 & U 10 & U2 & \\
\hline 557. & PW-12D & $8 / 12 / 99$ & DB & 430 & 65 & 71 & U 5 & U 5 & U 25 & $\cup 5$ & \\
\hline 558. & $P W-12 R$ & $8 / 12 / 99$ & DB & 46 & 490 & 570 & U 10 & U 10 & U 50 & U 10 & \\
\hline 0 & equip blank & $8 / 13 / 99$ & DB & $\cup 2$ & U2 & U2 & U2 & U2 & U 10 & U2 & \\
\hline 0 & trip blank & $9 / 9 / 99$ & DB & $\cup 2$ & U2 & U2 & U 2 & U2 & $\cup 10$ & U 2 & \\
\hline 345 & $M W-16 R$ & $9 / 10 / 99$ & DB & 210 & 36 & 41 & $\cup 2$ & U2 & U 10 & U 2 & \\
\hline 409 & B95-15 & $9 / 10 / 99$ & DB & 86 & 12 & 9.6 & $\cup 2$ & U2 & U 10 & U 2 & \\
\hline 555 & $P W-12 S$ & $9 / 10 / 99$ & DB & 21 & U 2 & U2 & $\cup 2$ & U2 & U 10 & $\cup 2$ & \\
\hline 556 & PW-12M & $9 / 10 / 99$ & DB & U4 & 5.3 & 380 & U4 & U4 & U 20 & U 4 & \\
\hline 557 & PW-12D & $9 / 10 / 99$ & DB & 380 & 41 & 53 & U 5 & U 5 & U 25 & U 5 & \\
\hline 558 & $P W-12 R$ & $9 / 10 / 99$ & DB & 53 & 760 & 490 & U 10 & U 10 & U 50 & U 10 & \\
\hline 408 & B95-13 & $9 / 10 / 99$ & DB & 690 & 30 & 71 & $\cup 10$ & $\cup 10$ & U 50 & U 10 & \\
\hline
\end{tabular}




\begin{tabular}{|c|c|c|c|c|c|c|c|c|c|c|c|}
\hline Appe & endix 2c. Maj & or detectec & a volati & organ & ompo & nds (VOC & . May 1 & 77 to $\mathrm{Se}$ & tomber 19 & 999 , Milfor & rd, New Han \\
\hline Well & & & Pump & & & & & & & Vinyl & \\
\hline$\#$ & Name & Date & TYPE & PCE & TCE & CIS-DCE & $111-T r i$ & MTBE & Acetone & Chloride & Comments \\
\hline 535 & $P W-2 R$ & $9 / 10 / 99$ & DB & 38 & 4 & U2 & U2 & U2 & U 10 & U2 & \\
\hline 542 & $P W-5 R$ & $9 / 10 / 99$ & DB & 190 & 22 & 13 & 5.8 & U 2 & U 10 & U2 & 3.9 Toluene \\
\hline 546 & $P W-6 R$ & $9 / 10 / 99$ & DB & 2000 & 47 & U 40 & $\cup 40$ & U 40 & U 200 & U 40 & \\
\hline 565 & EW-I & $9 / 10 / 99$ & NA & 820 & 41 & 54 & U 20 & U 20 & U 100 & U 20 & \\
\hline 566 & $E W-2$ & $9 / 10 / 99$ & NA & 520 & 44 & 77 & $\cup 10$ & U 10 & U 50 & U 10 & \\
\hline 409 & B95-15 & $9 / 10 / 99$ & peri & 82 & 9.3 & 7.9 & U 2 & U2 & $\cup 10$ & U2 & \\
\hline 0 & lab blank & $9 / 10 / 99$ & $\mathrm{DB}$ & U2 & U2 & U2 & U2 & U 2 & $\cup 10$ & U2 & \\
\hline 0 & equip blank & $9 / 10 / 99$ & DB & U2 & U 2 & U2 & U 2 & U2 & $\cup 10$ & U 2 & \\
\hline 562 & PW-14S & $9 / 10 / 99$ & DB & 640 & 31 & 41 & $\cup 10$ & U 10 & U 50 & U 10 & \\
\hline 563 & PW-14M & $9 / 10 / 99$ & DB & 1100 & 87 & 200 & U 20 & U 20 & U 100 & U 20 & \\
\hline 564 & $P W-14 D$ & $9 / 10 / 99$ & DB & 2700 & 150 & 110 & U 40 & U 40 & U 200 & $\cup 40$ & \\
\hline 559 & PW-13S & $9 / 10 / 99$ & DB & 41 & 3.3 & 6.1 & U 2 & U2 & U 10 & U2 & \\
\hline 560 & PW-13M & $9 / 10 / 99$ & DB & 120 & 8.6 & 9.1 & U2 & U2 & U 10 & U 2 & \\
\hline 561 & PW-13D & $9 / 10 / 99$ & DB & 69 & 160 & 1800 & $\cup 40$ & $\cup 40$ & U 200 & U 40 & \\
\hline 321 & $M W-16 B$ & $9 / 10 / 99$ & DB & 320 & 9.7 & 4.1 & U 4 & U4 & U 20 & U4 & \\
\hline 344 & $M W-16 C$ & $9 / 10 / 99$ & DB & 860 & 45 & 38 & U 20 & U 20 & U 100 & U 20 & \\
\hline
\end{tabular}




\begin{tabular}{|c|c|c|c|c|c|}
\hline 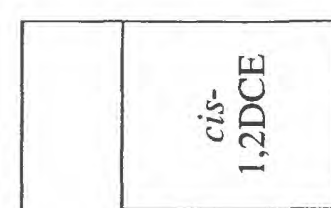 & $\ddot{\because} \cong \cong$ & 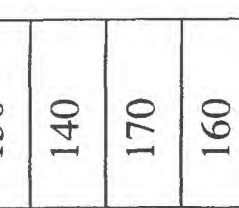 & $8: 8$ & & \\
\hline 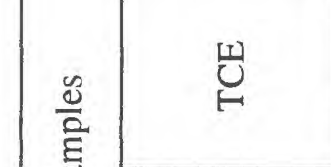 & $=\approx$ & $\approx \approx$ & $\approx \approx$ & & $\infty=$ \\
\hline 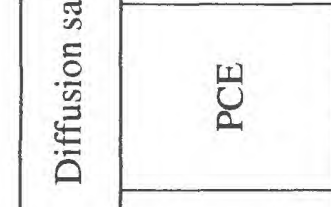 & 离 & $8 \%$ & 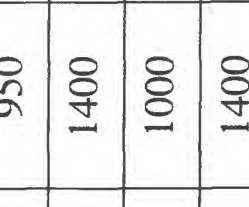 & $\frac{9}{9}$ & $\cong$ \\
\hline 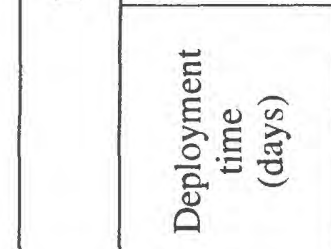 & $\%: 0: 3$ & $D=$ & $\approx \infty$ & & \\
\hline 葛 & $7 \cong \cong$ & $\underline{0}$ & 8 & & $\approx \pm$ \\
\hline 崖 & 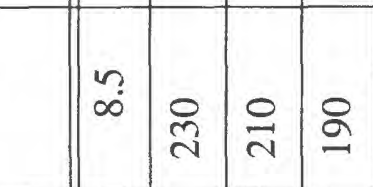 & $\approx \equiv$ & $=\infty \approx$ & $\Rightarrow \pi$ & $\pm \pm=$ \\
\hline 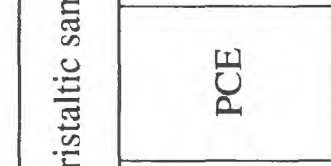 & 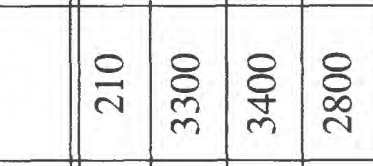 & 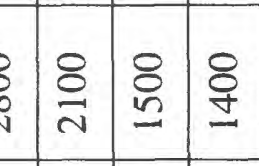 & 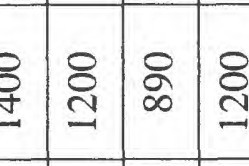 & 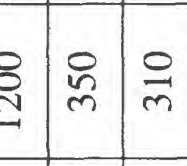 & $=\bar{\sigma}:$ \\
\hline 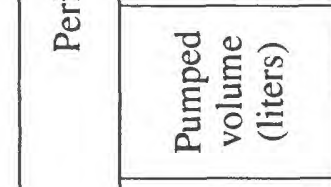 & $\tilde{g}$ & $\cong \cong$ & 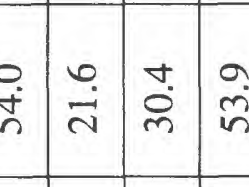 & 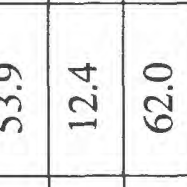 & $\frac{2}{8}=\frac{a}{3}$ \\
\hline 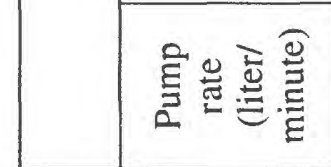 & 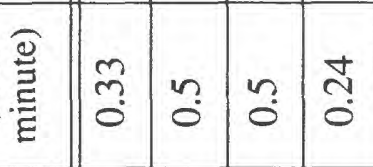 & \begin{tabular}{l|l}
0 \\
\hdashline
\end{tabular} & 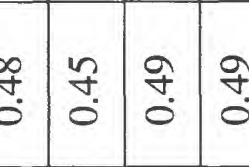 & & $8: \frac{7}{0}$ \\
\hline 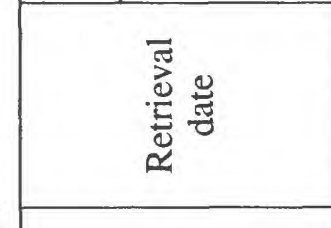 & 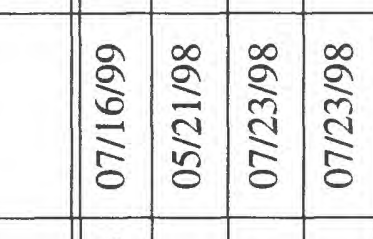 & & 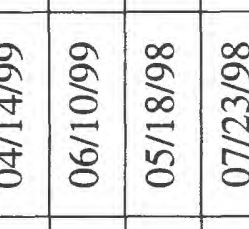 & & 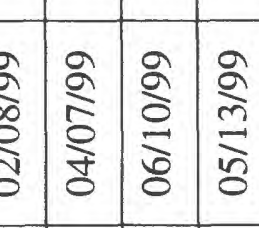 \\
\hline 撞毫 & 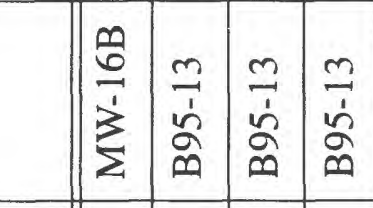 & $\begin{array}{ll}m \\
\dot{n}\end{array}$ & 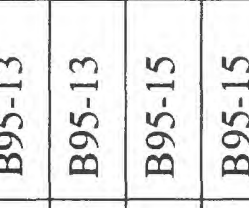 & 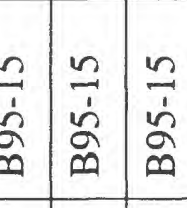 & \\
\hline 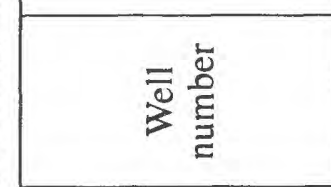 & & 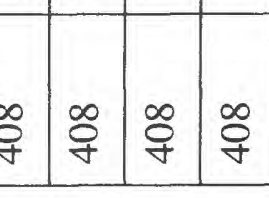 & & & \\
\hline
\end{tabular}




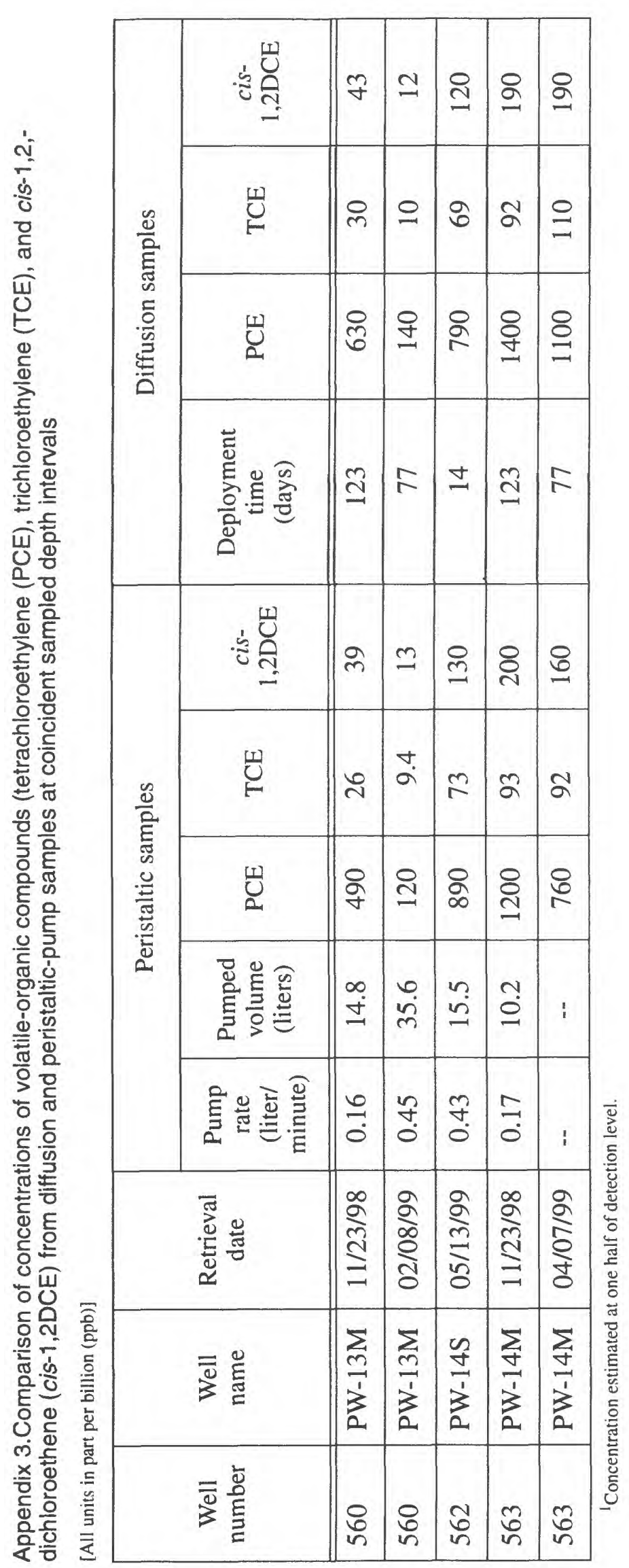




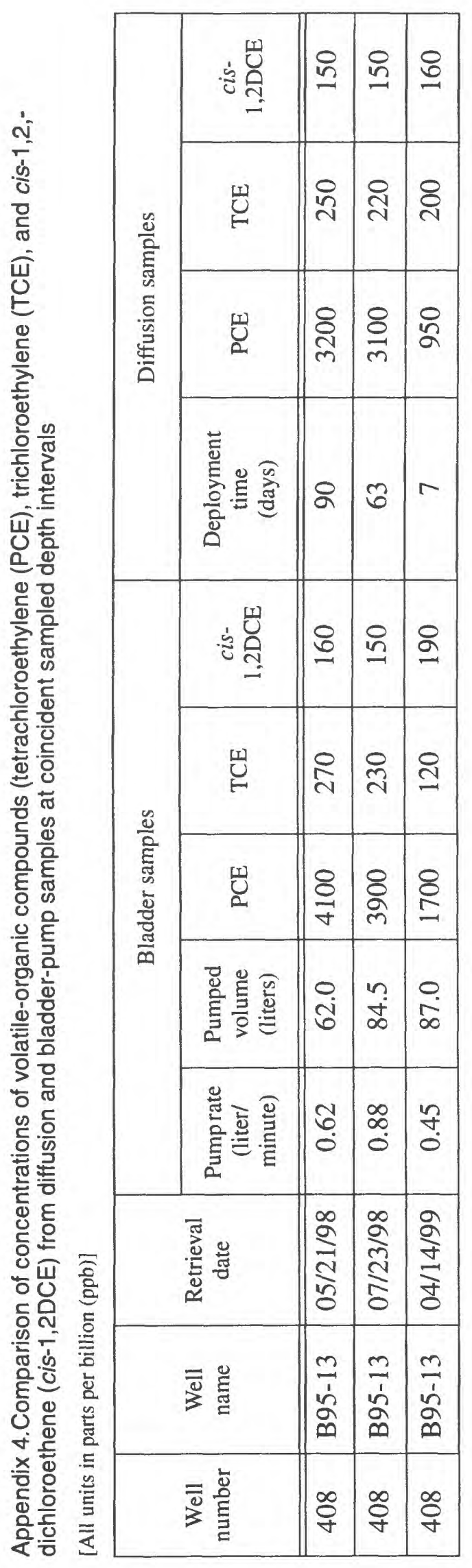




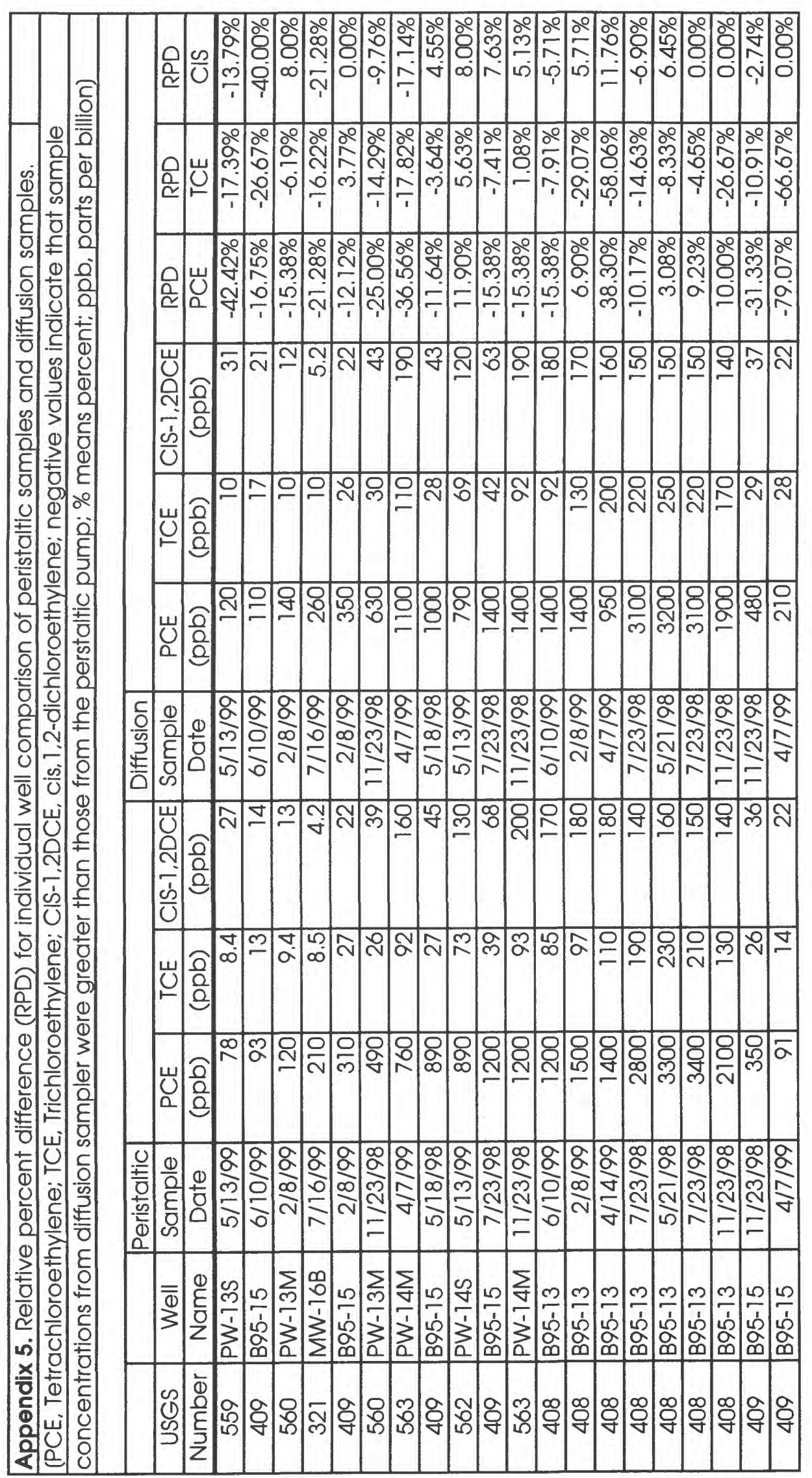




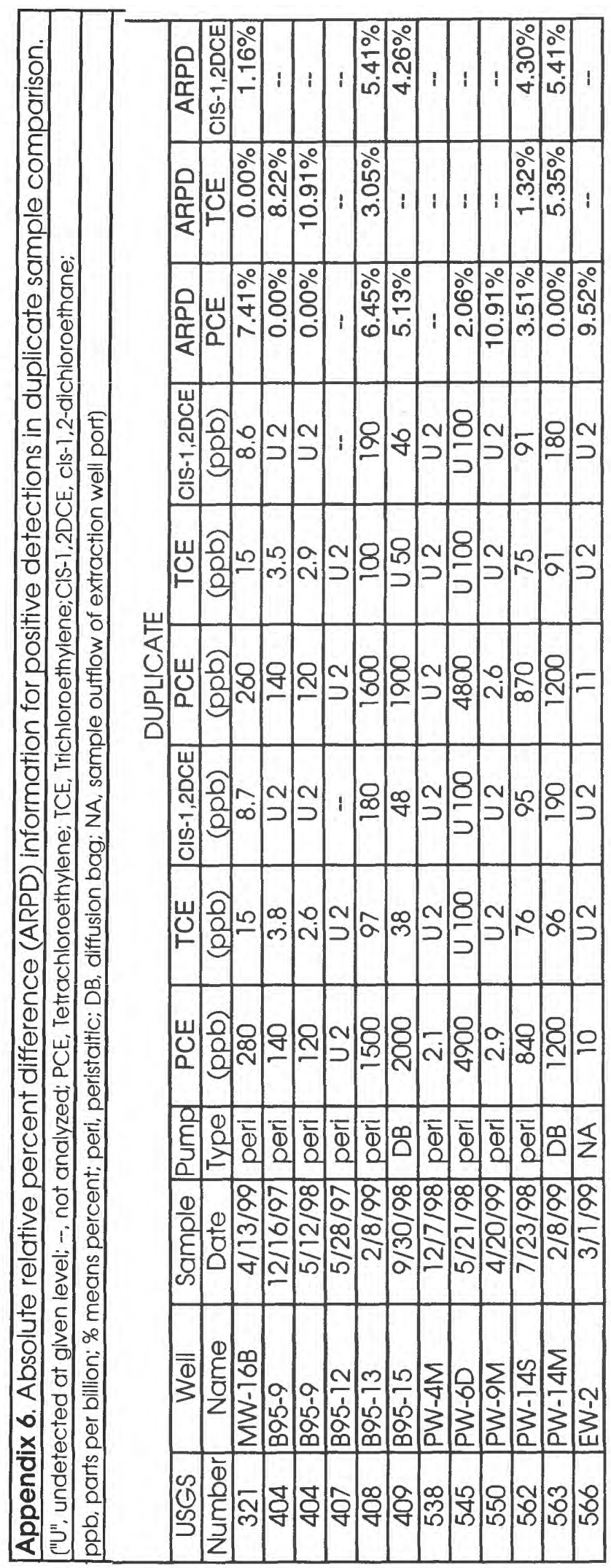

